\title{
A Framework for Energy Optimization of Small, Two-Stroke, Natural Gas Engines for Combined Heat and Power Applications
}

\author{
Mahdi Darzi \\ madarziboorkhani@mix.wvu.edu
}

Follow this and additional works at: https://researchrepository.wvu.edu/etd

Part of the Energy Systems Commons

\section{Recommended Citation \\ Darzi, Mahdi, "A Framework for Energy Optimization of Small, Two-Stroke, Natural Gas Engines for Combined Heat and Power Applications" (2019). Graduate Theses, Dissertations, and Problem Reports. 4019. \\ https://researchrepository.wvu.edu/etd/4019 \\ This Dissertation is protected by copyright and/or related rights. It has been brought to you by the The Research Repository @ WVU with permission from the rights-holder(s). You are free to use this Dissertation in any way that is permitted by the copyright and related rights legislation that applies to your use. For other uses you must obtain permission from the rights-holder(s) directly, unless additional rights are indicated by a Creative Commons license in the record and/ or on the work itself. This Dissertation has been accepted for inclusion in WVU Graduate Theses, Dissertations, and Problem Reports collection by an authorized administrator of The Research Repository @ WVU. For more information, please contact researchrepository@mail.wvu.edu.}


2019

\section{A Framework for Energy Optimization of Small, Two-Stroke, Natural Gas Engines for Combined Heat and Power Applications}

Mahdi Darzi 
A Framework for Energy Optimization of Small, Two-Stroke, Natural Gas Engines for Combined Heat and Power Applications

\author{
Mahdi Darzi
}

Dissertation submitted to Benjamin M. Statler College of Engineering and Mineral Resources at West Virginia University in partial fulfillment of the requirements of the degree of Ph.D. in Mechanical Engineering

Derek Johnson, PhD, Chair

Nigel Clark, PhD

Hailin Li, PhD

Marc Besch, PhD

Matthew Robinson, PhD

Department of Mechanical and Aerospace Engineering

\author{
Morgantown, West Virginia
}

2019

Keyword: Two-stroke, Natural gas, GENSETS, CHP, LPDI, Simulation

Copyright 2019 Mahdi Darzi 


\title{
ABSTRACT \\ A Framework for Energy Optimization of Small, Two-Stroke, Natural Gas Engines for
}

\author{
Combined Heat and Power Applications
}

\begin{abstract}
Mahdi Darzi
This research was focused on the development of a framework for the energy optimization a natural gas engine for small combined heat and power (CHP) applications operating with lowpressure natural gas (NG) available at homes. The required targets of the ARPA-E GENSETS program for $1 \mathrm{~kW}$ electric power generation and previous GENSETS simulation at West Virginia University, suggested a design space for the engine which is currently dominated by simple twostroke designs. Hence this research focused on screening, modeling, and experimentally evaluation of cost-effective technologies to achieve a system design that maximized thermal efficiency and utilization factor, while reducing emissions. A baseline engine was selected which started with $8 \%$ brake thermal efficiency (BTE) on natural gas operation. By implementing intake and exhaust optimization BTE increased up to around $12 \%$ and with head design optimization and exhaust backpressure, the engine reached 15\% BTE. Though the initial optimization methods almost doubled efficiency, it was realized that further increases in BTE must be achieved for a commercially competitive design. The engine was redesigned to utilize modified porting for enhanced breathing and scavenging and a method to deploy low-pressure direct injection (LPDI) was developed. With these enhancements, BTE increased to around 24\%. A second round of optimization was performed then, by modeling the whole system in a 1D platform and using a genetic algorithm and experimental data to further optimize scavenging which increased the efficiency up to around $26 \%$. Finally, a 3D computational fluid dynamics (CFD) was developed to investigate the stratification effects of LPDI and determine the optimal spark plug location. This effort increased the BTE to around $27.5 \%$. To assess issues with commercial deployment, three different NG compositions and propane operation were investigated. With an energy balance and exergy distribution analysis for each fuel, fuel quality effects on the CHP system performance were determined. At the end, with combination literature review, experiments, $1 \mathrm{D}$ and 3D simulations, a framework for optimization of micro-CHP systems operating on gaseous fuels was developed that can serve industry to highlight methods that can more than triple brake thermal efficiency of small two-stroke engines while improving the energy distribution for CHP systems.
\end{abstract}




\section{Acknowledgment}

Special thanks to Dr. Johnson for his support and mentorship throughout my PhD program. I thank my dedicated PhD committee members for their guidance and valuable feedback to improve this dissertation. I would like to thank Mr. Chris Ulishney, Mr. Richard Atkinson, and Mr. Zachary Luzader for assisting in experiments and data acquisition efforts. I also thank Dr. Parviz Famouri, Project PI, Professor, and Director of the Electro-Mechanical Systems Laboratory at West Virginia University. This work was made possible under an award from the Department of Energy's Advanced Research Projects Agency-Energy (ARPA-E), DE-AR0000608 under direction of Dr. David Tew. Observations and views expressed herein are those of the authors and do not necessarily represent the official views of the Department of Energy. 


\section{Table of Contents}

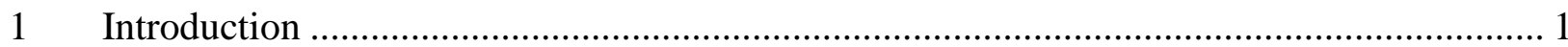

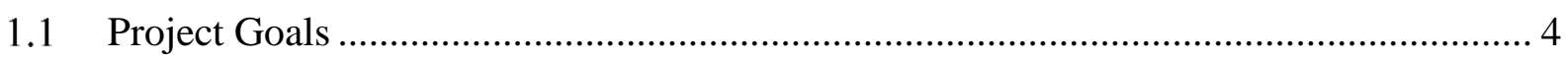

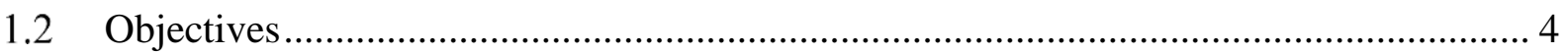

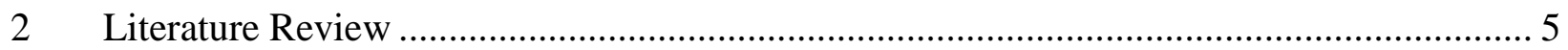

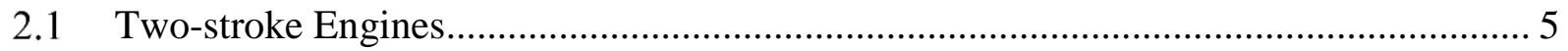

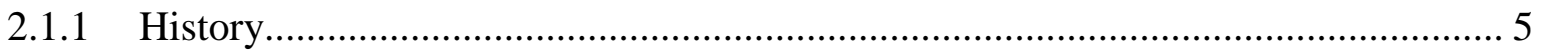

2.1.2 Basic Design ............................................................................................... 5

2.2 Natural Gas in Internal Combustion Engines............................................................... 7

2.3 Two-stroke Engine's Air Handling (Breathing)......................................................... 8

2.3.1 Intake Optimization .................................................................................... 9

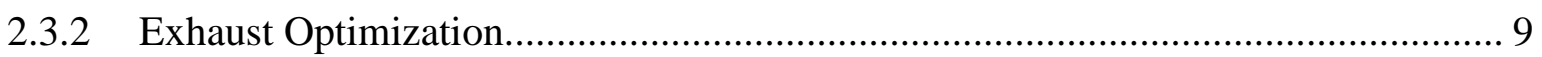

2.4 Effect of Compression Ratio …………………..................................................... 10

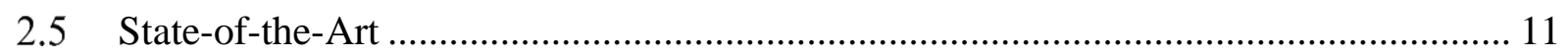

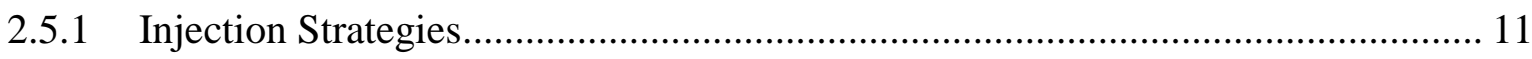

2.5.2 Advanced Combustion................................................................................. 13

2.5.3 Exhaust Gas Recirculation ................................................................................. 13

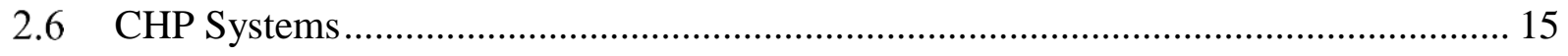

2.6.1 Energy Balance …………………………………...................................... 16

2.6.2 Fuel Quality Effects ................................................................................ 18

2.6.3 Current Commercial CHP Systems ……………………....................................... 19

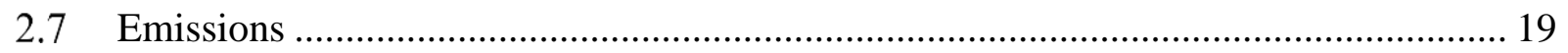

2.8 Simulation of Two-stroke Engines............................................................................ 20

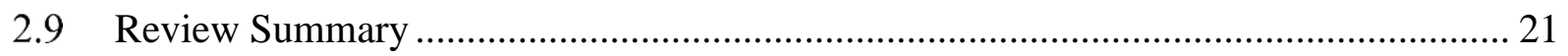

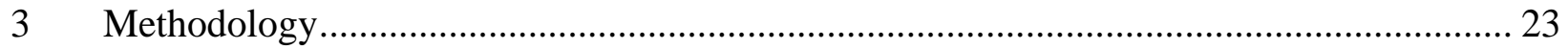




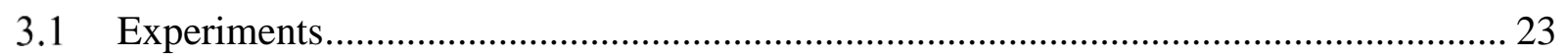

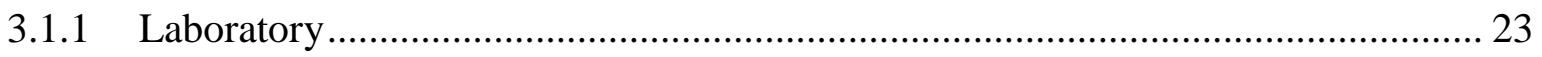

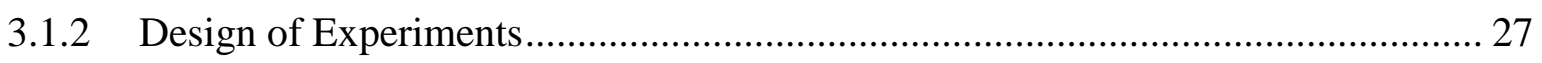

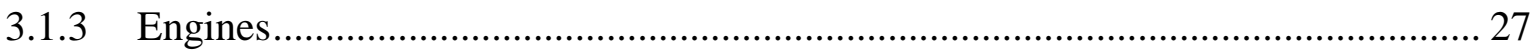

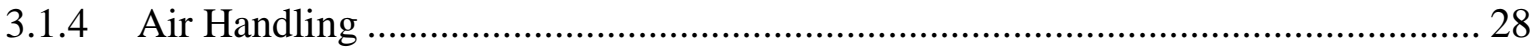

3.1.5 Injection Strategies and Control........................................................................ 35

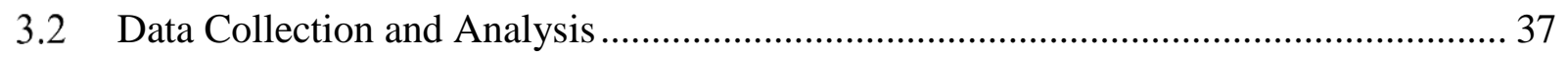

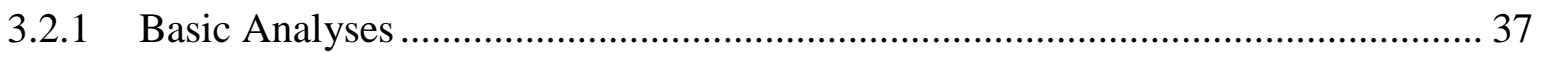

3.2.2 Detailed Energy Analysis for CHP Application ……………………………….... 38

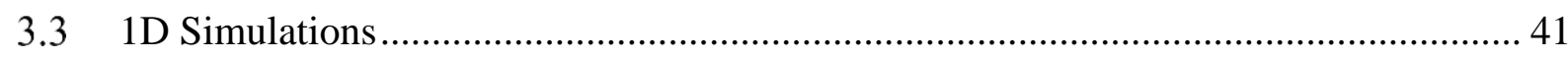

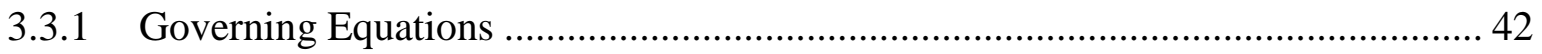

3.3.2 Reed Valve Model ……………………………....................................... 44

3.3.3 Boundary Conditions ...................................................................................... 46

3.3.4 Exhaust Resonator's Genetic Algorithm Optimization ........................................... 52

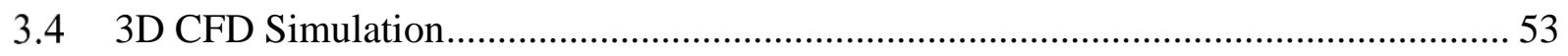

3.4.1 Engine Geometry ......................................................................................... 53

3.4.2 CFD Model Boundaries ................................................................................. 54

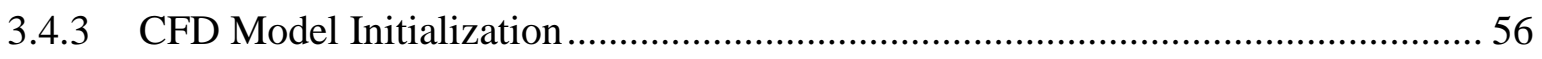

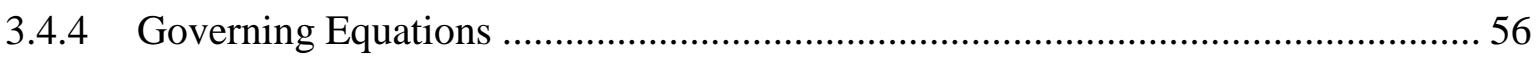

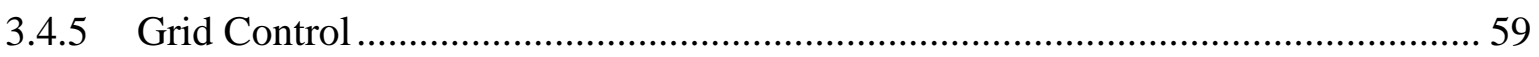

3.4.6 CFD Study Objectives ................................................................................... 59

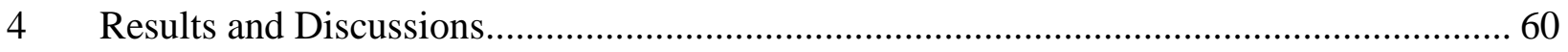

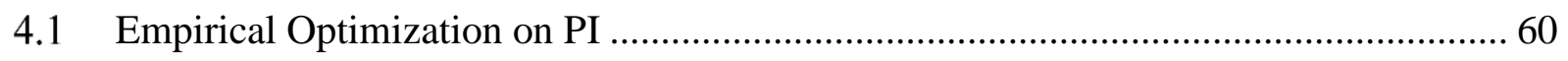

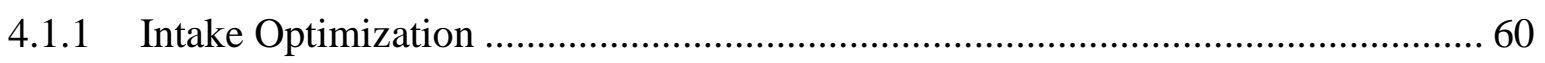

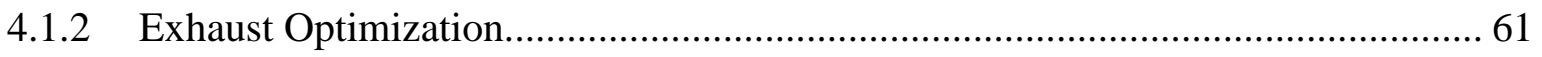




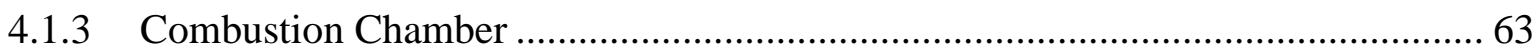

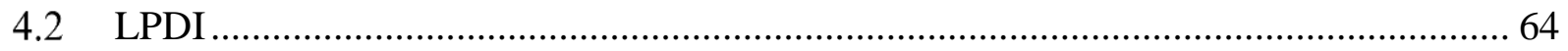

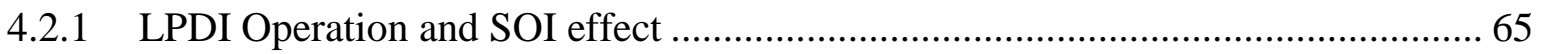

4.2.2 Effect of Engine Speed on LPDI Operation ........................................................ 72

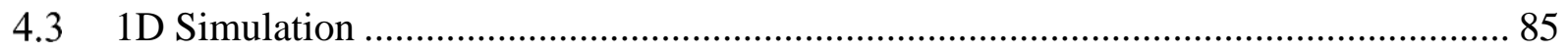

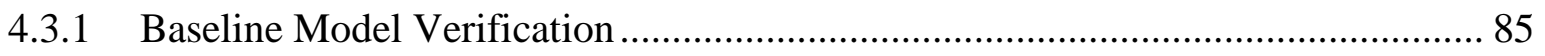

4.3.2 GA Evolution Curve and Sensitivity Curves ………………………………...... 88

4.3.3 Experimental Comparison of Optimized Exhaust with the Beta ............................ 92

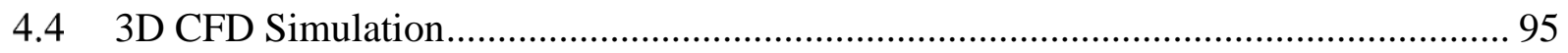

4.4.1 Experimental Validation for Spark Plug Location Optimization .......................... 101

4.5 Fuel Quality Effect on the Performance............................................................... 106

4.5.1 CHP Potential Analysis..................................................................................... 110

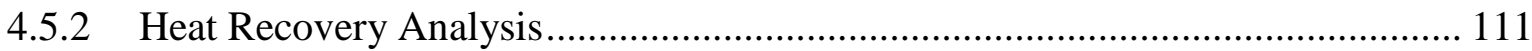

4.6 Oxidation Catalyst Experiments ............................................................................. 113

4.7 Energy, Emissions, and Cost Analysis ...................................................................... 118

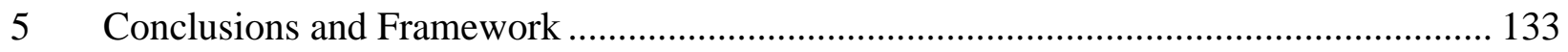

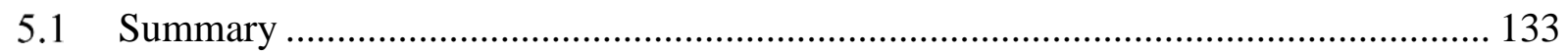

5.2 Major Conclusions ………………………………............................................. 134

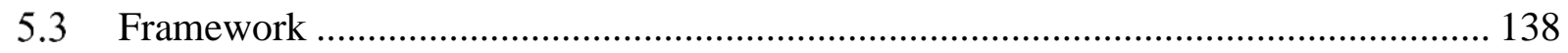

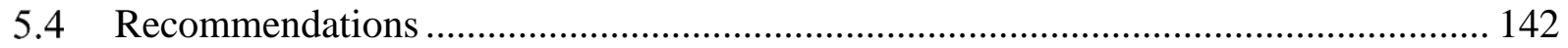

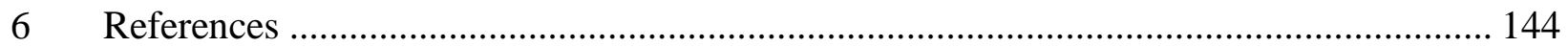




\section{Table of Figures}

Figure 1. US energy consumption summary in 2017 [1].

Figure 2. Scavenge flow patterns for the four basic scavenging approaches. Note the uniflow approach is the only one that uses an exhaust valve as opposed to an exhaust port $[14,23]$.

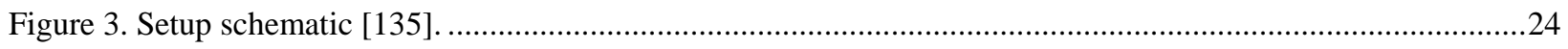

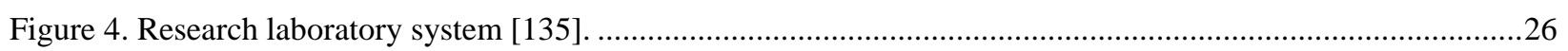

Figure 5. Baseline engine (right) and second (boosted) engine design (left). ........................................................28

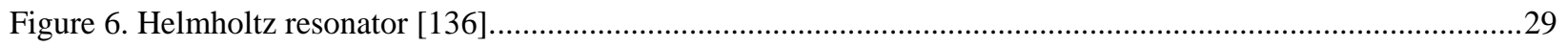

Figure 7. Exhaust suction wave [33] ........................................................................................................

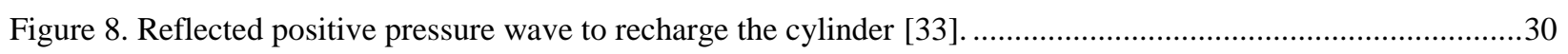

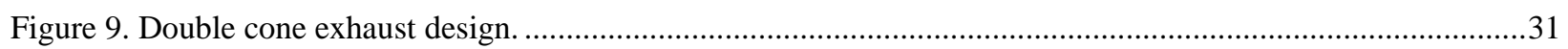

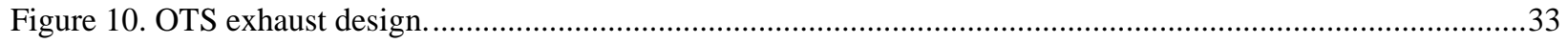

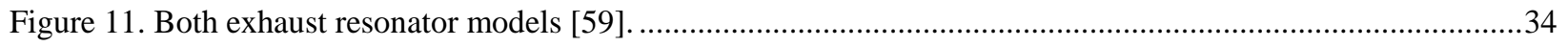

Figure 12. Direct injection setup, showing relocation of the spark plug for LPDI (left), Port injection (right) [135]. 36

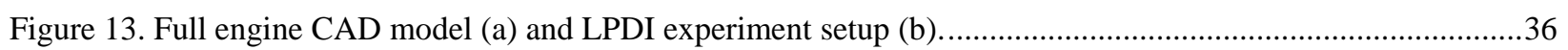

Figure 14. Input variables to the 1D model from experimental data and system design. .........................................42

Figure 15. Schematic of staggered grid approach: scalars calculated at centroid, vector quantities at boundaries

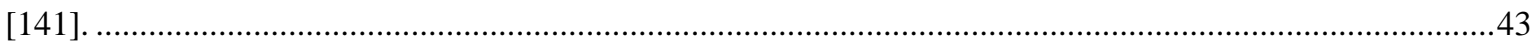

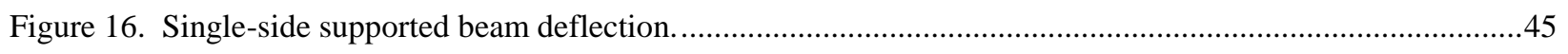

Figure 17. Young's Modulus measurement experiments (left) and experimental results (right). .............................45

Figure 18. Reed valve body simplification to a flow split element. ..........................................................................46

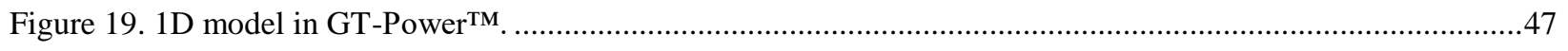

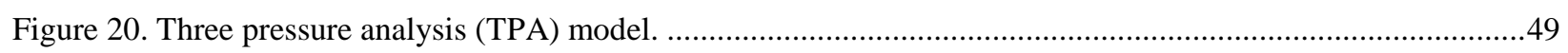

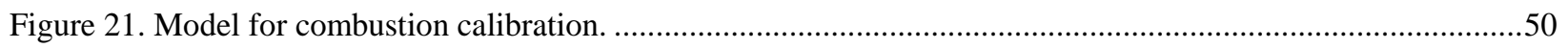

Figure 22. Pressure curve of an uncalibrated combustion versus measured curve ....................................................51

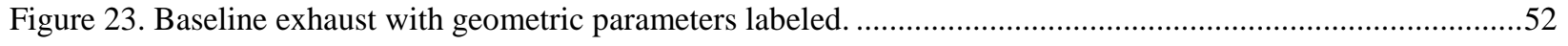

Figure 24. (a) Main geometry regions (b) transparent fluid domain showing piston, connecting rod and crank and

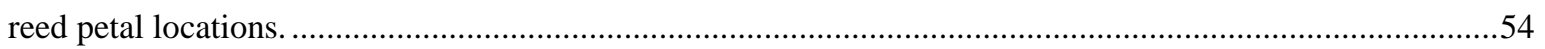

Figure 25. Reed valve flow rate profile from verified 1D simulation results. ...........................................................54

Figure 26. Exhaust boundary conditions from experimental measurements, an average of 200 recorded cycles. ......55

Figure 27. Delivery ratio and power increased as length decreased to the target length, which yielded a tuned frequency of $185 \mathrm{~Hz}$.

Figure 28. Combustion stability as defined by the coefficient of variation (COV) of IMEP for varied intake lengths.

Figure 29. Delivery versus AFR for all exhausts with a tuned intake. ................................................................62

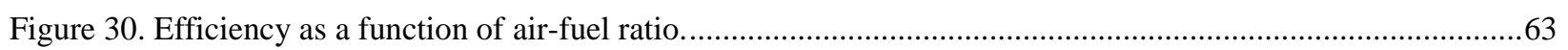

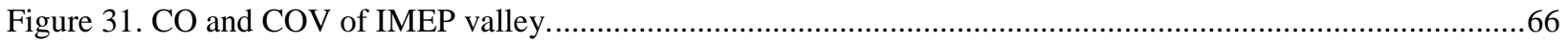


Figure 32. Delivery ratio on PI and LPDI running on different SOI, each point is averaged value for 90 seconds of steady state operation.

Figure 33. Peak pressure for PI and LPDI by varying the SOI, each point is averaged over 200 cycles on PI and LPDI operations

Figure 34. Rate of heat release for PI and LPDI by varying SOI, each curve was averaged over 200 recorded cycles at steady state operation.

Figure 35. IMEP averaged over 200 cycles on PI and preliminary LPDI operations vs $\lambda *$...... 68

Figure 36. COV of IMEP averaged over 200 cycles on PI and initial LPDI operations vs $\lambda *$. 69

Figure 37. Combustion Duration averaged over 200 cycles on PI and initial LPDI operations vs $\lambda *$ . .70

Figure 38. Indicated thermal efficiency on PI and LPDI, averaged over 90 seconds steady state operation for each point vs $\lambda^{*}$. .70

Figure 39. THC emissions on PI and preliminary LPDI vs $\lambda^{*}$, averaged over 90 seconds of steady state operation.

These emissions arise both from the scavenging process and from incomplete combustion. 71

Figure 40. NMHC plus $\mathrm{NO}_{\mathrm{x}}$ on PI and preliminary LPDI vs $\lambda^{*}$, averaged over 90 seconds of steady state operation.

Figure 41. Delivery ratio vs $\lambda *$ for PI and LPDI, each point is averaged over 90 seconds of steady state operation. 73 Figure 42. Energy balance of LPDI at 6000 RPM and PI at 5400 RPM as percentage of total injected fuel energy, data was averaged over 90 of seconds steady state operation.

Figure 43. Heat transfer rate as a percentage of total injected fuel energy vs $\lambda *$ for PI and LPDI, each point was averaged over 90 seconds of steady state operation.

Figure 44. Rate of heat released averaged on 200 cycles for different speeds on LPDI near stoichiometric operation.

Figure 45. In-cylinder pressure averaged on 200 cycles for different speeds on LPDI near stoichiometric operation.

Figure 46. Peak pressure averaged on 200 cycles for different speeds on LPDI and 5400RPM on PI. . .77

Figure 47. Indicated efficiency for PI and LPDI vs $\lambda^{*}$, averaged over 90 seconds steady state operation for each point.

Figure 48. Exhaust thermal energy as a fraction to total fuel input energy vs $\lambda *$ for PI and LPDI, averaged over 90 seconds steady state operation for each point.

Figure 49. Fuel slip rate as a percentage of total injected fuel.

Figure 50. Exhaust CO energy as a percentage of total injected fuel energy for PI and LPDI, each point was averaged over 90 seconds of steady state operation.

Figure 51. 50\% MFB averaged on 200 cycles for different speeds on LPDI and 5400 RPM on PI......................82

Figure 52. COV of IMEP averaged on 200 cycles for different speeds on LPDI and 5400 RPM on PI.

Figure 53. CO emissions on PI and different speeds on LPDI, averaged over 90 seconds of steady state operation for each point. 
Figure 54. Methane emissions on PI and different speeds on LPDI, averaged over 90 seconds of steady state operation for each point.

Figure 55. NMHC emissions on PI and different speeds on LPDI.

Figure 56. Motoring crankcase pressure at 3600 RPM for engine operating with beta design, experiment curve was averaged over 200 cycles

Figure 57. Combusting crankcase pressure curves at 5400 RPM engine speed operating on beta exhaust, experiment curve was averaged over 200 cycles.

Figure 58. In-cylinder combusting pressure at 5400 RMP engine speed operating with beta exhaust design,

experiment curve was averaged over 200 cycles.

Figure 59. Exhaust pressure wave validation at 5400 RPM engine speed operating on beta exhaust design; experiment curve was averaged over 200 cycles. .88

Figure 60. Indicated efficiency evolution versus design iteration. .89

Figure 61. Engine response sensitivity to the exhaust design parameters.

Figure 62. Exhaust pressure waves validation for the engine operating with optimized exhaust at 5400 RPM and full load; experiment curve was averaged over 200 cycles.

Figure 63. In-cylinder pressure validation of the engine with optimized exhaust at 5400 RPM full load operation; experiment curve was averaged over 200 cycles. . .92

Figure 64. Delivery ratio for beta design and optimized design. Stars are showing results from 1D simulation........93

Figure 65. Engine BTE for exhaust optimization.

Figure 66. Exhaust HC content. . .95

Figure 67. Full engine geometry modeled in CONVERGETM. . .96

Figure 68. Crankcase pressure, 1D (GT-Power $\left.{ }^{\mathrm{TM}}\right)$ simulation, 3D (CONVERGETM) simulation, and experimental data, experiment curve was averaged over 200 recorded cycles. . .96

Figure 69. Exhaust resonators effect on in-cylinder gas dynamics and fuel trapping efficiency. . .98

Figure 70. In-cylinder stratification evolution at different cranks angle degrees before TDC, spark timing was at 26 BTDC, color bar is showing methane mass fraction, red is showing $10 \%$ and blue $0 \%$ methane mass fraction.

Figure 71. Delivery ratio comparison for base location and optimized location of spark plug, each datapoint is averaged over 90 seconds of continuous data measurement.

Figure 72. BTE comparison for base location and optimized location of spark plug, each datapoint is averaged over

90 seconds of continuous data measurement.

Figure 73. Exhaust total HC comparison for base location and optimized location of spark plug, each datapoint is averaged over 90 seconds of continuous data measurement

Figure 74. Exhaust $\mathrm{Co}$ and $\mathrm{H}_{2}$ energy for base location and optimized location of spark plug, each datapoint is averaged over 90 seconds of continuous data measurement.

Figure 75. Total combustible content of exhaust for base location and optimized location of spark plug, each datapoint is averaged over 90 seconds of continuous data measurement. 
Figure 76. Indicated efficiency for base location and optimized location of spark plug, fuel flow was averaged over 90 seconds of continuous data measurement and IMEP averaged over 200 cycles.

Figure 77. Combustion duration comparison for base location and optimized location of spark plug, each datapoint is averaged over 200 engine cycles.

Figure 78. COV of IMEP for base location and optimized location of spark plug, each datapoint is averaged over 200 cycles.

Figure 79. Combustion stability for different fuels, each point was averaged over 90 seconds of steady state operation

Figure 80. BTE and brake power for different fuels, each point was averaged over 90 second of steady state operation.

Figure 81. Cylinder heat transfer for different fuel operations, each point was averaged over 90 second of steady state operation.

Figure 82. Ignition delay and combustion duration for different fuels, each point was averaged over 200 recorded cycles

Figure 83. Unburnt ( $\mathrm{CO}$ and $\mathrm{H}_{2}$ ) energy and total $\mathrm{HC}$ energy in exhaust, each point was averaged over 90 second of steady state operation.

Figure 84. Overall utilization factor versus the required heat exchanger effectiveness for the CHP system.

Figure 85. CO oxidation plot from cold-start to light-off temperature of the catalyst.

Figure 86. Delivery ratio before and after catalyst installation for methane and propane operation, each point was averaged over 90 seconds of steady state operation.

Figure 87. Indicated efficiency before and after catalyst installation for methane and propane operation, each point was averaged over 90 seconds of steady state operation.

Figure 88. Total available heat before and after catalyst installation for methane and propane operation, each point was averaged over 90 seconds of steady state operation.

Figure 89. Propane operation chemical energy losses before and after catalyst, each point was averaged over 90 seconds of steady state operation.

Figure 90. Methane operation chemical energy losses before and after catalyst, each point was averaged over 90 seconds of steady state operation.

Figure 91. Energy distribution of peak BTE point with COV of IMEP less than 5\% for CNG1, results are averaged for 90 second steady state operating condition.

Figure 92. Energy distribution of peak BTE point with COV of IMEP less than 5\% for CNG2, results are averaged for 90 second steady state operating condition.

Figure 93. Energy distribution of peak BTE point with COV of IMEP less than 5\% for pure methane, results are averaged for 90 second steady state operating condition.

Figure 94. Energy distribution of peak BTE point with COV of IMEP less than 5\% for pure propane, results are averaged for 90 second steady state operating condition.

Figure 95. State-of-the-art micro-CHP system’s engine energy distribution. .121 
Figure 96. Engine energy distribution operating on methane with oxidation catalyst installed after exhaust resonator, the operating point was the peak BTE with COV of IMEP less than 5\%.

Figure 97. Engine energy distribution operating on propane with oxidation catalyst installed after exhaust resonator, the operating point was the peak BTE with COV of IMEP less than 5\%.

Figure 98. Final waterfall chart showing the evolution of system BTE when each modification was applied. Note results presented for CNG1.

Figure 99. Stepping chart for price evolution for single engine modifications to achieve highest BTE as presented in

Figure 98 .126

Figure 100. Electric generation cost from grid, NG engine and propane engine, engine is referred to the current research engine.

Figure 101. Total energy cost form different source of heat for homes.

Figure 102. $\mathrm{CO}_{2}$ equivalent results for different sources of total energy. 131

Figure 103. $\mathrm{NO}_{\mathrm{x}}$ emissions from different sources of energy providing total energy of a home in a year. 


\section{Table of Tables}

Table 1. Summary of two-stroke engines advantages and disadvantages...............................................................

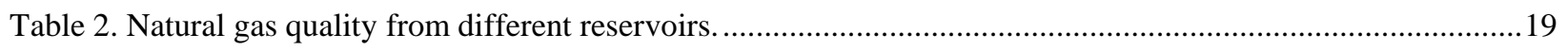

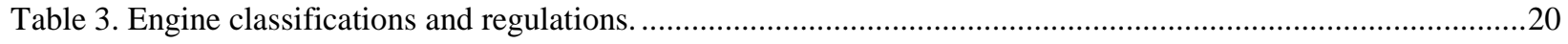

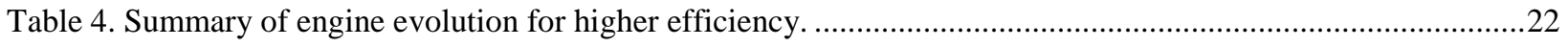

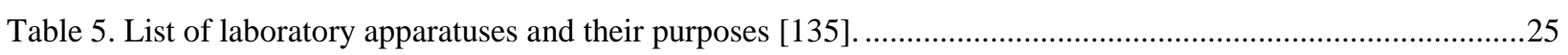

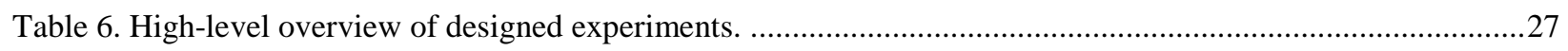

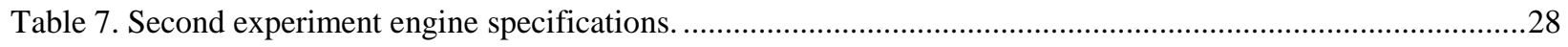

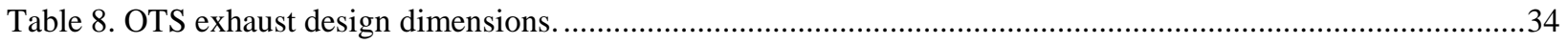

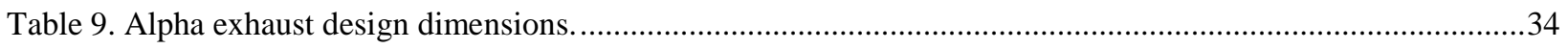

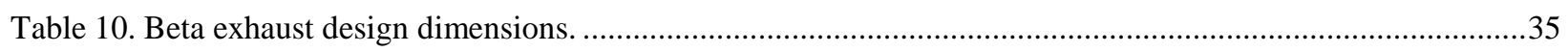

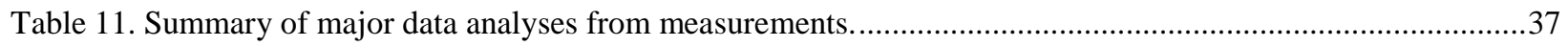

Table 12. Combustion calibration model inputs and parameters.......................................................................50

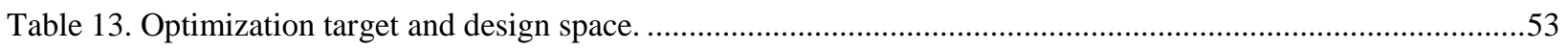

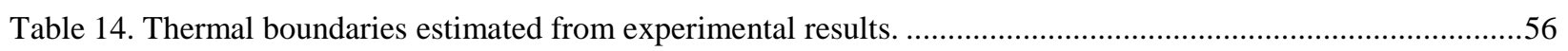

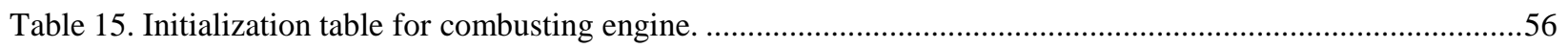

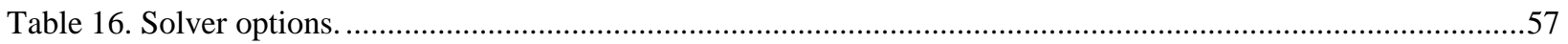

Table 17. Maximum brake power output in $\mathrm{kW}$ for all exhaust configurations with a tuned intake..........................62

Table 18. Results of combustion dome design change with optimized intake and exhaust.......................................63

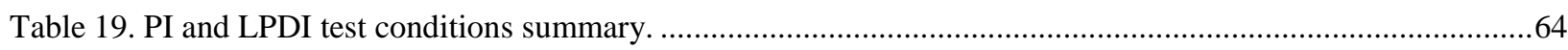

Table 20. Heat transfer change on LPDI relative to PI based on in-cylinder heat released, heat loss was averaged over 90 seconds steady state operation and heat release was average over 200 cycle recorded.....................75

Table 21. Indicated efficiency change on LPDI operation relative to PI, exhaust sensible was averaged over 90 seconds steady state operation and heat release was average over 200 cycle recorded......................................78

Table 22. Exhaust thermal energy change on LPDI operation relative to PI based on in-cylinder heat released.........79

Table 23. Fuel slip rate on LPDI and PI operation as a percentage of total injected fuel. .........................................80

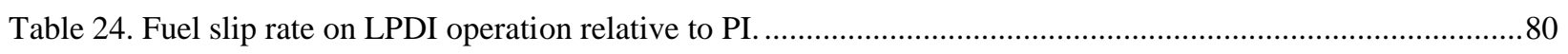

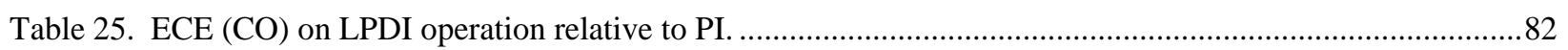

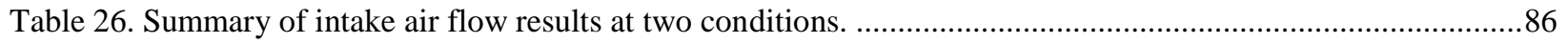

Table 27. Comparing the beta design and 1D simulation optimized design, 1D simulation started with beta design dimensions as baseline values of the exhaust resonator. .............................................................................91

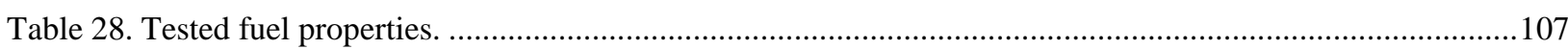

Table 29. CO oxidation added heat averaged over the range of AFR, numbers are calculated based on experimental $\mathrm{CO}$ concentration from Equation (70).

Table 30. Cylinder and exhaust heat for different fuels and their occurring temperatures for best BTE points, peak UF is based on $100 \%$ heat recovery. 
Table 31. System's UF calculated for incremental heat exchanger effectiveness values, cylinder heat transfer plus exhaust heat accounted for total available heat in heat exchanger.

Table 32. System UF at peak BTE point for each fuel in [\%] of total fuel injected, 75\% effectiveness was assumed to waste heat recovery.

Table 33. Specific emissions in $\mathrm{g} / \mathrm{kWhr}$ for two ends of the fuel spectrum, values represent raw emissions for peak BTE points with COV of IMEP less than 5\%.

Table 34. Energy distribution for Honda micro-CHP system.

Table 35. Engine and system comparison for Honda state-of-the-art CHP system and engine used in this research, methane and propane were run on the two-stroke engine.

Table 36. Specific Emissions in $\mathrm{g} / \mathrm{kWhr}$ for all fuels, values represent measurements after DOC catalyst for peak BTE points with COV of IMEP less than 5\%.

Table 37. Net cost of hardware optimization for engine optimization.

Table 38. Cost analysis of three major modifications on the engine, based on $1.24 \mathrm{~kW}$ output for one year 24/7 operation.

Table 39. Simplified energy source combination of residential applications for cost and emission analysis. 128 


\section{Abbreviations}

\begin{tabular}{|c|c|}
\hline \multicolumn{2}{|c|}{ Acronyms } \\
\hline AFR & Air-Fuel Ratio \\
\hline AMR & Adaptive Mesh Refinement \\
\hline ATDC & After Top Dead Center \\
\hline BDC & Bottom Dead Center \\
\hline BMEP & Brake Mean Effective Pressure \\
\hline BSFC & Brake Specific Fuel Consumption \\
\hline BTDC & Before Top Dead Center \\
\hline BTE & Brake Thermal Efficiency \\
\hline $\mathrm{CA}$ & Crank Angle \\
\hline $\mathrm{CAD}$ & Crank Angle Degrees \\
\hline $\mathrm{cc}$ & Cubic Centimeters \\
\hline CFD & Computational Fluid Dynamics \\
\hline CFR & Code of Federal Regulations \\
\hline $\mathrm{CH}_{4}$ & Methane \\
\hline CHP & Combined Heat and Power \\
\hline $\mathrm{CNG}$ & Compressed Natural Gas \\
\hline $\mathrm{CO}$ & Carbon Monoxide \\
\hline $\mathrm{CO}_{2}$ & Carbon Dioxide \\
\hline $\mathrm{COV}$ & Coefficient of Variation \\
\hline $\mathrm{CR}$ & Compression Ratio \\
\hline DI & Direct Injection \\
\hline DME & Dimethyl Ether \\
\hline DOI & Duration of Injection \\
\hline DR & Delivery Ratio \\
\hline $\mathrm{ECE}$ & Exhaust Chemical Energy \\
\hline ECU & Engine Control Unit \\
\hline EGR & Exhaust Gas Recirculation \\
\hline EIA & Energy Information Administration \\
\hline EPA & Environment Protection Agency \\
\hline EPC & Exhaust Port Closing \\
\hline EPO & Exhaust Port Opening \\
\hline $\mathrm{FC}$ & Fuel Consumption \\
\hline FTIR & Fourier-Transform Infrared Spectroscopy \\
\hline g & Grams \\
\hline
\end{tabular}




\begin{tabular}{|c|c|}
\hline GA & Genetic Algorithm \\
\hline GENSETS & Generators for Small Electrical and Thermal Systems \\
\hline GHG & Greenhouse Gas \\
\hline GWP & Global Warming Potential \\
\hline $\mathrm{H}_{2}$ & Hydrogen \\
\hline $\mathrm{H}_{2} \mathrm{O}$ & Water \\
\hline $\mathrm{HC}$ & Hydrocarbon \\
\hline HCCI & Homogenous Charge Compression Ignition \\
\hline HPDI & High Pressure Direct Injection \\
\hline $\mathrm{HZ}$ & Hertz \\
\hline IC & Internal Combustion \\
\hline ICE & Internal Combustion Engine \\
\hline IEA & International Energy Agency \\
\hline IMEP & Indicated Mean Effective Pressure \\
\hline ITE & Indicated Thermal Efficiency \\
\hline $\mathrm{K}$ & Degrees Kelvin \\
\hline $\mathrm{kHz}$ & Kilohertz \\
\hline $\mathrm{kJ}$ & Kilojoules \\
\hline $\mathrm{kWe}$ & Kilowatts of Electrical Power \\
\hline LFE & Laminar Flow Element \\
\hline LHV & Lower Heating Value \\
\hline LPDI & Low-Pressure Direct Injection \\
\hline LPG & Liquefied Petroleum Gas \\
\hline MBT & Maximum Brake Torque \\
\hline MBTU & Thousand British Thermal Units \\
\hline MFB & Mass Fraction Burned \\
\hline MFB50 & $50 \%$ mass fraction burnt \\
\hline MFC & Mass Flow Controller \\
\hline MJ & Megajoule \\
\hline $\mathrm{mm}$ & Millimeter \\
\hline $\mathrm{MN}$ & Methane Number \\
\hline NG & Natural Gas \\
\hline NMHC & Non-Methane Hydrocarbons \\
\hline $\mathrm{NO}_{\mathrm{x}}$ & Nitrogen Oxides \\
\hline $\mathrm{O}_{2}$ & Diatomic Oxygen \\
\hline OEM & Original Equipment Manufacturer \\
\hline OTS & Off the Shelf \\
\hline
\end{tabular}




\begin{tabular}{|c|c|}
\hline PCCI & Premixed Charge Compression Ignition \\
\hline PI & Port Injection \\
\hline PISO & Pressure Implicit with Splitting of Operators \\
\hline PM & Particulate Matter \\
\hline PSIA & Pound-force per Square Inch Absolute \\
\hline RCCI & Reactivity Controlled Charge Ignition \\
\hline RMSE & Root Mean Square Error \\
\hline ROHR & Rate of Heat Release \\
\hline ROI & Return of Investment \\
\hline RPM & Revolution per Minute \\
\hline SCFM & Standard Cubic Foot per Minute \\
\hline SCR & Selective Catalyst Reduction \\
\hline SI & Spark Ignited \\
\hline SLPM & Standard Liter per Minute \\
\hline SOI & Start of Injection \\
\hline ТВC & Thermal Barrier Coating \\
\hline TDC & Top Dead Center \\
\hline TE & Trapping Efficiency \\
\hline THC & Total Hydrocarbons \\
\hline TKE & Turbulent Kinetic Energy \\
\hline TPA & Three Pressure Analysis \\
\hline TPO & Transfer Port Opening \\
\hline TR & Trapping Ratio \\
\hline TSCI & Thermally Stratified Charge Ignition \\
\hline UF & Utilization Factor \\
\hline US & United States \\
\hline VE & Volumetric Efficiency \\
\hline VOC & Volatile Organic Compounds \\
\hline WOT & Wide Open Throttle \\
\hline \multicolumn{2}{|c|}{ Variables } \\
\hline $\mathrm{AFR}_{\text {stoich }}$ & Stoichiometric Air to Fuel Ratio \\
\hline$\overline{a_{i}}$ & Polynomial Constants \\
\hline$\overline{\mathrm{C}}_{\mathrm{p}}$ & Heat Capacity at Constant Pressure Molar Based \\
\hline$\overline{\mathrm{C}}_{\mathrm{p}_{\mathrm{ex}}}$ & Heat Capacity of Exhaust \\
\hline $\mathrm{C}_{\mu}$ & Turbulence model constant \\
\hline$\dot{\mathrm{E}}_{\mathrm{ex}}$ & Exhaust Energy \\
\hline$\dot{\mathrm{E}}_{\mathrm{ex}}^{\mathrm{fuel}}$ & Exhaust Fuel Energy \\
\hline
\end{tabular}




\begin{tabular}{|c|c|}
\hline$\dot{\mathrm{E}}_{\mathrm{ex}}^{\mathrm{ub}}$ & Exhaust Unburnt Energy $\left(\mathrm{CO}\right.$ and $\left.\mathrm{H}_{2}\right)$ \\
\hline$\dot{\mathrm{E}}_{\mathrm{ex}}^{\mathrm{HC}}$ & Exhaust HC Energy \\
\hline$\dot{\mathrm{E}}_{\text {in }}^{\text {fuel }}$ & Fuel energy \\
\hline$\overline{\overline{\mathrm{h}}_{\mathrm{f}_{\mathrm{i}}}^{\mathrm{o}}}$ & Enthalpy Formation at Standard Reference State \\
\hline$\overline{\mathrm{h}}_{\mathrm{i}}$ & Sensible Enthalpy at Specified State \\
\hline$\overline{\mathrm{h}}_{\mathrm{i}}^{\mathrm{o}}$ & Sensible Enthalpy at Standard Reference State \\
\hline$\dot{\mathrm{H}}_{\text {products }}$ & Total Enthalpy Flow Rate of Products \\
\hline$\dot{\mathrm{H}}_{\text {reactants }}$ & Total Enthalpy Flow Rate of Reactants \\
\hline IMEP & Indicated Mean Effective Pressure \\
\hline $\mathrm{K}_{\mathrm{wg}}$ & Equilibrium Constant \\
\hline $\mathrm{LHV}_{\mathrm{CO}}$ & Lower Heating Value of Carbon Monoxide \\
\hline $\mathrm{LHV}_{\text {fuel }}$ & Lower Heating Value of Fuel \\
\hline $\mathrm{LHV}_{\mathrm{H}_{2}}$ & Lower Heating Value of Hydrogen \\
\hline $\mathrm{LHV}_{\mathrm{i}}$ & Lower Heating Value \\
\hline$\dot{\mathrm{m}}_{\text {air }}$ & Intake Air Mass Flow \\
\hline$\dot{\mathrm{m}}_{\text {fuel }}$ & Fuel Mass Flow \\
\hline $\mathrm{N}$ & Operating Speed \\
\hline$\dot{\mathrm{n}}_{\text {exh }}$ & Exhaust Molar Flow Rate \\
\hline $\mathrm{P}_{\mathrm{amb}}$ & Ambient Pressure \\
\hline $\mathrm{P}_{\mathrm{ex}}$ & Exhaust Pressure \\
\hline$\dot{\mathrm{Q}}_{1}$ & Heat Loss \\
\hline$\dot{\mathrm{Q}}_{\mathrm{ex}}^{\text {th }}$ & Exhaust Thermal Energy \\
\hline$\overline{\mathrm{R}}$ & Universal Gas Constant \\
\hline Sc & Schmidt number \\
\hline$\dot{\mathrm{S}}$ & Entropy Rate \\
\hline$s_{f_{i}}^{0}$ & Entropy of Formation \\
\hline $\mathrm{T}$ & Temperature \\
\hline $\mathrm{T}_{\mathrm{ad}}$ & Adiabatic Flame Temperature \\
\hline $\mathrm{T}_{\mathrm{amb}}$ & Ambient Temperature \\
\hline $\mathrm{T}_{\text {boundary }}$ & Coolant Temperature \\
\hline $\mathrm{T}_{\text {exh }}$ & Exhaust Temperature \\
\hline $\mathrm{T}_{\text {in }}$ & Intake Temperature \\
\hline $\mathrm{T}_{0}$ & Reference Temperature \\
\hline $\mathrm{V}_{\mathrm{d}}$ & Displacement Volume \\
\hline $\mathrm{V}_{\mathrm{m}}$ & Molar Volume \\
\hline$\omega_{\mathrm{n}}$ & Natural Frequency \\
\hline$v_{\mathrm{CO}}$ & Mole Fraction of Carbon Monoxide \\
\hline
\end{tabular}




\begin{tabular}{|l|l|}
\hline$v_{\mathrm{H}_{2}}$ & Mole Fraction of Hydrogen \\
\hline $\mathrm{v}_{\mathrm{i}}$ & Component Mole Fraction \\
\hline$\dot{\mathrm{W}}_{\text {indicated }}$ & Indicated Power \\
\hline${ }^{\circ} \mathrm{C}$ & Degrees Celsius \\
\hline$\Delta_{\mathrm{r}} \mathrm{H}$ & Enthalpy of CO oxidation reaction \\
\hline$\Delta_{\mathrm{f}} \mathrm{H}\left\{\mathrm{CO}_{(\mathrm{g})}\right\}$ & Enthalpy of CO formation \\
\hline$\Delta_{\mathrm{f}} \mathrm{H}\left\{\mathrm{CO}_{2(\mathrm{~g})}\right\}$ & Enthalpy of $\mathrm{CO}_{2}$ formation \\
\hline$\Delta \mathrm{H}\left\{\mathrm{O}_{(\mathrm{Pt})}\right\}$ & Heat absorption for releasing O radicals \\
\hline$\Delta \mathrm{t}$ & Time step in 1D simulation \\
\hline$\Delta \mathrm{x}$ & Discretization Length in1D simulation \\
\hline$\delta_{\mathrm{max}}$ & Beam end deflection \\
\hline$\delta_{\mathrm{ij}}$ & Kronecker Delta \\
\hline$\mu$ & Viscosity \\
\hline$\mu_{\mathrm{mol}}$ & molecular viscosity \\
\hline$\mu_{\mathrm{tot}}$ & Total Viscosity \\
\hline$\mu^{\prime}$ & Dilatational viscosity \\
\hline$\lambda$ & Air Fuel Equivalence Ratio \\
\hline$\eta_{\mathrm{II}}$ & $2^{\text {nd }}$ law efficiency \\
\hline$\chi_{1}$ & Design Constant for Resonator \\
\hline$\chi_{2}$ & Design Constant for Resonator \\
\hline$\phi$ & Passive scalar \\
\hline
\end{tabular}




\section{Introduction}

With an industry shift towards clean energy, increasingly stringent regulations have driven energy researchers to create more energy efficient systems. While efficiency is of utmost concern, utilizing the available alternative energy resources may be more cost effective and, in some cases, offer emissions reductions. Natural gas (NG), due its abundance, low price, applicability to current power generation systems, and lower carbon content has become the dominant energy provider in power generation for the first time in 2016 surpassing coal [1]. NG utilization is primarily split between industrial purposes and electrical generation on large scales [2]. It has also been used for large displacement two-stroke engines and four-stroke engines in the transportation sector for decades, however this has not been widespread due to required, costly fuel supply infrastructure changes [3]. It has been used in dedicated NG engines and dual fuel engines to lower operating costs [4]. NG is available in over $61 \%$ of US homes [5]. Currently, it is a major source of energy for residential applications as shown in Figure 1 [1]. It is used for heating (furnaces, boilers), appliances (stoves, water heaters), and backup power. Nearly $50 \%$ of US households utilize natural gas as an energy source for cooking or home heating [6]. However, its potential dedicated use for decentralized power generation has not yet been exploited 


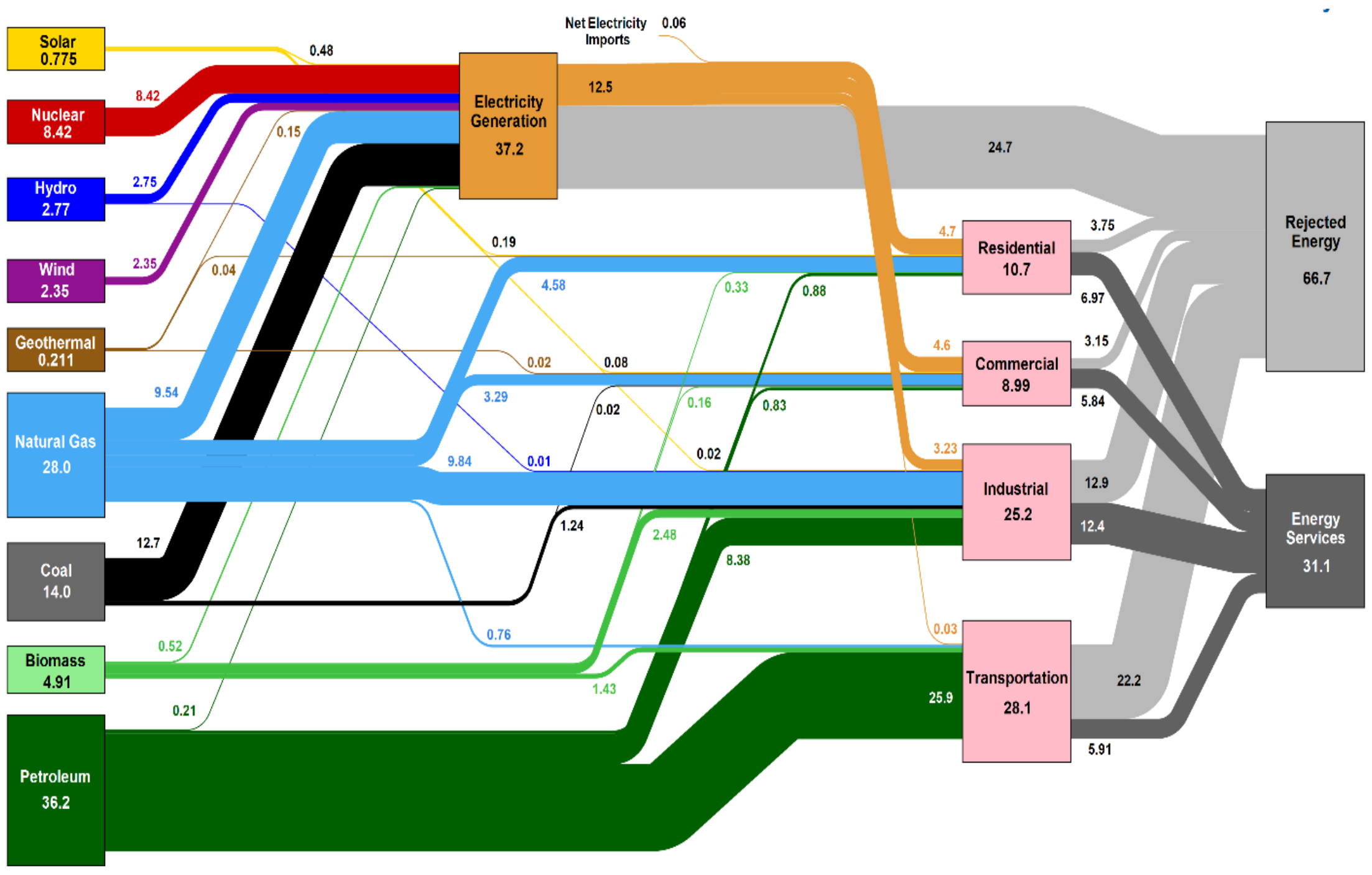

Figure 1. US energy consumption summary in 2017 [1]. 
Realizing the fuel availability and electrical generation and transmission efficiency issues, the Advanced Research Projects Agency - Energy (ARPA-E) conceived the Generators for Small Electrical and Thermal Systems (GENSETS) program to develop transformative generator technologies to enable widespread deployment of residential combined heat and power (CHP) systems [7].

This research was part of an ARPA-E GENSETS program at West Virginia University (WVU), which aimed to develop a high-efficiency and low-cost combined heat and power generation system, powered by a two-stroke engine fueled with low-pressure NG available at homes [7]. Based on a previous studies, the average daily electricity consumption per household in US is about 29.2 kilowatt-hours (kW-hr) setting the average power to around $1.2 \mathrm{~kW}[8,9]$. Therefore, the target electric power for GENSETS was set to $1 \mathrm{kWe}$ to account for the move towards higher household efficiency [7]. This means the engine must produce more than $1 \mathrm{~kW}$ brake power, to offset any inefficiency in the mechanical to electrical conversion system.

Typically, engines of this power rating are dominated by two-stroke designs. These engines are simple, cheap to produce, and have higher power density compared to four-stroke engines [10]. On the other hand, this research was assumed to be transferred to a linear alternator driven by a single cylinder engine on one side and a spring mechanism on the other side [11]. This required having a power cycle on each oscillation which is achievable only with two-stroke engines. In addition, because of the absence of rotary motion in the linear alternator, it would be difficult to easily implement a four-stroke engine, based on the need for linear valve actuation.

My research was conducted under the broad objective of converting chemical energy in natural gas to useful work and heat locally in the home, seeking to minimize criteria pollutants and climate change emissions, while increasing efficiency and maximizing waste heat recovery. I found that little information was available on the performance of small two-stroke engines fueled by NG, which would serve as the prime mover of a small CHP system.

My objective was to evaluate recent technologies deployed in small two-stroke engines and to create a framework for energy optimization of small CHP systems operating on gaseous fuels. Such a framework combined extensive experimental design and evaluation, 1D and 3D modeling for optimization (with experimental validation), and a complete energy analysis. This framework can serve as a general guideline for researchers and industry to follow on the path towards 
improved efficiency for small, decentralized power generation systems. To achieve this objective and align with project objectives, the following goals were targeted.

\subsection{Project Goals}

The ARPA-E GENSETS program efficiency target for NG to electric conversion was $37 \%$. The electric power output target was $1 \mathrm{~kW}$. NG was considered as the primary fuel and it was noted it was only available at low pressures as found in residential applications. Finally, an assessment of available energy for a complete CHP system was required. Long life and low cost were required for the application but were not the main drivers of my research.

\subsection{Objectives}

Based on NG being the only fuel for GENSETS required by ARPA-E and previous assessment of researchers at West Virginia University a two-stroke engine was selected for the GENSETS. The objective of this research is to develop a framework for energy optimization of a small two-stroke natural gas engine for micro-CHP application. Energy optimization mainly includes raising brake thermal efficiency, maximizing useable heat while maintain or improving combustion stability. To develop this framework a combination of experimental research, advanced simulation, and literature review was required. This resulting framework should clearly identify the path of energy efficiency evolution of the system. It should consider gaseous fuel variation effects on the GENSETS performance and provide cost and emission analyses for the micro-CHP system. The final framework can be used by researchers and industry as a set of "rules of thumb or guidelines"

for the design or modification of small engines that could serve as the prime movers of micro-CHP systems. 


\section{Literature Review}

This work was focused on various possible technologies that could have been deployed in advanced two-stroke engines operating on NG. CHP system evaluation also was set at the final stage of the project's goals. So, in this section, a variety of topics including two-stroke engine history, technologies, NG as an internal combustion engine fuel, and CHP systems are reviewed to assess the potential improvements from a variety of technology candidates.

\subsection{Two-stroke Engines}

\subsubsection{History}

The first two-stroke engine was designed in 1877, and was patented in 1881 [12]. Two-stroke engines were deployed in small vehicle transportation, marine engines, handheld equipment, and numerous other applications over the past 13 decades. There was a brief surge of interest in twostroke engines for automotive applications during the 1980's-90's by many manufacturers with the focus of direct injection and electronic control, however deep market penetration was not realized except for marine applications $[13,14]$.

Most handheld lawn and logging equipment use gasoline fueled two-stroke engines operating with carburetors. However, industry has developed small four-stroke engines to replace conventional two-stroke engines in motorcycles and even some handheld equipment due to emissions regulations [15, 16]; however, fuel injection for two-stroke chainsaws is arriving in the marketplace [17]. By nature of operation, port scavenged two-stroke engines tend to have excessive hydrocarbon (HC) emissions due to short-circuited fuel and oil lost via the exhaust port during the scavenging process. These emissions are regulated and represent a significant efficiency penalty $[18,19]$. In the past decade, research efforts primarily focused on redesign of the twostroke engine for alternative fuel usage and power density, as well as to achieve higher efficiency via more complex porting systems [20-22].

\subsubsection{Basic Design}

Two-stroke engines operate with one power stroke and one compression stroke per cycle. For this reason, both the intake and exhaust ports are simultaneously open for some duration. A cycle begins with the piston moving towards top dead center (TDC). When the piston reaches TDC, 
combustion expansion pushes it downward creating the power stroke until the exhaust port becomes exposed. After the exhaust is partially expelled, transfer ports become exposed which deliver fresh fuel and air charge that pushes additional exhaust out of the cylinder; however, in conventionally fueled designs this action also loses some fuel and air charge. Crankshaft inertia causes the piston to begin another upward stroke, which after the exhaust port is fully closed the piston compresses the remaining mixture for the next cycle [10]. Table 1 shows a summary of advantages and disadvantages of two-stroke engines over four-stroke counterparts.

Table 1. Summary of two-stroke engines advantages and disadvantages.

\begin{tabular}{|c|c|}
\hline Two-str & Disadvantages \\
\hline $\begin{array}{l}\text { - Higher power density than four-stroke engines of } \\
\text { the same displacement } \\
\text { - Valve train not required except for uniflow design } \\
\text { - No oil pump loss } \\
\text { - Higher operating speeds versus four-stroke engine } \\
\text { counterparts } \\
\text { - Less output torque fluctuation per cycle than four- } \\
\text { - } \text { stroke engines [13] } \\
\text { More cost effective to manufacture than four-stroke } \\
\text { engines }\end{array}$ & $\begin{array}{l}\text { - Increased hydrocarbon (HC) emissions due to } \\
\text { typical carbureted engines scavenging with an air- } \\
\text { fuel mixture } \\
\text { - Higher heat flux near TDC causing increased heat } \\
\text { losses } \\
\text { - Pumping losses in the case of crankcase } \\
\text { compression } \\
\text { - Misfires at low speeds due to poor scavenging } \\
\text { - Incomplete combustion }\end{array}$ \\
\hline
\end{tabular}

Two-stroke engine designs are normally differentiated by one of the various scavenging methods employed by the porting style. Common scavenging methods include cross-scavenging, loop scavenging, reverse loop scavenging, and uniflow scavenging as shown in Figure 2.
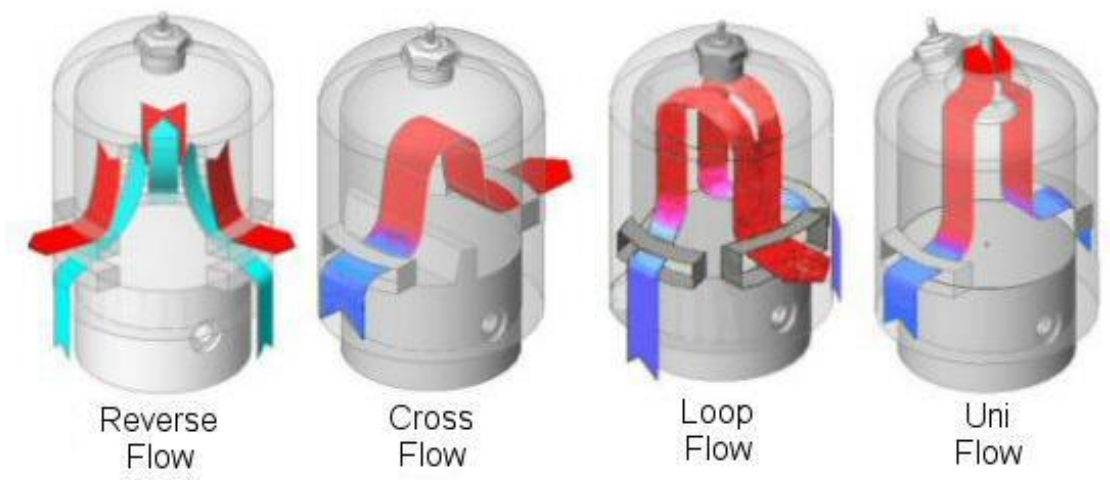

Figure 2. Scavenge flow patterns for the four basic scavenging approaches. Note the uniflow approach is the only one that uses an exhaust valve as opposed to an exhaust port $[14,23]$. 
The most challenging part of designing two-stroke engines is determining the best scavenging method for the engine. The difficulty lies within the randomness of cycle-to-cycle variations of incylinder gas flow motion. Large uniflow diesel two-stroke engines have been the most thermally efficient engines ever constructed at over 50\%. The uniflow scavenged type is the only one which relies on an exhaust valve, while all others are port controlled. Uniflow is commonly recognized as the best method but optimized loop/cross scavenging can be made to be nearly as efficient as uniflow [18]. However, due to the goal of implementation onto a linear system and lack of rotary motion for simple valve actuation, a uniflow scavenge design that included a valve was not selected.

Most two-stroke engines use the crankcase as a mixing chamber for the fuel and air intake prior to passage into the cylinder via transfer ports. This is known as crankcase compression. The pistons upward motion draws the fresh mixture into the crankcase and during the subsequent downward motion that follows it compresses the charge. Engines may use cylinder and piston porting to prevent back flow or have a reed valve in the crankcase to allow flow only into the crankcase and seal under pressurization. This reed valve method is quite common in medium displacement

engines. For both cases, air induction occurs with the piston's upward motion; followed by compression and release of the fresh charge into the combustion chamber [10]. Crankcase compression engines rely on the piston's upward movement for breathing. However, pumping losses during the piston's downward motion are inevitable. Crankcase compression engines can reach brake specific fuel consumption of $450 \mathrm{~g} / \mathrm{kW}$-hr using gasoline in a 50 cubic centimeter (cc) engine [24].

\subsection{Natural Gas in Internal Combustion Engines}

Recent literature addresses fuel choices, but for engines that were different from the hardware considered. Chandra et al. converted a small diesel engine to run as spark-ignited (SI) using NG, biogas, and methane enriched biogas to show the benefits of alternative fuel usage. Under port fuel fumigation, the efficiency of pure biogas was higher than compressed natural gas (CNG) over a range of ignition timings [25]. Yousefi and Birouk performed research on a dual fuel NG and diesel pilot ignited engine where they showed reductions in oxides of nitrogen $\left(\mathrm{NO}_{\mathrm{x}}\right)[26]$. Other dual fuel research on NG-diesel operation showed the possibility to reduce carbon monoxide (CO) and hydrocarbon (HC) emissions by $38.3 \%$ and $34.7 \%$, respectively when changing the intake air 
strategy to reduce the bulk quenching [27]. Navaro et al. conducted experimental research on NG blended with hydrogen in SI engines. They showed a reduction in carbon dioxide $\left(\mathrm{CO}_{2}\right)$ emissions and an increase in power output [28]. Djermouni and Ouadha investigated the impact of a turbocharger on the thermodynamic performance of a homogenous charge compression ignition (HCCI) engine fueled with NG. They indicated that both energy and exergy efficiency were enhanced with an increase of compressor and turbine efficiency [29]. Alamia et al. showed biomethane as a promising future fuel alternative, easily applied to engines [30]. Kan et al. performed fuel testing of biogas and syngas, which showed the benefits of the NG renewable alternative under premixed, SI engine operation [31]. Yang et al. examined injection timing impacts in a dual fuel NG piloted diesel. A pilot injection timing variation of 9 degrees crank angle was shown to improve the efficiency by up to $5 \%$ [32].

\subsection{Two-stroke Engine's Air Handling (Breathing)}

Tuning of two-stroke engines has occurred over the last 50 years mainly targeting increased power over a wide range of engine speeds, as applicable to performance two-stroke engines used in snowmobiles and dirt bikes. Tuning of such engines is nearly as much art as science due to the complex gas dynamics and numerous engine configurations [12, 18, 33]. Small handheld engines (e.g. chainsaws, lawn equipment) typically do not use intake and exhaust tuning because of packaging limitations, while larger engines such as performance dirt bikes are required to operate over a wide speed range, which reduces the impact of fixed geometry intake and exhaust systems. However, stationary two-stroke NG engines can benefit greatly since weight and packaging are not critical factors when compared to efficiency and stability. Current commercial designs include both two-stroke and four-stroke engines, fueled with gasoline, natural gas, propane, and diesel fuel. For back-up or temporary power generation, efficiency and stability are perhaps of less concern; however, for long term, independent power generation or sensitive applications like hospital's back-up power generation, both are critical. Air handling directly affects the power density and combustion stability and research on small diesel generators showed that stability of the electricity generated was directly proportional to combustion stability [34]. 


\subsubsection{Intake Optimization}

Intake optimization of two-stroke engines primarily consists of making geometrical changes to the intake system. The base geometry of the intake is characterized by overall length, volume, and taper angles of any Helmholtz resonator chambers. Mitianiec's experiment showed that by varying the overall length of the intake pipe, the delivery ratio of fresh charge was directly impacted. This was also true with variance of the diameter of the intake pipe. The addition of a side volume in the intake system also improved delivery ratio [35]. Delivery ratio is the ratio of intake air mass to the theoretical mass calculated based on engine total displacement. A study showed that by varying the length of inlet pipe at constant engine speed, a 17\% gain in compression pressure was achieved [36]. Adding Helmholtz resonator cones to the intake pipe improved the delivery ratio [37]. A study showed that intake resonators, which operated at approximately twice the frequency of the piston, raised both power and inducted mass [38]. The primary pressure wave sought to be captured was that of the final closing of the intake port, which would be reflected at such a time that assists the next intake process. It is also noted that wave velocity increased with increased pipe diameter [36]. Intake systems with common rail type branching showed advantages over those with completely separated ducting $[38,39]$. Overall, intake optimization must be tailored for each specific type and size of engine [33].

\subsubsection{Exhaust Optimization}

Understanding of the gas flow dynamics over the scavenging period is essential to improve the performance of any engine [40, 41]. Though many investigators have contributed greatly to the theoretical design, the complexity of the wave dynamics in the exhaust pipe still requires a deep understanding. Due to packaging considerations in most two-stroke engine applications, the exhaust pipe was designed to improve power density rather than the improving trapping ratio. A study considered the effects of exhaust's lead-in pipe length, expansion angles, and attachment of the muffler to the exhaust pipe of scooter type motorcycles and showed that the maximum power of the engine decreased linearly with increased angles of the first expansion [42]. A buildup of exhaust pressure prevented the escape of fresh mixture from the cylinder, hence proper arrangement of convergent cone and expansion length were required for timely arrival of the 
reflected wave front. Blair reported the construction of the divergent cone was three to four times longer when compared to convergent cone for best results [18].

Scavenging efficiency showed improvements by proper timing of the downstream, low-pressure wave during the overlap period via lowering the concentration of trapped residual gases inside the engine cylinder [42]. Tuning the exhaust pipe demonstrated better emptying of the burnt matter from the cylinder, better combustion of fuel, and less required throttling for a given engine speed [43]. Experiments on tuned exhausts increased engine power by $15.8 \%$ and reduced brake specific fuel consumption (BSFC) by 12\% when compared to the Original Equipment Manufacturer (OEM) exhaust system [44]. Designing a tuned exhaust system for an opposed piston two-stroke HCCI engine led to a more efficient and smoother engine operation with $15 \%$ improvement in trapping efficiency when compared to an untuned pipe [45]. Exhaust tuning of the small two-stroke engines in handheld power tools was studied by Gustafsson to meet emissions regulations without effecting the power density [46]. Computational modeling of diverse designs of exhaust manifolds for multi-cylinder, two-stroke, $\mathrm{NG}$ engines with the objective of reducing $\mathrm{NO}_{\mathrm{x}}$ emissions, showed possible reductions of 10-30\% in those emissions [42]. Additional studies regarding exhaust tuning of single cylinder two-stroke engines are found in literature [47-49].

\subsection{Effect of Compression Ratio}

As for the effects of compression ratio (CR) on engine performance, thermal efficiency, BSFC, brake torque (BT), air-fuel ratio (AFR), and exhaust emissions have been mainly investigated [50, 51]. Research carried out on a two-stroke engine at Yamaha Motor Company showed 1-3\% improvement in fuel consumption for each unit increase in CR between 6.6 and 13.6 at an engine speed of 4500 revolutions per minute (RPM) [52]. Another study investigated the effects of CR ranging from 8 to 14 on a four-stroke, SI, and direct injection NG engine. They reduced penetration distance of the fuel jet and had relatively strong mixture stratification due to higher CRs, which led to faster burn rate and higher thermal efficiency at low to medium engine loads. Their experiments showed maximum BTE at a CR of 12 for higher engine loads [53]. In a study focused on a single-cylinder, two-stroke, SI engine using methanol as fuel, researchers showed that a CR of 8.56 provided high BTE within the entire engine load range from $20 \%$ to $100 \%$ [54]. A twostroke engine was tested to compare the effects of CR on different fuels including diesel fuel, hydrogen, gasoline, and NG. Results showed an increase in efficiency of the engine with the 
exception of hydrogen due to its faster combustion. It was added that higher CR would result in higher frequency and power density [55]. The effect of an increase in CR from 7 to 8 was tested in a two-stroke engine with direct injection of gasoline under motoring conditions. The results showed a decrease in turbulent kinetic energy (TKE) and tumble ratio by $13 \%$ and $26 \%$, respectively [56].

\subsection{State-of-the-Art}

In previous investigations using a port-injection (PI) configuration, I observed that two-stroke engines, even those with improved breathing and CR, suffered from fuel slip losses[57-60]. That is why direct injection was found to be necessary for energy optimization.

\subsubsection{Injection Strategies}

To overcome deficiency of PI, a direct injection strategy was evaluated in a small NG two-stroke engine which resulted in a more than $60 \%$ relative improvement in BTE [61]. A study conducted in Japan investigated the effects of low-pressure CNG injection into the transfer (scavenging) ports of a two-stroke SI engine. The thermal efficiency of the engine increased by $25 \%$ at best as compared to the baseline gasoline operation. Injecting into a secondary transfer port had better performance than injection in the main transfer port due to better scavenge/fuel jet interactions [62]. Hatakeyama et al. compared small two-stroke engine performance between NG manifold and in-cylinder injection, and carbureted gasoline operation. The peak BTE achieved was slightly under $20 \%$ for in-cylinder injection of NG [63]. A computational fluid dynamics (CFD) model by Bozza et al. showed insufficient removal of burnt gases near the center of the cylinder in a loopscavenging configuration. NG operation at ignition timing set for maximum brake torque (MBT), was shown to have a lower in-cylinder peak pressure than gasoline operation due to the combination of low flame speed and high engine speed. This effect caused lower exhaust port temperatures and would inherently need a tuned exhaust designed separately from the OEM configuration [64].

Pradeep et al. conducted experiments on a $200 \mathrm{cc}$ engine with air-injection into the transfer ports and induction of liquefied petroleum gas (LPG) into the intake manifold in the gas phase. The engine experienced a $40 \%$ reduction in $\mathrm{HC}$ emissions and an increase in power at $25 \%$ throttle. Low pressure direct injection (LPDI) within the boost port was also considered but only showed a 
small reduction in $\mathrm{HC}$ emissions, while power density deteriorated at wide-open-throttle (WOT) [65]. Staged LPDI combined with high-pressure direct injection (HPDI) showed better combustion stability over HPDI alone [66]. In-cylinder LPDI reduced HC emissions by up to $93 \%$ at injection pressures of 4-5 bar for start-of-injection (SOI) ranging from 10-40 crank angle degrees (CAD) before bottom dead center (BDC). For WOT throttle conditions it was determined that injection at $30 \mathrm{CAD}$ before BDC was the best balance between reduced $\mathrm{HC}$ emissions and maximum BTE. The combustion rate improved over the standard manifold PI operation, with higher CO and lower $\mathrm{NO}_{\mathrm{x}}$ emissions due to a richer trapped mixture. Operation of the engine at different throttle positions did not require large variations in injection timing [22]. Tadesse and Aziz found that LPDI in the boost port, allowed for injection during intake opening, making the LPDI more effective because pressurized air kept fuel from flowing back out of the intake port [67].

$\mathrm{Hu}$ et al. examined LPDI of CNG for a four-stroke engine. They examined the optimal injection window for best fuel-air mixing. It was shown that compound direct injection with a primary injection pulse around 280 CAD before top dead center (BTDC) coupled with a secondary injection between 200-170 CAD BTDC was beneficial over a single injection period for improvements in mixing [68]. A 3 bar LPDI system was controlled by an overhead valve coupled to an air injection system and showed reduced emissions over carbureted models. The system also had excellent cold start and acceleration capabilities [69]. In residential NG applications where NG is available at low pressures, LPDI is beneficial over HPDI in terms of the required energy for gas compression. LPDI is better for operating in the homogenous charge region with a longer mixing duration as compared to HPDI being predominantly stratified. LPDI also had similar power output and torque when compared to HPDI [70].

While there have been a variety of research projects conducted around the direct injection of liquid or gaseous fuels for two-stroke engines, there have also been commercial interest in deploying direct injection fuel strategies. A novel approach was used by Mercury Marine in a variety of their outboard engines for small watercraft. They found that direct injection of gasoline lead to fuel stratification and therefore deployed a fuel and air direct injection system (based on the Orbital Technology) to ensure proper air fuel control and mixing [71, 72]. More recently, Husqvarna and KTM have begun to sell high-performance two-stroke dirt bikes equipped with LPDI, in the form of transfer port injection (TPI) of their 250 and $300 \mathrm{cc}$ series engines [73-75]. While no technical 
publications were found for their specific TPI applications, the companies claimed reductions in emissions of $40 \%$.

\subsubsection{Advanced Combustion}

In addition, NG is widely used in advanced combustion systems such as HCCI, premixed charge compression ignition (PCCI), reactivity-controlled compression ignition (RCCI) and thermally stratified compression ignition (TSCI) systems along with other fuels [76-78]. HCCI, PCCI, and RCCI combustion modes showed improved thermal efficiency while simultaneously reducing both $\mathrm{NO}_{\mathrm{x}}$ and particulate matter (PM) emissions [79, 80]. The deficiencies of HCCI and PCCI combustion were the high levels of $\mathrm{CO}$ and unburnt $\mathrm{HC}$ emissions in most cases. However, in recent years several researchers have demonstrated that boosted HCCI and PCCI combustion can exhibit nearly $100 \%$ combustion efficiency. Intake pressure was varied from 100 to $325 \mathrm{kPa}$ absolute. For highest boost pressure combustion efficiency was $99 \%$ and brake thermal efficiency was around $47 \%$ [81].

Nieman et al. replaced the gasoline with NG to examine the sensitivity of RCCI combustion at high load to injection system parameters. Since NG had lower reactivity compared to gasoline, it was proposed as a better fuel for RCCI combustion to control the maximum pressure rise rate by using the large reactivity gradient that existed between these two fuels [81]. In addition, RCCI was shown to enable high load operation when compared to HCCI [82]. Literature has identified that RCCI can be controlled through the ratios of fuels, injection parameters (start-of-injection, SOI; number of pulses, etc.), level of exhaust gas recirculation (EGR), compression ratio and combustion chamber design [83]. Increasing the ratio of NG to fuels like dimethyl ether (DME) tended to improve efficiency with increase brake mean effective pressure and decrease HC and CO emissions [84].

HCCI was not a implemented because of fuel composition variations throughout the US [85]. RCCI was not used because it required a secondary fuel - which is against the principle of using NG or LPG as the sole fuel source for CHP systems.

\subsubsection{Exhaust Gas Recirculation}

With new standards for emissions, especially $\mathrm{NO}_{\mathrm{x}}$, EGR implementation is widespread these days. While EGR helps to reduce the $\mathrm{NO}_{\mathrm{x}}$ it can negatively impact combustion stability, especially at 
low load operations [19]. Off-road engine emissions typically lag those of on-road engines in terms of lower emissions limits [86]. However, many off-road engines are implementing proven technologies such as EGR. Rates of EGR can be up to $30 \%$ of the total intake volume [87]. EGR is achieved both internally and externally [88]. Internal EGR is achieved on four-stroke engines through the use of variable valve actuation [89]. Alternatively, for two-stroke engines with fixed port geometries the exhaust design and exhaust throttling can serve as a method of inducing internal EGR. The lengths and angles of the convergent and divergent resonator sections directly impact the scavenging efficiency and thus level of internal EGR [10, 18, 42, 44, 46, 59].

For small, less sophisticated engines, external EGR can be achieved by passages between the intake and exhaust port manifolds. Such a method has been used to reduce emissions of small diesel fueled engines used for electrical generation [34]. Such a simplistic method was shown to decrease $\mathrm{NO}_{\mathrm{x}}$ emissions by 2.7 to $25.6 \%$ depending on load, which was proportional to EGR rate. The rate of EGR and engine load also influenced combustion and electrical production stability.

However, the application of EGR onto two-stroke engines depends on the scavenging of the engine itself. EGR can be applied as external EGR as is common to four-stroke engines. Work performed by Johnson et al. on a large-bore, lean-burn, natural gas engine investigated the effects of EGR. The system used a low pressure external EGR loop and examined volumetric percentages of 0, 2.5 and 5\%. Tests showed that indicated mean effective pressure (IMEP) was nearly constant over the span, while the coefficient of variation (COV) of IMEP decreased. A decrease in BSFC was reported for an external EGR rate of $2.5 \%$ and was attributed to the increased combustion stability. $\mathrm{NO}_{\mathrm{x}}$ and formaldehyde emissions were noted to decrease while THC, $\mathrm{CO}$, and volatile organic compounds (VOCs) increased at an EGR level of 2.5\% [90].

Watson et al. simulated the performance of a small two-stroke engine with the application of exhaust pipe restrictions and validated the simulation results with experimental research. They showed THC emissions were reduced by $24 \%$ while the CO emissions were reduced by $25 \%$. In addition, they presented simulated plots of trapping efficiency, delivery ratio, and scavenging efficiency for different exhaust throttling conditions [91].

A recent study by Hurakaldi et al. [92], explored the impact of EGR on a $100 \mathrm{cc}$, two-stroke, gasoline fueled engine and found that thermal efficiency improved while BSFC improved at higher speeds with EGR. Furthermore, they concluded that at lower EGR rates, $\mathrm{NO}_{\mathrm{x}}$ emissions were 
reduced without impact on performance and emissions while at higher rates, the performance and emissions were deteriorated along with the reduction of $\mathrm{NO}_{\mathrm{x}}$. A similar study examined EGR on a different $100 \mathrm{cc}$, two-stroke gasoline fueled engine [93]. They also showed reduced $\mathrm{NO}_{\mathrm{x}}$ emissions with increased levels of EGR but reported increased CO and THC emissions. Note that in both cases the EGR was external.

In electrical generation systems, for the sake of the generator, the engine operates at a constant speed to keep the electricity frequency fixed. Those engines usually operate at WOT conditions to obtain peak efficiency. As a consequence of balancing the electrical supply and demand, it is necessary to vary the engine load. One method to achieve this without losing efficiency is through application of EGR. While in four-stroke engines, internal EGR can be achieved using variable valve timing, in two-stroke engines it can be achieved by exhaust throttling. As part of my research, I investigated the effect of exhaust throttling on an engine's performance and emissions, which could later be used as a load control method [60].

Note that with DI, internal EGR induced by exhaust throttling was redundant for mitigating shortcircuiting since HC was already decreased by DI. On the other hand, given that external EGR deteriorates the combustion stability, one should consider internal EGR and keep in mind that it would most likely decrease the efficiency rather than decreasing emissions.

\subsection{CHP Systems}

A suite of research projects was focused on development of CHP systems that use NG as the fuel, as part of the ARPA-E GENSETS program [7,94]. The program target was to generate $1 \mathrm{~kW}$ of electrical power at high efficiencies for in-home power generation. In addition, these power sources can be used to develop heat used for domestic hot water, home heating, or other uses. The Environmental Protection Agency's (EPA) current CHP partnership supports the increased use of CHP systems due to the cost-effective emissions reduction they may provide. CHP systems benefit from dual stage energy utilization, such as electrical generation with waste heat being used for residential heating and hot water needs. Traditional (large-scale) electrical generation technologies have average efficiencies in the upper $30 \%$. The average coal power plant efficiency in US was around $33 \%$, while natural gas was $43 \%$ [95]. 
CHP systems however, are capable of achieving utilization factors (UF) over $80 \%$ [96]. Where UF is a ratio of both useful heat and work to the total heat energy (typically chemical fuel energy) supplied to the system. With an aim of developing efficient CHP systems, proper sizing of the heat-exchanging device relies heavily upon knowledge of the energy availabilities and the combined optimization of mechanical work and heat pathways.

Ondeck et al. introduced a framework for simultaneous optimization of the design and operating strategy of residential CHP systems to satisfy future power needs. They noted that new developments in small power generation were required [97]. Bianchi et al. developed guidelines for residential micro-CHP system designs, stressing the importance of proper sizing as a key factor for profitability and single family houses could allow for use of CHP systems that produce $<5 \mathrm{~kW}$ of electricity [98].

Gokul et al. showed that further understanding of the need for highly efficient NG engines was found in a techno-economic analysis of CHP systems. The research showed the benefits of local power production from energy savings and emissions viewpoints. It is expected that if the CHP systems meet the ARPA-E GENSET program targets, $\mathrm{CO}_{2}, \mathrm{VOCs}, \mathrm{CO}$, and $\mathrm{NO}_{\mathrm{x}}$ emissions would also be reduced relative to conventional power plants [99].

Research was conducted on a microgeneration unit that produced $10 \mathrm{~kW}$ of electrical power - well above the power required for most residential applications. It focused on converting a diesel engine to NG and deploying advanced engine concepts such as the Atkinson cycle. Even with a larger, four-stroke engine with Atkinson operation, the overall electrical generation efficiency ranged from 24-31.5\% [100]. Alternatively, Mikalsen et al. compared the Miller and Otto cycle for small NG engines for use in small-scale CHP systems. They showed that while the Miller cycle improved efficiency, it was at the cost of power density [101]. Honda demonstrated a $1.5 \mathrm{~kW}$ CHP system with an over expanded Atkinson cycle for improved thermal efficiency. Yanmar on the other hand presented a high efficiency unit with $5 \mathrm{~kW}$ output [102].

\subsubsection{Energy Balance}

CHP systems are well-defined by their electric efficiency and UF. To fully understand how to improve the design to target the highest UF with maximized electric efficiency, quantifying all energies associated with the system was necessary. As such, $1^{\text {st }}$ and $2^{\text {nd }}$ law analyses were 
performed by researchers for different engine applications for similar purposes [103]. Li et al. performed a thorough energy analysis on a four-stroke engine with three different combustion regimes, two of which used NG fuels. They found that HCCI and RCCI operation with NG, demonstrated lower exergy destruction than conventional diesel combustion [104]. An energy balance was performed by Ausserer et al. on a small two-stroke engine and showed that brake power accounted for $13 \%$ of the total incoming fuel energy, while short-circuiting losses were 40$60 \%$, and incomplete combustion was approximately $20 \%$ making it the second largest loss pathway [105]. Trattner et al. studied small, SI, two- and four-stroke engines up to $150 \mathrm{cc}$ and outlined further possible loss pathways. Imperfect combustion, wall heat transfer, gas exchange losses, and mechanical losses were monitored. The study showed that heat losses were higher at throttled, part load operation as opposed to WOT operation [106]. Piecha et al. completed a detailed wall heat transfer analysis in addition to energy balance methods on a $46 \mathrm{cc}$ two-stroke engine. They showed that the energy was split into $27 \%$ thermal exhaust, $19 \%$ unburned fuel, $19 \%$ effective or useful, $18 \%$ scavenging losses, $14 \%$ wall heat transfer, and $3 \%$ friction [107]. In other research, Orbaiz showed peak thermal efficiency for NG SI engines occurred during lean operation when in-cylinder heat loss and incomplete combustion were at a minimum [108]. Exergy balance simulations on larger scale CHP systems showed annual average exergetic efficiencies up to $62.8 \%$. The results showed higher exergy recovery during warmer parts of the year [109].

Other energy and exergy balance research highlighted possible energy savings from advanced heat transfer designs. It was found the thermal barrier coating (TBC) improved thermal efficiency [110]. An exergy analysis examined impact of AFR and showed peak $1^{\text {st }}$ and $2^{\text {nd }}$ law efficiencies while operating slightly below equivalence ratio of 0.9 [111]. Ebrahimi and Koch examined the differences in the energy and exergy flow paths of SI engines compared to HCCI engines while designing a micro-CHP system for residential use. The work showed SI energy distributions of work output, exhaust losses, and heat transfer losses were all similar and in the range of 25-30\% while incomplete combustion was between 5-10\% depending on ignition advance [112]. Other areas of CHP research included simulation of the energy flow in a community pool of micro-CHP systems and how ambient temperatures affected the systems. Since the load of an individual microCHP unit was so small, they studied pooling of a large number of devices. This was considered necessary to provide services to the grid or to actively participate in electricity markets [113]. Note that my research focused on a single system independent of other CHP systems and the grid. 


\subsubsection{Fuel Quality Effects}

A significant improvement in efficiency was observed with LPDI operation of a small two-stroke engine when compared to PI [61]. However, the effects of fuel composition on the CHP system viability were not explored. A change in fuel quality, could change the performance of the LPDI engine significantly.

In real applications, NG composition could vary both temporally and spatially. Also, widely available in the US for home heating applications is LPG and propane could potentially be used interchangeably with a NG system. Development of gaseous fueled products for use in multiple areas requires knowledge of sensitivity to fuel variations. Standard pipeline natural gas requires a minimum methane mole fraction of 75\% [114-116]. Some companies have their own standards such as Union Gas where their natural gas will only vary in mole fraction from 87 to $96 \%$ of methane in their supply region [117].

Methane number $(\mathrm{MN})$ is the gaseous fuel equivalent of octane number. $\mathrm{MN}$ is a measure of the fuel's knock resistance, where a MN of 70 would correspond to equivalent knock characteristics as a mixture of $70 \%$ methane and $30 \% \mathrm{H}_{2}$. Higher alkanes affect the combustion characteristics when utilized in an internal combustion (IC) engine. In a study examining fuel composition, ethane, propane, and butane were added separately into a known baseline NG blend. For all three additives, an increase in fuel energy density was counteracted by worsened knock resistance, lower fuel efficiency, and higher $\mathrm{CO}_{2}$ emissions. This penalty was caused by required ignition retard [118].

Research was conducted on 5 different heavy-duty natural gas engines fueled with 8 separate fuel blends. Engine power was shown to increase slightly with decreased MN and increased Wobbe Index. For fuels with higher Wobbe Index the brake specific fuel consumption decreased [119]. The Wobbe Index is a measure of the interchangeability of fuel gases and their relative ability to deliver energy in combustion process. Another study found engine power was proportional to the Wobbe Index at WOT conditions [120]. Experiments conducted on a single cylinder SI engine examined the addition of $10-40 \%$ propane balanced with pure methane. It was found that increased propane content also increased IMEP, while it decreased the COV of IMEP and duration of combustion [121]. Methane and hydrogen mixtures have also been tested for SI engine power characteristics [122]. 
A study by Keith Bullin et al. in 2008 showed gas qualities from different reservoirs or even different wells of a single reservoir were variable. They studied multiple wells for different reservoirs including, Barnett, New Albany, Antrim, and Fayetteville shale gas. They showed that methane composition was as low as $27 \%$ in some wells. In Barnett shale gas for example, measurements showed that methane could vary from around 80\% up to around 94\% [85]. A summary of their findings is presented in Table 2.

Table 2. Natural gas quality from different reservoirs.

\begin{tabular}{|l|c|c|c|c|c|}
\hline $\begin{array}{c}\text { Shale Gas } \\
\text { Reservoir }\end{array}$ & Methane [\%] & Ethane [\%] & Propane [\%] & $\mathbf{C O}_{2}$ [\%] & N [\%] \\
\hline Marcellus & 79 to 95.5 & 3 to 16.1 & 1 to 4 & 0.1 to 0.9 & 0.2 to 0.4 \\
\hline Barnett & 80 to 94 & 2.6 to 8 & 0 to 2.3 & 0.3 to 2.7 & 1 to 7.9 \\
\hline New Albany & 87.7 to 92.8 & 0.8 to 1.7 & 0.6 to 2.5 & 5.6 to 10.4 & - \\
\hline Antrim & 27.5 to 85.6 & 3.5 to 4.9 & 0.4 to 1 & 0 to 9 & 0.7 to 65 \\
\hline Fayetteville (avg) & 97.3 & 1 & 0 & 1 & 0.7 \\
\hline
\end{tabular}

\subsubsection{Current Commercial CHP Systems}

Currently, there are limited choices for commercial CHP systems for deployment at the home level [123]. One of the first was the Honda ECOWILL. Round robin research conducted on this current state-of-the-art micro-CHP prototype system showed 27.2\% BTE from the driving IC engine with a total system UF of $74.5 \%$. The total electrical efficiency was $23.5 \%$. Other case studies that focused on the Honda technology showed an electrical efficiency of 22\% [124]. The Honda technology used a four-stroke, NG engine that operated on an over expanded Atkinson cycle for improved thermal efficiency. Other commercially available systems typically have larger electrical power output capacity - for example Yanmar offers a $5 \mathrm{~kW}$ system [102]. Independent research on this unit was not verified but Yanmar advertised an efficiency of $28.3 \%$ with a UF of $85 \%$. While some research has been completed, it is acknowledged that there is a critical gap in the literature surrounding performance data of $1 \mathrm{~kW}$ micro-CHP systems [125].

\subsection{Emissions}

Current downfalls of two-stroke engines include low efficiency and high fuel slip rates, which raise THC emissions. Most EPA regulations focus on gasoline engines in this displacement range and are applicable to stationary and handheld engines. For non-handheld engines under $66 \mathrm{cc}$ (class 
$\mathrm{I}-\mathrm{A})$, the EPA regulation for $\mathrm{HC}+\mathrm{NO}_{\mathrm{x}}$ is $50 \mathrm{~g} / \mathrm{kWhr}$ and less. The same regulation applies to class IV handheld engines [126]. Fuel slip in NG engines is doubly important. First, due to their significant effect on fuel efficiency and second because of their combined greenhouse gas (GHG) effect. Methane's $\left(\mathrm{CH}_{4}\right) \mathrm{GHG}$ effect is almost 25 times of $\mathrm{CO}_{2}$ [127]. Catalysts could be implemented to reduce $\mathrm{CH}_{4}$ emissions, but their $\mathrm{CH}_{4}$ reduction efficiency is low [128]. According to CFR section 90 , handheld and non-handheld engines are classified based on their displacement and their class defines the regulations for them as shown in Table 3 [129]. The regulations applicable to engines examined in this work are bold.

Table 3. Engine classifications and regulations.

\begin{tabular}{|c|c|c|c|c|c|}
\hline $\begin{array}{c}\text { Engine } \\
\text { class }\end{array}$ & Type & $\begin{array}{c}\text { Displacement } \\
{[\mathbf{c c}]}\end{array}$ & $\begin{array}{c}\mathbf{H C + N O} \\
{[\mathbf{g} / \mathbf{k W h r}]}\end{array}$ & $\begin{array}{c}\text { NMHC+ NOx } \\
{[\mathbf{g} / \mathbf{k W h r}]}\end{array}$ & $\begin{array}{c}\mathbf{C O} \\
{[\mathbf{g} / \mathbf{k W h r}]}\end{array}$ \\
\hline Class I-A & $\begin{array}{c}\text { non-handheld equipment } \\
\text { engine }\end{array}$ & $\mathbf{V}_{\mathrm{d}}<\mathbf{6 6}$ & $\mathbf{5 0}$ & - & $\mathbf{6 1 0}$ \\
\hline Class I-B & $\begin{array}{c}\text { non-handheld equipment } \\
\text { engine }\end{array}$ & $66 \leq \mathrm{V}_{\mathrm{d}}<100$ & 40 & 37 & 610 \\
\hline Class I & $\begin{array}{c}\text { non-handheld equipment } \\
\text { engine }\end{array}$ & $100 \leq \mathrm{V}_{\mathrm{d}}<225$ & 16.1 & 14.8 & 610 \\
\hline Class II & $\begin{array}{c}\text { non-handheld equipment } \\
\text { engine }\end{array}$ & $225 \leq \mathrm{V}_{\mathrm{d}}$ & 12.1 & - & 805 \\
\hline Class III & $\begin{array}{c}\text { handheld equipment } \\
\text { engine }\end{array}$ & $\mathrm{V}_{\mathrm{d}}<20$ & 50 & $\mathbf{8 0 5}$ \\
\hline Class IV & $\begin{array}{c}\text { handheld equipment } \\
\text { engine }\end{array}$ & $\mathbf{2 0} \leq \mathbf{V}_{\mathbf{d}}<\mathbf{5 0}$ & $\mathbf{5 0}$ & - & 603 \\
\hline Class V & $\begin{array}{c}\text { handheld equipment } \\
\text { engine }\end{array}$ & $66 \leq \mathrm{V}_{\mathrm{d}}<100$ & 72 & - & $\mathbf{8 0 5}$ \\
\hline
\end{tabular}

\subsection{Simulation of Two-stroke Engines}

Most two-stroke engine simulations focused on simulating 3D geometries with CFD modeling of the in-cylinder phenomena. Fuel injection and 1D simulations were found to be limited. A CFD model showed that 10 bar liquid fuel injection benefitted fuel jet penetration by induced fuel air mixing and reduced short-circuited fuel. It also allowed for shorter injection duration, and wider range of SOI as compared to 3 or 5 bar operation [130]. However, it was noted that these benefits were at the expense of the energy needed to compress the fuel, which is typically a few percent of the fuel energy delivered to the engine. Another CFD study showed that an LPDI system should be placed in the cylinder wall to decouple injection timing from port timing. It was found that for 
a high power output speed of 7500 RPM the injectors would be best placed opposite to the exhaust port in order to harness the flow of the scavenging process for mixing. It was also found that mixing was promoted by placing the injector at an angle toward piston crown at BDC and opposed to the scavenging flow [131]. In a follow up study, it was shown that the LPDI setup had superior efficiency, and reduced brake specific fuel consumption over PI and carbureted fuel systems. HC emissions were also reduced by factors of 3-8 depending on throttle position [132].

Yang et al. presented research on premixed, lean-burn, NG engine operation studying the effects on combustion instabilities and injection timing. CFD modeling showed that for lean NG mixtures at low load, there was a band of injection timing that produced unreliable mixture concentrations and poor flame kernel formation. Injection was best performed early or late - avoiding the 30 to 90 crank angle degrees (CAD) after top dead center (ATDC) region [133]. A CFD model of NG direct injection by Fan et al. found that burn rate increased by nearly $30 \%$ under an optimized injection strategy versus premixed fueling via the intake [134].

\subsection{Review Summary}

Based on literature review and GENSETS project's targets, I identified a primary path to achieve the program targets. Although the literature provides energy audits of two-stroke engines, when it comes to small displacement LPDI NG engines, none exist that offer an attractive pathway for local CHP applications. In addition, fuel variation effects were not addressed by literature. To investigate it, I tested three different NG compositions and propane. A full energy distribution analysis was required at every step to determine the energy efficiency improvements. This research - by combining literature review, experiments, 1D and 3D simulations - led to a framework for energy optimization of micro-CHP systems operating on gaseous fuels. Table 4 presents the summary of path to improve the system's energy efficiency. 
Table 4. Summary of engine evolution for higher efficiency.

\begin{tabular}{|c|c|c|}
\hline Action & Method to Implement & Outcome \\
\hline $\begin{array}{c}\text { Baseline Conversion to } \\
\text { NG }\end{array}$ & Experimental & \multirow{6}{*}{$\begin{array}{l}\text { An energy optimization framework } \\
\text { for micro-CHP application driven } \\
\text { by small two-stroke engines from } \\
\text { literature review, experiments, data } \\
\text { analysis, 1D simulation, and 3D } \\
\text { simulation. }\end{array}$} \\
\hline $\begin{array}{l}\text { Air Handling (Intake } \\
\text { and Exhaust) }\end{array}$ & $\begin{array}{l}\text { Literature Review, Helmholtz theory } \\
\text { formula, Experimental }\end{array}$ & \\
\hline $\begin{array}{l}\text { Low Pressure Direct } \\
\text { Injection }\end{array}$ & Literature Review, Experimental & \\
\hline $\begin{array}{l}\text { Final System Level } \\
\text { Optimization }\end{array}$ & $\begin{array}{l}\text { 1D simulation interface with genetic } \\
\text { algorithm optimization, Experiments }\end{array}$ & \\
\hline $\begin{array}{l}\text { In-cylinder } \\
\text { Optimization }\end{array}$ & $\begin{array}{l}\text { 3D CFD simulation of engine, } \\
\text { Experiments }\end{array}$ & \\
\hline Fuel Quality and CHP & $\begin{array}{c}\text { Literature Review, Experimental, Data } \\
\text { Analyses }\end{array}$ & \\
\hline
\end{tabular}




\section{Methodology}

\subsection{Experiments}

\subsubsection{Laboratory}

I assisted Dr. Derek Johnson in the development of a micro-engine laboratory specifically for research and development of small displacement engines under $3 \mathrm{~kW}$. Figure 3 shows a schematic of the laboratory setup. Table 5 presents a detailed description experimental apparatus. Quality assurance (QA) of apparatuses was performed and data were recorded at low-frequency of up to $10 \mathrm{~Hz}$ (averaged for $1 \mathrm{~Hz}$ analysis). The research laboratory system is shown in Figure 4. 


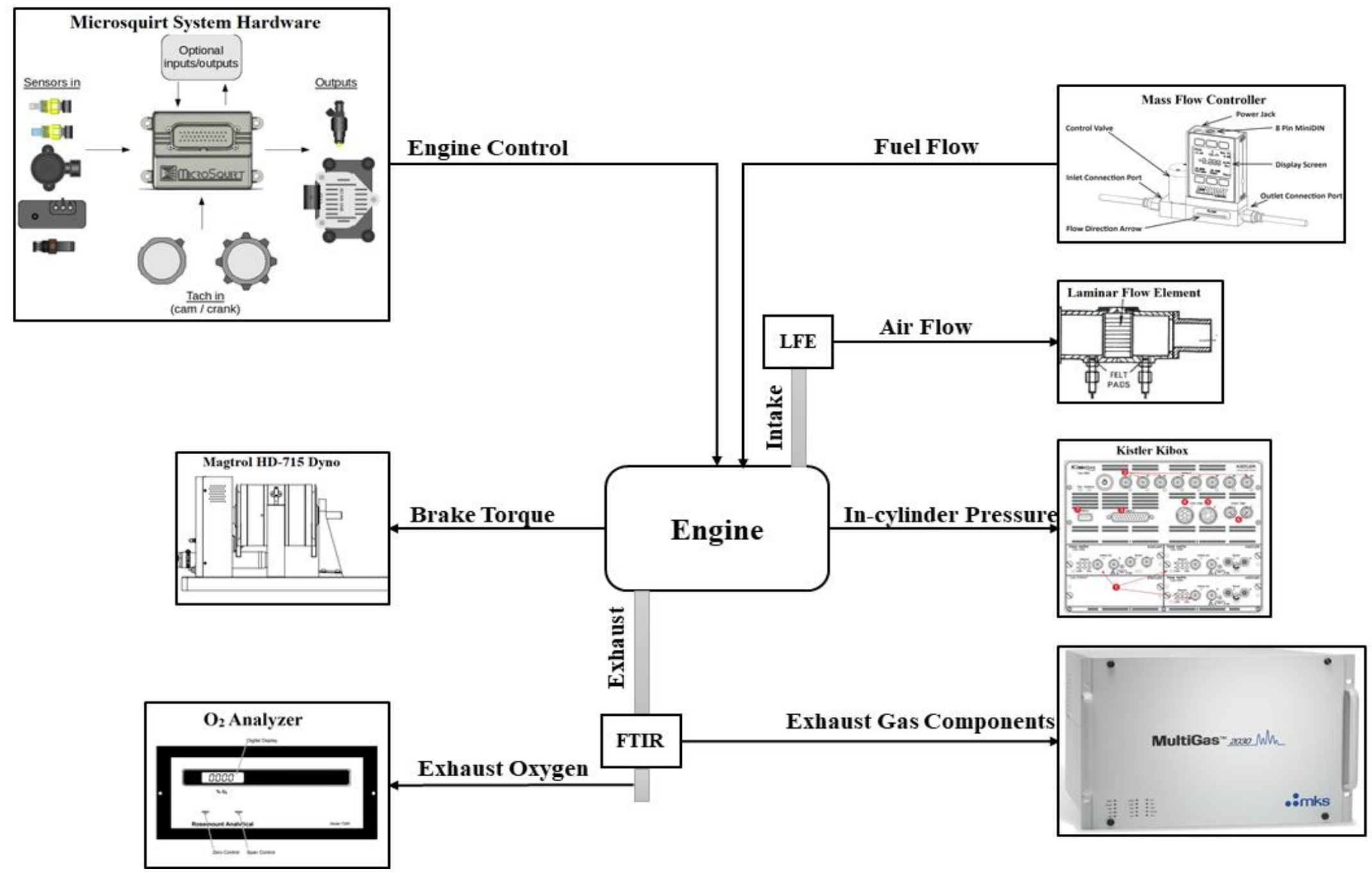

Figure 3. Setup schematic [135]. 
Table 5. List of laboratory apparatuses and their purposes [135].

\begin{tabular}{|c|c|c|}
\hline Purpose & $\begin{array}{c}\text { Tools } \\
\end{array}$ & Memo \\
\hline Ignition and Injection Control & $\begin{array}{l}\text { Hardware: Microsquirt Open } \\
\text { ECU } \\
\text { Software: Tuner Studio }\end{array}$ & \\
\hline $\begin{array}{c}\text { Engine Brake Torque } \\
\text { Measurement }\end{array}$ & $\begin{array}{l}\text { Hardware: Magtrol HD-715 } \\
\text { hysteresis load absorber and a } \\
\text { DSP6000 dynamometer } \\
\text { controller } \\
\text { Software: Inhouse }\end{array}$ & $\begin{array}{c}\text { HD-715 } \\
\text { Maximum Torque: } 55 \text { in-lb } \\
\text { Max Speed: } 25000 \text { RPM } \\
\text { Accuracy: } \pm 0.25 \% \text { (full scale) }\end{array}$ \\
\hline Exhaust Gas Concentrations & $\begin{array}{l}\text { Hardware: MKS 2030 FTIR } \\
\text { continuous gas analyzer. } \\
\text { Software: MultiGas } 2030\end{array}$ & Measuring frequency: $5 \mathrm{~Hz}$ \\
\hline $\begin{array}{l}\text { Exhaust Oxygen } \\
\text { Concentration }\end{array}$ & $\begin{array}{c}\text { Hardware: 755-R Rosemount } \\
\text { Paramagnetic Oxygen Analyzer } \\
\text { Software: In-house }\end{array}$ & $\begin{array}{c}\text { Range: } 0-25 \% \text { oxygen } \\
\text { Repeatability: } \pm 1 \% \text { of full-scale } \\
\text { Zero and Span Drift: } \pm 1 \% \\
\text { fullscale per } 24 \text { hours }\end{array}$ \\
\hline Intake Air Flow Measurement & $\begin{array}{c}\text { Hardware: HEISE PTE1 } \\
\text { Pressure Calibrator along with } \\
\text { HSQ-2 module, HSQ-1 module, } \\
\text { and an eight standard cubic feet } \\
\text { per minute (SCFM) laminar flow } \\
\text { element (LFE) } \\
\text { Software: In-house }\end{array}$ & $\begin{array}{c}\text { HSQ1 (Pressure Difference) } \\
\text { Range: } 0-25 \text { inch of } \mathrm{H}_{2} \mathrm{O} \\
\text { Sensitivity: } \pm 0.002 \% \text { of span } \\
\text { Repeatability: } \pm 0.02 \% \text { of span } \\
\text { HSQ-2 (Absolute Pressure) } \\
\text { Range: } 0-30 \text { PSIA } \\
\text { Sensitivity: } \pm 0.002 \% \text { of span } \\
\text { Repeatability: } \pm 0.01 \% \text { of span }\end{array}$ \\
\hline $\begin{array}{c}\text { Test room Temperature, } \\
\text { Relative Humidity }(\mathrm{RH}), \text { and } \\
\text { Barometric Pressure }\end{array}$ & $\begin{array}{l}\text { Hardware: Omega I-server } \\
\text { environmental instrument } \\
\text { Software: In-house }\end{array}$ & $\begin{array}{c}\text { RH Accuracy: } \pm 2 \% \\
\text { RH Repeatability: } \pm 0.1 \% \\
\text { Temp. Accuracy: } \pm 0.5^{\circ} \mathrm{C} \text { for } 5 \text { to } \\
45^{\circ} \mathrm{C} \\
\text { Pressure Accuracy: } \pm 2 \text { mbar for } 10 \\
\text { to } 1100 \text { mbar }\end{array}$ \\
\hline $\begin{array}{l}\text { In-cylinder Pressure } \\
\text { Measurements }\end{array}$ & $\begin{array}{l}\text { Hardware: Kistler Kibox data } \\
\text { logger along with a 6054A } \\
\text { piezoelectric pressure transducer } \\
\text { Software: Kibox Cockpit }\end{array}$ & $\begin{array}{c}\text { Range: } 0-300 \mathrm{bar} \\
\text { Sensitivity: } 13.4 \mathrm{pC} / \mathrm{bar} \\
\text { Sensitivity change: } \pm 2 \% \text { for } 23 \text { to } \\
200 \mathrm{C} \\
\text { Frequency: } 312.5 \mathrm{kHz}\end{array}$ \\
\hline Fuel Flow Measurement & $\begin{array}{c}\text { Hardware: MC-20 series Alicat } \\
\text { Mass Flow Controller (MFC) } \\
\text { Software: In-house }\end{array}$ & $\begin{array}{c}\text { Maximum Flow: } 20 \text { SLPM } \\
\text { Accuracy: } \pm(0.8 \% \text { of Reading }+ \\
0.2 \% \text { of Full Scale }) \\
\text { Repeatability: } \pm 0.2 \% \text { Full Scale } \\
\text { Operating Range: } 0.5 \% \text { to } 100 \% \\
\text { Full Scale }\end{array}$ \\
\hline Engine/Exhaust Temperatures & $\begin{array}{l}\text { Hardware: k-type thermocouples } \\
\text { along with an ICP device } \\
\text { Software: In-house }\end{array}$ & \\
\hline
\end{tabular}




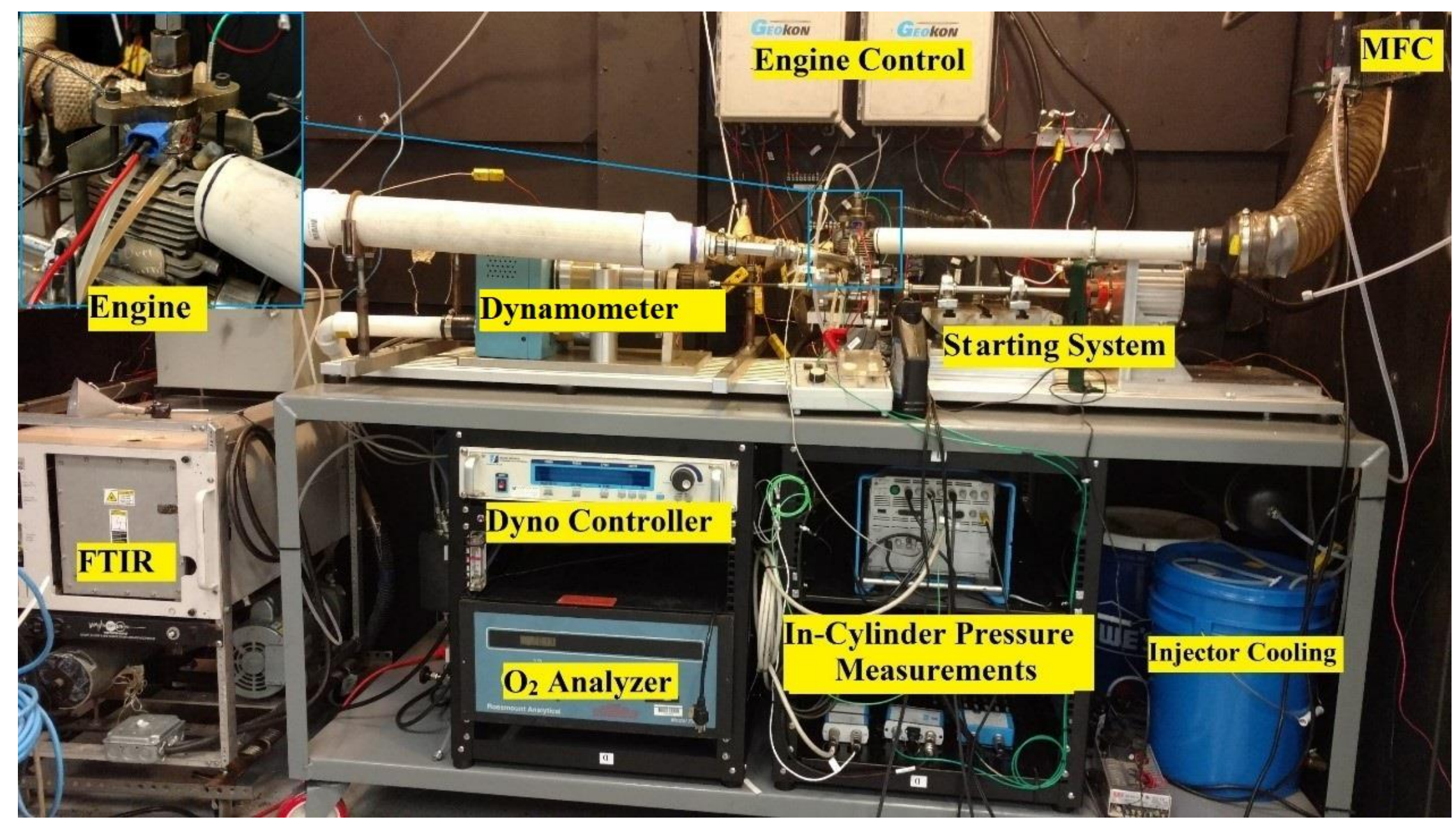

Figure 4. Research laboratory system [135]. 


\subsubsection{Design of Experiments}

Engine design space, project's objectives, and literature review were the basis of design of experiments. A high-level summary of designed experiments is shown in Table 6.

Table 6. High-level overview of designed experiments.

\begin{tabular}{|c|c|c|c|}
\hline Steps & Action & Observations/Considerations & Memo \\
\hline 1 & $\begin{array}{l}\text { Engine selection for } 1 \mathrm{~kW} \text { limited to } \\
\qquad 30 \mathrm{~mm} \text { stroke. }\end{array}$ & & \multirow{4}{*}{$\begin{array}{c}\text { Research on a } 30 \text { cc engine, } \\
\text { with four transfer ports } \\
\text { (baseline engine). The engine } \\
\text { used piston-controlled port } \\
\text { timing crankcase } \\
\text { compression (not reed } \\
\text { valves). }\end{array}$} \\
\hline 2 & $\begin{array}{c}\text { Baseline Conversion to NG } \\
\text { Operation }\end{array}$ & $\begin{array}{c}\% \text { fuel efficiency } \approx 7, \mathrm{DR} \\
\approx 0.28, \text { Brake Power } \approx 230 \mathrm{~W}\end{array}$ & \\
\hline 3 & Intake Optimization & $\begin{array}{c}\text { fuel efficiency } \approx 10 \%, \\
\mathrm{DR} \approx 0.53, \text { Brake Power } \approx 500 \\
\mathrm{~W}\end{array}$ & \\
\hline 4 & $\begin{array}{l}\text { Exhaust Optimization (Multi-cone } \\
\text { and double-cone) }\end{array}$ & $\begin{array}{l}\text { fuel efficiency } \approx 13 \%, \mathrm{DR} \approx 0.9, \\
\text { Brake Power } \approx 870 \mathrm{~W}\end{array}$ & \\
\hline 5 & $\begin{array}{l}\text { Selected a similar engine with } \\
\text { slightly higher displacement and } \\
\text { modified scavenging strategies }\end{array}$ & \multirow{2}{*}{$\begin{array}{c}\text { fuel efficiency } \approx 16 \%, \\
\mathrm{DR} \approx 0.85, \text { Brake Power } \approx \\
1400 \mathrm{~W}\end{array}$} & \multirow{6}{*}{$\begin{array}{l}34 \mathrm{cc} \text { engine with a rear } \\
\text { boost port. Transferred the } \\
\text { intake and exhaust } \\
\text { optimization to the new } \\
\text { engine (boosted engine). The } \\
\text { new engine used reed valve } \\
\text { induction for crankcase } \\
\text { compression. }\end{array}$} \\
\hline 6 & $\begin{array}{l}\text { Retune the intake and exhaust for } \\
\text { the new engine }\end{array}$ & & \\
\hline 7 & Low-Pressure Direct Injection & fuel efficiency $\approx 24 \%, \mathrm{DR} \approx 0.9$ & \\
\hline 8 & $\begin{array}{l}\text { 1D modeling and exhaust resonator } \\
\text { optimization with genetic algorithm } \\
\text { with fine control of injection and } \\
\text { ignition timing }\end{array}$ & fuel efficiency $\approx 26 \%$ & \\
\hline 9 & $\begin{array}{l}\text { Stratification investigation and } \\
\text { optimize the spark plug location }\end{array}$ & fuel efficiency $\approx 27 \%$ & \\
\hline 10 & $\begin{array}{l}\text { Operate different fuels and detailed } \\
\text { analysis on their effect on CHP } \\
\text { system }\end{array}$ & & \\
\hline
\end{tabular}

\subsubsection{Engines}

As stated in Table 6, two engines were used in this research. Figure 5 shows both engine design overviews. Note that the boosted engine (left) was used for direct injection through final optimization. Table 7 shows both engines' specifications. Note that the boosted engine had higher bore size, modified transfer ports, and added rear boost port. These combined with a reed valve, resulted in higher brake power output on the boosted engine, while maintaining the maximum stroke of $30 \mathrm{~mm}$. Note that stroke limitations were imposed at a maximum of $30 \mathrm{~mm}$ based on 
linear system design constraints beyond the scope of this research. The crankcase used for both engines were similar.

Table 7. Second experiment engine specifications.

\begin{tabular}{|l|c|c|c|c|c|}
\hline & Baseline & Boosted engine & & Baseline & Boosted engine \\
\hline Number of & 1 & 1 & Number of ports & 5 & 6 \\
\hline Type & 2 -Stroke & 2 -Stroke & Boost Port & No & Yes \\
\hline Bore & $34[\mathrm{~mm}]$ & $38[\mathrm{~mm}]$ & Reed Valve & No & Yes \\
\hline Stroke & $30[\mathrm{~mm}]$ & $30[\mathrm{~mm}]$ & $\begin{array}{c}\text { Compression Ratio } \\
\text { (Geometric) }\end{array}$ & Variable & 12.76 (measured) \\
\hline $\begin{array}{l}\text { Connecting Rod } \\
\text { Length }\end{array}$ & $52[\mathrm{~mm}]$ & $52[\mathrm{~mm}]$ & $\begin{array}{c}\text { Compression Ratio } \\
\text { (Effective) }\end{array}$ & Variable & 8.15 (measured) \\
\hline Induction & Naturally & Naturally & Exhaust Port Open & 96 CAD & 92 CAD ATDC \\
\hline Displaced & $30[\mathrm{cc}]$ & $34[\mathrm{cc}]$ & Transfer Port Open & $120 \mathrm{CAD}$ & 120 CAD ATDC \\
\hline
\end{tabular}
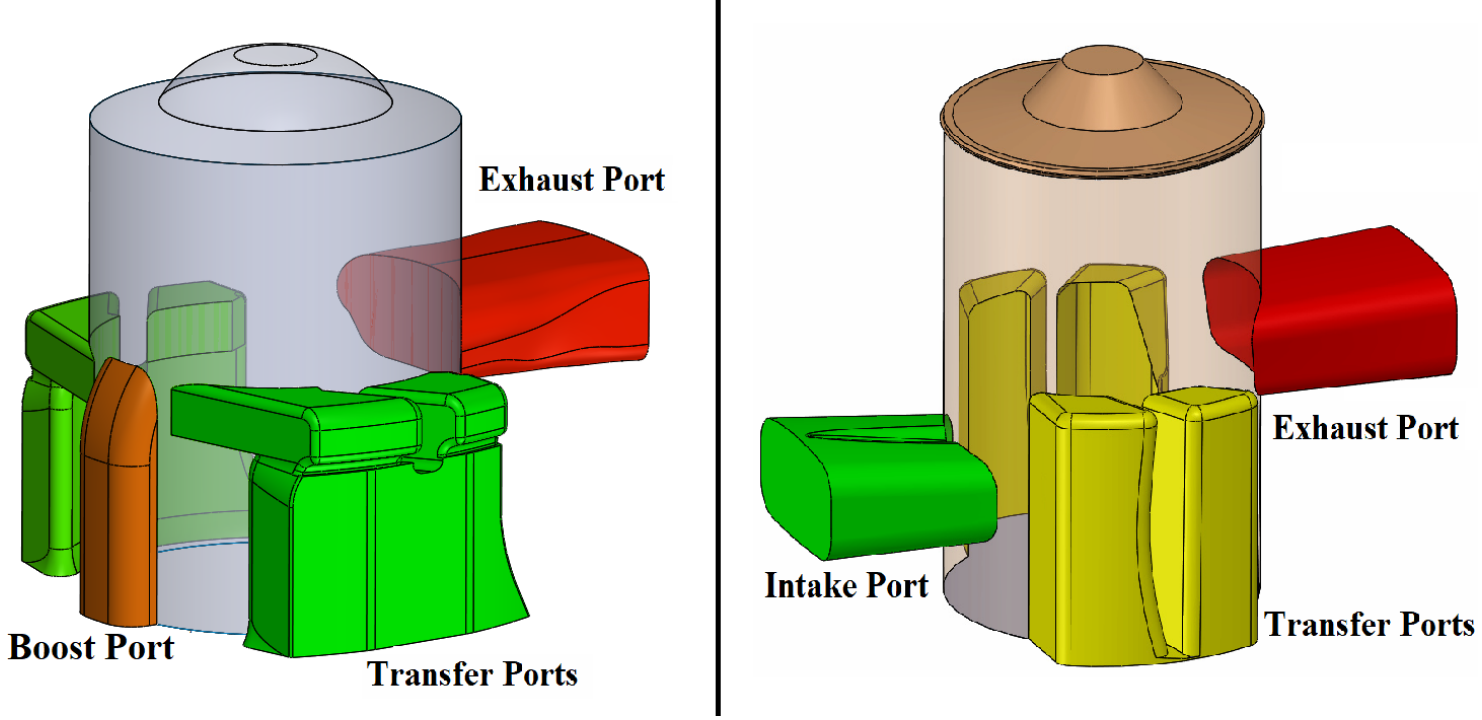

Figure 5. Baseline engine (right) and second (boosted) engine design (left).

\subsubsection{Air Handling}

\section{Intake Optimization}

Intake optimization was easy and quick to implement for experimental validation. Engelman's electrical analogy (Equations 1-3) was used to convert intake system (Figure 6) equivalent to capacitances and inductances. 


$$
\begin{aligned}
& \text { Inductance }(I)=\left(\frac{L}{A}\right) \\
& \text { Capacitance }(C)=V \\
& \omega_{n}=\frac{1}{\sqrt{I C}}=\sqrt{\frac{k}{m}}
\end{aligned}
$$

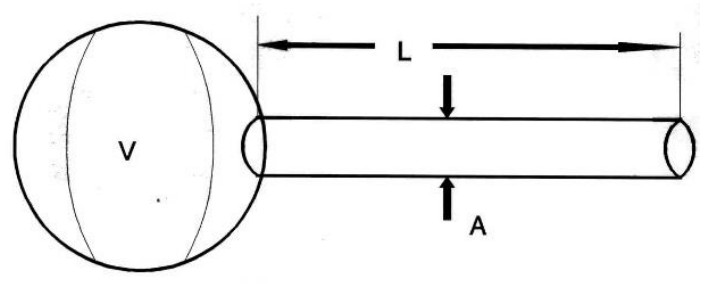

Figure 6. Helmholtz resonator [136].

The natural frequency of the such an intake was calculated by Equations 4-6.

$$
\begin{aligned}
& f_{H}=\frac{c}{2 \pi} \sqrt{\frac{A}{L \times V}} \\
& L=l+.3 d=\text { effective length } \\
& V_{e f f}=\frac{V_{d}}{2}+V_{c l}
\end{aligned}
$$

Where, $V_{d}$ is swept volume, $V_{c l}$ is the clearance volume, $V_{\text {eff }}$ is the effective volume based on effective length $L$, and $c$ is the speed of sound. The peak delivery ratio was expected to occur when the natural frequency of intake resonator was about twice the piston frequency.

\section{Exhaust Optimization}

A general design of an exhaust resonator is shown Figure 7. At exhaust port opening (EPO), high pressure gases will form a wave front that moves down the pipe. The first expansion inverts the positive pressure wave into a negative wave (suction wave). This is the function of first expansion in the exhaust resonator design, to improve scavenging [33]. This suction wave helps to clear burnt gas from the cylinder and draw the fresh charge through the transfer ports [33]. 

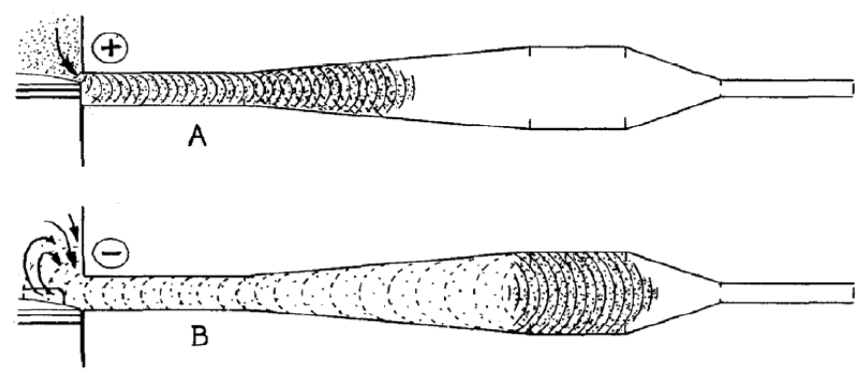

Figure 7. Exhaust suction wave [33].

The suction wave reflects from the nozzle-shaped section (convergent cone) to recharge the cylinder as the port closed (Figure 8). This improves trapping efficiency.
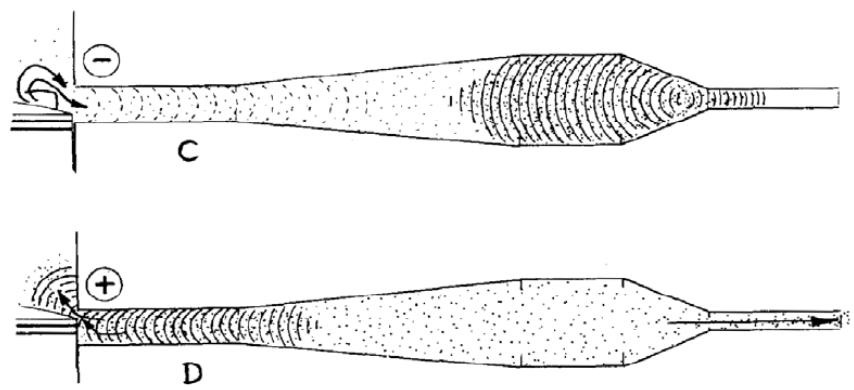

Figure 8. Reflected positive pressure wave to recharge the cylinder [33].

Exhaust tapered sections can be single cone or multi cones. The multi cones have the ability to tune the engine over a wider range of engine speeds when compared to single cone [37]. Two exhaust resonators were designed and manufactured using Helmholtz theory to target operation at 5400 RPM [59]. The baseline engine came with an off the shelf (OTS) exhaust design. Figure 9 shows a double cone design for the exhaust resonator. 


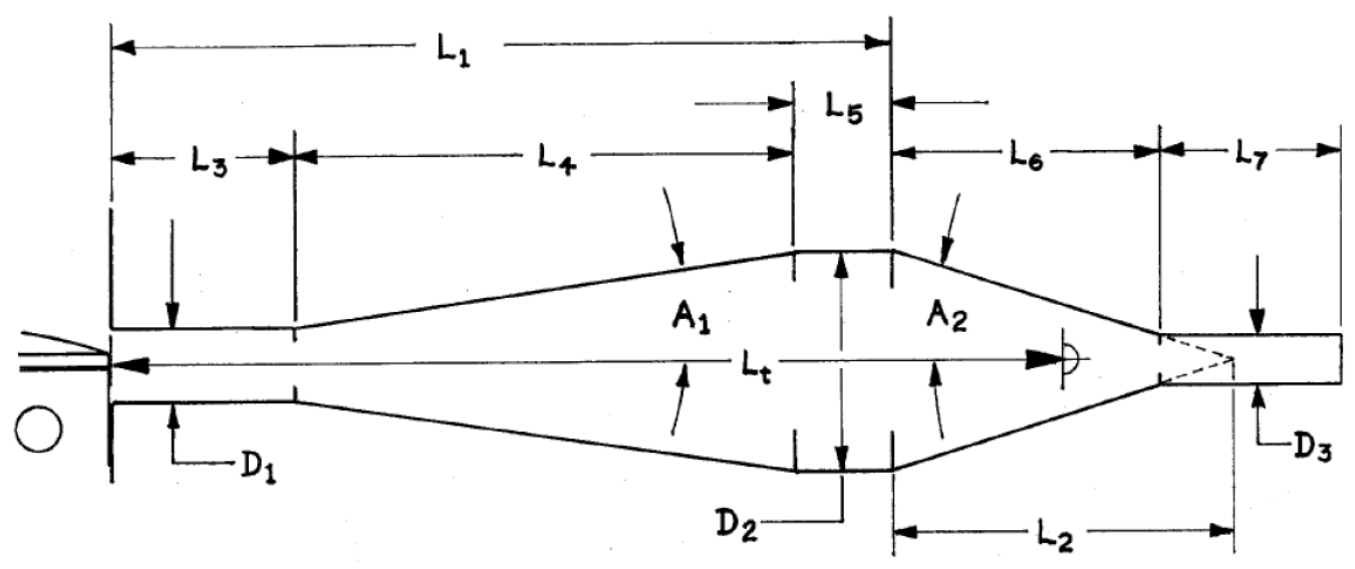

Figure 9. Double cone exhaust design.

Double cone exhaust design recommendation by literature was calculated from Equation (7) to (18) [33]:

$$
\begin{aligned}
& L_{T}[\text { in }]=\frac{E_{0}[\text { degree }] V_{S}\left[\frac{f t}{S}\right]}{N(R P M)} \\
& L_{1}=L_{T}-\frac{L^{2}}{2} \\
& L_{2}=\frac{D_{2}}{2} \cot \left(A_{2}\right) \\
& L_{3}=D_{1} \times 6 \\
& L_{4}=\frac{D_{2}-D_{1}}{2} \cot \left(A_{1}\right) \\
& L_{5}=L_{1}-\left(L_{3}+L_{4}\right) \\
& L_{6}=\frac{D_{2}-D_{3}}{2} \cot \left(A_{2}\right) \\
& L_{7}=D_{3} \times 12
\end{aligned}
$$

$D_{1}=(1.1-1.15) \sqrt{\frac{4 \times A_{\text {exhport }}}{\pi}}$ 


$$
\begin{aligned}
& D_{2}=\sqrt{6.25 \times D^{2}} \\
& D_{3}=D_{1} \times(0.57-0.62) \\
& V_{s}=\sqrt{\gamma R_{i} T_{\text {exh }}} \times 3.28\left[\frac{\mathrm{ft}}{\mathrm{m}}\right]
\end{aligned}
$$

$E_{0}$ is the exhaust open duration. $A_{1}$ and $A_{2}$ are 10 and 4.5 degrees respectively as recommended by literature for maximum delivery ratio and power [33].

Multi-cone resonator's design parameters were calculated based on Equation (19) to (35) [33] [18]:

$$
\begin{aligned}
& D_{0}=\sqrt{\frac{4 \times A_{\text {exhport }}}{\pi}} \\
& D_{1}=a_{1} \times D_{0} \\
& a_{1}=\left(0.0083 \times B M E P^{2}\right)-0.1917 \times B M E P+1.7=1.125 \\
& L_{1}=L_{T} \\
& L_{2}=0.275 \times L_{T} \\
& L_{3}=0.183 \times L_{T} \\
& L_{4}=0.092 \times L_{T} \\
& L_{5}=0.11 \times L_{T} \\
& L_{6}=0.24 \times L_{T} \\
& L_{7}=L_{6} \\
& D_{4}=3.25 \times D_{0} \\
& \chi_{1}=\left(\frac{L_{2}}{L_{2}+L_{3}+L_{4}}\right)^{1.5 \times \ln \left(D_{4} / D_{1}\right)} \\
& \chi_{2}=\left(\frac{L_{2}+L_{3}}{L_{2}+L_{3}+L_{4}}\right)^{1.5 \times \ln \left(D_{4} / D_{1}\right)}
\end{aligned}
$$




$$
\begin{aligned}
& D_{2}=D_{1} \times \exp \left(\chi_{1}\right) \\
& D_{3}=D_{1} \times \exp \left(\chi_{2}\right) \\
& D_{5}=D_{4} \\
& D_{7}=D_{6}=D_{1}
\end{aligned}
$$

Where BMEP in Equation (21) was calculated based engine speed of 5400 RPM and $1 \mathrm{~kW}$ brake power.

Figure 10 shows the OTS exhaust design and Table 8 shows its dimensions. Figure 11 shows two exhaust designs. The alpha was a multi cone diffuser and the beta was single cone diffuser.

Table 9 and Table 10 show the dimensions for the two designs based on 5400 RPM frequency, exhaust port timing, and exhaust temperature form experiments.

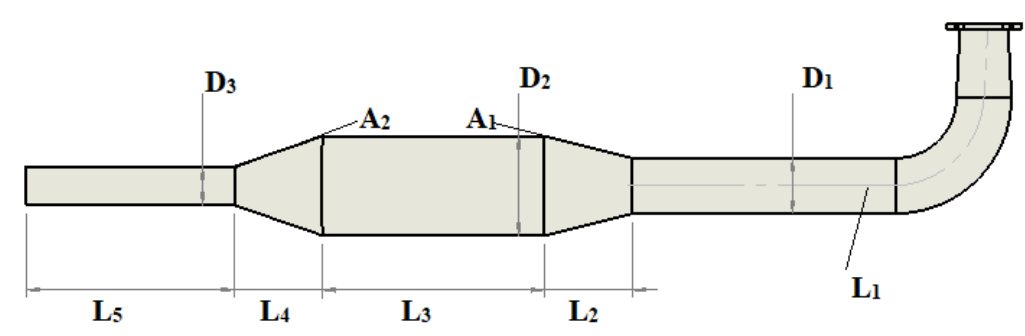

Figure 10. OTS exhaust design. 


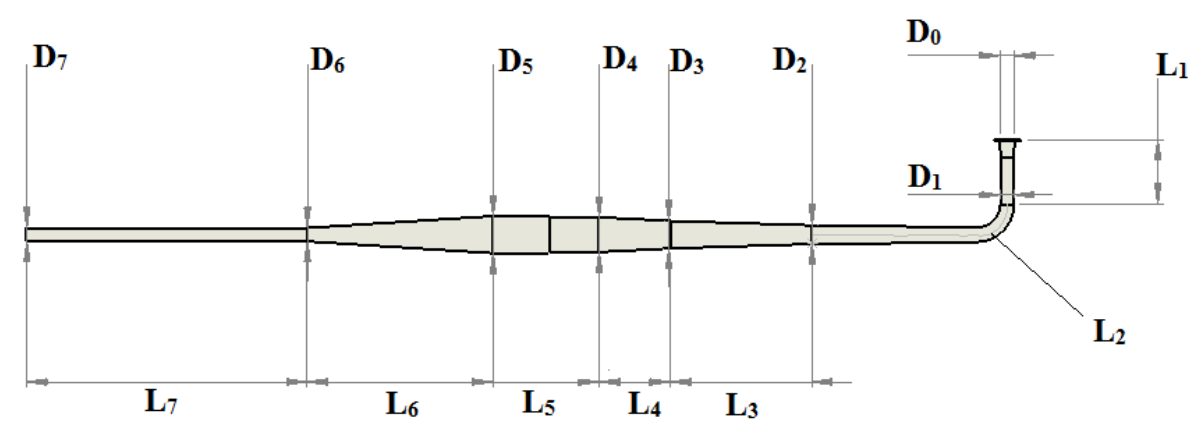

\section{Alpha Design}
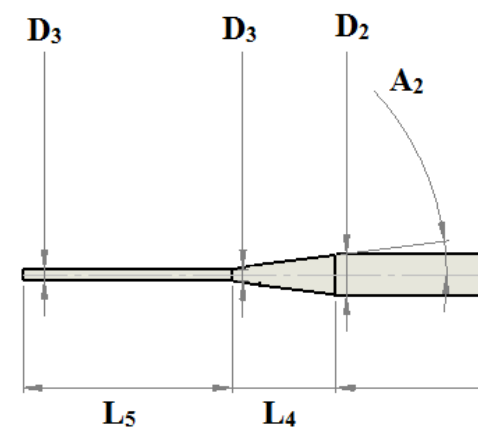

\section{Beta Design}

Figure 11. Both exhaust resonator models [59].

Table 8. OTS exhaust design dimensions.

\begin{tabular}{|c|c|c|c|}
\hline Diameter/ Angle & Value & Length & Value [mm] \\
\hline $\mathbf{D}_{\mathbf{1}}$ & $25.4[\mathrm{~mm}]$ & $\mathbf{L}_{\mathbf{1}}$ & 250 \\
\hline $\mathbf{D}_{\mathbf{2}}$ & $50[\mathrm{~mm}]$ & $\mathbf{L}_{\mathbf{2}}$ & 50 \\
\hline $\mathbf{D}_{\mathbf{3}}$ & $15.8[\mathrm{~mm}]$ & $\mathbf{L}_{\mathbf{3}}$ & 125 \\
\hline $\mathbf{A}_{\mathbf{1}}$ & $14[$ degree] & $\mathbf{L}_{\mathbf{4}}$ & 50 \\
\hline $\mathbf{A}_{\mathbf{2}}$ & $14[$ degree] & $\mathbf{L}_{\mathbf{5}}$ & 120.6 \\
\hline
\end{tabular}

Table 9. Alpha exhaust design dimensions.

\begin{tabular}{|c|c|c|c|}
\hline Diameter & Value [in] & Length & Value [in] \\
\hline $\mathbf{D}_{\mathbf{0}}$ & 0.63 & -- & -- \\
\hline $\mathbf{D}_{\mathbf{1}}$ & 0.71 & $\mathbf{L}_{\mathbf{1}}$ & 13.49 \\
\hline $\mathbf{D}_{\mathbf{2}}$ & 1.04 & $\mathbf{L}_{\mathbf{2}}$ & 8.94 \\
\hline $\mathbf{D}_{\mathbf{3}}$ & 1.60 & $\mathbf{L}_{\mathbf{3}}$ & 4.49 \\
\hline $\mathbf{D}_{\mathbf{4}}$ & 2.06 & $\mathbf{L}_{\mathbf{4}}$ & 5.37 \\
\hline $\mathbf{D}_{\mathbf{5}}$ & 2.06 & $\mathbf{L}_{\mathbf{5}}$ & 11.72 \\
\hline $\mathbf{D}_{\mathbf{6}}$ & 0.71 & $\mathbf{L}_{\mathbf{6}}$ & 11.72 \\
\hline $\mathbf{D}_{\mathbf{7}}$ & 0.71 & $\mathbf{L}_{\mathbf{7}}$ & \\
\hline
\end{tabular}


Table 10. Beta exhaust design dimensions.

\begin{tabular}{|c|c|c|c|}
\hline Diameter/ Angle & Value & Length & Value [in] \\
\hline $\mathbf{D}_{\mathbf{1}}$ & $0.71[\mathrm{in}]$ & $\mathbf{L}_{\mathbf{1}}$ & 4.26 \\
\hline $\mathbf{D}_{\mathbf{2}}$ & $1.775[\mathrm{in}]$ & $\mathbf{L}_{\mathbf{2}}$ & 6.76 \\
\hline $\mathbf{D}_{\mathbf{3}}$ & $0.426[\mathrm{in}]$ & $\mathbf{L}_{\mathbf{3}}$ & 35.4 \\
\hline $\mathbf{A}_{\mathbf{1}}$ & $4.5[$ degree] & $\mathbf{L}_{4}$ & 3.82 \\
\hline $\mathbf{A}_{\mathbf{2}}$ & $7.5[$ degree] & $\mathbf{L}_{\mathbf{5}}$ & 5.11 \\
\hline
\end{tabular}

\subsubsection{Injection Strategies and Control}

To improve engine breathing and power density, the baseline engine was replaced with the custom boosted engine. The experimental methods of intake and exhaust tuning were then employed on this engine but peak BTE still remained low at only around 16\%. Nearly $40 \%$ of the fuel energy was lost as slipped fuel. Thus, there was a need for direct injection but due to limitations on available pressures; we focused on application of LPDI for residential applications.

For NG engines, LPDI offered benefits over the fumigated or PI methods because both the fuel and air were gaseous and competed for intake charge volume. Due to this, LPDI may raise trapped mixture mass and reduce slip in two-stroke engines. Both options used relatively low injection pressures ( $<5$ bar). PI occurred in either the intake or crankcase. For these injection locations, the fuel air mix communicated with the exhaust port for the entire duration. This led to high $\mathrm{CH}_{4} \mathrm{slip}$, which contributed to lower efficiency and high GHG emissions. LPDI decreased the exposure of the fuel air mix to the open exhaust port, which decreased $\mathrm{CH}_{4}$ slip. HPDI might present a unique solution, since the fuel never communicates with the open exhaust port but HPDI requires excessive compression power to use low-pressure NG available at residential applications. To target reduced compression work, this research focused on a semi-novel method to deliver low pressure natural gas directly to the combustion cylinder through the use of an outwardly opening poppet style injector to achieve LPDI. Figure 12 and Figure 13 show the modifications applied for LPDI research on the boosted engine. 


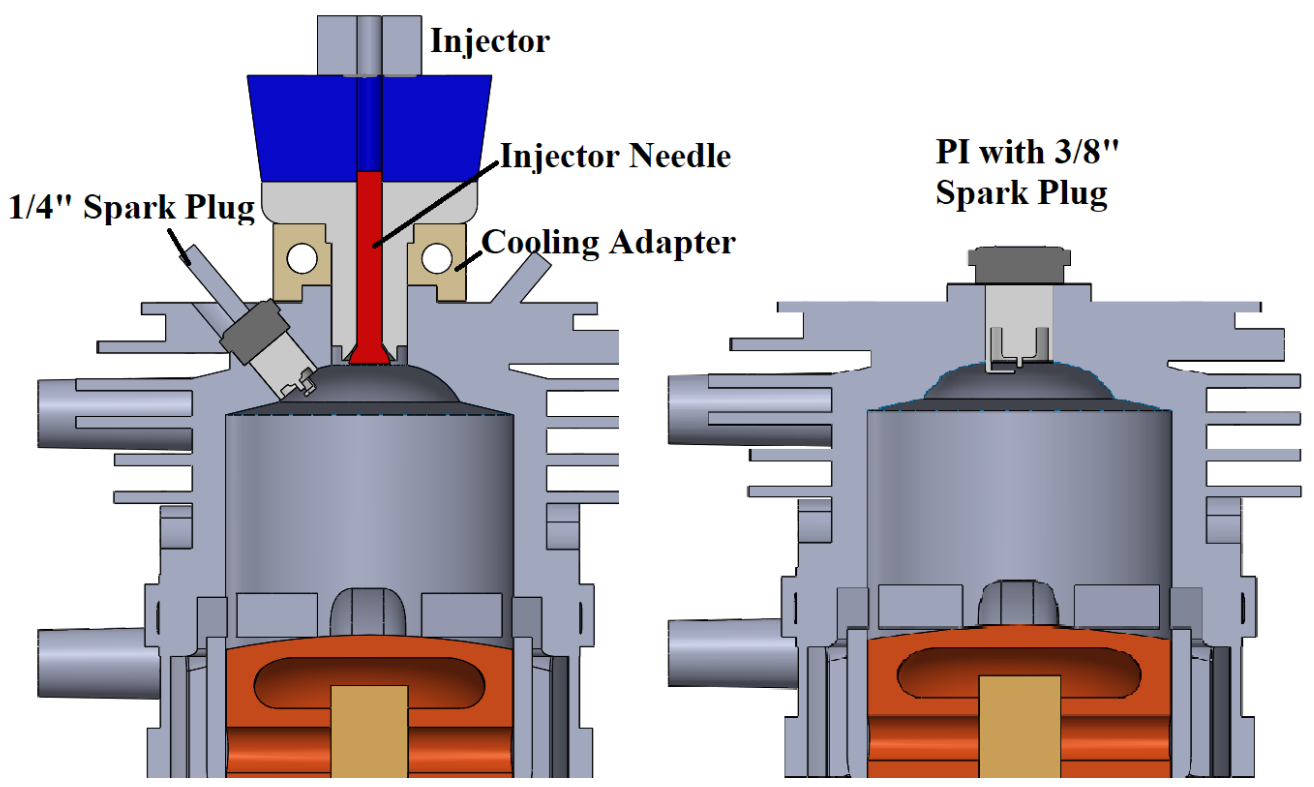

Figure 12. Direct injection setup, showing relocation of the spark plug for LPDI (left), Port injection (right) [135].

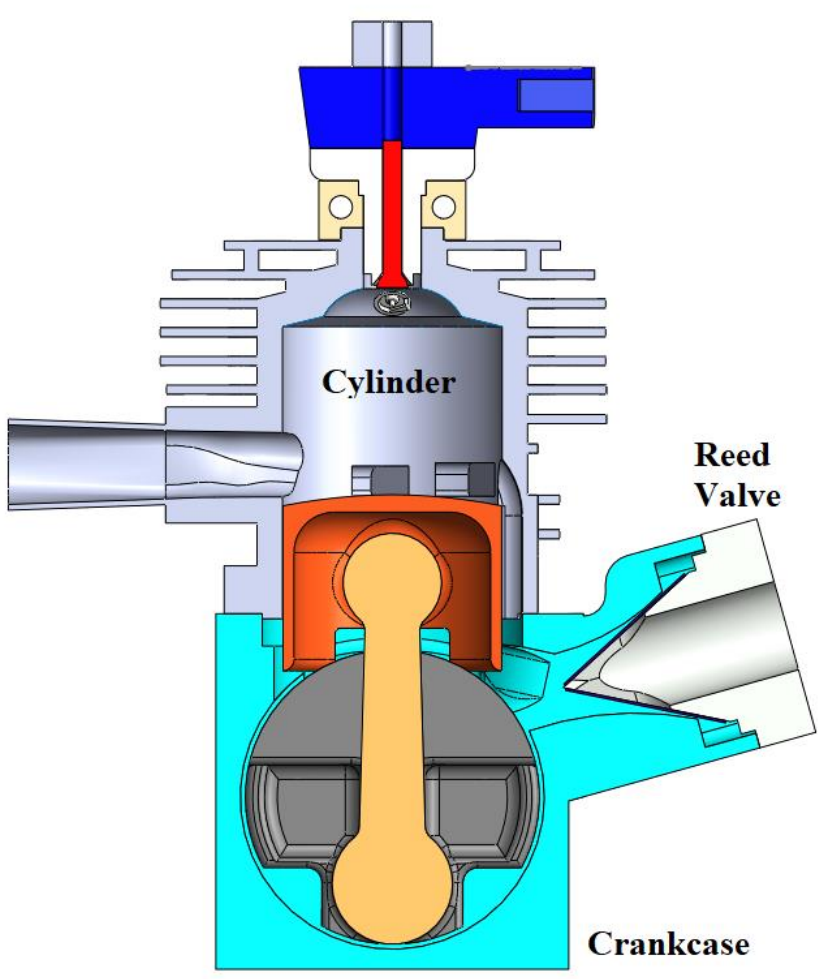

(a)

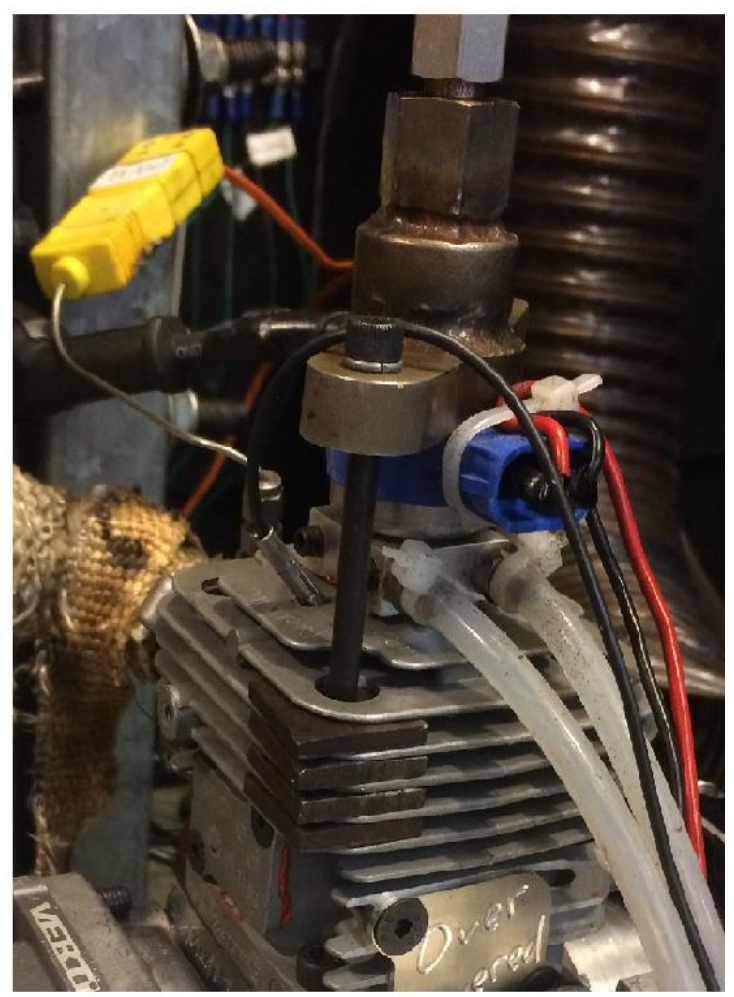

(b)

Figure 13. Full engine CAD model (a) and LPDI experiment setup (b). 
For LPDI to work in harmony with a tuned exhaust resonator, injection timing control parameters must be adjusted to optimal values. Also, there was an expected change in optimal spark timing due to operation with a more stratified mixture when compared to operation as homogeneous in the case of fumigation or PI.

\subsection{Data Collection and Analysis}

Data collection frequency was explained in Table 6. A set of data analyses was performed on the recorded data to track the system's behavior and for decision making. Table 11 shows types of data analyses performed on experimental data.

Table 11. Summary of major data analyses from measurements.

\begin{tabular}{|c|c|c|}
\hline Measured Parameters & Basic Calculations & Other Calculations \\
\hline Fuel flow & $\begin{array}{c}\text { BTE \& Indicated thermal efficiency } \\
\text { (ITE) }\end{array}$ & Energy Balance \\
\hline Air flow & Delivery Ratio & Volumetric Efficiency \\
\hline Temperatures & Exhaust Heat Energy & Energy Balance \\
\hline Exhaust gas concentration & $\begin{array}{c}\text { Exhaust Molar Flow Using Carbon } \\
\text { Balance }\end{array}$ & Trapping Efficiency \\
\hline In-cylinder Pressure & ITE, Combustion Phasing, IMEP & \\
\hline
\end{tabular}

\subsubsection{Basic Analyses}

Gas exchange parameters were used repetitively in my analyses. Three major gas exchange parameters in two-stroke engines are:

1. Delivery ratio (DR)

2. Trapping ratio $(\mathrm{TR})$

3. Volumetric efficiency (VE)

Delivery ratio was calculated by Equation 36:

$$
D R=\frac{\text { intake airflow }(S L P M)+\text { Fuel flow }(\text { slpm })}{V_{d}(L) \times N(r p m)}
$$


$V_{d}$ is the engine displacement. Note that since fuel was gaseous it was included in the delivery ratio calculations in this research both for PI and LPDI.

For PI, fuel trapping and air trapping ratios are equal. In LPDI however, these two are different:

$$
\begin{aligned}
& T R_{\text {air }}=1-\frac{\mathrm{O}_{2} \text { in the exhaust }}{\mathrm{O}_{2} \text { in the intake }} \\
& T R_{\text {fuel }}=1-\frac{H C \text { in the exhaust }}{H C \text { in the intake }}
\end{aligned}
$$

Note that mass-based approach was used in this study for trapping ratio estimation.

VE is the amount of fresh charge trapped inside of the cylinder compared to maximum theoretical value based on $V_{d}$ and with no boost pressure.

$$
\mathrm{VE}=\mathrm{TR} \times \mathrm{DR}
$$

\subsubsection{Detailed Energy Analysis for CHP Application}

The first step for completing a detailed energy analysis was to calculate exhaust molar flow rate. This enabled for calculation of all energy pathways in addition to brake power.

The energy distribution was itemized as following:

1. Indicated Power $\left(\dot{W}_{\text {indicated }}\right)$

2. Exhaust Energy $\left(\dot{E}_{\text {ex }}\right)$
a. Exhaust thermal energy $\left(\dot{Q}_{e x}^{t h}\right)$
b. Exhaust fuel energy $\left(\dot{E}_{e x}^{f u e l}\right)$ from slipped fuel
c. Exhaust unburnt content from $\mathrm{CO}$ and $\mathrm{H}_{2}\left(\dot{E}_{e x}^{u b}\right)$

3. Heat Loss and Blow-by $\left(\dot{Q}_{l}\right)$

Note that all HCs in the exhaust were considered as slipped fuel, because without a fast in-cylinder sampling system, it was impossible to distinguish slipped fuel from unburnt fuel. We did not have access to fast sampling instrument. 


$$
\dot{E}_{\text {in }}^{\text {fuel }}=\dot{Q}_{l}+\underbrace{\dot{Q}_{e x}^{t h}+\dot{E}_{e x}^{H C}+\dot{E}_{e x}^{u b}}_{\dot{E}_{e x}}+\dot{W}_{\text {indicated }}
$$

Indicated power was calculated by Equation (12):

$$
\dot{W}_{\text {indicated }}=I M E P \times V_{d} \times N
$$

where $V_{d}$ is displacement volume, $N$ is speed, and $I M E P$ is indicated mean effective pressure.

Exhaust thermal energy, $Q_{e x}^{\dot{t h}^{h}}$, was determined by Equations (42-44) [137]:

$$
\begin{aligned}
& \dot{Q}_{\text {ex }}^{t h}=\dot{n}_{\text {exh }}\left[\frac{\bar{C}_{p, \text { exh }}\left(T_{\text {exh }}\right)+\bar{C}_{p, \text { exh }}\left(T_{i n}\right)}{2}\right]\left(T_{\text {exh }}-T_{i n}\right) \\
& \bar{C}_{p, i}(T)=a_{0, i}+a_{1, i} T+a_{2, i} T^{2}+a_{3, i} T^{3} \\
& \bar{C}_{p, \text { exh }}=\sum v_{i} \bar{C}_{p, i}\left[\frac{k J}{k m o l K}\right]
\end{aligned}
$$

The exhaust molar flow rate $\left(\dot{n}_{\text {exh }}\right)$ was calculated by an iterative CFR carbon balance algorithm and molar fraction of components $\left(v_{i}\right)$ were measured from the FTIR continuous gas analyzer and the oxygen analyzer. Note that maximum error in energy balance based on carbon balance results was $3 \%$.

HC losses from the combination of fuel slip and unburnt HCs was determined by Equation (4547):

$$
\begin{aligned}
& \text { HC Loss Rate }=\frac{\dot{E}_{\text {ex }}^{H C}}{\dot{E}_{\text {in }}^{\text {fuel }}} \\
& \dot{E}_{\text {ex }}^{\text {fuel }}=\sum_{C_{1}}^{C_{3}} \dot{n}_{\text {exh }} v_{\text {exh }, i} L H V_{i}
\end{aligned}
$$




$$
\dot{E}_{\text {in }}^{\text {fuel }}=\dot{m}_{\text {fuel }} \times L H V_{\text {fuel }}
$$

where $v_{\text {exh }, i}$, is the molar fraction of component ' $\mathrm{i}$ ' in the exhaust. Note that for NG only components from $\mathrm{C}_{1}$ to $\mathrm{C}_{3}$ were considered. Combination of the fuel short-circuiting on LPDI and unburnt $\mathrm{HCs}$, formed the total $\mathrm{HC}$ losses. $\dot{m}_{f u e l}$, was known from measurements and $L H V_{\text {fuel }}$ was calculated from fuel composition on molar basis.

The exhaust unburnt energy, $\dot{E}_{e x}^{u b}$, considered $\mathrm{CO}$ and $\mathrm{H}_{2}$ from incomplete combustion and was derived from Equation (48):

$$
\dot{E}_{e x}^{u b}=\dot{n}_{e x h} \times\left(L H V_{C O} \times v_{C O}+L H V_{H_{2}} \times v_{H_{2}}\right)
$$

where, $v_{C O}$ is the molar fraction of $\mathrm{CO}$ in the exhaust. $v_{\mathrm{H}_{2}}$ was calculated based on following reaction:

$$
\mathrm{CO}_{2}+\mathrm{H}_{2} \stackrel{\text { Equilibrium }}{\Longleftrightarrow} \mathrm{CO}+\mathrm{H}_{2} \mathrm{O} \quad \text { Equilibrium Constant: } \mathrm{K}_{\mathrm{wg}}
$$

Where,

$$
K_{w g}=\frac{[\mathrm{CO}]\left[\mathrm{H}_{2} \mathrm{O}\right]}{\left[\mathrm{CO}_{2}\right]\left[\mathrm{H}_{2}\right]}
$$

With known molar fraction of $\mathrm{CO}, \mathrm{CO}_{2}$, and water $\left(\mathrm{H}_{2} \mathrm{O}\right)$ from measurements, $\mathrm{H}_{2}$ mole fraction was estimated assuming a constant $K_{w g}$ value. The equilibrium constant depends on temperature. In most combustion analyses, a value of 3.5 is assumed for this constant, which was based on an average combustion temperature around $1750{ }^{\circ} \mathrm{C}$ from 1D simulation results [138]. This temperature was estimated using $1 \mathrm{D}$ engine simulations. The rate of reaction for this temperature wass reported around $9 \times 10^{7}$ which meant the reaction was fast enough to consider it as equilibrium [139]. Even though the reaction in Equation (49) is similar to the water-gas shift 
reaction equilibrium, the constant equilibrium 3.5 is not the accurate value of the $K_{w g}$ at the measurement temperature. The value was selected from empirical data, which showed to have a reasonable correlation with actual data and combustion analyses. In most cases, low $\mathrm{H}_{2}$ concentrations yielded minimal inaccuracies in this calculation [140].

The heat transfer and blow-by loss, $\dot{Q}_{l}$, was obtained by Equation (51).

$$
\begin{aligned}
& \dot{Q}_{l}=\dot{W}_{\text {indicated }}+\sum \dot{H}_{\text {products }}-\sum \dot{H}_{\text {reactants }} \\
& \dot{H}_{i}=\sum \dot{n}_{i}\left(\bar{h}_{f_{i}}^{o}+\bar{h}_{i}+\bar{h}_{i}^{o}\right)
\end{aligned}
$$

Where $\dot{H}_{i}$ is the enthalpy rate, $\dot{n}_{i}$ is the molar flow rate, $\bar{h}_{f_{i}}^{o}$ is the enthalpy of formation, $\bar{h}_{i}$ is enthalpy at the experiment condition, $\bar{h}_{i}^{o}$ is the enthalpy at ambient condition for component $\mathrm{i}$.

\subsection{D Simulations}

1D models are very useful tools for design optimization due to their fast response and thus they are also good tools for system level optimization. For a 1D model to be more accurate, in addition to very accurate dimension inputs, many correlations must be deployed to make the model both simple and realistic. The core of my 1D model is as follows:

1. Appropriate geometry simplification.

2. Accurate dimension inputs.

3. Correlations to model a component in the model, e.g. reed valve.

4. Correlations to model a phenomenon, like combustion, heat transfer, and gas exchange.

5. Boundary conditions such as wall temperatures and environmental conditions.

Note that since 1D models solve the model iteratively, they are not sensitive to initial conditions as long as they are within a reasonable range. Implementing the right correlations requires 
knowledge, experience, and engineering judgement in the specific application. In this research GT-Power ${ }^{\mathrm{TM}}$ was used as 1D simulation tool, allowing semi-dimensional system simulation. Figure 14 shows the inputs to the model developed in this research.

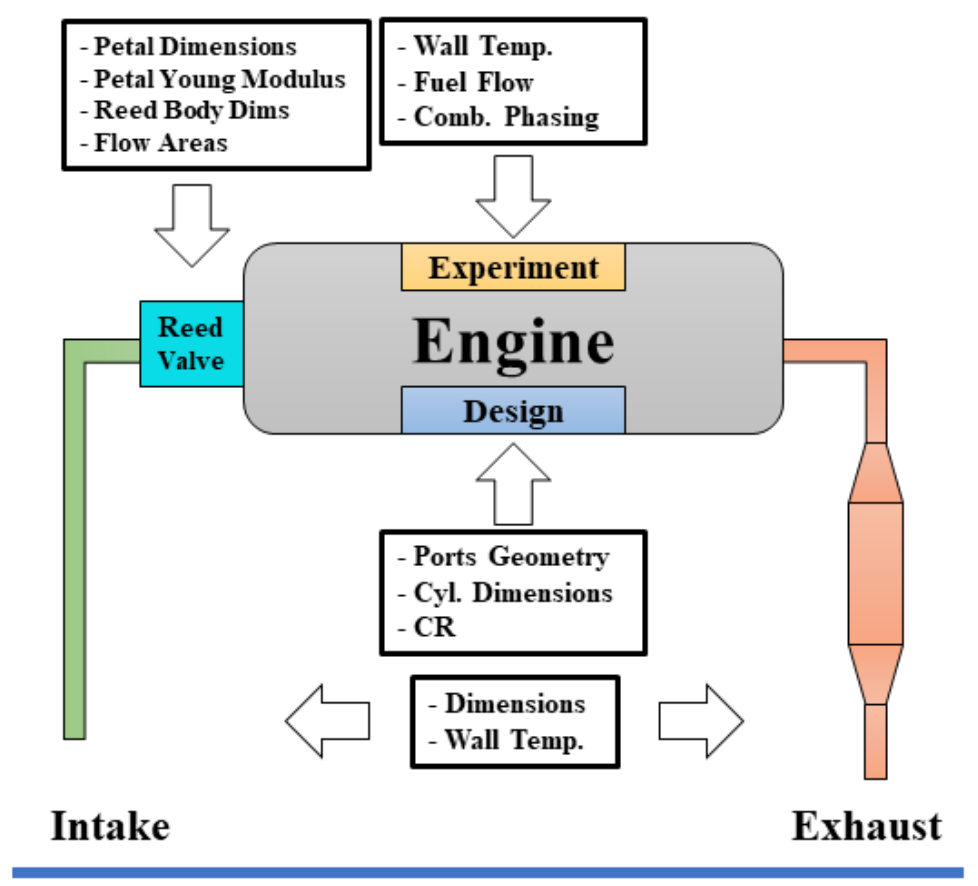

Figure 14. Input variables to the 1D model from experimental data and system design.

\subsubsection{Governing Equations}

The flow model involved the solution of the Navier-Stokes equations, namely the conservation of continuity, momentum, and energy equations. These equations were solved in one dimension, meaning that all quantities were in the flow direction representing the cross section average values. There were two choices of time integration methods, which affected the solution variables and placed limitations on time steps. The time integration methods included an explicit and an implicit integrator. The primary solution variables in the explicit method were mass flow, density, and internal energy. The primary solution variables in the implicit method were mass flow, pressure, and total enthalpy.

The whole system was discretized into many volumes, where each flow split was represented by a single volume, and every pipe was divided into one or more volumes. These volumes were connected by boundaries. The scalar variables (pressure, temperature, density, internal energy, 
enthalpy, species concentrations, etc.) were assumed to be uniform over each volume. The vector variables (mass flux, velocity, mass fraction fluxes, etc.) were calculated for each boundary. This type of discretization was referred to as a "staggered grid" (Figure 15).

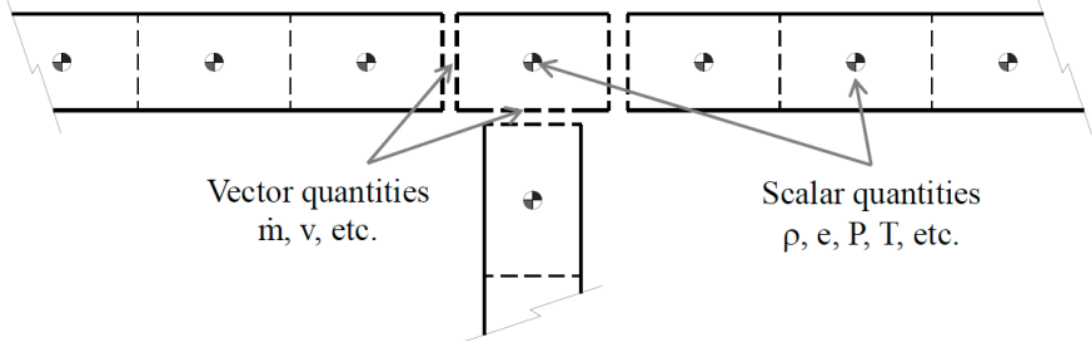

Figure 15. Schematic of staggered grid approach: scalars calculated at centroid, vector quantities at boundaries [141].

The conservation equations solved include[141]:

$$
\begin{array}{ll}
\text { Continuity: } & \frac{d m}{d t}=\sum \dot{m}{ }_{\text {boundaries }} \\
\text { Momentum: } & \frac{d \dot{m}}{d t}= \\
& \frac{d p A+\sum\left[(\dot{m} u)-4 C_{f} \frac{\rho u|u|}{2} \frac{d x A}{D}-K_{p}\left(\frac{1}{2} \rho u|u|\right) A\right]_{\text {boundaries }}}{d x} \\
\text { Energy: } & \frac{d(m e)}{d t}=-p \frac{d V}{d t}+\sum\left[(\dot{m} H)-h A_{S}\left(T_{\text {fluid }}-\right.\right. \\
\text { (Explicit Solver) } & \left.\left.T_{\text {wall }}\right)\right]_{\text {boundaries }} \\
\text { Enthalpy: } & \frac{d \rho H V}{d t}=\sum\left[(\dot{m} H)+V \frac{d p}{d t}-h A_{S}\left(T_{\text {fluid }}-\right.\right. \\
\text { (Implicit Solver }) & \left.\left.T_{\text {wall }}\right)\right]_{\text {boundaries }}
\end{array}
$$

Where:

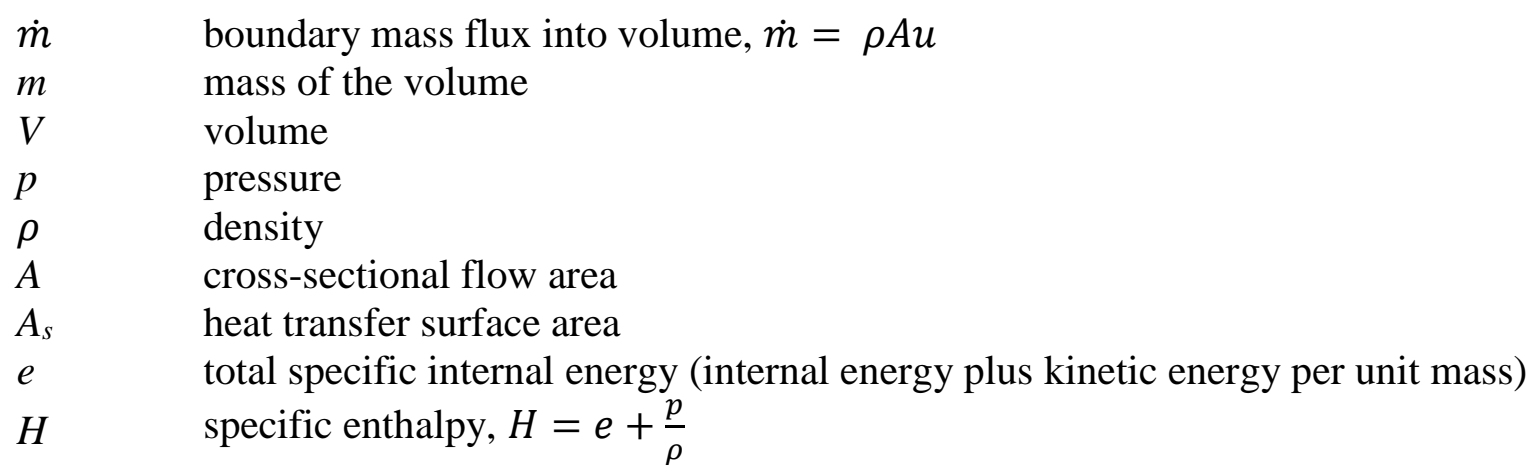




$\begin{array}{ll}h & \text { heat transfer coefficient } \\ T_{\text {fluid }} & \text { fluid temperature } \\ T_{\text {wall }} & \text { wall temperature } \\ u & \text { velocity at the boundary } \\ C_{f} & \text { Fanning friction factor } \\ K_{p} & \text { pressure loss coefficient (commonly due to bend, taper or restriction) } \\ D & \text { equivalent diameter } \\ d x & \text { length of mass element in the flow direction (discretization length) } \\ d p & \text { pressure differential acting across } d x\end{array}$

A single pipe part can be discretized into multiple sub-volumes, which provided a calculation of pressure at multiple locations at each time step. This better resolved the pressure distribution along the length of the pipe. Note that for the explicit flow solver, the time step required by a pipe was proportional to the discretization length. Smaller discretization lengths may result in longer run times due to smaller time steps as well as the fact that the solver has to calculate the solution at more locations [141].

$$
\Delta t \propto \frac{\Delta x}{c+|u|}
$$

where $\Delta t$ is the time step for the explicit flow solver only (implicit solver time step is userimposed), $\Delta x$ is the pipe discretization length, $c$ is the fluid speed of sound, and $u$ is the fluid velocity. In this research, the explicit solver was used and the time step was calculated for each iteration based on minimum $\Delta x$ and previous step's values for $c$ and $u$.

\subsubsection{Reed Valve Model}

Reed petals were the most critical variables that affected the inflow and their operation was a function based on stiffness, flow area, and engine frequency. They were modeled as single-side supported beams that opened based on pressure difference and exposed area on each side (Figure 16). The Young's Modulus of the reed petals was measured experimentally in one of WVU's Strength of Material Laboratories as shown in Figure 17 using a 20KN SHIMADZU tensile test machine. Experiments were performed using a tensile test cell which measured the force versus petal deflection to export the Young's Modulus for simulations. 


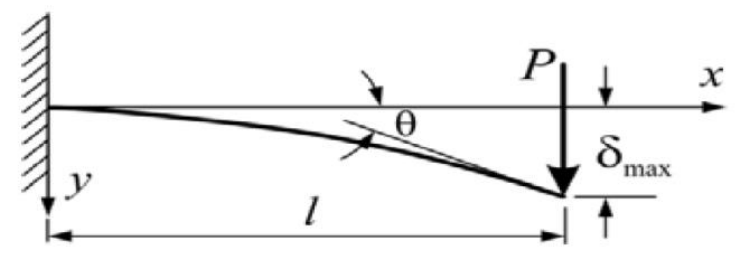

Figure 16. Single-side supported beam deflection.

$$
\delta_{\max }=\frac{P l^{3}}{3 E I}
$$

With known values of length $(l)$, force $(P)$, and maximum deflection $\left(\delta_{\text {max }}\right)$ from experiments and known moment of inertia (I) from petal geometry, the Young's Modulus was determined experimentally and used as an input within the 1D simulations.
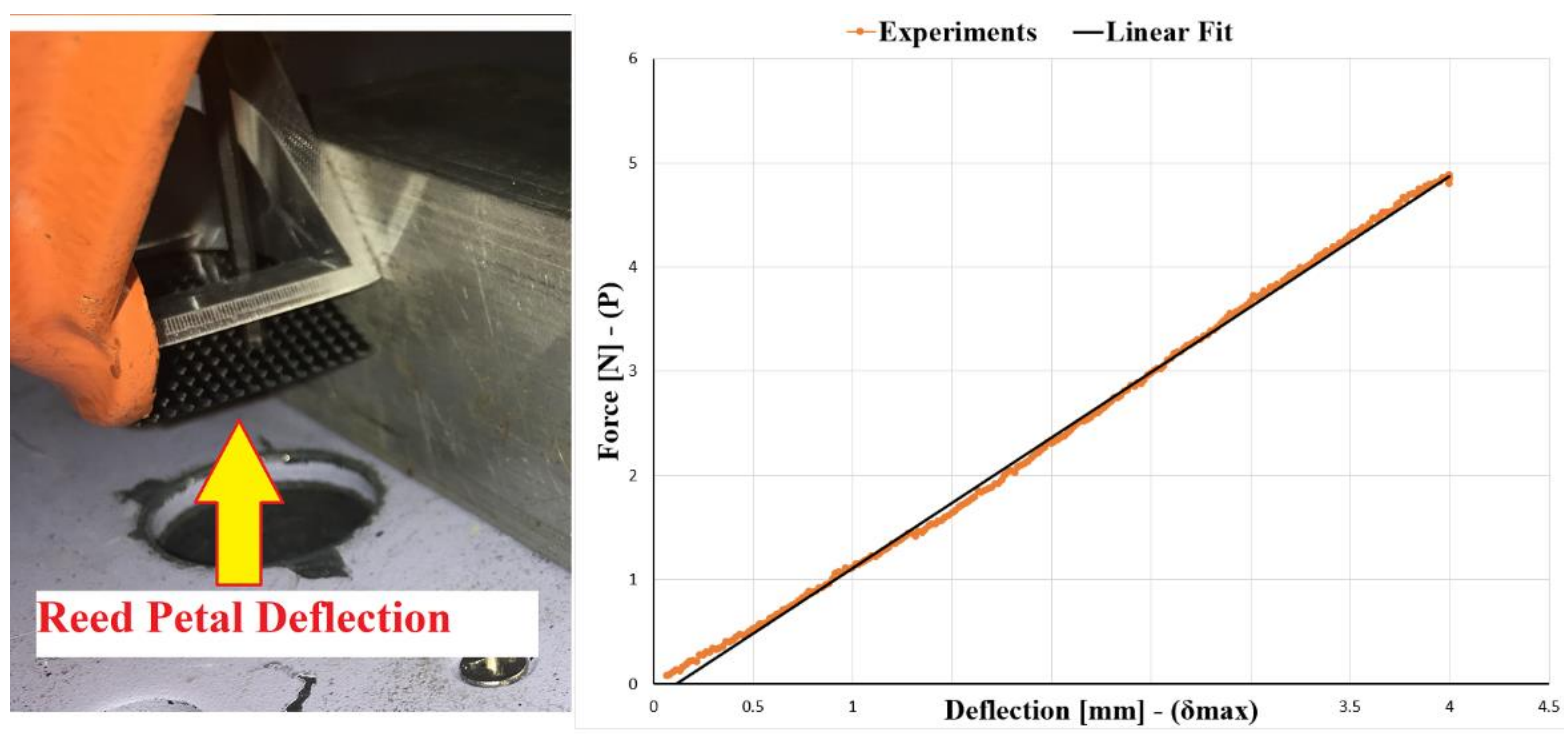

Figure 17. Young's Modulus measurement experiments (left) and experimental results (right).

The GEM3D tool within GT-Power ${ }^{\mathrm{TM}}$ was used to convert complicated internal volumes into equivalent 1D components. This was achieved since a 3D scan of the cylinder and all the internal volumes was available. These simplifications were performed for the boost port, transfer ports, exhaust manifold, and reed valve internal volumes. This conversion led to proper geometry, considering the proper volumes, surface areas, inlet and outlet areas, flow area changes from inlet to outlet, inlet and outlet angles, and discharge coefficients. Figure 18 shows the simplification of 
the reed valve body to a $1 \mathrm{D}$ component. Notice that the area and angle of boundaries are very critical to achieve a more accurate split model.

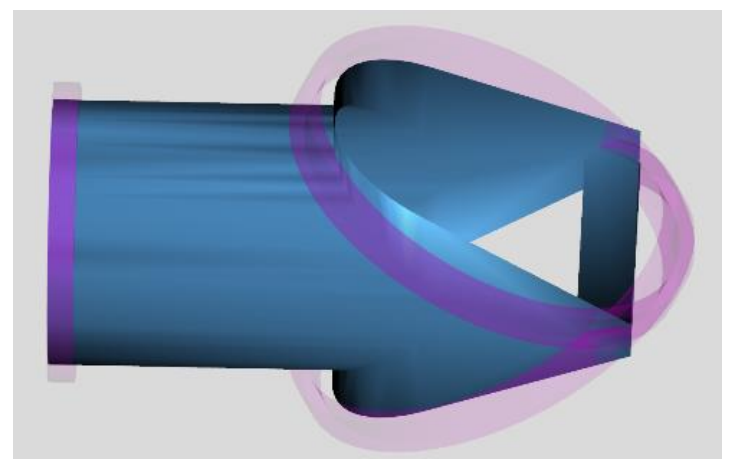

\section{Figure 18. Reed valve body simplification to a flow split element.}

The port windows' shapes and timings were also accurately extracted from the 3D cylinder scan and final experimental assembly by accurately measuring the clearance height. Exhaust geometry was accurately measured from the experimental setup and imported to the model.

\subsubsection{Boundary Conditions}

Most boundary conditions for this model were thermal boundaries from the intake through the exhaust. These were imported or estimated from experimental results. Two other boundaries were environmental boundaries of pressure and temperature, measured by an environmental sensor. Figure 19 shows the complete system model including intake, reed valve, engine, and exhaust resonator sub models. 


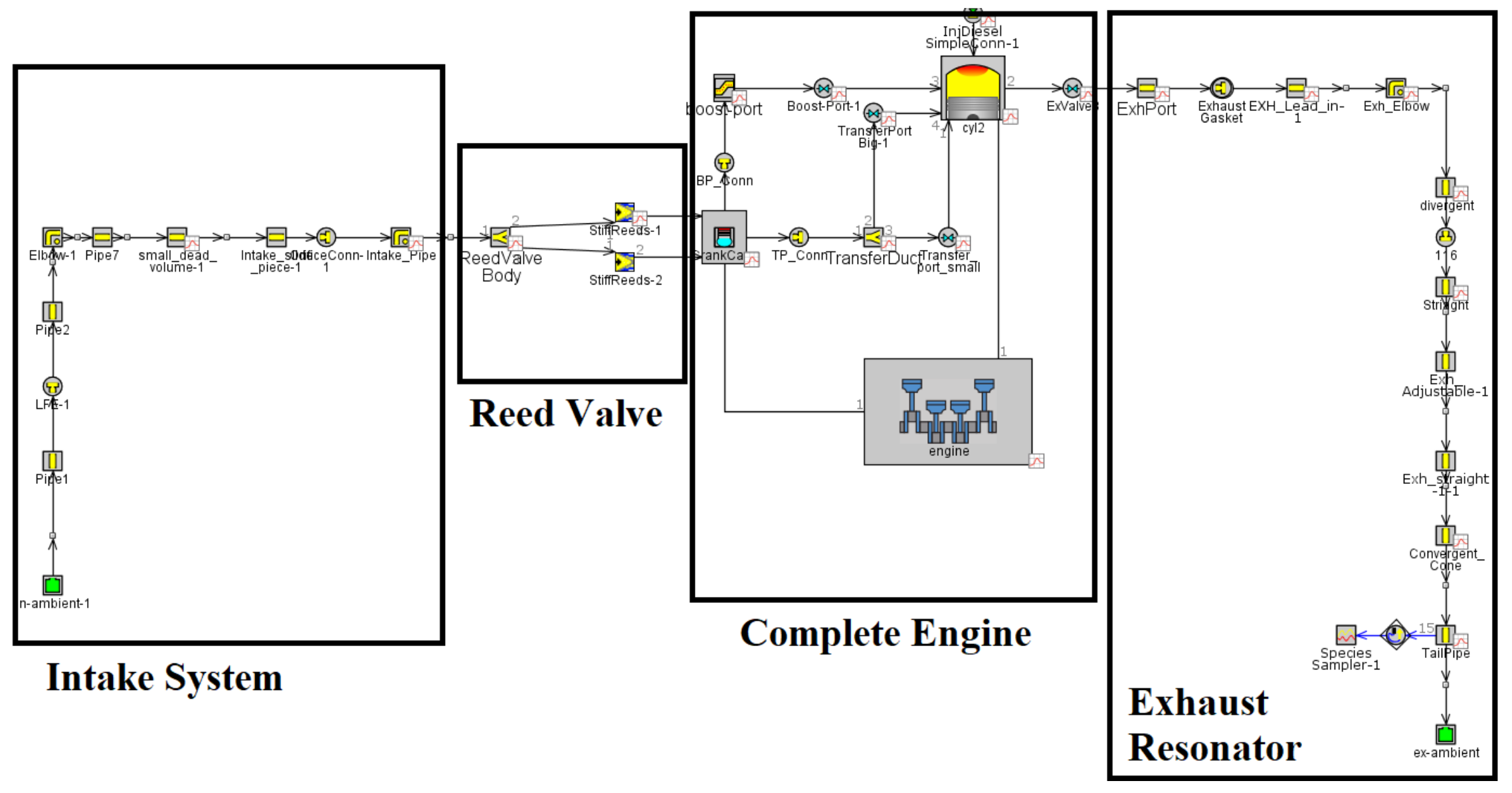

Figure 19. 1D model in GT-PowerTM. 


\section{Baseline Validations}

Calibration of the engine model was divided in two major steps: combustion model calibration and full engine model calibration.

\section{Combustion Model Calibration}

To isolate combustion from other errors associated in the full engine model, removal of the intake and exhaust systems when intake, exhaust, and cylinder pressures were available is common. This was a twostep process. First, the model was evaluated in the three-pressure analysis mode to accurately estimate the volumetric efficiency and trapping efficiencies, which were later used for combustion calibration. Note that in this study, the trapping ratio was estimated by measuring oxygen content in the exhaust and following formula:

$$
\eta_{t r}=1-\frac{O_{2_{\text {exh }}}}{O_{2_{\text {intake }}}}
$$

However, there are uncertainties associated with measurements especially in lean operations. GTPower ${ }^{\mathrm{TM}}$ offeres a solution for estimating trapping ratio initial conditions for combustion calibration models. It had the ability of operating the model in analysis mode where the combustion sub model was completely turned off. Instead, in cylinder, exhaust and intake pressure curves versus crank angle for one cycle were provided for the model. Such a model is called a threepressure analysis (TPA) model. With intake and exhaust average temperature provided in analysis mode, GT-Power ${ }^{\mathrm{TM}}$ artificially imposed a heat release to match the simulated cylinder pressure curve with the experiment. This allowed the 1D model solution based on experimental pressure curves and enabled calculation of all gas exchange parameters, including trapping ratio. In addition, initial burnt mass fraction needed for combustion calibration was calculated with the TPA model. As shown in Figure 20, a modified model was developed, and three pressure curves were used as inputs from experiments. The model attempted to impose an artificial combustion object that simulated the combustion and finally estimated the performance based on experimental data and geometry setup in the model. These included gas exchange properties and compositions. 


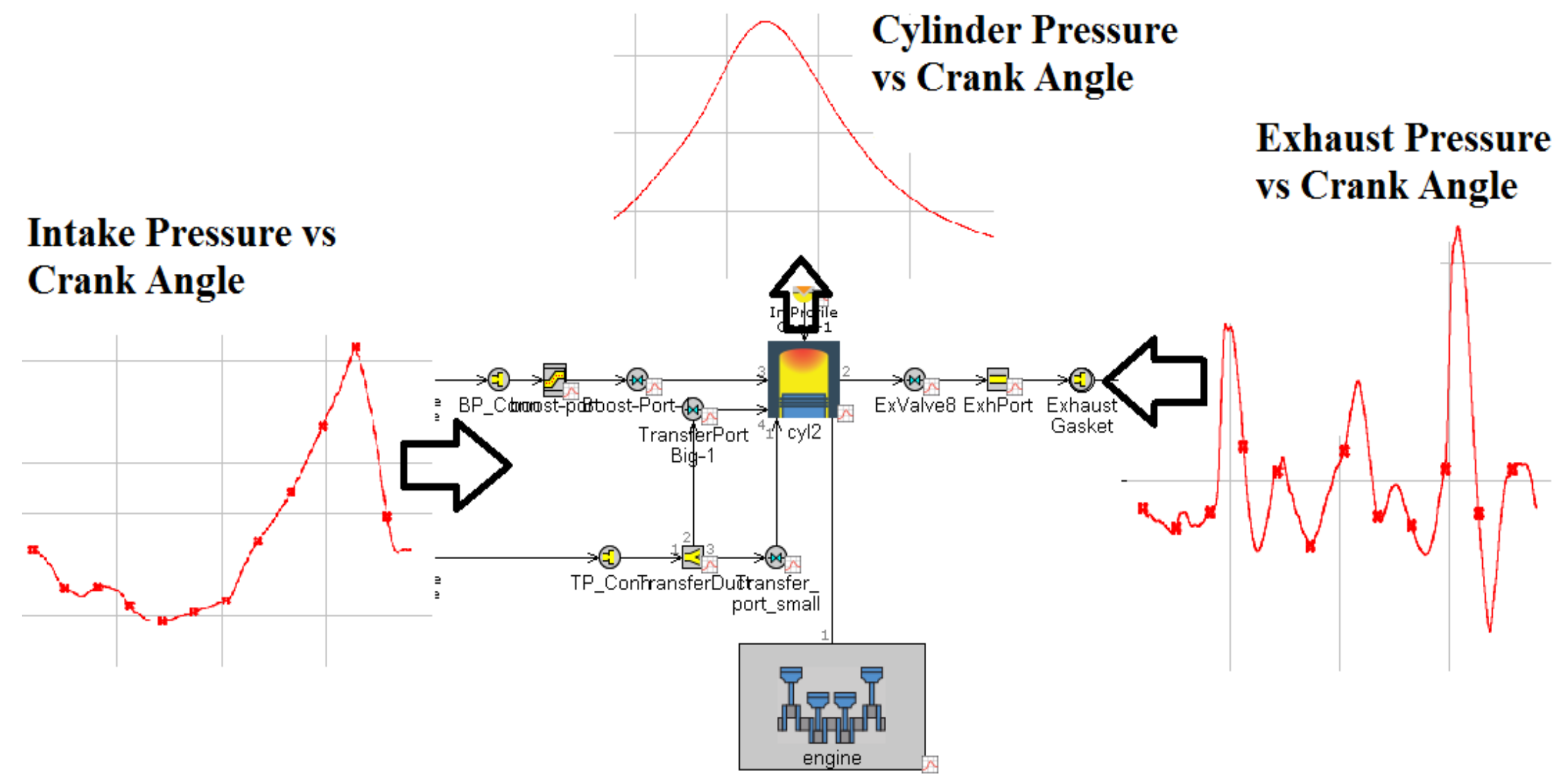

* Each curve is average of 200 cycles recorded in the experiments

Figure 20. Three pressure analysis (TPA) model. 
A predictive combustion model was then used for combustion calibration. The model attempted to estimate turbulent flame speed and match the heat release curve and consequently the pressure curve. A different model was developed for combustion calibration and it included only the cylinder, injector, and crank-train as shown Figure 21. Running the model in calibration mode allowed for exclusion of the intake and exhaust systems. Alternatively, volumetric efficiency, trapping ratio, and burnt gas fraction at the start of the cycle, were calculated from the TPA model and input to this model. Table 12 presents the major inputs to the combustion calibration model and their source. As shown in Table 12, there were four calibration parameters.

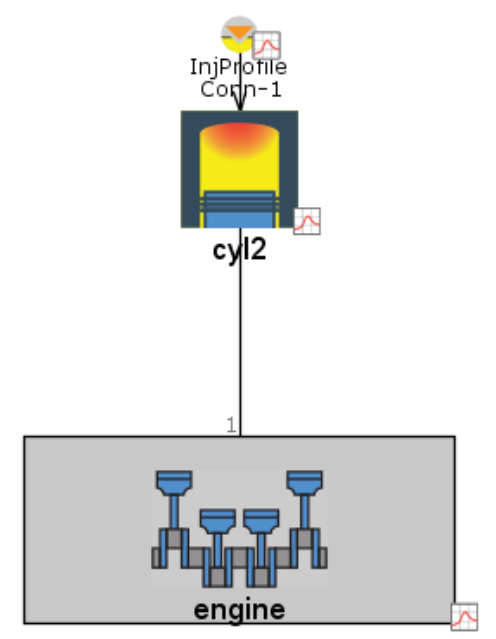

Figure 21. Model for combustion calibration.

Table 12. Combustion calibration model inputs and parameters.

\begin{tabular}{|c|c|c|}
\hline Categories & Objects & Source of data \\
\hline \multirow{4}{*}{ Initial State } & Volumetric Efficiency & \multirow{2}{*}{ Three Pressure Analysis Model } \\
\cline { 2 - 3 } & Trapping Ratio & Experiments \\
\cline { 2 - 3 } & Residual Gas Fraction & Estimate from Experiments \\
\cline { 2 - 3 } Wall Temperatures & Fuel Composition & Estimate from Experiments \\
\cline { 2 - 3 } & Liner & Estimate from Estimation \\
\cline { 2 - 3 } & Head & $\begin{array}{c}\text { Heat transfer multiplier is calibrated before and } \\
\text { after combustion calibration }\end{array}$ \\
\hline \multirow{3}{*}{ Heat Transfer } & Piston & Calibration Parameter \\
\hline \multirow{3}{*}{ Combustion } & Woschni & Calibration Parameter \\
\cline { 2 - 3 } & Dilution Effect Multiplier & Calibration Parameter \\
\cline { 2 - 3 } & Turbulent Flame Speed Multiplier & Calibration Parameter \\
\cline { 2 - 3 } & Taylor Length Scale Multiplier & $\begin{array}{c}\text { Taken from geometry, it affects the flame speed } \\
\text { and combustion duration }\end{array}$ \\
\hline \multirow{3}{*}{ Flame Object } & Spark plug location & $\begin{array}{c}\text { Taken from geometry and used to estimate the } \\
\text { gas motion inside of the cylinder }\end{array}$ \\
\cline { 2 - 3 } & Head and piston Geometry & \\
\cline { 2 - 3 } & &
\end{tabular}


Calibration was performed by minimizing the root mean square error (RMSE) between measured and predicted pressure curves. Figure 22 shows an example of the difference between simulated and measured curves before calibration. The target was set to minimize the RMSE between simulated and all measured curves provided for calibration.

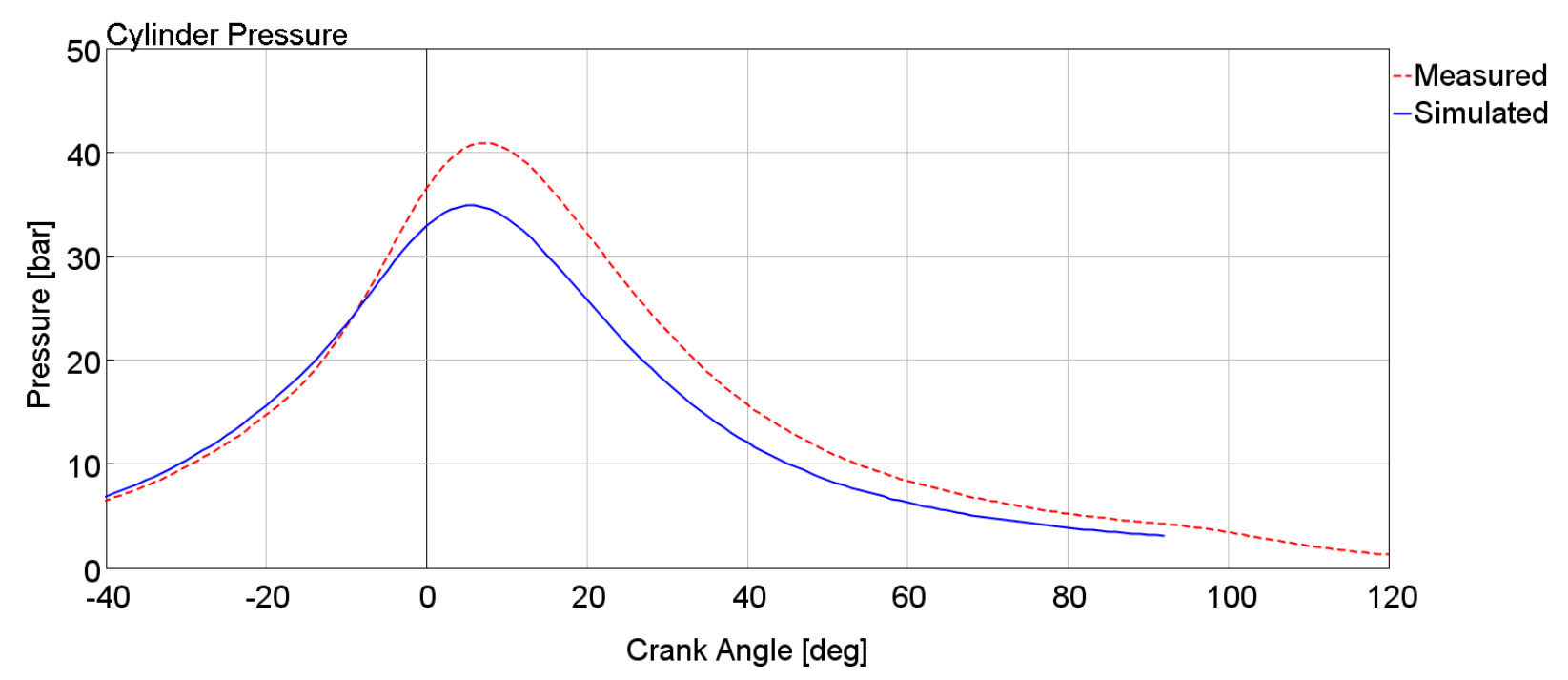

Figure 22. Pressure curve of an uncalibrated combustion versus measured curve.

Calibration was achieved using a genetic algorithm (GA) setup, where the objective was to minimize the RMSE between measured and simulated results. Factors were calibration parameters, which were varied by the GA platform. Engine speed of 5400 RPM was selected for optimization to match with experiments. The minimization of RMSE between measured and predicted curves was performed for all the selected data points and the best set of parameter values were selected.

For the validation of the full engine model with the intake and exhaust, the validation of air flow and crankcase pressure was completed using motored data. This model included the full intake, reed valve, cylinder, and exhaust resonator geometries as shown in Figure 19. That led to matching the compression side of the in-cylinder pressure curve. Note that in the motoring model there was no combustion. Secondly, calibrated combustion parameters were applied to the full model to validate the combustion pressure curve. 


\subsubsection{Exhaust Resonator's Genetic Algorithm Optimization}

The calibrated model was used to perform a GA optimization on the exhaust resonator design. The baseline exhaust design in the model was the beta design presented in Figure 11. The beta design was used for all the experiments before GA optimization. Figure 23 shows the parametric schematic of the baseline exhaust design. The best results (given that L3 was adjustable) were determined experimentally and were presented in Table 13.

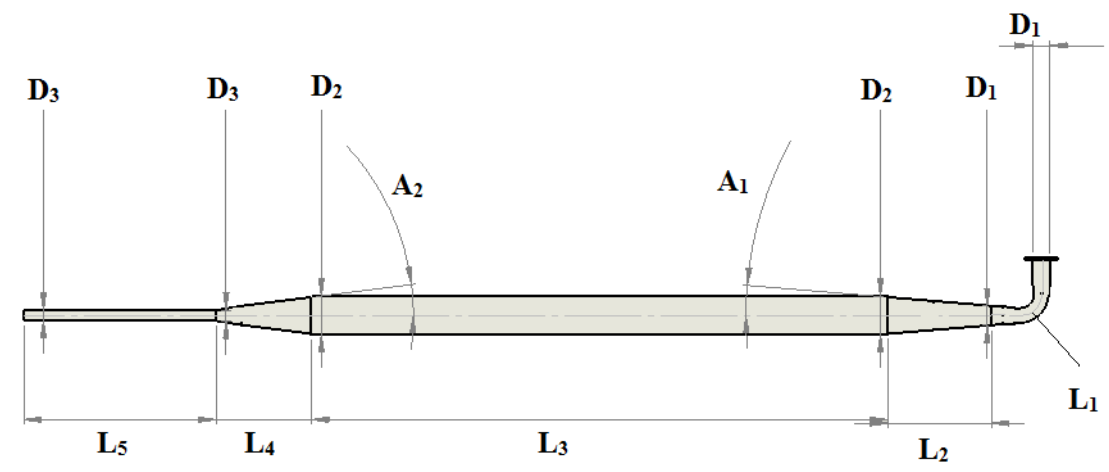

Figure 23. Baseline exhaust with geometric parameters labeled.

To assign a reasonable objective for the optimization problem required definition of the main function of the exhaust resonator. Exhaust resonators have two functions, (1) controlling the delivery ratio as defined by the divergent cone and (2) controlling the trapping ratio as defined by the straight section length $\left(\mathrm{L}_{3}\right)$ and the convergent cone.

For the following reasons, maximization of the engine's indicated efficiency was selected as the optimization objective. In crankcase compression two-stroke engines, unlike four-stroke engines, cylinder indicated efficiency is not equal to engine indicated efficiency. This was due to additional pumping losses imposed by the crankcase compression. Engine indicated efficiency considered the pumping loss associated with crankcase compression as well as the increased volumetric efficiency.

Table 13 shows the range of variable parameters that defined the design space for the optimization problem. These values were selected based on experience with the exhaust resonator experimental results and good engineering judgement from rules of thumb presented in literature [12] [33] [10]. 
The number of designs in each generation was selected to be 20 and the maximum number of generations was 50, which yielded up to 1000 design points.

Table 13. Optimization target and design space.

\begin{tabular}{|c|c|c|c|}
\hline Target & \multicolumn{3}{|c|}{ Maximum Engine Indicated Efficiency } \\
\hline Variable & Baseline value [mm] & Lower Limit & Upper limit \\
\hline $\mathbf{D}_{\mathbf{1}}$ & 15 & 13 & 21 \\
\hline $\mathbf{D}_{\mathbf{2}}$ & 45 & 35 & 65 \\
\hline $\mathbf{D}_{\mathbf{3}}$ & 10.5 & 8 & 15 \\
\hline $\mathbf{L}_{\mathbf{1}}$ & 41 & 20 & 80 \\
\hline $\mathbf{L}_{\mathbf{2}}$ & 167 & 100 & 250 \\
\hline $\mathbf{L}_{3}$ & 818 (Adjustable in experiments) & 650 & 1000 \\
\hline $\mathbf{L}_{4}$ & 127 & 70 & 190 \\
\hline
\end{tabular}

\subsection{D CFD Simulation}

The core components of the CFD study used in this research are as follows:

1. Extracting and cleaning the geometry

2. Defining regions (Cylinder, Crankcase and exhaust)

3. Implement the proper equations to solve in the active domain

4. Grid control with fixed embedding and adaptive mesh refinement (AMR), where higher resolution was required such as around the spark plug at the experimental spark timing.

5. Proper initialization

6. Boundary conditions.

\subsubsection{Engine Geometry}

In two-stroke engine modeling, to consider the most realistic scavenging, in addition to the cylinder, the engine crankcase was also included into the simulations. This enabled consideration of the cylinder's upstream pressure caused by crankcase compression. Figure 24 (a) shows the main geometry regions of the CFD model while Figure 24 (b) shows the transparent fluid domain. 


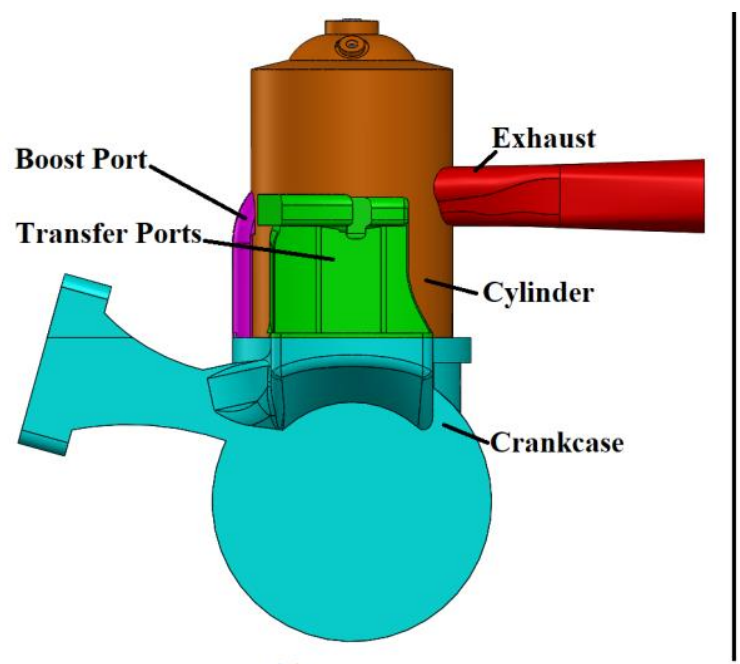

(a)

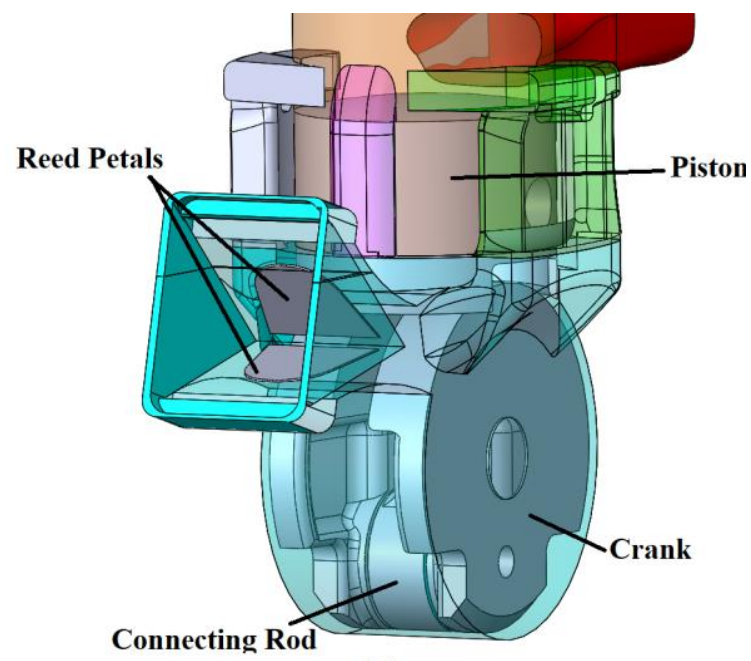

(b)

Figure 24. (a) Main geometry regions (b) transparent fluid domain showing piston, connecting rod and crank and reed petal locations.

\subsubsection{CFD Model Boundaries}

\section{Intake Boundary}

To reduce simulation time, instead of modeling the physical reed petals, a reed valve flow rate was assigned to the boundaries. This flow rate was obtained from the verified 1D model of the system. Any error from 1D simulation was removed by integrating the mass flow curve and scaling it to match the experimental manifold air mass flow measurements. Note that a constant flow rate would not be an appropriate approach, because it affected the crankcase pressure. Figure 25 shows the mass flow rate through the reed valve over the course of a single cycle which was an output of a calibrated 1D model.

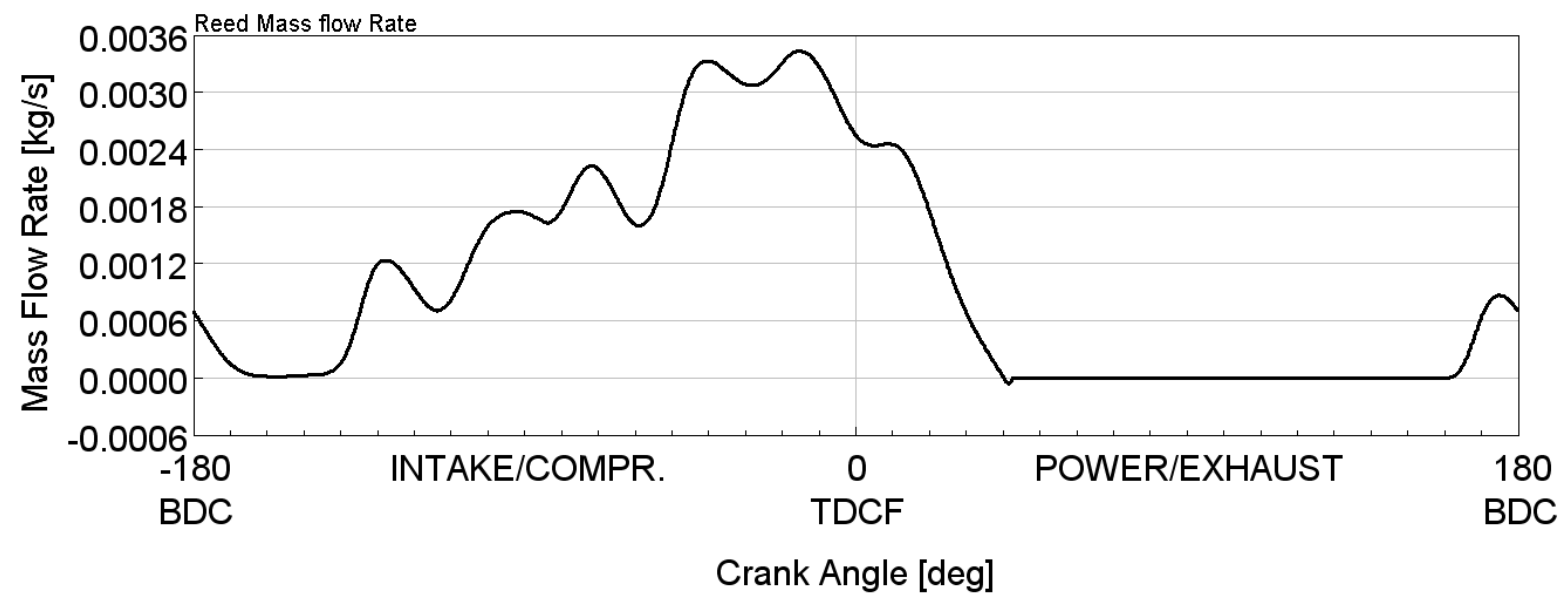

Figure 25. Reed valve flow rate profile from verified 1D simulation results. 


\section{Exhaust Boundary}

Due to presence of the exhaust resonator on the engine setup, a traveling wave caused pressure fluctuations at the exhaust port. These fluctuations were important because they affected the scavenging process and the final trapped mass inside of the cylinder. A high frequency piezoresistive pressure sensor measured the exhaust pressure and that was assigned as the exhaust boundary conditions in the CFD simulation. Note that the exhaust pressure sensor location in experiments and exhaust boundary location in the CFD model were matched. Figure 26 shows exhaust pressure near the exhaust port.

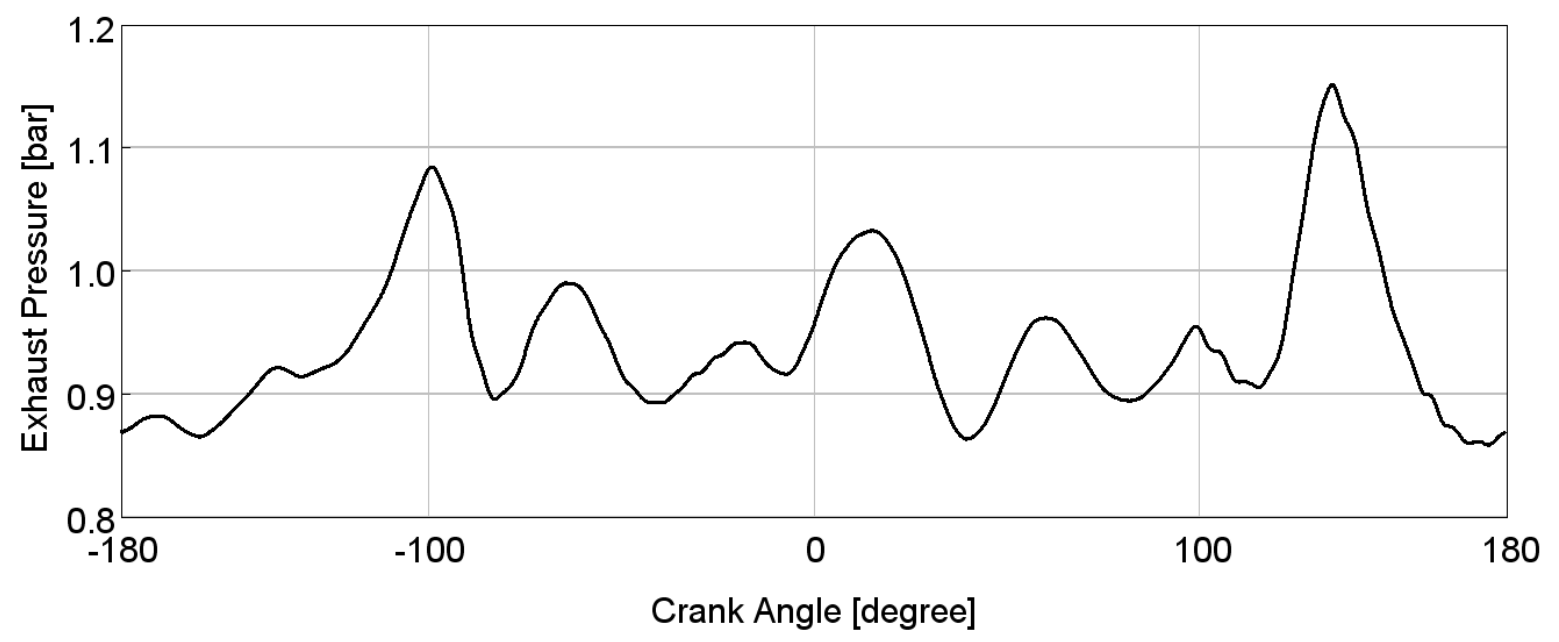

Figure 26. Exhaust boundary conditions from experimental measurements, an average of 200 recorded cycles.

\section{Moving Boundaries}

The piston had three moving boundaries interacting with different regions. The piston top interacted with the in-cylinder region. The piston skirt interacted with the cylinder wall and ports. The piston bottom interacted with the crankcase regions. The connecting rod and crankshaft were included in the crankcase region and defined the piston motion.

\section{Thermal Boundaries}

All walls in the system were considered to have a fixed temperature and it was estimated from the experimental results. Table $\mathbf{1 4}$ presents the thermal boundary conditions. 
Table 14. Thermal boundaries estimated from experimental results.

\begin{tabular}{|c|c|}
\hline Wall Type & Temperature [K] \\
\hline Cylinder Wall & 450 \\
\hline Cylinder Head & 550 \\
\hline Piston Top & 550 \\
\hline Piston Skirt & 450 \\
\hline Piston Bottom & 400 \\
\hline Exhaust manifold & 650 \\
\hline Crankcase, connecting rod and crank & 400 \\
\hline
\end{tabular}

\subsubsection{CFD Model Initialization}

Since the model solved only one cycle, a proper initialization was needed for accurate results. A pressure and temperature initialization were needed for each region, see Table 15. The model had three defined regions: cylinder, crankcase, and exhaust. For initialization, a combination of experimental and numerical data were provided. Temperature initialization was completed mostly with 1D modeling results while pressure initialization was from experiments.

Table 15. Initialization table for combusting engine.

\begin{tabular}{|c|c|c|c|}
\hline \multirow{2}{*}{ Region } & Parameter & $\begin{array}{c}\text { Value at Simulation } \\
\text { Start (EPO) [Unit] }\end{array}$ & Source \\
\hline \multirow{2}{*}{ Cylinder } & Pressure & $458[\mathrm{kPa}]$ & Experiments \\
\cline { 2 - 4 } & Temperature & $1250[\mathrm{~K}]$ & 1D modeling \\
\hline \multirow{2}{*}{ Crankcase } & Pressure & $130[\mathrm{kPa}]$ & Experiments \\
\cline { 2 - 4 } & Temperature & $360[\mathrm{~K}]$ & 1D modeling \\
\hline \multirow{2}{*}{ Exhaust Manifold } & Pressure & $94[\mathrm{kPa}]$ & Experiments \\
\cline { 2 - 4 } & Temperature & $648[\mathrm{~K}]$ & 1D modeling \\
\hline
\end{tabular}

\subsubsection{Governing Equations}

The dynamics of fluid flow were governed by equations that described the conservation of mass, momentum, and energy. Additional equations described turbulence and the transport of passive scalars and species. Table 16 shows summary of the proper solver options for different equations. 
Table 16. Solver options.

\begin{tabular}{|c|c|c|}
\hline Equation & Description & Solved Variables \\
\hline Mass & Conservation of Mass & Total mass in regions \\
\hline Momentum & Conservation of Momentum & Pressure and velocity \\
\hline Energy & Conservation of Energy & Pressure and temperature \\
\hline Species & Species mass fraction in each region (Stratification) & Mass fraction \\
\hline Passives & Monitor the flow motion and scavenging & Not affecting the solution \\
\hline Turbulence & Monitor Mixing & TKE, Dissipated energy \\
\hline
\end{tabular}

\section{Mass and Momentum Transport}

The compressible equations for mass transport and momentum transport are given by Eq. (60-62):

$$
\begin{array}{ll}
\text { Mass } & \frac{\partial \rho}{\partial t}+\frac{\partial \rho u_{i}}{\partial x_{i}}=S \\
\text { Momentum } & \frac{\partial \rho u_{i}}{\partial t}+\frac{\partial \rho u_{i} u_{j}}{\partial x_{j}}=-\frac{\partial P}{\partial x_{i}}+\frac{\partial \sigma_{i j}}{\partial x_{j}}+S_{i} \\
\text { Viscous stress tensor } & \sigma_{i j}=\mu\left(\frac{\partial u_{i}}{\partial x_{j}}+\frac{\partial u_{j}}{\partial x_{i}}\right)+\left(\mu^{\prime}-\frac{2}{3} \mu\right)\left(\frac{\partial u_{k}}{\partial x_{k}} \delta_{i j}\right)
\end{array}
$$

In the above equations, $u$ is velocity, $\rho$ is density, $S$ is the source term, $P$ is pressure, $\mu$ is viscosity, $\mu^{\prime}$ is the dilatational viscosity (set to zero), and $\delta_{i j}$ is the Kronecker Delta. Note that if a turbulence model (e.g., k-e) was activated, the viscosity was replaced by the total viscosity, which is given by Equation (63):

$$
\mu_{t o t}=\mu_{m o l}+C_{\mu} \rho \frac{k^{2}}{\varepsilon}
$$

where $\mu_{m o l}$ is the molecular viscosity, $C_{\mu}$ is a turbulence model constant, $k$ is the TKE, and $\varepsilon$ is the turbulent dissipation.

Equations (60 and (61) both allowed for source terms. For the momentum equation, the source terms can arise from, for example, gravitational acceleration, spray coupling, or mass sources. For the mass conservation equation, the source term may arise from evaporation or other sub models. The momentum equation was solved in finite volume form. When solving the momentum equation, conserved values at the face were expressed in terms of primitive values at the cell center. 
The pressure-velocity coupling was achieved using a modified Pressure Implicit with Splitting of Operators (PISO) method of Issa (1986) [142]. The PISO algorithm was implemented with a predictor step where the momentum equation was solved. After the predictor, a pressure equation was derived and solved, which led to a correction, this was then applied to the momentum equation. The process of correcting the momentum equation and re-solving can be repeated as many times as necessary to achieve the desired accuracy which was set to 0.001 in this study. This was equivalent of $0.1 \%$ variation between iterations. After the momentum predictor and first corrector step were completed, the other transport equations were solved in series. Momentum and mass transport can be solved for compressible or incompressible flows. For compressible flows, an equation of state was required to couple density, pressure, and temperature. CONVERGE contains several equation of state options: ideal gas, Redlich-Kwong, Redlich-Kwong-Soave, and PengRobinson. In this research, gas was solved as compressible and the Redlich-Kwong equation of state was used which is formulated as Equation (64) [143]:

$$
p=\frac{R T}{V_{m}-b}-\frac{a}{\sqrt{T} V_{m}\left(V_{m}+b\right)}
$$

where $p$ is the gas pressure, $R$ is the gas constant, $T$ is temperature, $V_{m}$ is the molar volume $(V / n)$, $a$ is a constant that corrects for attractive potential of molecules, and $b$ is a constant that corrects for volume. The constants are different depending on which gas is being analyzed. The constants can be calculated from the critical point data of the gas by Equation (65-66).

$$
\begin{aligned}
& a=0.42748 \frac{R^{2} T_{C}^{2.5}}{P_{c}} \\
& b=0.08664 \frac{R T_{c}}{P_{c}}
\end{aligned}
$$

where, $T_{c}$ is the temperature at the critical point, and $P c$ is the pressure at the critical point and they were $133 \mathrm{~K}$ and $3.77 \mathrm{MPa}$, respectively. 


\section{Passive and Scalar Transport}

Scalar quantities may be passive or non-passive. This differentiation was drawn due to the form of the convergence criterion for the PISO algorithm. A passive scalar was a calculated quantity that did not directly affect the calculation of the temperature or the gas constant.

The compressible form of the passive scalar transport equation is given by

$$
\frac{\partial \rho \phi}{\partial t}+\frac{\partial \rho u_{j} \phi}{\partial x_{j}}=\frac{\partial}{\partial x_{j}}\left(\rho D \frac{\partial \phi}{\partial x_{j}}\right)+S
$$

where $u$ is velocity, $\rho$ is density, $D$ is the diffusion coefficient, $S$ is the source term, and $\phi$ is a passive scalar. The diffusion coefficient is given by

$$
D=\frac{v}{S c}
$$

where $S c$ is the Schmidt number, which can be defined for each passive individually.

\subsubsection{Grid Control}

The grid started with a base value. The two type of mesh refinements have been added to the simulation: fixed embedding and adaptive mesh refinement (AMR). Fixed embedding are those types that refine the mesh in the simulation regardless, while with AMR, depend on the gradient the parameter defines in AMR, it may or may not refine the mesh during the simulation. The simulation was run on WVU's Spruce Knob supercomputer network.

\subsubsection{CFD Study Objectives}

The objective of the CFD analysis was to examine charge stratification, especially around ignition timing, to determine the optimal location for the spark plug to enable lean combustion for improved efficiency. In addition, CFD results were qualitatively compared to experimental data. 


\section{Results and Discussions}

\subsection{Empirical Optimization on PI}

\subsubsection{Intake Optimization}

\section{Delivery ratio and power density}

Intake length, diameter, and crankcase volume were translated into the frequency of the installed Helmholtz resonator. On the peak of tuning, the resonator's frequency was calculated as $185 \mathrm{~Hz}$, which was almost twice the piston frequency (5400 RPM or $90 \mathrm{~Hz}$ ). Figure 27 shows that delivery ratio increased from 0.28 to about 0.52 . This led to a change brake power from 0.22 to $0.5 \mathrm{~kW}-$ an increase by a factor of 2.27 as shown in the left of Figure 27.
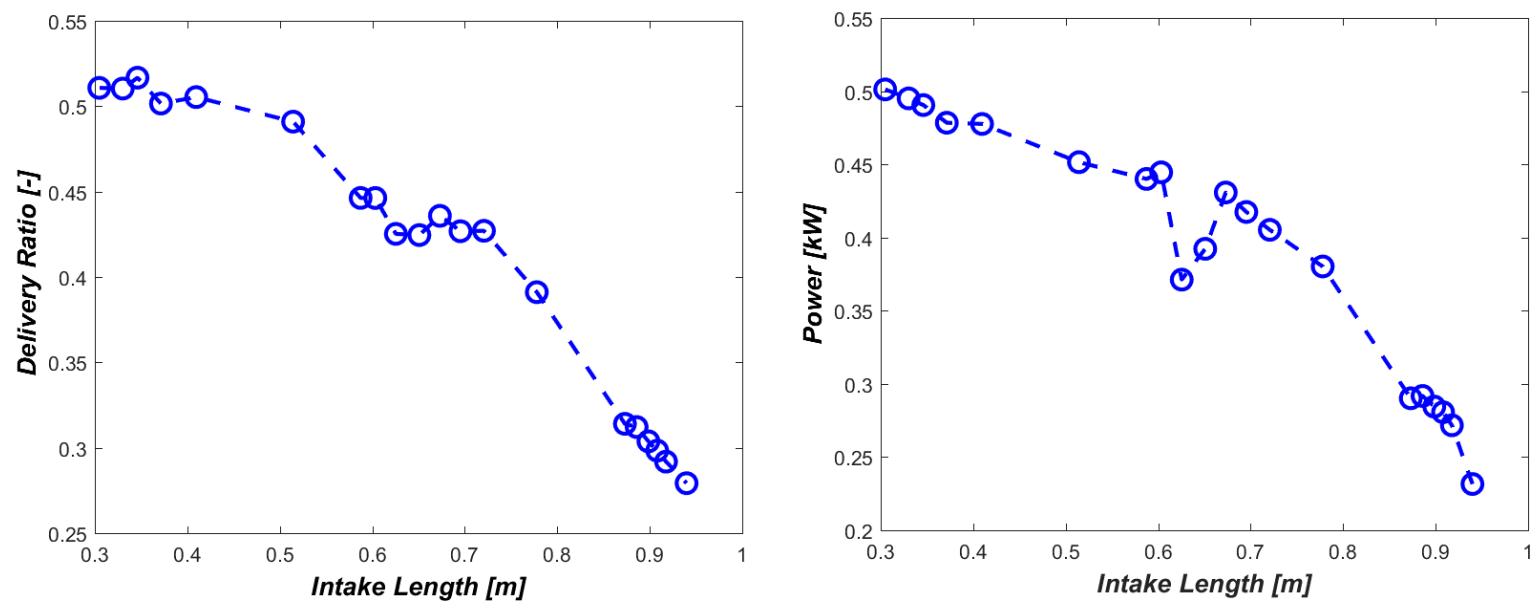

Figure 27. Delivery ratio and power increased as length decreased to the target length, which yielded a tuned frequency of $185 \mathrm{~Hz}$.

\section{Combustion Stability}

Higher fresh charge trapped inside the cylinder from intake tuning led to higher heat release per cycle and improved combustion stability. In addition, with higher trapped mass, stronger turbulences were created at smaller scales, which likely helped to create a faster flame front, thus causing combustion to be more stable. In general, turbulences tend to make the flame front more corrugated which inhibited growth of instabilities [144]. Figure 28 shows the COV of IMEP for different intake lengths. 


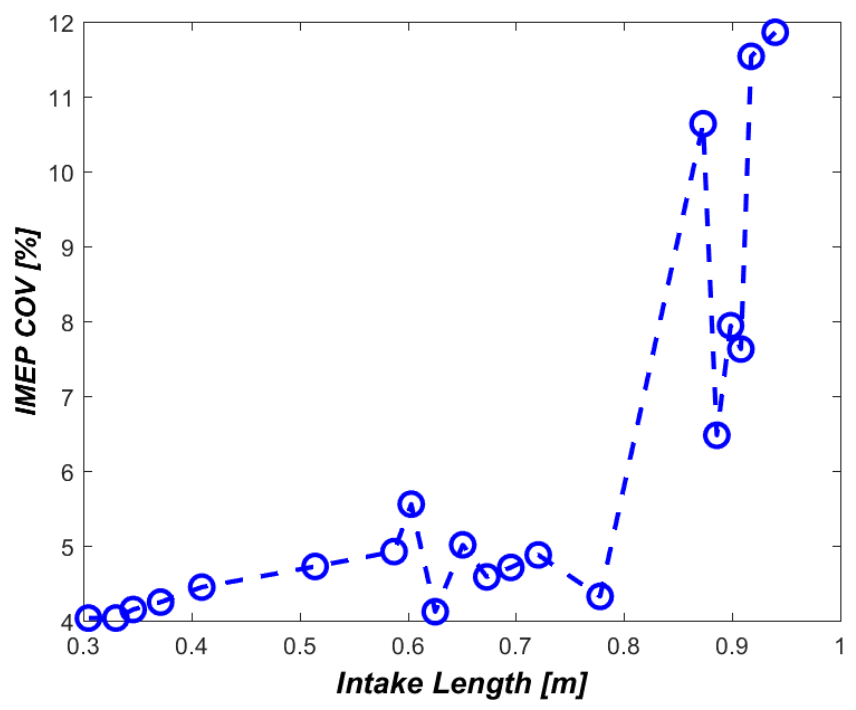

Figure 28. Combustion stability as defined by the coefficient of variation (COV) of IMEP for varied intake lengths.

\subsubsection{Exhaust Optimization}

\section{Delivery Ratio and Power}

Figure 29 shows further increases in delivery ratio for the alpha and beta exhausts as compared to the OTS exhaust. While the engine with the OTS exhaust showed delivery ratio of around $60 \%$, the alpha and beta exhausts on average had delivery ratios of $95 \%$ and $85 \%$, respectively. The alpha design used a longer multi-cone design for the diffuser (divergent cone) when compared to the beta. It created a stronger suction wave that pulled more gas out of the cylinder and resulted into a higher delivery ratio - but not necessarily a higher trapping efficiency. 


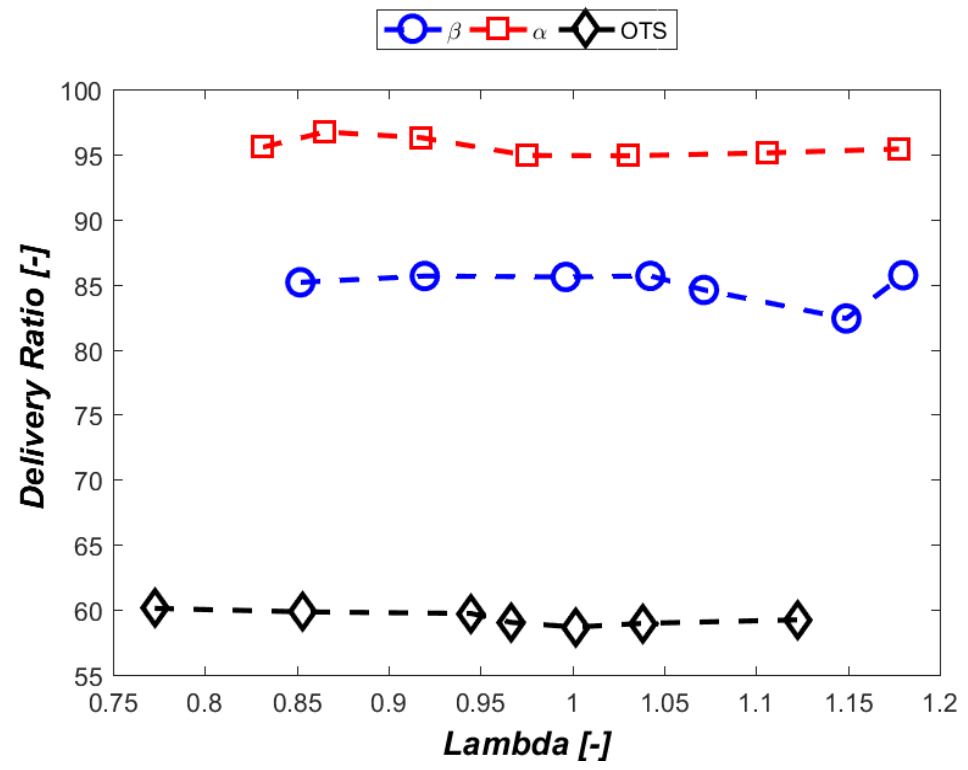

Figure 29. Delivery versus AFR for all exhausts with a tuned intake.

Power density, which is directly related to the delivery ratio, was mostly affected by the divergent section as shown in Table 17. The divergent section of the OTS exhaust was the shortest which did not create a strong suction wave and led to the lowest delivery ratio. In addition, the lead pipe cross section area was larger than the exhaust port area, causing thermodynamic irreversibility from the sudden expansion. This was eliminated as much as possible (machining and component limitations) for the alpha and beta designs. The beta design showed the highest power output around a lambda of $1-55 \%$ higher than OTS exhaust. The alpha exhaust showed slightly lower power than the beta exhaust, but still 50\% higher than OTS exhaust. Each case of Table 17 corresponds to the AFR in figures and they follow the left to right trends.

Table 17. Maximum brake power output in $\mathbf{k W}$ for all exhaust configurations with a tuned intake.

\begin{tabular}{|c|c|c|c|c|c|c|c|}
\hline Case & $\mathbf{1}$ & $\mathbf{2}$ & $\mathbf{3}$ & $\mathbf{4}$ & $\mathbf{5}$ & $\mathbf{6}$ & $\mathbf{7}$ \\
\hline Beta & 0.95 & 0.96 & 0.96 & 0.91 & 0.85 & 0.76 & 0.71 \\
\hline Alpha & 0.85 & 0.92 & 0.93 & 0.91 & 0.87 & 0.81 & 0.74 \\
\hline OTS & 0.35 & 0.54 & 0.60 & 0.62 & 0.62 & 0.59 & 0.51 \\
\hline
\end{tabular}

\section{Efficiency}

Figure 30 presents the BTE for the different exhaust configurations with the tuned intake. The beta design showed the highest efficiency over a broad range of AFR. Around stoichiometric 
operation, the OTS design showed higher efficiency compared to the alpha, but in rich and lean zones the alpha design showed better efficiencies. The alpha design yielded lower efficiency than the beta exhaust because of its longer diffuser section and lower trapping efficiency.

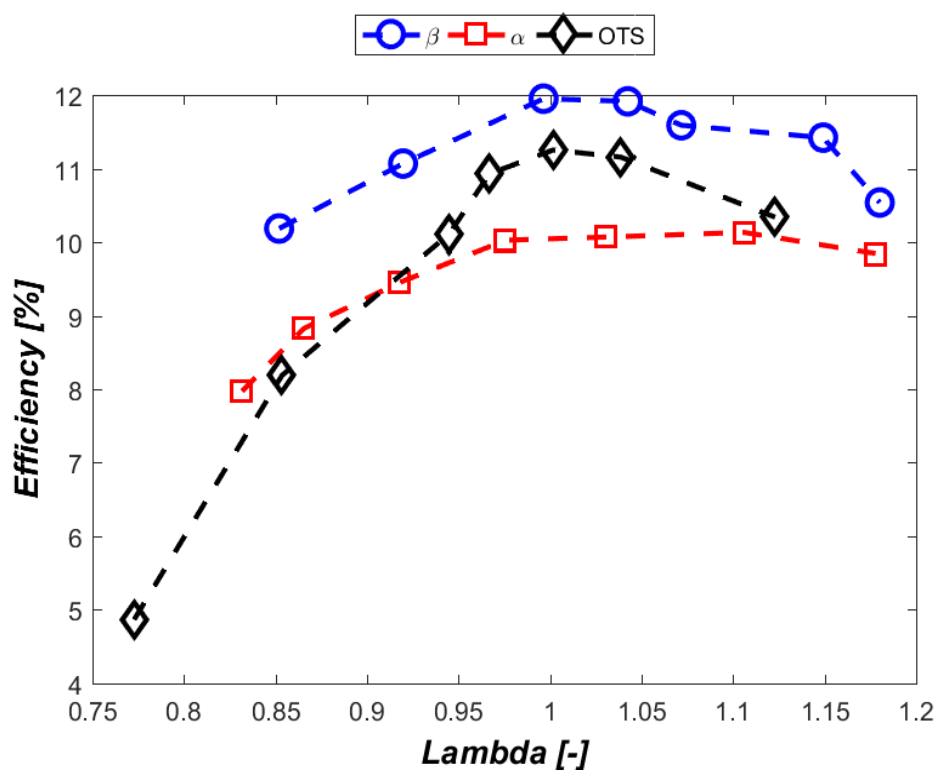

Figure 30. Efficiency as a function of air-fuel ratio.

\subsubsection{Combustion Chamber}

The combustion dome was modified to reduce sharp edges and squish volume. Table 18 presents the results from the OTS and redesigned combustion chamber. The chamber geometry did not affect the delivery ratio; however, it improved the power output and efficiency by $10.4 \%$ and $8.8 \%$, respectively. These data were collected with stoichiometric AFR, MBT timing, tuned intake, and the beta exhaust design.

Table 18. Results of combustion dome design change with optimized intake and exhaust.

\begin{tabular}{|c|c|c|c|c|c|}
\hline & Lambda [-] & Power [kW] & BTE [\%] & IMEP [bar] & $\begin{array}{c}\text { Delivery ratio } \\
\text { [\%] }\end{array}$ \\
\hline New Head & 0.97 & 1.06 & 13 & 4.6 & 89 \\
\hline OTS Head & 0.99 & 0.96 & 11.95 & 4.3 & 85 \\
\hline
\end{tabular}

The power was not high enough to compensate the generator and friction losses and provide at least $1 \mathrm{~kW}$ of power. In addition, BTE was quite low with this engine, so a new engine was 
selected. The new engine retained the same stroke but had a larger bore, included custom porting, added boost port, and used reed valve in hopes to further increase delivery and trapping efficiency.

\subsection{LPDI}

From this point forward, all the experimental results are from the second generation engine, identified as the boosted engine. Note that all of the intake and exhaust optimization work was transferred from baseline engine to the boosted engine using the same proven approaches. Also, when selecting the boosted engine, it was confirmed that the combustion chamber had a proper dome shape as this was previously showed to further increase efficiency in the baseline engine. The custom engines were provided by O’Neill Brother's Racing located in California.

Table 19 shows the summary of experimental conditions for migrating from PI to LPDI. After the LPDI was enabled to work with proper injection timing, it was observed that exhaust resonator's length needed to be readjusted. While injection pressure in PI operation was around 0.5 bar, on LPDI it was around 2 bar. The initial experimental study examined the effect of injection timing on engine performance. Then the effect of engine speed on LPDI operation was investigated. Engine performance parameters were compared for all cases. Note that for MBT ignition timing, a spark sweep test was performed for each case to find the MBT timing.

Table 19. PI and LPDI test conditions summary.

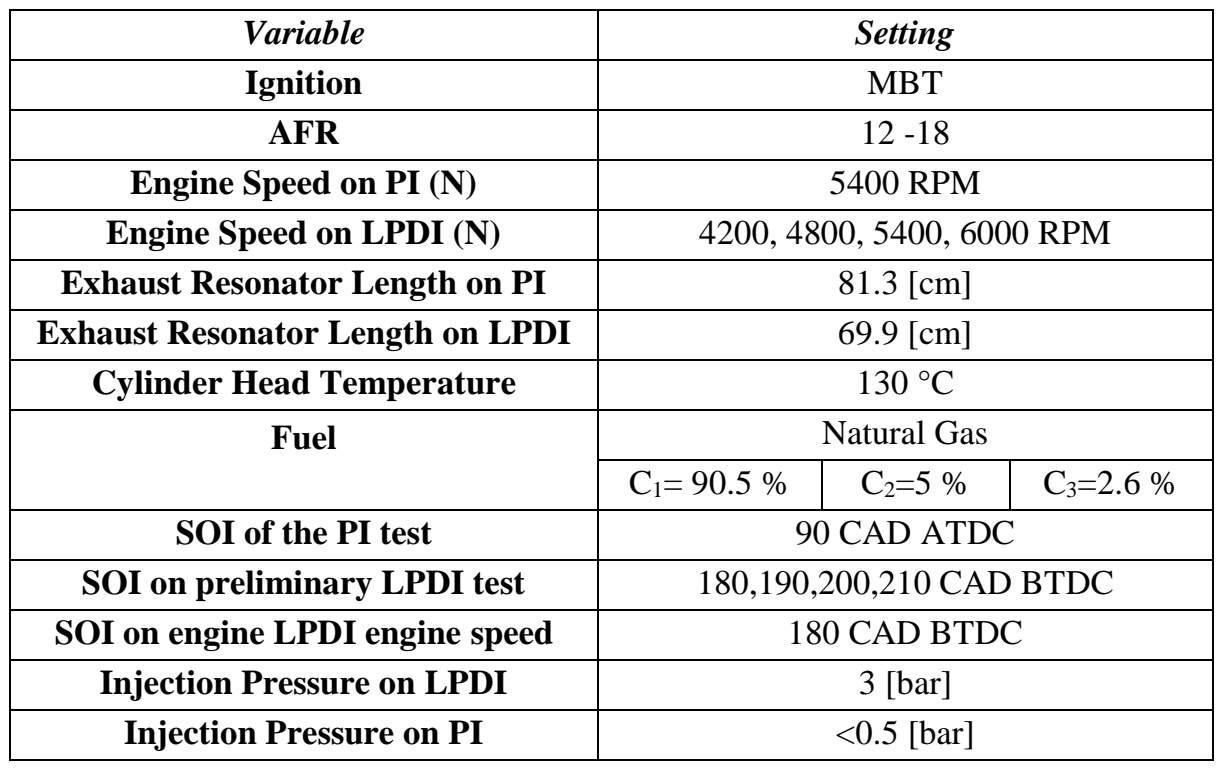




\subsubsection{LPDI Operation and SOI effect}

Moving to LPDI operation required less fuel and resulted in higher air mass flow when compared to PI. Higher fuel trapping ratio compared to air trapping ratio, made the AFR calculated from intake air mass flow appear higher than trapped AFR. For this reason, I chose to create a modified AFR parameter called $\lambda^{*}$. It is defined as follows:

$$
\lambda^{*}=\frac{\dot{m}_{\text {air }} / \dot{m}_{\text {fuel }}}{A F R_{\text {stoich }}}
$$

Note that $\lambda^{*}$ was calculated based on total intake air flow and total injected fuel. For PI this value was equal to trapped lambda whereas in LPDI this value is higher than trapped lambda. Note that due to air short circuiting and contamination of two-stroke lubricating oil, a typical lambda sensor was not a reliable device to monitor in-cylinder lambda. One accurate way to measure the incylinder lambda could be using a fast sampling instrument which was not available in our experimental setup.

We used an alternative approach to sweep the rich to lean operating range in our experiments. Exhaust CO and COV of IMEP were monitored in all LPDI tests, where high CO content in the exhaust was an indicator of in-cylinder rich operation and increasing COV of IMEP at the lean limit was an indicator of passing the stoichiometric zone as shown in Figure 31. The bottom of the valley was assumed the stoichiometric region while the left side was considered rich and right side was lean operation. So, $\lambda^{*}$ for LPDI is not the in-cylinder $\lambda$, but this approach was taken to cover the rich to lean operation range. 


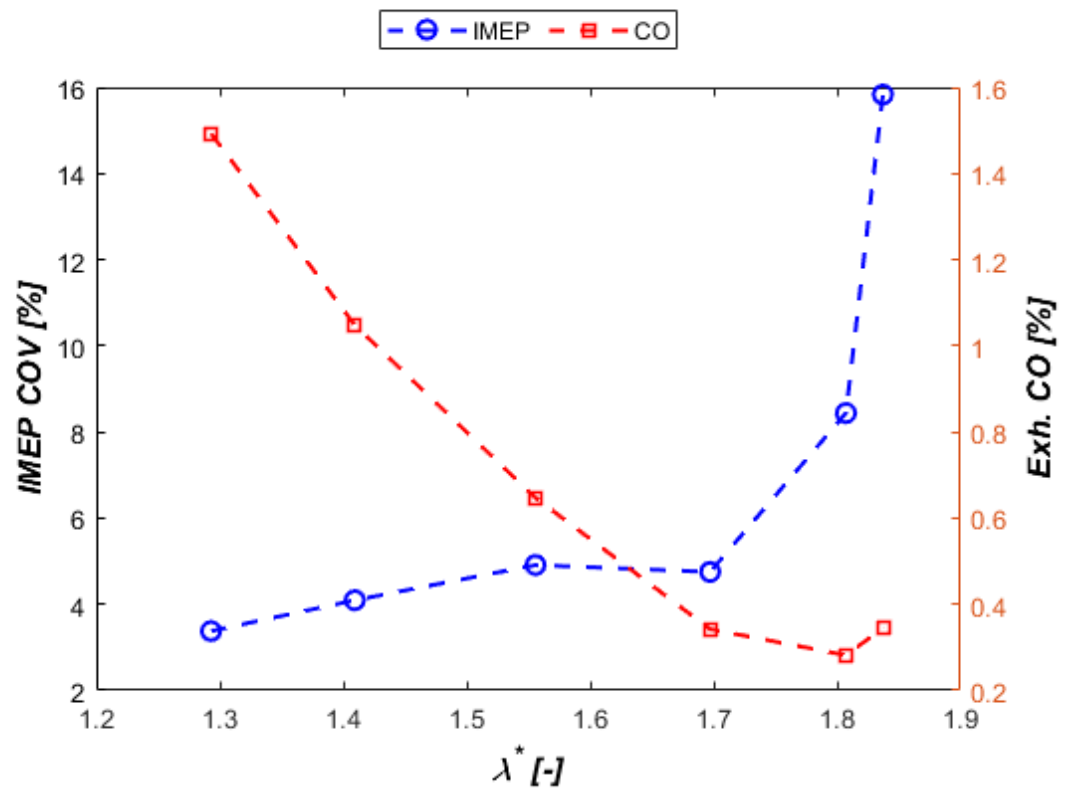

Figure 31. CO and COV of IMEP valley.

Figure 32 shows the delivery ratio for PI and LPDI with varied SOI. During PI operation, fuel displaced around $10 \%$ of the intake charge volume which was then available to air during LPDI and promoted an increased delivery ratio. Hence LPDI had higher trapped mass and higher incylinder peak pressures. As shown in Figure 33, conversion to LPDI increased maximum peak pressure from about 28 bar to 36 bar - or by $28.6 \%$. This was important since it enabled the exhaust resonator to draw in more charge through the cylinder and additionally increase the delivery ratio. The SOI of 180 CAD BTDC showed the highest peak pressure in general which translated to the highest trapped fuel compared to other injection timings. This is doubly confirmed from efficiency results later in this section. Heat release curves in Figure 34 show that the SOI of CAD 180 BTDC had the highest heat release rate in a cycle. 


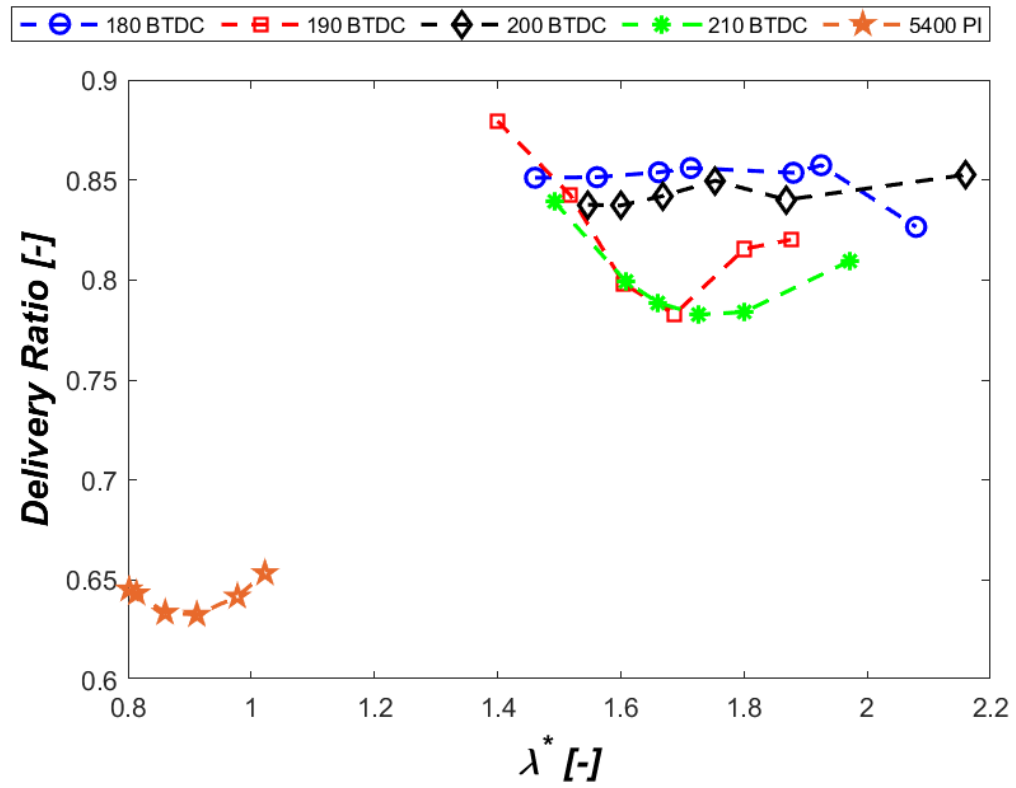

Figure 32. Delivery ratio on PI and LPDI running on different SOI, each point is averaged value for 90 seconds of steady state operation.

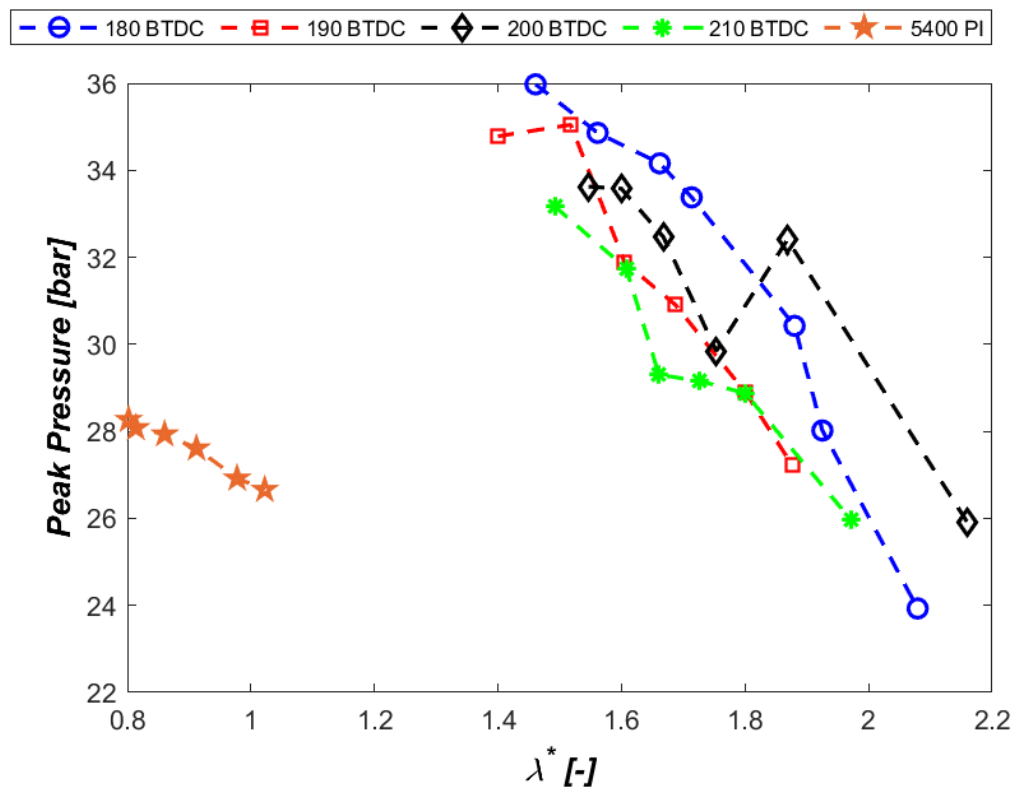

Figure 33. Peak pressure for PI and LPDI by varying the SOI, each point is averaged over 200 cycles on PI and LPDI operations. 


\begin{tabular}{|llllllll}
\hline$\circ$ & $180 \mathrm{BTDC}$ & $\square$ & $190 \mathrm{BTDC}$ & $\diamond$ & $200 \mathrm{BTDC}$ & $*$ & $210 \mathrm{BTDC}$
\end{tabular}

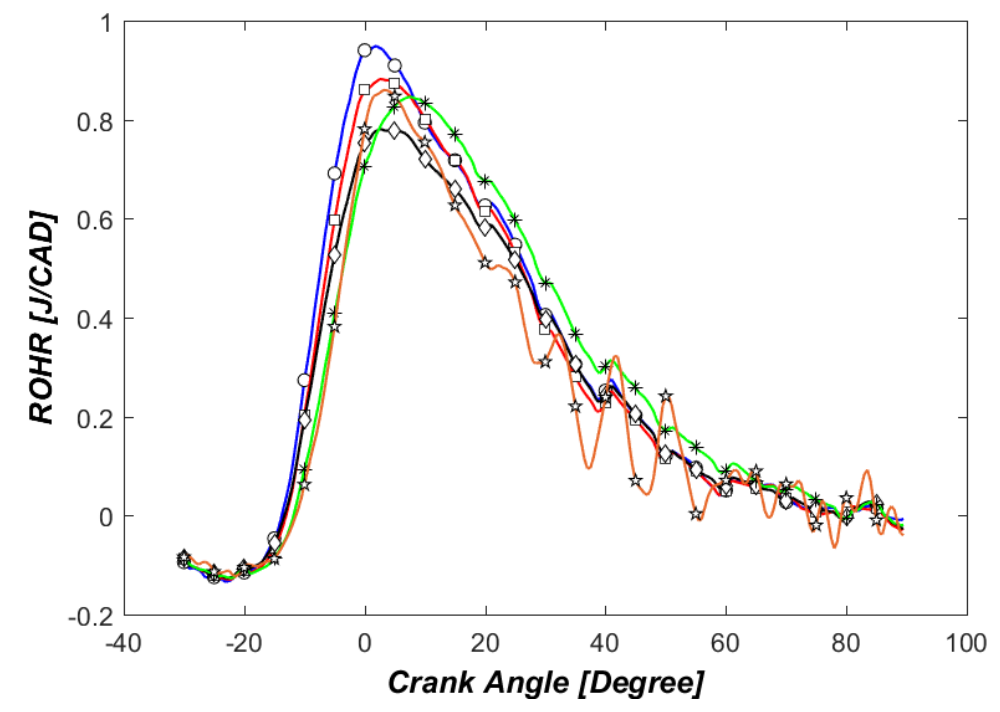

Figure 34. Rate of heat release for PI and LPDI by varying SOI, each curve was averaged over 200 recorded cycles at steady state operation.

Figure 35 presents the average IMEP for PI and LPDI with varied SOI. LPDI yielded higher trapped fuel and thus showed higher power density. The peak IMEP was 4.7 bar, for LPDI at a SOI of 180 CAD BTDC. This was $23.7 \%$ higher than the peak value for PI. As shown in Figure 35, in all but three cases which were lean, LPDI operations showed higher IMEP when compared to PI. Lower IMEP in those cases was due to combustion instability caused by charge stratification.

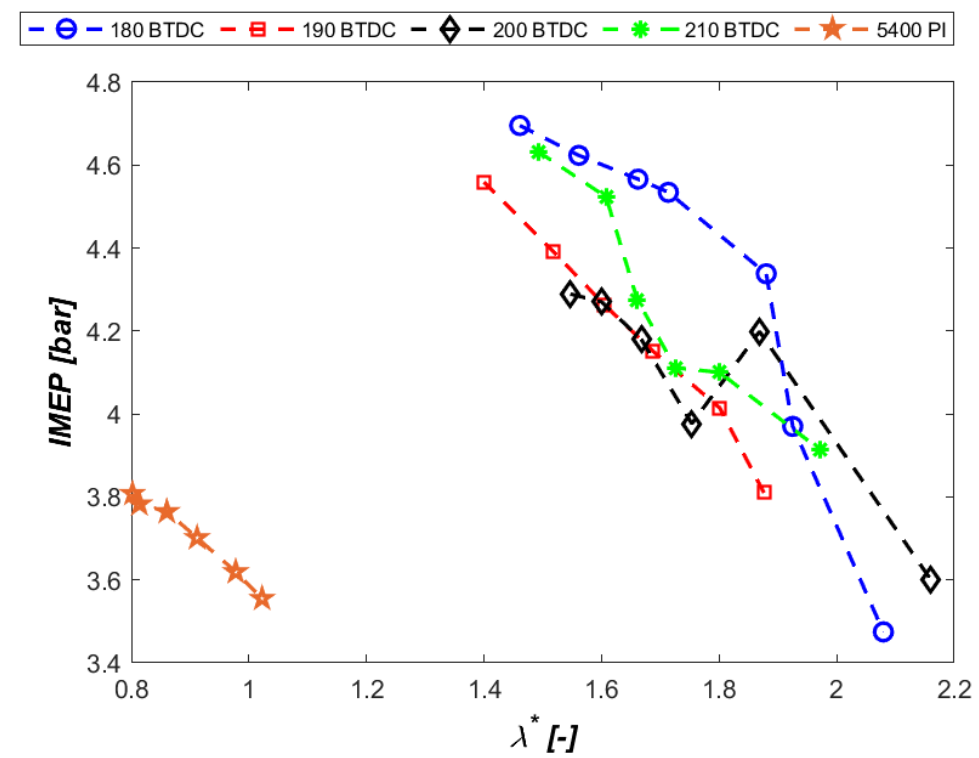

Figure 35. IMEP averaged over 200 cycles on PI and preliminary LPDI operations vs $\lambda$ *. 
Charge stratification was of the biggest concerns when operating on LPDI. It caused unstable combustion near lean limits as shown Figure 36. To understand mixture stratification for the LPDI case, a CFD study was required and performed later in this research. For LPDI operation with SOI of 180 CAD BTDC, a COV of less than $10 \%$ was achieved for $\lambda^{*}$ less than 1.7. Some literature recommends an acceptable threshold of $10 \%$ for the COV of IMEP [19], while recently this criteria has been reduced to $5 \%$ by industry [61].

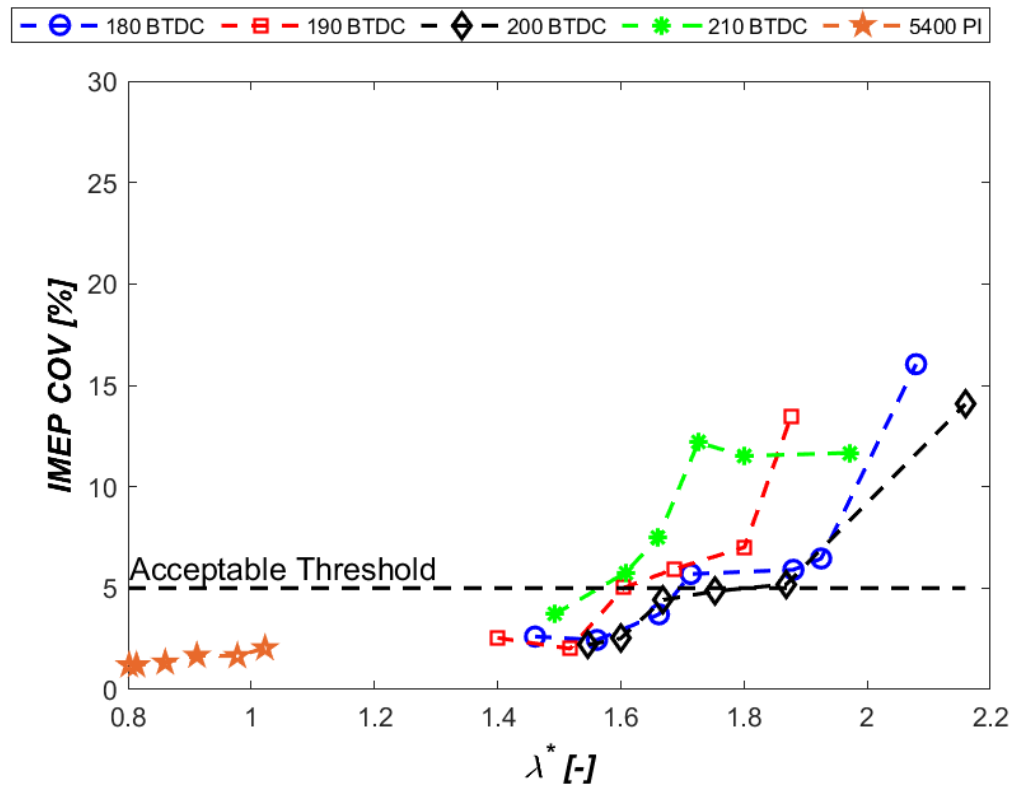

Figure 36. COV of IMEP averaged over 200 cycles on PI and initial LPDI operations vs $\lambda$ *.

In line with combustion instability, combustion duration increased for unstable combustion cases as shown in Figure 37. Combustion duration was defined by the CAD from 10\% mass fraction burned (MFB) to 90\% MFB. The earliest SOI showed decreased combustion duration likely due to lower fuel trapping and power density. For the best case of SOI of 180 CAD BTDC, and with $\lambda *$ ranging from 1.4-1.5 similar combustion durations were observed for both PI and LPDI. 


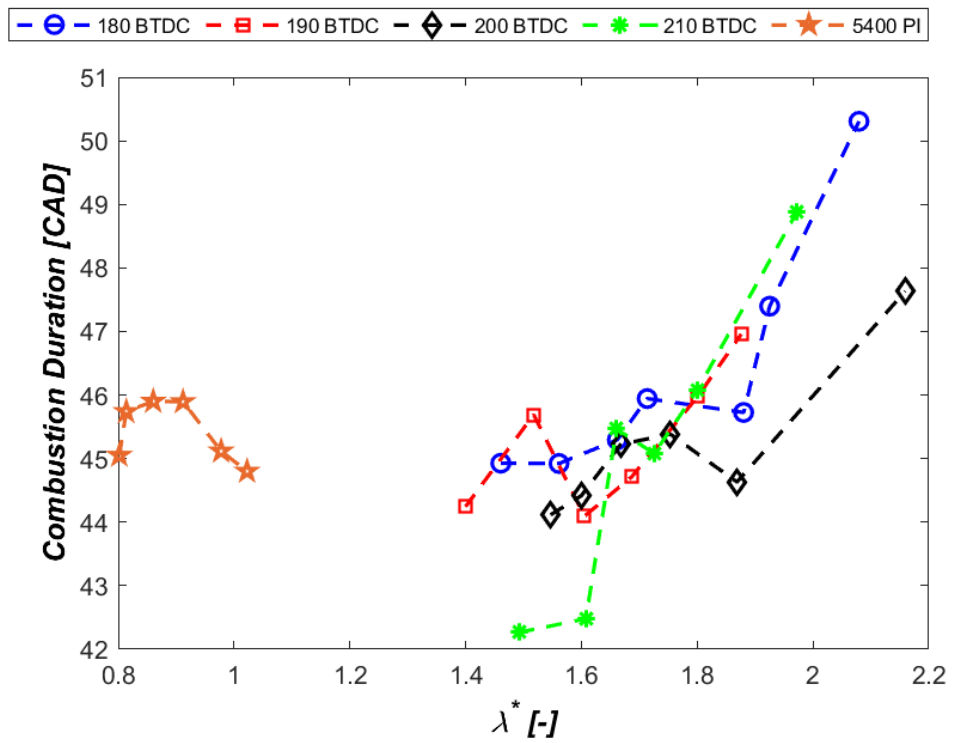

Figure 37. Combustion Duration averaged over 200 cycles on PI and initial LPDI operations vs $\lambda$ *.

Indicated efficiency is shown in Figure $\mathbf{3 8}$ for PI and LPDI with varied SOI. The higher fuel trapping ratio was the major reason for the significant increase in efficiency between fueling configurations. It was found that a SOI of 180 CAD BTDC provided peak efficiency. Earlier SOI led to increased fuel slip in the scavenging flow before exhaust port closing (EPC).

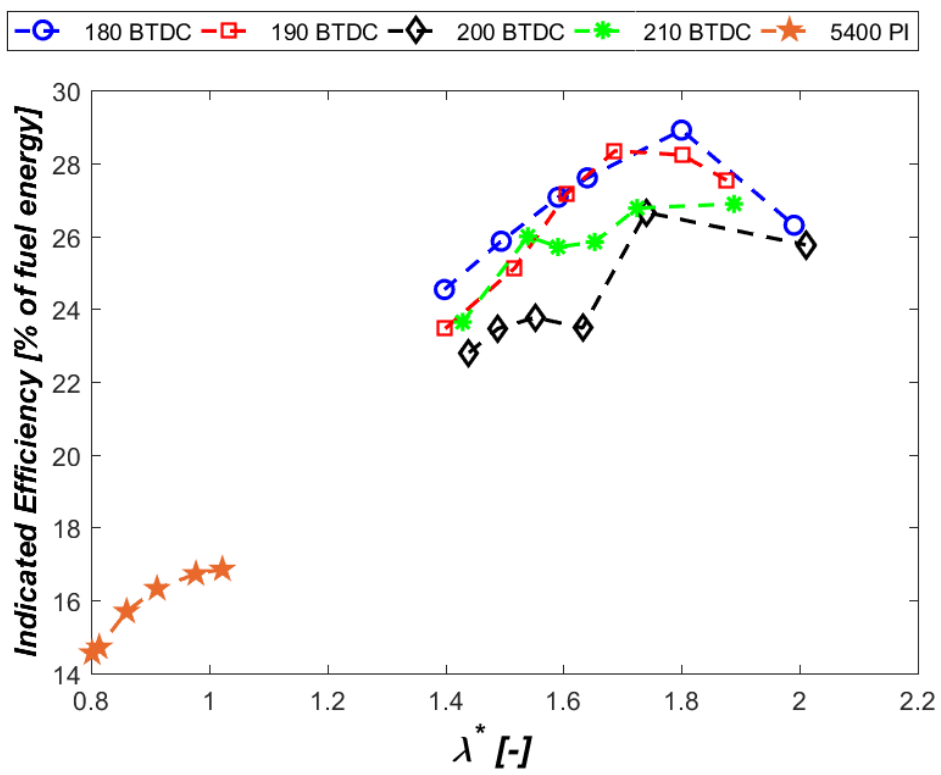

Figure 38. Indicated thermal efficiency on PI and LPDI, averaged over 90 seconds steady state operation for each point vs $\lambda *$. 
To investigate the difference in slipped HC in the exhaust, Figure 39 shows the brake-specific THC emissions for PI and LPDI with varied SOI. THC was defined as the sum of C1-C3 exhaust components and it was dominated by $\mathrm{CH}_{4}$ as expected. For the best LPDI case, THC emissions were reduced by $73 \%$ when compared to PI.

As stated above, for this engine size and application, the EPA regulation for $\mathrm{HC}+\mathrm{NO}_{\mathrm{x}}$ is $<50$ $\mathrm{g} / \mathrm{kWhr}$ [86]. The LPDI with SOI of $180 \mathrm{CAD}$ BTDC met current regulations (Figure 39 and Figure 40). Though $\mathrm{CH}_{4}$ is not currently regulated for these engine families.

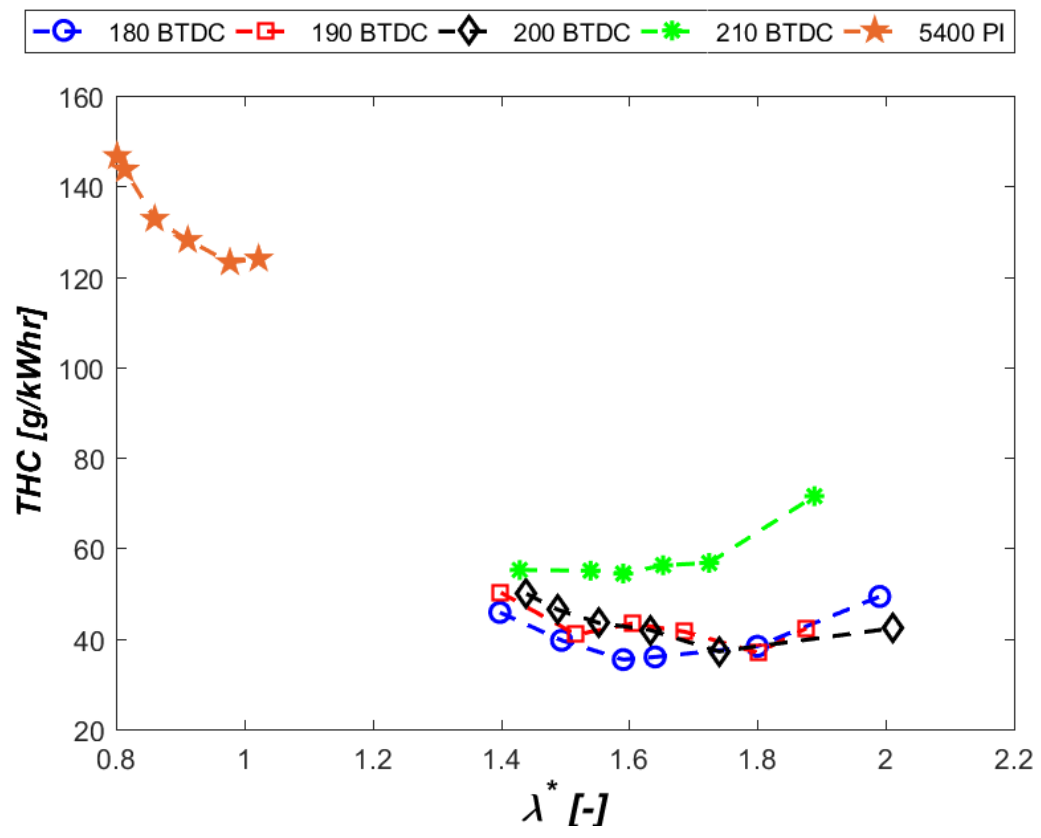

Figure 39. THC emissions on PI and preliminary LPDI vs $\lambda *$, averaged over 90 seconds of steady state operation. These emissions arise both from the scavenging process and from incomplete combustion. 


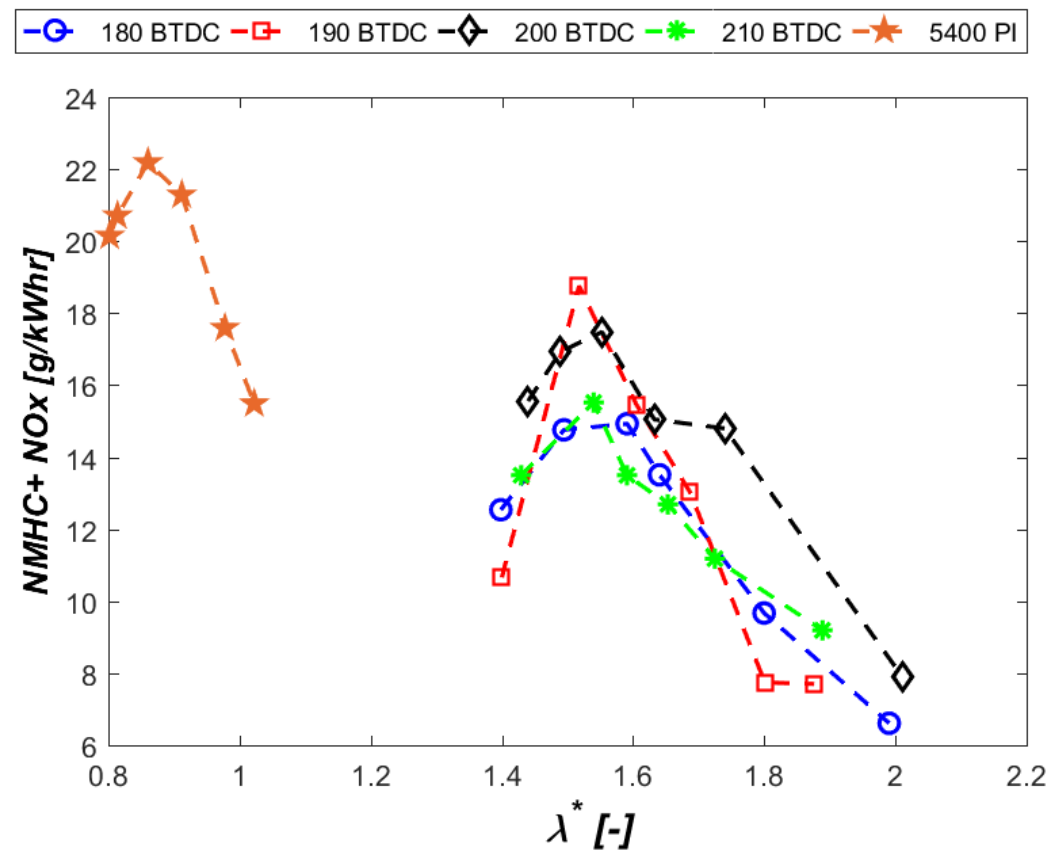

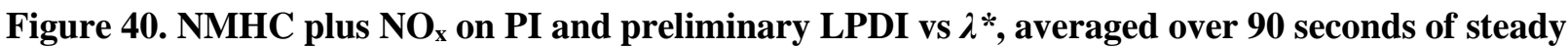
state operation.

The detailed energy break-down comparison for PI and LPDI is presented as part of the speed effect study in the next section.

\subsubsection{Effect of Engine Speed on LPDI Operation}

After determining the optimal injection strategy for an engine speed of 5400 RPM, the engine was operated at different speeds to examine any potential benefits from different speed operation.

Figure 41 shows the delivery ratios for varied engine speed while the SOI was held optimal. Delivery ratio increased at LPDI operation with two mechanisms: absence of gaseous fuel in the intake and higher in-cylinder pressure at EPO. Higher pressure at EPO created a stronger suction wave causing more flow through the engine. Because of highly unstable combustion at 4800 RPM, peak pressures were very low, which in turn yielded weaker suction waves. This caused lower delivery ratio at this speed.

To examine one variable at a time, the exhaust resonator geometry was kept fixed for all cases at the previously optimized length for 5400 RPM. Other than exhaust resonators effect, at 4200 and 4800 RPM, lower piston speed naturally led to a weaker suction within the crankcase and less flow 
through the engine. The exhaust resonator had a strong effect on in-cylinder charge, and poor tuning led to unstable combustion. This effect led to higher THC emissions at 4800 RPM.

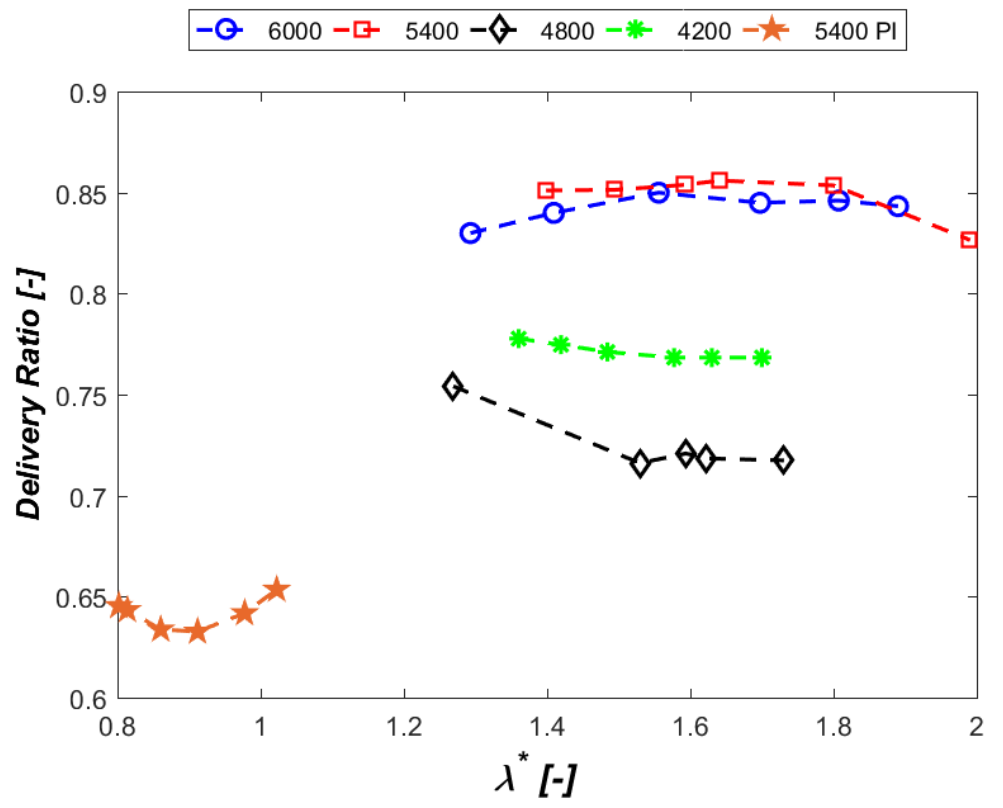

Figure 41. Delivery ratio vs $\lambda *$ for PI and LPDI, each point is averaged over 90 seconds of steady state operation.

As explained in section 3.2.2, five major energy pathways were identified for this engine. While 6000 RPM LPDI showed the best overall performance, PI showed the worst performance. A full energy balance analysis for these two extreme cases is presented in Figure $\mathbf{4 2}$.

Fuel loss (slipped and unburnt) ranged from $38 \%$ to $41 \%$ of total fuel energy in PI operation. This was comparable with previous research [105]. On LPDI operation, fuel slip ranged from $9 \%$ to $15 \%$ of total fuel energy.

Heat loss was second in PI ranging from 29\% to 33\%. In LPDI heat loss was the highest loss ranging from 29 to $36 \%$ of the total fuel energy. This size of engine showed higher heat losses compared to those reported for larger engines [51]. The main reason was the considerably larger area to volume ratio compared to larger engines.

Exhaust thermal energy ranged from $16 \%$ to $18 \%$ for PI while it ranged from 25 to $28 \%$ for LPDI. This higher percentage was due to lower total fuel injected in LPDI and almost the same amount of exhaust thermal energy. 
Indicated efficiency was only 14.5 to $16.8 \%$ in PI operation and it ranged $26 \%$ to $29 \%$ with LPDI operation. Reducing the slipped fuel was the main reason for increased energy efficiency.

Due to well-mixed charge in PI operation, combustion inefficiency was as low as $3.4 \%$ during richer combustion. This was where the LPDI had higher incomplete combustion energy content.
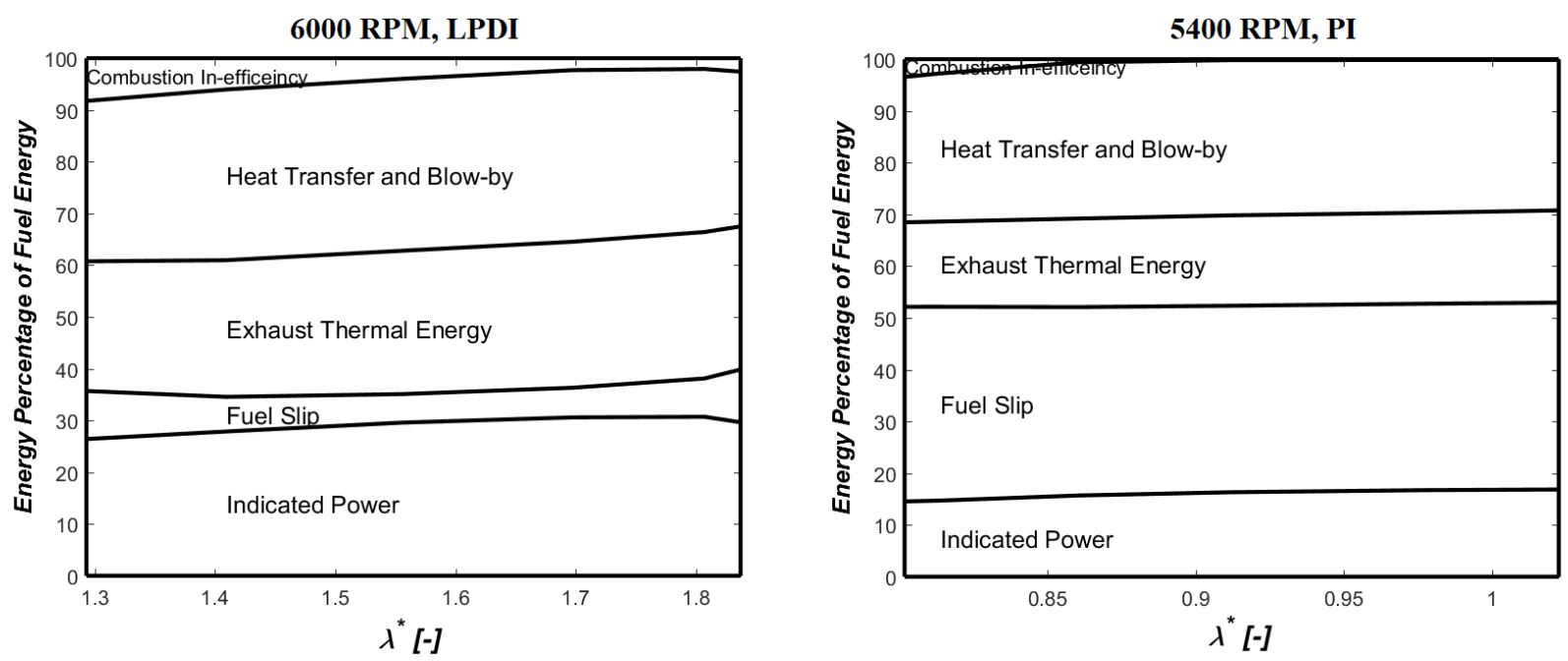

Figure 42. Energy balance of LPDI at 6000 RPM and PI at 5400 RPM as percentage of total injected fuel energy, data was averaged over 90 of seconds steady state operation.

For LPDI, heat losses were less than PI. However, given the engine's small size, its area to volume ratio was considerably large at EPC $\left(200\left[\mathrm{~m}^{-1}\right]\right)$, a higher portion of released heat was lost by convective and radiative heat transfer. For perspective, the same bore and stroke ratio in a $500 \mathrm{cc}$ engine yielded an area to volume ratio of around $80[1 / \mathrm{m}]$. Since fuel slip was reduced by conversion to LPDI, the largest loss pathway was heat loss, which ranged from 29 to $36 \%$ of the total fuel energy. Combustion inefficiency increased, due in part to increased cyclic variability as shown in the COV of IMEP - likely caused by mixture stratification. Average indicated efficiency for LPDI was $29 \%$ as compared to $15 \%$ for PI. To investigate each energy pathway in more detail, they are presented here separately.

\section{Heat Loss}

Figure 43 shows the heat losses for PI and LPDI with varied speed. As percentage of total fuel energy, LPDI showed an increase compared to PI. This was mainly due to lower total fuel required per cycle in LPDI. 
For a better comparison on a trapped energy basis, in-cylinder heat release was used to compare heat transfer as shown in Table 20. To compare all cases, PI operation at 5400 RPM was used as the baseline. For the comparison, a parameter was calculated dividing heat loss by in-cylinder heat release for each case. Then a relative change of that parameter is presented in Table 20, considering the PI 5400 RPM as baseline. For all LPDI cases, heat losses decreased, and the amount of reduction was higher with increased speed. For the same engine speed as the baseline (5400 RPM), LPDI operation decreased cylinder heat loss by about 31 to $39 \%$ when compare to PI as the baseline.

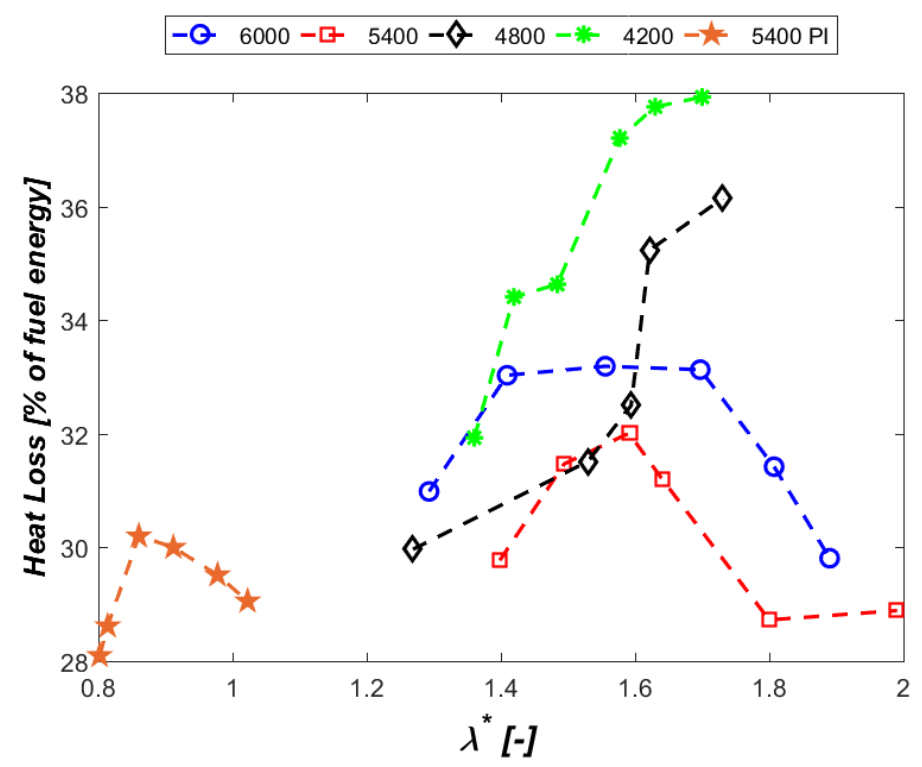

Figure 43. Heat transfer rate as a percentage of total injected fuel energy vs $\lambda *$ for PI and LPDI, each point was averaged over 90 seconds of steady state operation.

Table 20. Heat transfer change on LPDI relative to PI based on in-cylinder heat released, heat loss was averaged over 90 seconds steady state operation and heat release was average over 200 cycle recorded.

\begin{tabular}{|c|c|c|c|c|c|c|}
\hline Case no. & $\mathbf{1}$ & $\mathbf{2}$ & $\mathbf{3}$ & $\mathbf{4}$ & $\mathbf{5}$ & $\mathbf{6}$ \\
\hline LPDI 6000 RPM & -31.52 & -31.89 & -34.78 & -33.41 & -34.76 & -36.04 \\
\hline LPDI 5400 RPM & -30.71 & -30.66 & -32.12 & -32.32 & -38.61 & -36.11 \\
\hline LPDI 4800 RPM & -17.60 & -30.05 & -30.41 & -21.65 & -16.12 & -14.14 \\
\hline LPDI 4200 RPM & -14.22 & -12.25 & -14.82 & -6.92 & -2.29 & -1.79 \\
\hline PI 5400 RPM & baseline & baseline & baseline & baseline & baseline & baseline \\
\hline
\end{tabular}


Figure 44 shows the impact of different speeds on the rate of heat release (ROHR) at a given $\lambda^{*}$. For each point the integral of this curve showed the heat release energy per cycle. LPDI at 6000 RPM, had the highest trapping efficiency and a higher ROHR. This resulted into a higher incylinder pressure (Figure 45).

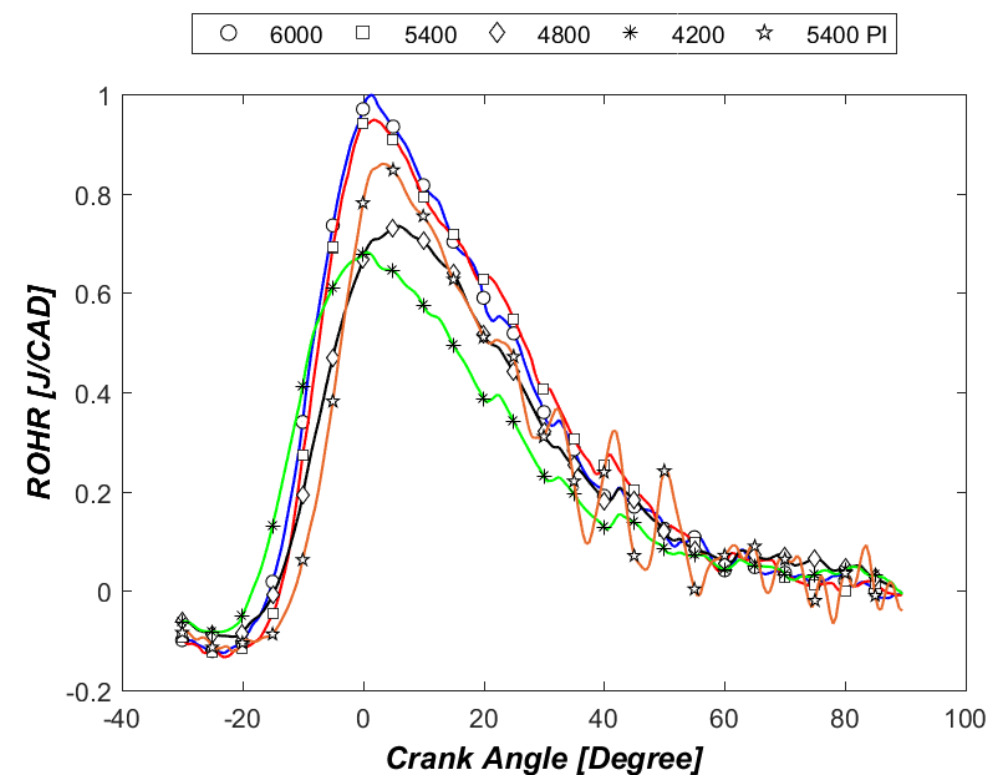

Figure 44. Rate of heat released averaged on 200 cycles for different speeds on LPDI near stoichiometric operation.

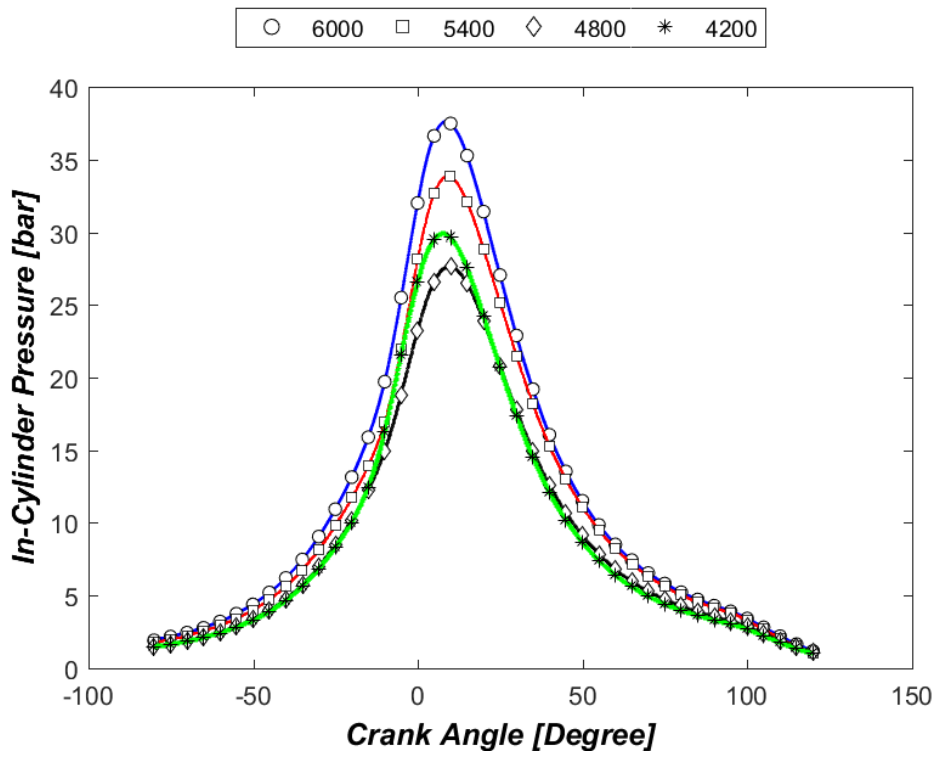

Figure 45. In-cylinder pressure averaged on 200 cycles for different speeds on LPDI near stoichiometric operation. 
Figure 46 shows the peak pressure results for all operating points averaged over 200 cycles. Higher peak pressure served as a mechanism to increase the delivery ratio from a stronger suction wave at the divergent section of exhaust resonator. Note that when examining the ROHR curve (Figure 44), higher peak pressure was expected at 6000 RPM as ignition timing was set to MBT in all cases.

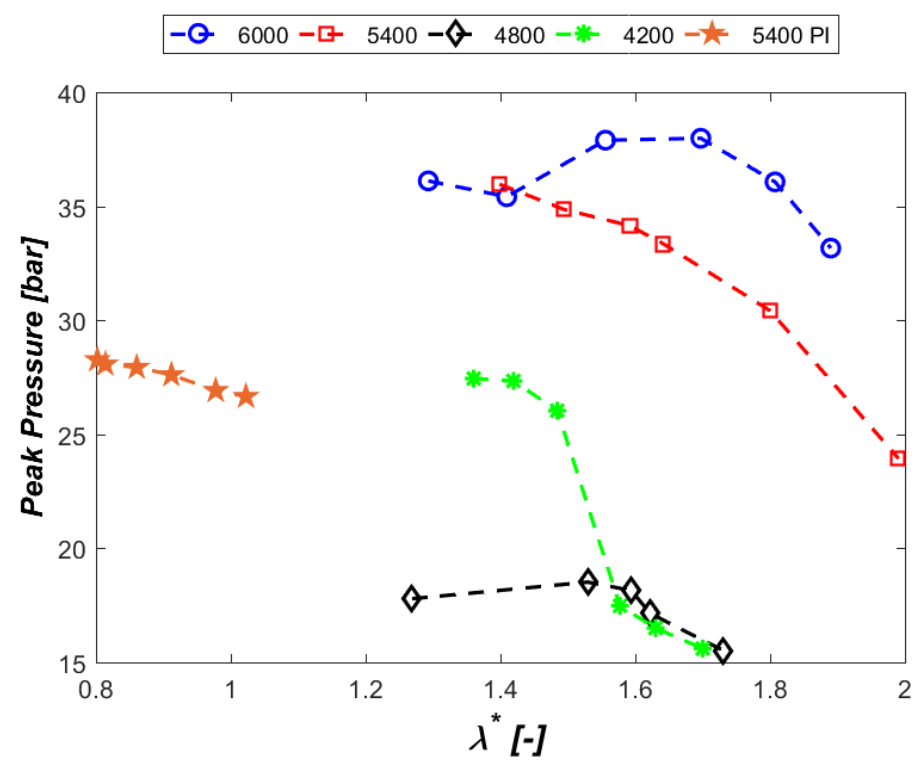

Figure 46. Peak pressure averaged on 200 cycles for different speeds on LPDI and 5400RPM on PI.

\section{Indicated Efficiency}

Figure 47 presents the indicated efficiency for all PI and LPDI cases. Since this research was geared toward free piston engine development, indicated efficiency was examined to remove any effect in friction changes within the driveline system (i.e. clutch and bearing wear). LPDI operation, showed higher indicated efficiency throughout the entire engine operation range compared to PI. This was mainly due to improved volumetric efficiency and reduced fuel slip. Table 21 shows the tabular results for each case compared to PI as baseline. The peak increase in indicated efficiency for the same engine speed as PI, was about $76 \%$. This further increased by up to around $90 \%$ at $6000 \mathrm{RPM}$. 


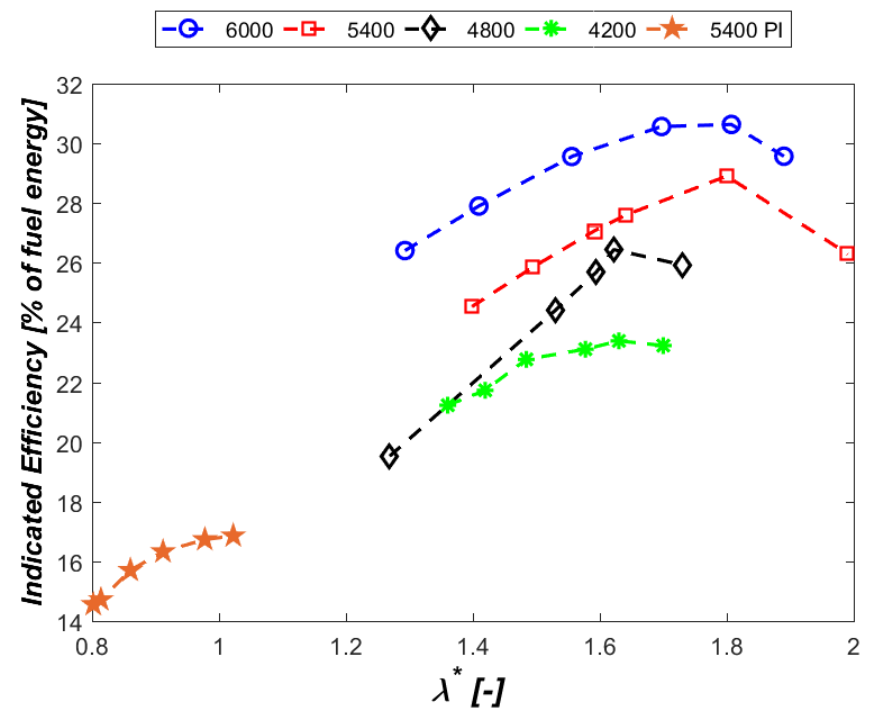

Figure 47. Indicated efficiency for PI and LPDI vs $\lambda *$, averaged over 90 seconds steady state operation for each point.

Table 21. Indicated efficiency change on LPDI operation relative to PI, exhaust sensible was averaged over 90 seconds steady state operation and heat release was average over 200 cycle recorded.

\begin{tabular}{|c|c|c|c|c|c|c|}
\hline Case no. & $\mathbf{1}$ & $\mathbf{2}$ & $\mathbf{3}$ & $\mathbf{4}$ & $\mathbf{5}$ & $\mathbf{6}$ \\
\hline LPDI 6000 RPM & +81.46 & +89.65 & +88.34 & +87.27 & +83.16 & +75.49 \\
\hline LPDI 5400 RPM & +68.55 & +75.75 & +72.43 & +69.08 & +72.82 & +56.05 \\
\hline LPDI 4800 RPM & +34.13 & +65.89 & +63.62 & +62.00 & +55.00 & +53.85 \\
\hline LPDI 4200 RPM & +45.84 & +47.68 & +45.03 & +41.56 & +39.80 & +37.83 \\
\hline PI 5400 RPM & baseline & baseline & baseline & baseline & baseline & baseline \\
\hline
\end{tabular}

\section{Exhaust Thermal Energy}

Figure 48 shows the results of exhaust thermal energy as fraction of total fuel input energy. The increase in LPDI was due to the dramatic reduction in fuel slip and the redistribution of the relative contribution for each energy pathway. Similar to heat transfer results in Table 20, the exhaust sensible energy was compared to in-cylinder heat released and presented in Table 22. Data showed very little change for the same engine speed as PI. 


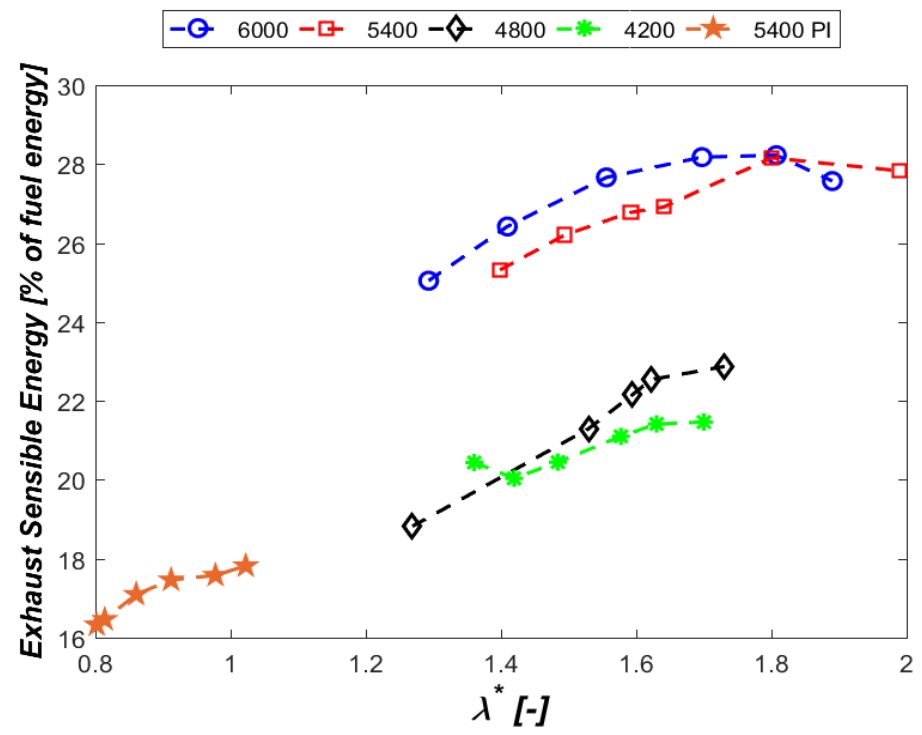

Figure 48. Exhaust thermal energy as a fraction to total fuel input energy vs $\lambda *$ for PI and LPDI, averaged over 90 seconds steady state operation for each point.

Table 22. Exhaust thermal energy change on LPDI operation relative to PI based on in-cylinder heat released.

\begin{tabular}{|c|c|c|c|c|c|c|}
\hline Case no. & $\mathbf{1}$ & $\mathbf{2}$ & $\mathbf{3}$ & $\mathbf{4}$ & $\mathbf{5}$ & $\mathbf{6}$ \\
\hline LPDI 6000 RPM & -4.72 & -5.28 & -3.95 & -2.67 & -1.58 & -3.53 \\
\hline LPDI 5400 RPM & 1.44 & 0.39 & 0.31 & 0.30 & 1.06 & 0.36 \\
\hline LPDI 4800 RPM & -10.93 & -17.82 & -16.20 & -13.89 & -10.88 & -11.40 \\
\hline LPDI 4200 RPM & -5.49 & -11.16 & -11.15 & -9.30 & -6.96 & -9.38 \\
\hline PI 5400 RPM & baseline & baseline & baseline & baseline & baseline & baseline \\
\hline
\end{tabular}

\section{Exhaust Chemical Energy (HC, CO)}

Chemical energy was divided in to two types: THC (unburnt and slipped), and CO as a result of incomplete combustion. Table 23 shows the fuel slip rate as a percentage of total injected fuel for all the cases. PI showed the highest fuel slip rate around $38 \%$ of total fuel injected. Figure 49 shows that LPDI operation at 6000 RPM had the lowest fuel slip rate with best case of $5.78 \%$ fuel slip. 
Table 23. Fuel slip rate on LPDI and PI operation as a percentage of total injected fuel.

\begin{tabular}{|c|c|c|c|c|c|c|}
\hline Case no. & $\mathbf{1}$ & $\mathbf{2}$ & $\mathbf{3}$ & $\mathbf{4}$ & $\mathbf{5}$ & $\mathbf{6}$ \\
\hline LPDI 6000 RPM & 9.52 & 6.78 & 5.78 & 6.02 & 7.91 & 10.81 \\
\hline LPDI 5400 RPM & 13.94 & 12.68 & 11.83 & 12.12 & 12.89 & 16.23 \\
\hline LPDI 4800 RPM & 21.16 & 14.54 & 11.52 & 11.22 & 12.04 & 12.04 \\
\hline LPDI 4200 RPM & 16.44 & 15.02 & 14.56 & 13.32 & 12.12 & 15.29 \\
\hline PI 5400 RPM & 37.61 & 37.45 & 36.41 & 36.03 & 36.02 & 36.11 \\
\hline
\end{tabular}

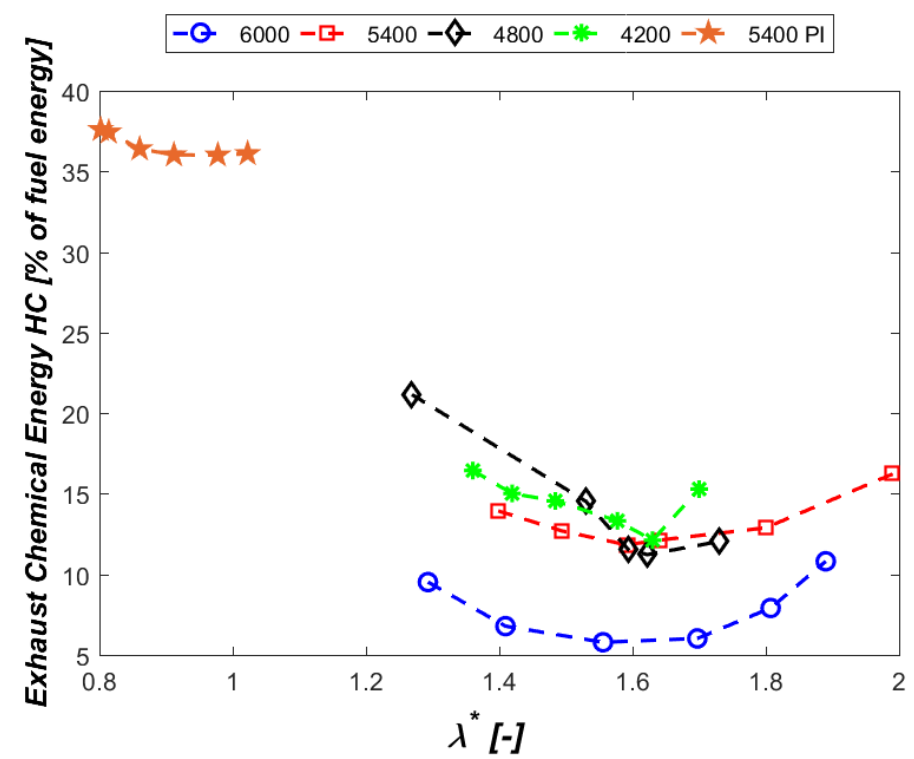

Figure 49. Fuel slip rate as a percentage of total injected fuel.

Fuel slip rate changes are presented in Table 24 considering PI at 5400 RPM as the baseline. All LPDI operations showed more than $60 \%$ reduction in fuel slip peaking at 6000 RPM for an intake lambda of 1.55 - an $87 \%$ reduction in exhaust THC energy when compared to PI.

Table 24. Fuel slip rate on LPDI operation relative to PI.

\begin{tabular}{|c|c|c|c|c|c|c|}
\hline Case no. & $\mathbf{1}$ & $\mathbf{2}$ & $\mathbf{3}$ & $\mathbf{4}$ & $\mathbf{5}$ & $\mathbf{6}$ \\
\hline LPDI 6000 RPM & -80.10 & -86.22 & -87.28 & -86.50 & -81.79 & -75.07 \\
\hline LPDI 5400 RPM & -70.50 & -74.25 & -75.08 & -73.49 & -72.96 & -69.37 \\
\hline LPDI 4800 RPM & -61.35 & -78.40 & -81.82 & -81.48 & -80.40 & -79.98 \\
\hline LPDI 4200 RPM & -74.61 & -77.34 & -76.98 & -78.87 & -80.62 & -76.07 \\
\hline PI 5400 RPM & baseline & baseline & baseline & baseline & baseline & baseline \\
\hline
\end{tabular}


Figure 50 presents the exhaust chemical energy from $\mathrm{CO}$. We recognized two major stratification mechanisms for LPDI and PI operations:

1. Strong stratification originating from limited mixing times for LPDI given high engine speeds in general.

2. Added stratification originating from lower turbulent intensity at reduced speeds regardless of PI or LPDI.

Strong stratification of the gaseous fuel in LPDI operation, increased the CO contribution in the exhaust chemical energy. Lower speeds likely had lower tumble strength and mixing which increased stratification and CO emissions. Table 25 shows the exhaust CO energy for LPDI and PI operation. LPDI at 4200 RPM, yielded 28 times higher exhaust CO energy when compared to PI.

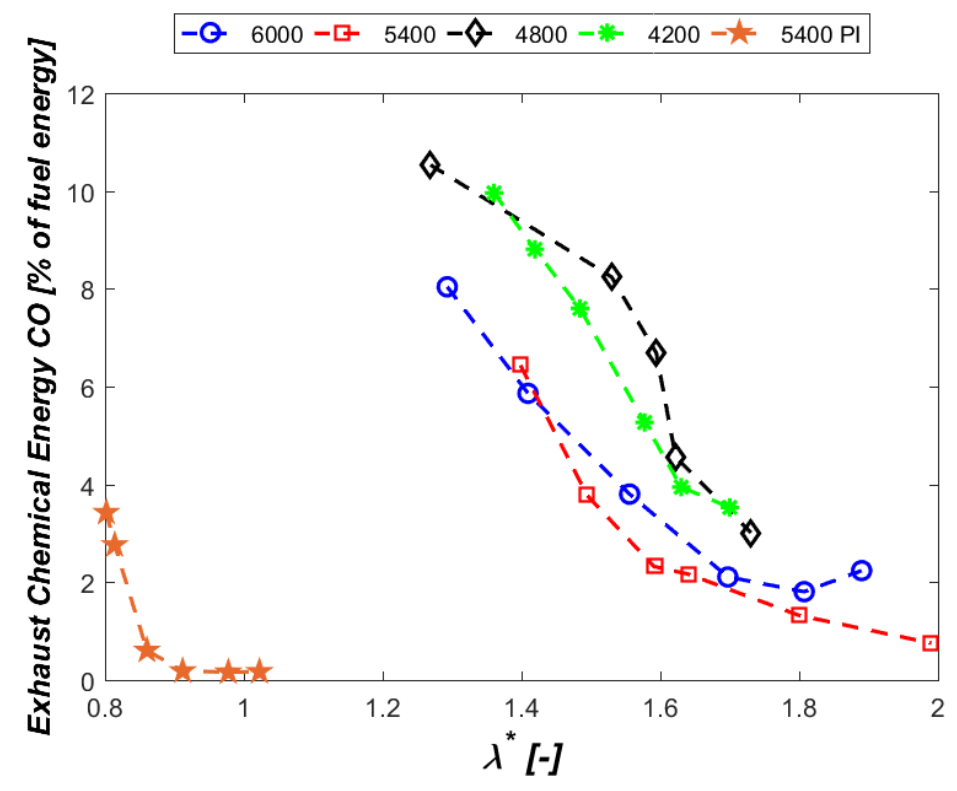

Figure 50. Exhaust CO energy as a percentage of total injected fuel energy for PI and LPDI, each point was averaged over 90 seconds of steady state operation. 
Table 25. ECE (CO) on LPDI operation relative to $P I$.

\begin{tabular}{|c|c|c|c|c|c|c|}
\hline Case no. & $\mathbf{1}$ & $\mathbf{2}$ & $\mathbf{3}$ & $\mathbf{4}$ & $\mathbf{5}$ & $\mathbf{6}$ \\
\hline LPDI 6000 RPM & 2.35 & 2.12 & 6.29 & 11.53 & 11.32 & 13.35 \\
\hline LPDI 5400 RPM & 1.88 & 1.37 & 3.84 & 11.84 & 8.27 & 4.49 \\
\hline LPDI 4800 RPM & 3.08 & 2.99 & 11.07 & 24.95 & 18.87 & 17.98 \\
\hline LPDI 4200 RPM & 2.91 & 3.19 & 12.57 & 28.83 & 24.72 & 21.07 \\
\hline PI 5400 RPM & baseline & baseline & baseline & baseline & baseline & baseline \\
\hline
\end{tabular}

\section{Combustion Phasing}

Figure 51 presents the 50\% MFB. Since engine geometry and fuel type were held constant, the ignition timing was always set to MBT. MFB 50\% was around 12 CAD ATDC for most stable operation. During leaner operation, combustion was stretched and had higher durations likely due to instabilities.

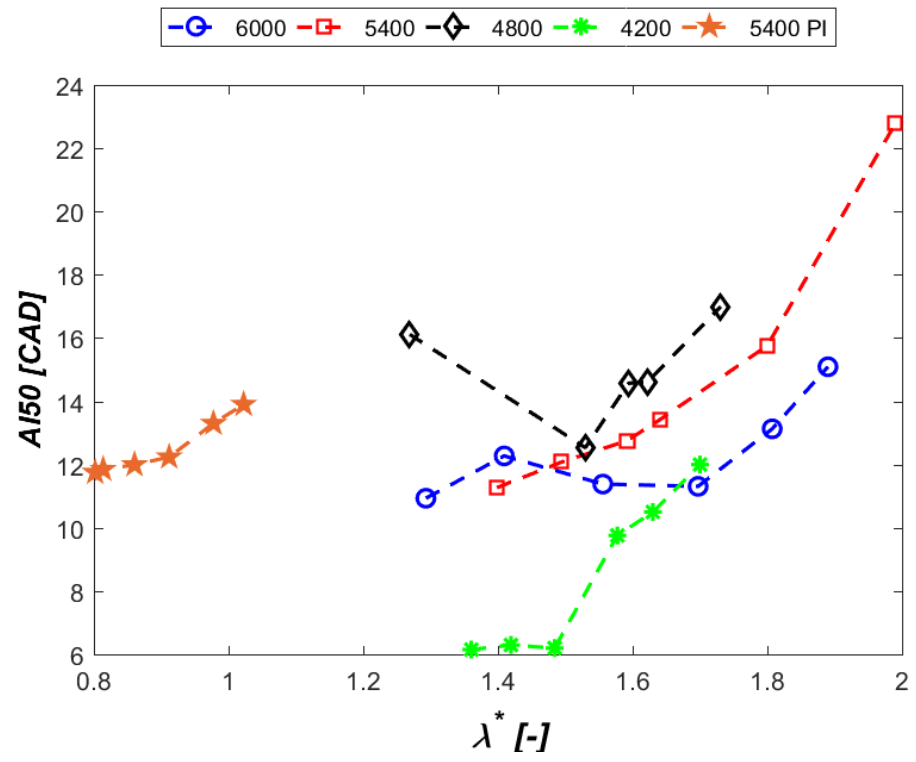

Figure 51. 50\% MFB averaged on 200 cycles for different speeds on LPDI and 5400 RPM on PI.

\section{Combustion Stability}

As shown in Figure 52, due to stratification along with turbulence and flow momentum at lower speeds, the COV of IMEP increased as speed decreased. At 4800 RPM the combustion was very unstable likely because of the exhaust resonator effects on the trapped mixture. More stable 
combustion at higher speeds allowed for a wider range of AFR adjustments not afforded at lower speeds.

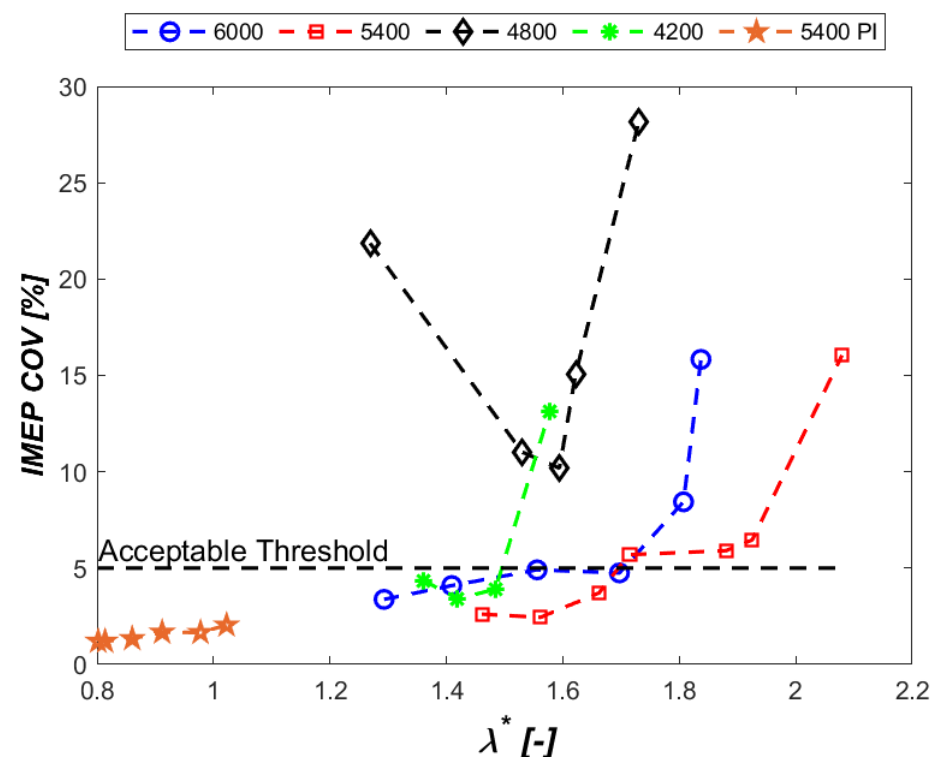

Figure 52. COV of IMEP averaged on 200 cycles for different speeds on LPDI and 5400 RPM on PI.

\section{Emissions}

The current research engine falls in the class I-A according to CFR classifications presented in Table 3. Class I-A non-handheld equipment is described by displacement in the range of less than $66 \mathrm{cc}$ ant their $\mathrm{CO}$ is regulated at $610 \mathrm{~g} / \mathrm{kWhr}$ as presented in Table 3. $\mathrm{HC}+\mathrm{NO}_{\mathrm{x}}$ is regulated at 50 $\mathrm{g} / \mathrm{kWhr}$. This is where NMHC+ $\mathrm{NO}_{\mathrm{x}}$ is not currently regulated for this size engine. The closest regulated class for $\mathrm{NMHC}+\mathrm{NO}_{\mathrm{x}}$ is class I-B with $37 \mathrm{~g} / \mathrm{kWhr}$ limit. The class I-B are non-handheld engines with displaced volume between 66 and $100 \mathrm{cc}$.

Figure 53 shows the CO emissions for LPDI and PI. The root cause of higher CO in LPDI was discussed above. CO regulations for 1-A and IV engines were 610 and $805 \mathrm{~g} / \mathrm{kWhr}$, respectively. Even with the increased CO emissions from LPDI, levels for all speeds were well below the regulation limits. 


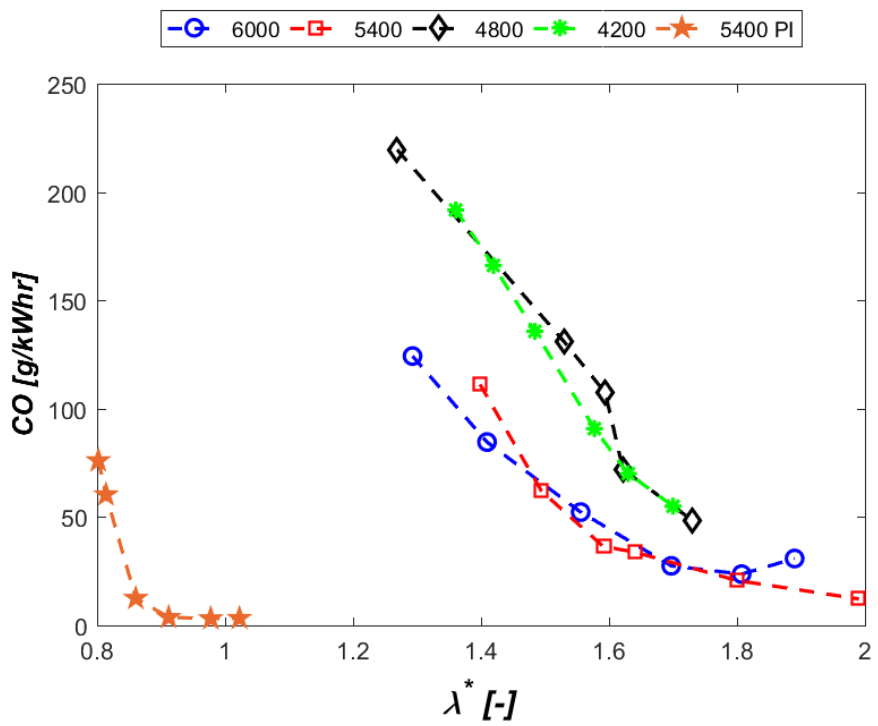

Figure 53. CO emissions on PI and different speeds on LPDI, averaged over 90 seconds of steady state operation for each point.

$\mathrm{HC}$ emissions in $\mathrm{NG}$ engines had two major parts, $\mathrm{NMHC}$ and $\mathrm{CH}_{4}$. Both emissions were important from an efficiency standpoint, however NMHCs affect the local air quality and are most frequently regulated along with $\mathrm{NO}_{\mathrm{x}}$. Figure 54 shows the $\mathrm{CH}_{4}$ emissions for all the cases. LPDI operation at $6000 \mathrm{RPM}$ showed an $85 \%$ reduction in $\mathrm{CH}_{4}$ emissions. Total $\mathrm{HC}_{\text {plus }} \mathrm{NO}_{\mathrm{x}}$ emissions for the highest efficiency case was $27.3 \mathrm{~g} / \mathrm{kWhr}$ - which was lower than the standard threshold of 50 .

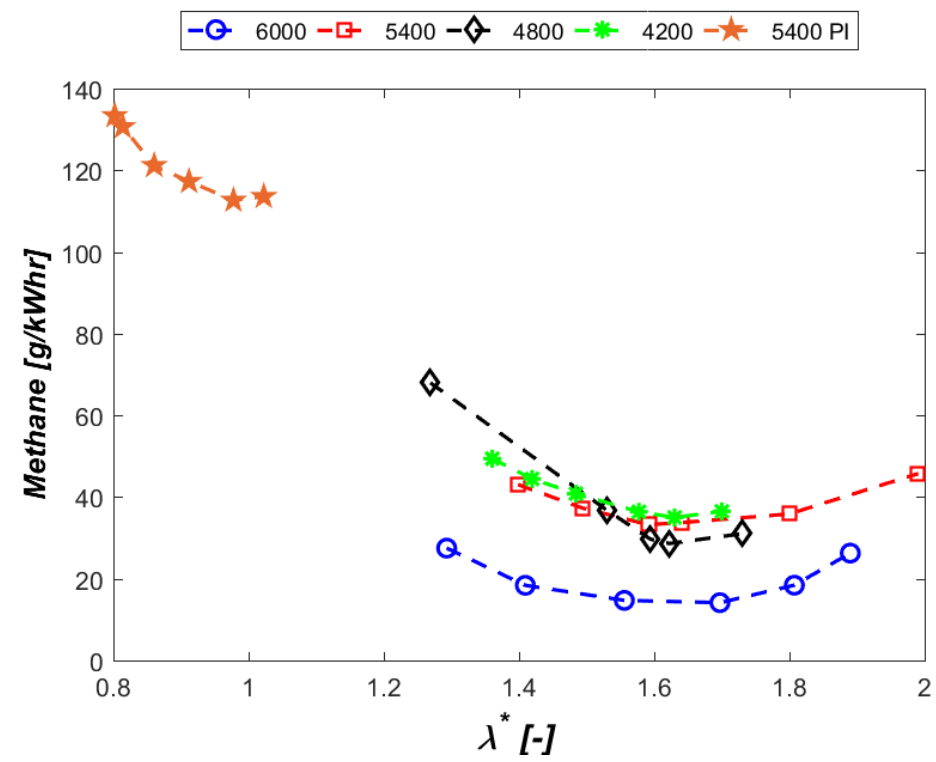

Figure 54. Methane emissions on PI and different speeds on LPDI, averaged over 90 seconds of steady state operation for each point. 
$\mathrm{NMHC}+\mathrm{NO}_{\mathrm{x}}$ emissions are shown in Figure 55. Operation at $6000 \mathrm{RPM}$ showed the highest reduction due to lower fuel slip.

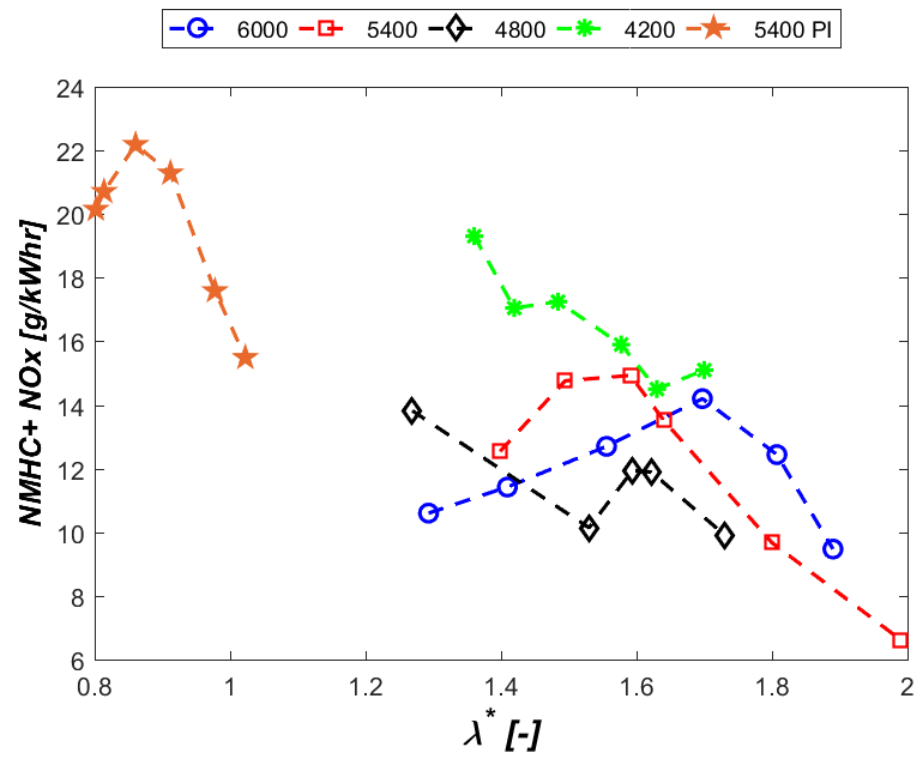

Figure 55. NMHC emissions on PI and different speeds on LPDI.

\subsection{D Simulation}

A 1D simulation was performed to first understand the system's behavior. Then it was used for GA optimization of the exhaust resonator as well as to provide initial and boundary conditions for my CFD study.

\subsubsection{Baseline Model Verification}

The first step in 1D model validation was to ensure flow was estimated accurately. This was verified with measured crankcase pressure and intake air flow as compared to modeled results. Figure 56 shows crankcase pressure from experiments and simulation. The maximum pressure difference between experiments and simulation occurred during scavenging and it was +0.08 bar $(+7 \%)$ error. Part of this error could have been attributed to the location at which sensor was installed and delay time of response whereas for 1D simulation, volumes had no dimension and respond immediately. The sensor was installed at the bottom of the crankcase. Low speed operation made this deviation more prominent. Maximum negative error was at peak pressure and it was -0.04 bar $(-2.6 \%)$. The engine motoring pressure curve was captured as hot motoring at 3600 
RPM. Hence, the model was run at this speed for this validation. Reed valve petal areas, Young's Modulus, and port discharge coefficients were the most impactful parameters in this validation. The exhaust resonator's dimensions showed to be very impactful on the crankcase pressure, so caution was taken to avoid any dimensional measurement errors. Note that intake air mass flow from simulations was within $\pm 3 \%$ of its value in the experiment's dependent on the engine settings (Table 26).

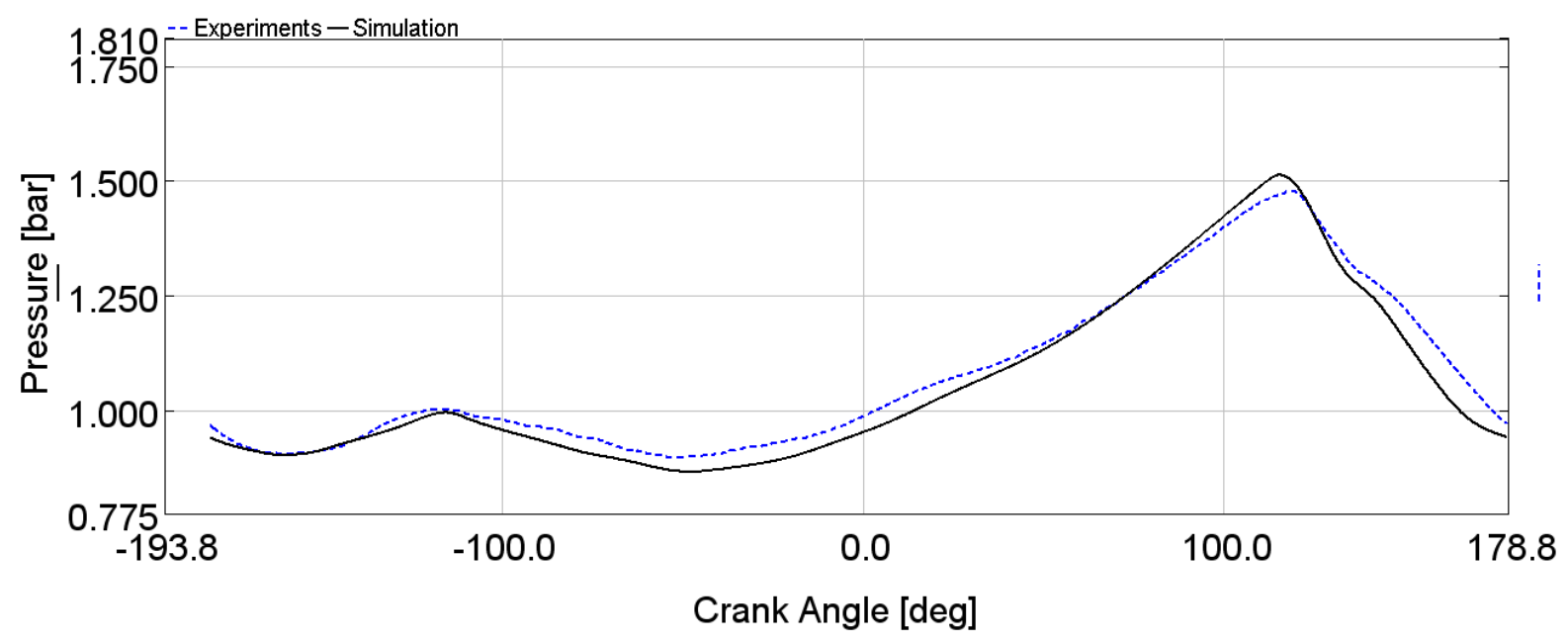

Figure 56. Motoring crankcase pressure at 3600 RPM for engine operating with beta design, experiment curve was averaged over 200 cycles.

Gas exchange parameter calibration included port discharge coefficients and was performed first using the motoring pressure curves and they were held constant afterward. However, one must know that other parameters such as exhaust dimensions will affect the gas exchange significantly. As presented later, the model showed to have reasonable fidelity for gas exchange parameters such as delivery ratio. Figure 57 shows the crankcase pressure where the model was operated on a different engine speed and in the firing condition. The maximum pressure difference between experiments and simulation occurred during scavenging and it was +0.06 bar $(+6.5 \%)$ error. Maximum negative error was at peak pressure and it was -0.02 bar $(-1.3 \%)$

Table 26. Summary of intake air flow results at two conditions.

\begin{tabular}{|c|c|c|c|}
\hline & \multicolumn{3}{|c|}{ Intake Air Flow } \\
\hline Condition & Experiments & Simulation & Relative Error \\
\hline 3600 RPM Motoring & 105 & 108 & $+2.8 \%$ \\
\hline 5400 RPM Combustion & 175 & 178 & $+1.7 \%$ \\
\hline
\end{tabular}




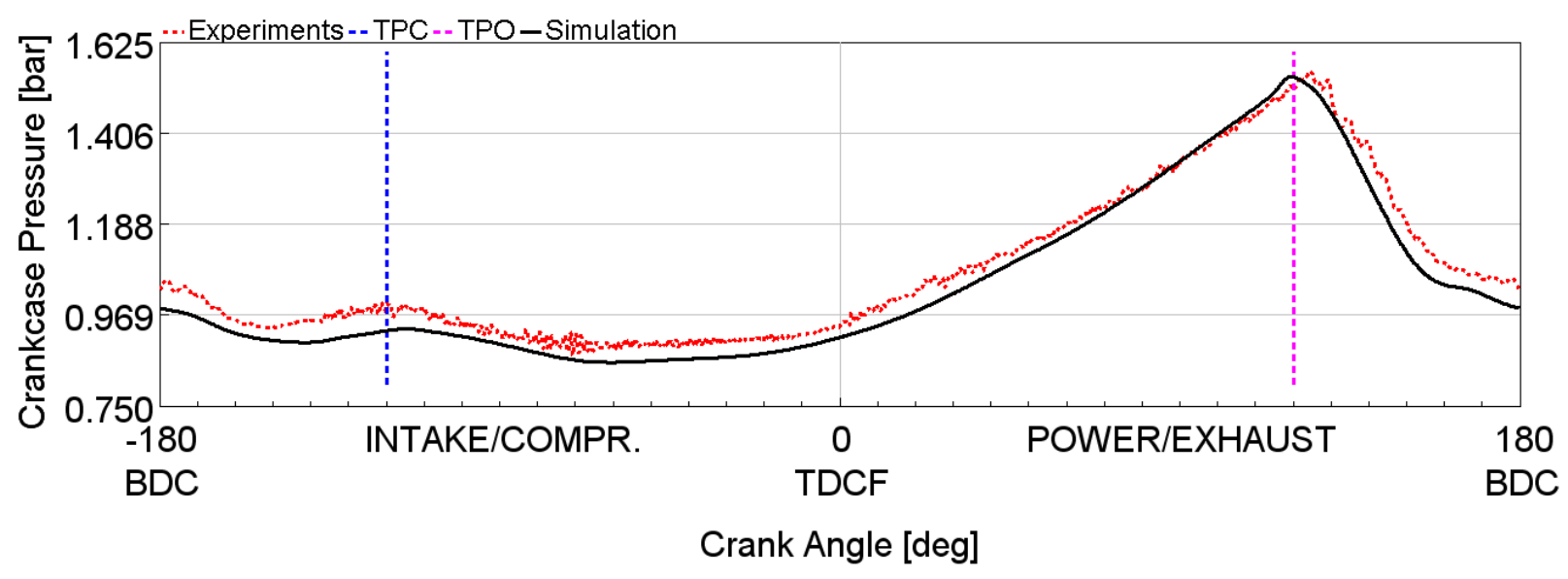

Figure 57. Combusting crankcase pressure curves at 5400 RPM engine speed operating on beta exhaust, experiment curve was averaged over 200 cycles.

Figure 58 shows the in-cylinder combustion pressure curves. For accurate trapped mass verification, the compression portion of in-cylinder pressure before spark timing was considered. Matching the compression curves before the start of the combustion confirmed that the trapped mass in the simulation matched with experiments. The RMSE error before starting the combustion calibration was 0.009 and at the end of combustion calibration it was 0.002 leading to the following simulation curve.

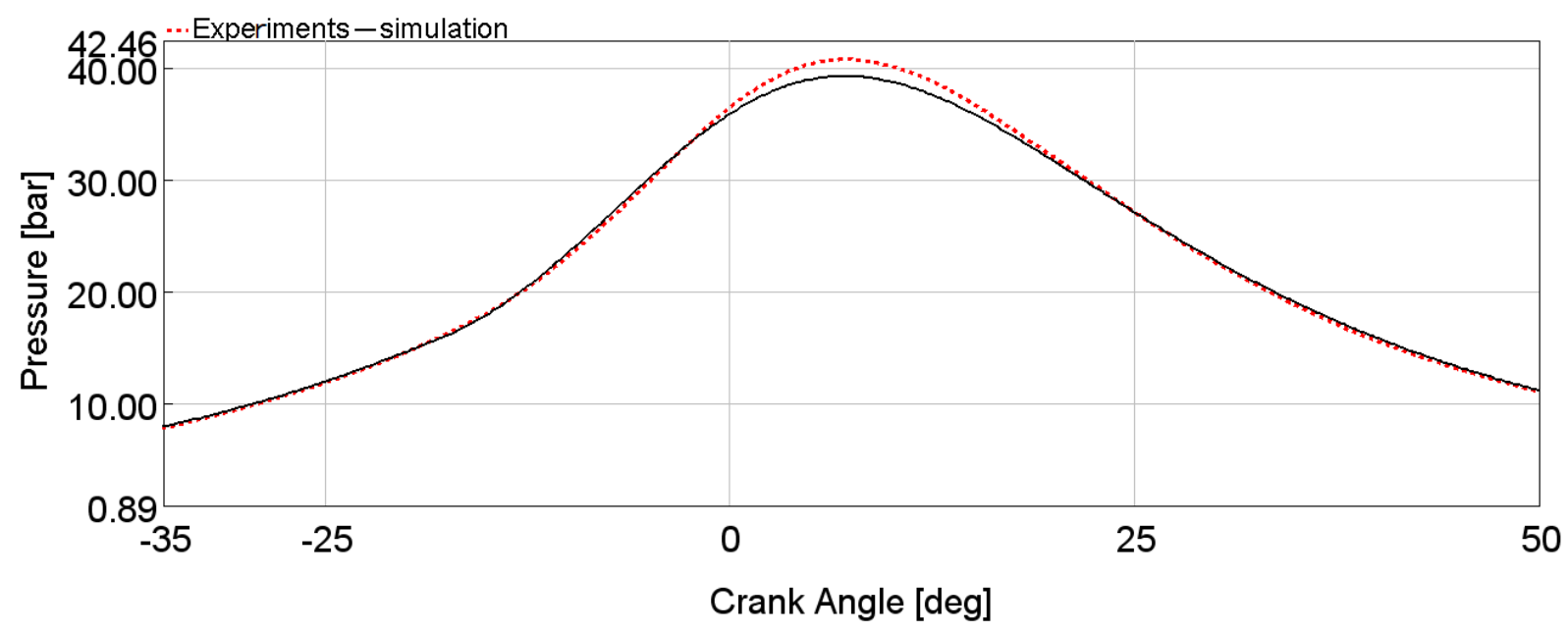

Figure 58. In-cylinder combusting pressure at 5400 RMP engine speed operating with beta exhaust design, experiment curve was averaged over 200 cycles. 
Lastly, exhaust pressure waves, which affected the in-cylinder gas dynamics, were validated for 5400 RPM as shown in Figure 59. Exhaust geometry and thermal boundaries were the most sensitive parameters. Notice that at EPO a pressure wave started down the resonator and right before EPC the reflected wave pushed some slipped charge back in to the cylinder which improved the trapping efficiency. These two areas were of highest important whereas the area in between will not significantly affect the cylinder gas dynamics. Maximum positive error between simulation and experiment was +.05 bar $(3.35 \%)$ at the EPO pressure pulse.

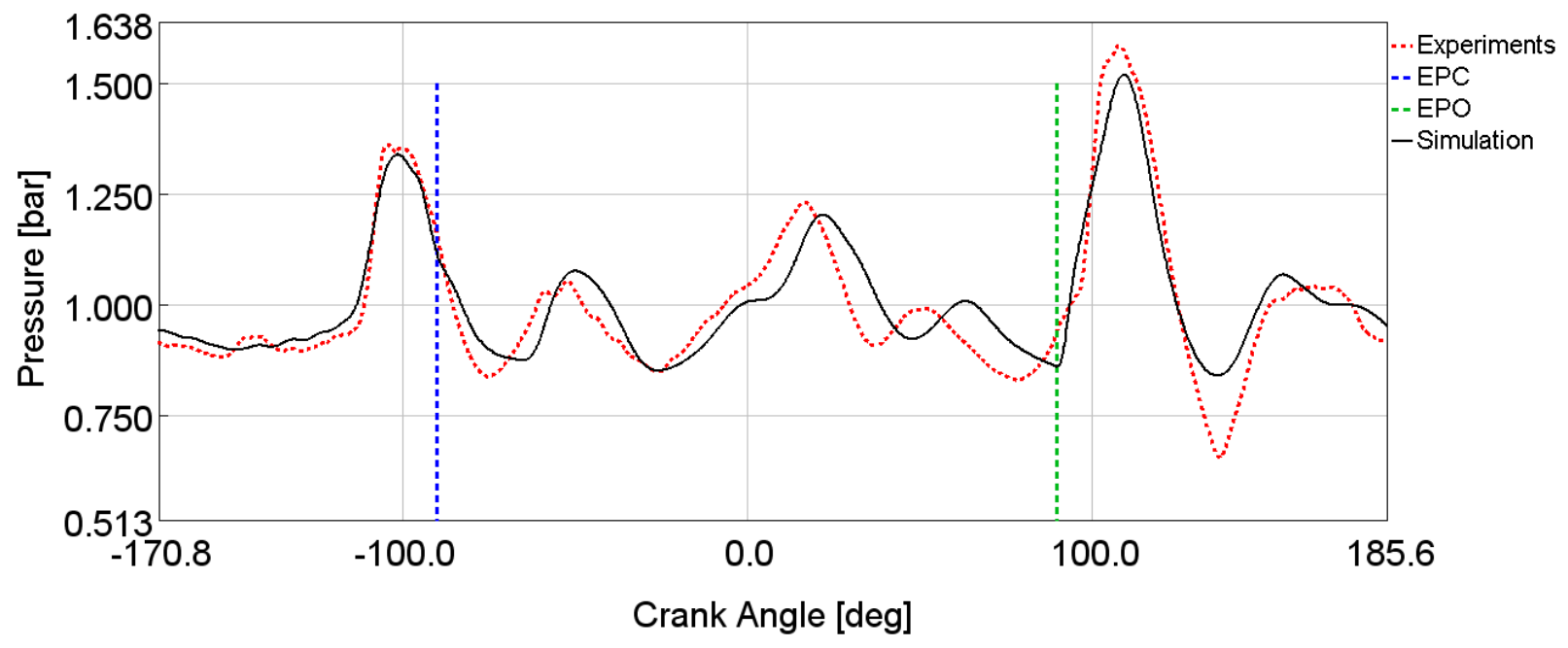

Figure 59. Exhaust pressure wave validation at 5400 RPM engine speed operating on beta exhaust design; experiment curve was averaged over 200 cycles.

Note that since engine operation was designed to be at $90 \mathrm{~Hz}$ for this study, the model calibration and validation were performed at this speed and full load. The same model served as the baseline model for GA optimization of exhaust resonator.

\subsubsection{GA Evolution Curve and Sensitivity Curves}

For the GA used to optimize the exhaust, seven parameters were considered as factors. A total of 20 designs were set for each of the 50 generations. The full engine simulation started with the beta design values as the initial case. Exhaust dimensions as explained in section 3.3.4, were set to randomly be selected toward an optimal solution by the GA platform. Figure $\mathbf{6 0}$ shows the 1D model's indicated efficiency results for the different iterations as a function of design points. Over 600 design points were examined in this study but due to marginal improvements after around $150^{\text {th }}$ design, the plot was truncated at the $400^{\text {th }}$ design point. Notice the asymptotic behavior of 
the plot after $150^{\text {th }}$ design. It showed that on the beta exhaust, efficiency was around $25 \%$, while the optimized design showed up to around $28 \%$. This difference was later investigated with experiments. Note that LPDI engine with the beta exhaust and tuned intake was the most efficient configuration achieved before implementing the GA.

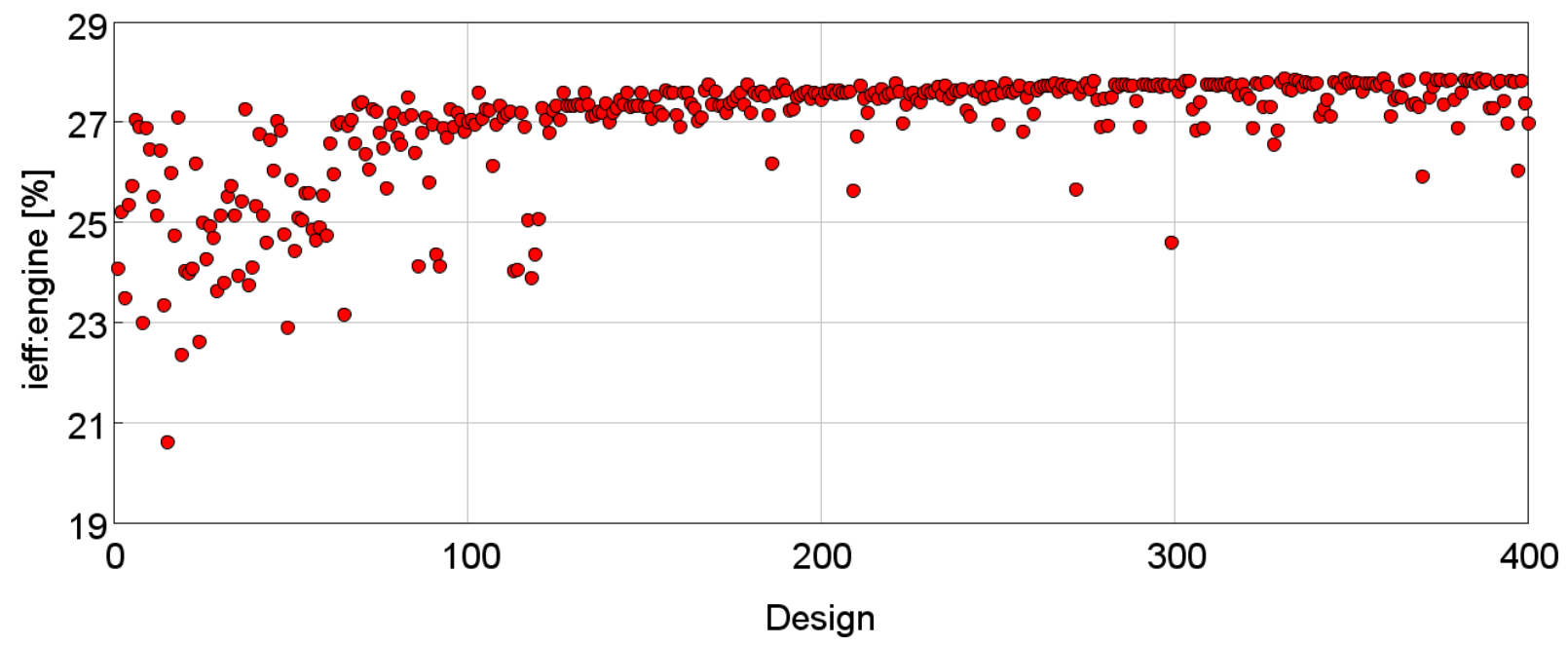

Figure 60. Indicated efficiency evolution versus design iteration.

Figure 61 shows the 1D model engine efficiency sensitivity to different dimensions of the exhaust resonator design. A copy of the exhaust resonator parametric figure is shown to quickly cross reference dimension locations. The length of the divergent cone (L2) and length of the straight section (L3) of the resonator were the most important parameters in the exhaust design. This was understandable because the function of the divergent cone was to create a suction wave, which directly affected the delivery ratio. On the other hand, the straight section of the resonator timed the reflected wave and affected the trapped mass inside of the cylinder. The length of the converged cone showed to be the third most important parameter. It controlled the intensity of the reflected wave (amplitude) and more sensitivity of the response to L3 showed that reflected wave timing was more impactful than reflected wave amplitude. According to this discussion, the most impactful parameters were divergent cone's angle, straight section length, and convergent cone's angle. 

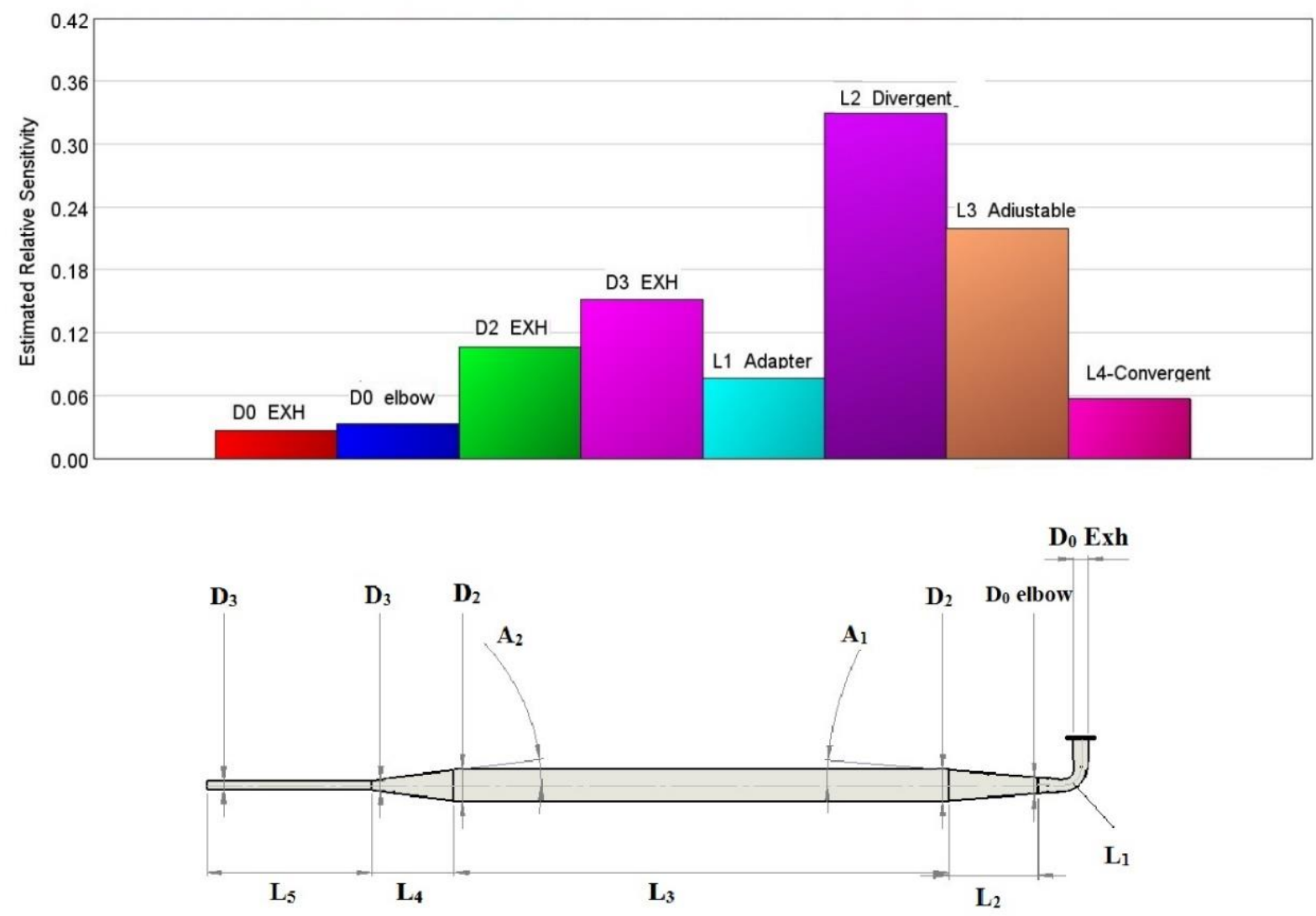

Figure 61. Engine response sensitivity to the exhaust design parameters.

Table 27 shows the dimension comparison between beta design and optimized designs. For $\mathrm{A}_{1}$, literature recommends a range of 3 to 4.5 degrees. It was reported that lower values resulted in weaker reflected pressure waves, with longer durations. In experiments for the beta design, $5.13^{\circ}$ was used for $A_{1}$ because of commercial availability of conical sections in the market. Another parameter affecting the wave strength was $\mathrm{L}_{2}$, which was related to $\mathrm{A}_{2}$. For $\mathrm{A}_{2}$, literature recommended an upper limit of $10^{\circ}$ for peak power and with a lower acceptable value of $7^{\circ}$ [33]. Based on high costs associated with rolling thin cones of such size, we used a commercially available cone with an angle of $7.7^{\circ}$.

After optimization, $A_{1}$ and $A_{2}$ were shown to be in the range which was recommended by literature. $A_{2}$ was closer to lower limit of the recommended range, while $A_{1}$ was closer to the higher limit. The most significant difference between rules of thumb presented in literature and this 1D simulation optimization was the length, $\mathrm{L}_{2}$, which was $31 \%$ greater from $1 \mathrm{D}$ simulation results 
when compared to the beta design. Given the sensitivity of the system response to this parameter as shown in Figure 61, it was expected to change results as presented later in this section.

Table 27. Comparing the beta design and $1 D$ simulation optimized design, $1 D$ simulation started with beta design dimensions as baseline values of the exhaust resonator.

\begin{tabular}{|c|c|c|c|}
\hline Variable & Beta Design [mm] (literature & Optimized design [mm] (1D & Percent difference \\
\hline $\mathbf{D}_{\mathbf{1}}$ & 15 & 17 & +13.3 \\
\hline $\mathbf{D}_{\mathbf{2}}$ & 45 & 50 & +11.1 \\
\hline $\mathbf{D}_{\mathbf{3}}$ & 10.5 & 12.9 & +22.9 \\
\hline $\mathbf{L}_{\mathbf{1}}$ & 41 & 64 & +56.1 \\
\hline $\mathbf{L}_{\mathbf{2}}$ & 167 & 219 & +31.1 \\
\hline $\mathbf{L}_{\mathbf{3}}$ & 818 & 738 & -9.8 \\
\hline $\mathbf{L}_{\mathbf{4}}$ & 127 & 134 & +5.5 \\
\hline $\mathbf{A}_{\mathbf{1}}$ & $5.13\left[^{\circ}\right]$ & $4.3\left[^{\circ}\right]$ & -16.2 \\
\hline $\mathbf{A}_{\mathbf{2}}$ & $7.73\left[^{\circ}\right]$ & $7.88\left[{ }^{\circ}\right]$ & 1.9 \\
\hline
\end{tabular}

\section{Optimized design validation}

As Figure 61 shows, system response had a high sensitivity to the straight section of the exhaust resonator. In addition, for LPDI experiments it was realized that engine stability was also sensitive to the length of the straight section. So, it was expected that an adjustment in the experiment was required for the best results. While the first result of the GA showed $738 \mathrm{~mm}$ for the straight section of the optimized design, in experiments, the most stable results were obtained for a length of 788 $\mathrm{mm}$. The idea was that in the GA optimization, an increased delivery ratio was proportional to flow momentum during scavenging and a stronger reflected pressure wave for trapping purposes. This function combined with LPDI operation, which takes place while exhaust port is still open, was expected to help with mixing and providing higher fuel trapping and consequently an increased efficiency.

Figure 62 shows the optimized exhaust resonators pressure curves from experiments and simulation. This is to make sure gas dynamics of the model were working as expected without further calibrations. Maximum positive error between simulation and experiment was +.05 bar $(4.1 \%)$ at EPC pressure pulse. 


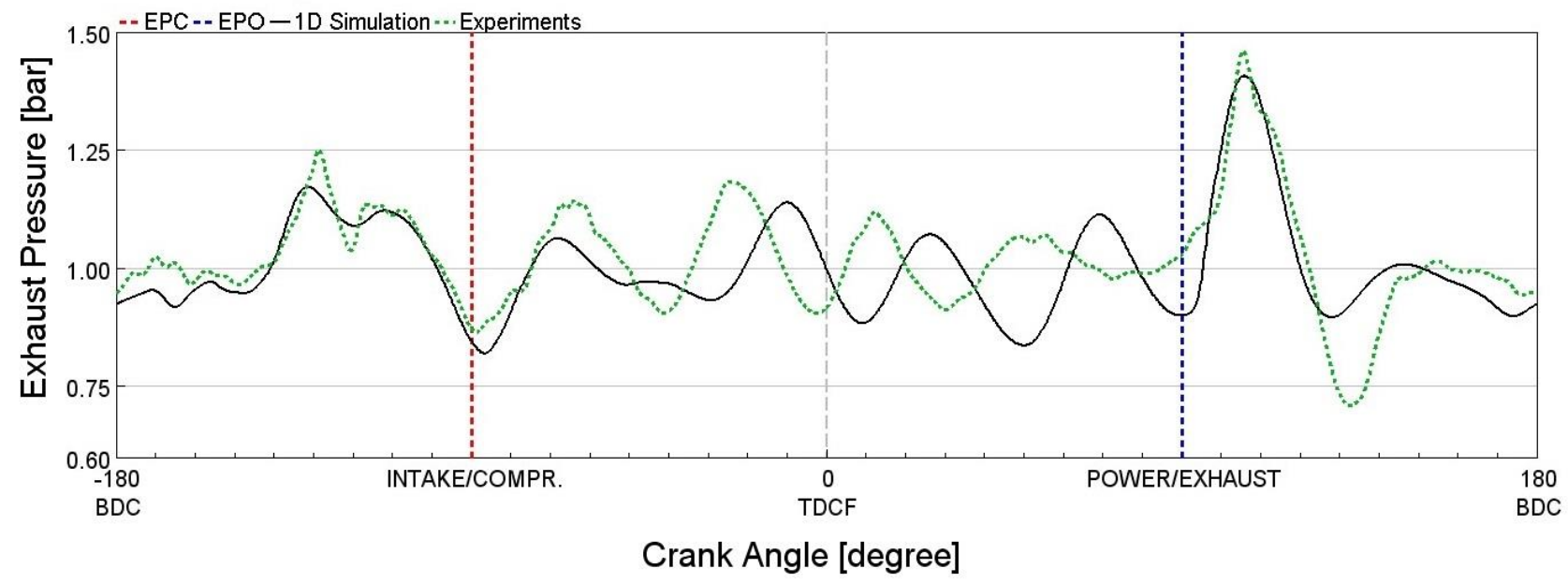

Figure 62. Exhaust pressure waves validation for the engine operating with optimized exhaust at 5400 RPM and full load; experiment curve was averaged over 200 cycles.

Figure 63 shows the combusting in-cylinder pressure of the engine operating with the optimized exhaust at 5400 RPM and full load. The RMSE error between simulation and experimental pressure curve was 0.0025 .

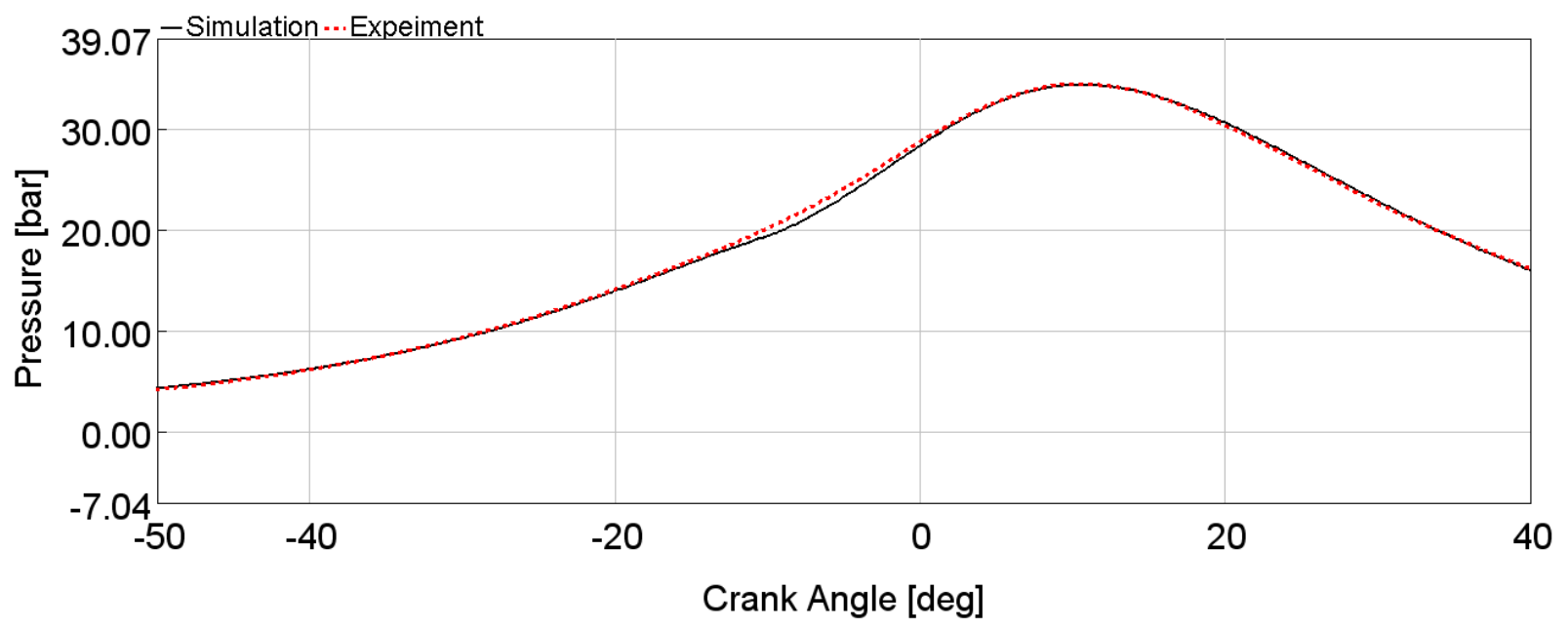

Figure 63. In-cylinder pressure validation of the engine with optimized exhaust at 5400 RPM full load operation; experiment curve was averaged over 200 cycles.

\subsubsection{Experimental Comparison of Optimized Exhaust with the Beta}

Note that 1D optimization was completed at a single operating point (5400 RPM and full load). This allowed faster modeling and comparisons. We extrapolated the AFR change behavior by 
means of an experimental study. In addition, in this program, it was never intended to operate on part-load for power generation. Notice that simulation started with the point near to beta design and reached near to optimized line after GA optimization.

Figure 64 shows delivery ratio results for the two exhausts designs obtained in the experiments. Notice that lambda was calculated based on total air versus total injected fuel and that is why it was higher than usual. In addition, due to the optimized design's higher delivery ratio and lower air trapping in general compared to fuel, the optimized design showed higher $\lambda^{*}$ values. Notice that stars show the results from 1D simulation. The error on the plot represents absolute error compared to corresponding experimental points.

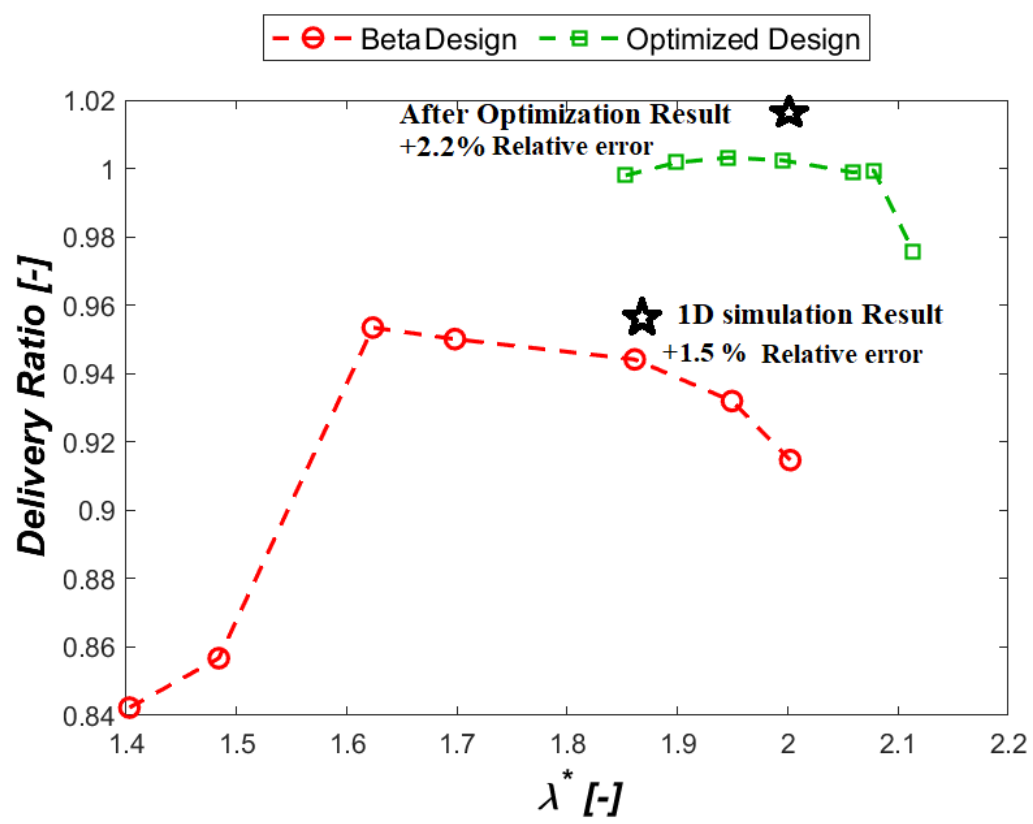

Figure 64. Delivery ratio for beta design and optimized design. Stars are showing results from 1D simulation.

Note that according to the literature, it is quite possible to have delivery ratios above 1 for tuned engines. Heywood showed that crankcase compression, two-stroke engines that include tuned intake and exhausts can exhibit delivery ratios greater than unity [10]. 
Figure 65 shows the engine brake efficiency as measured in the experiments. Note that in experiments we compared the engine brake efficiency while for simulations I used engine indicated efficiency including crankcase pumping losses. Note that the friction, combustion, and heat transfer sub models were associated with the error in brake thermal efficiency. By minimizing the RMSE between experiments and simulation pressure curves, this approached yielded the best results. The other theory was that because of the non-standard combustion hardware configuration it was in general more difficult to achieve a good calibration across a wide range of operation. This non-standard configuration included non-central spark plug location and stratified charge with LPDI.

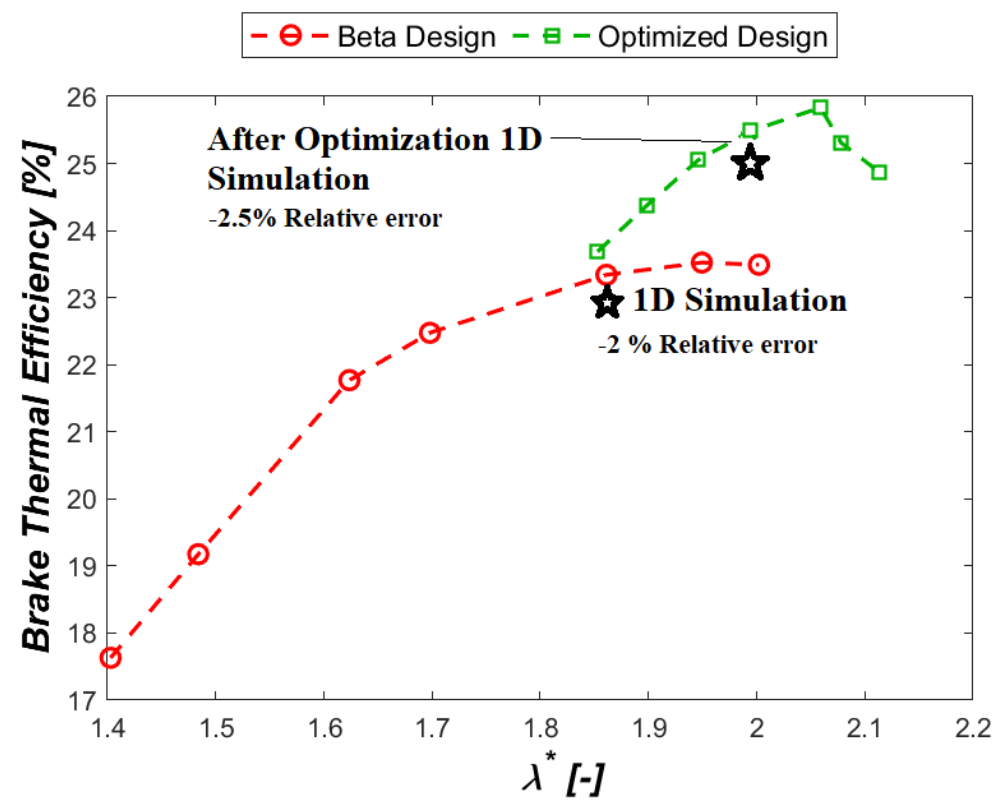

Figure 65. Engine BTE for exhaust optimization.

Figure 66 shows the total HC energy content for engine operation with both exhaust resonators. Note that this parameter was not investigated in simulations. Instead with a pressure analysis model and experiment results, fuel fraction burnt was adjusted to account for incomplete combustion and escaped fuel. This ensured efficiency values were realistic. 


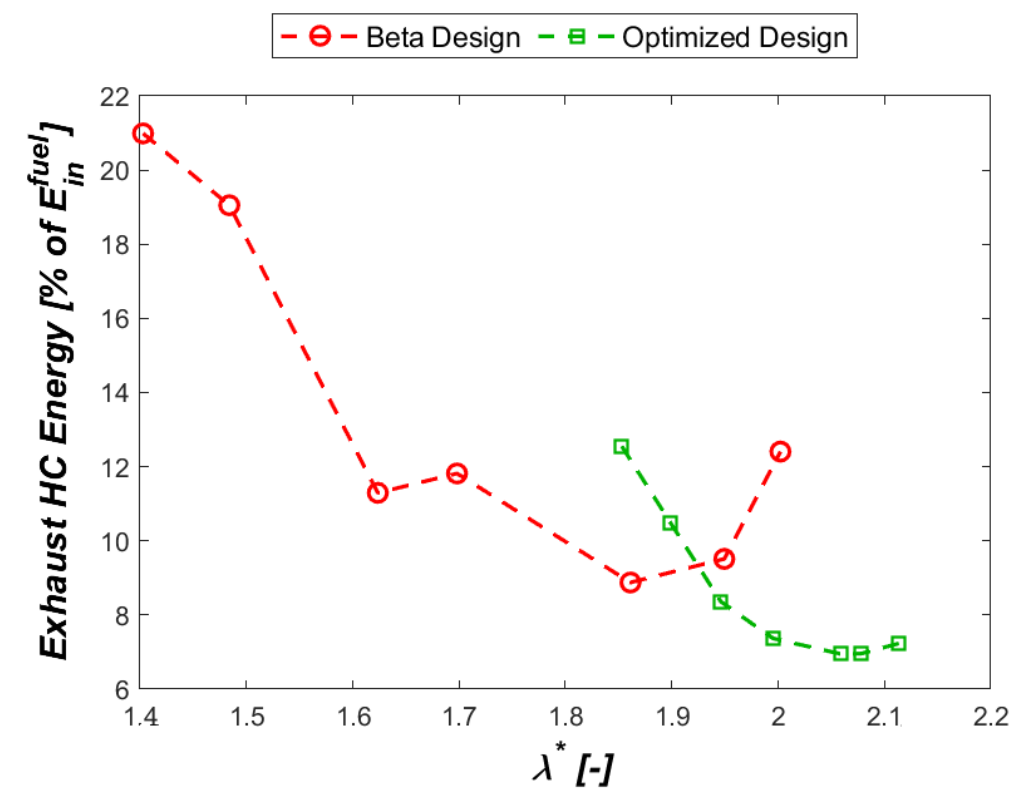

Figure 66. Exhaust HC content.

\subsection{D CFD Simulation}

The objectives of the CFD simulation were to investigate two phenomena:

1. To understand of the exhaust resonator's effect on cylinder gas dynamics

2. To investigate the mixture stratification before the start of combustion.

The 3D model included the full engine geometry including crankcase, piston, crankshaft, and connecting rod as shown in Figure 67. Intake mass flow boundary conditions were provided by 1D simulations. However, the intake air flow from 1D simulation had around $2 \%$ relative error when compared to experiments. So, the mass profile was scaled such that the total air flow into the crankcase matched with experiments. The exhaust boundary was directly defined by experimental data. Experimental exhaust pressure was averaged over 200 recorded cycles. 


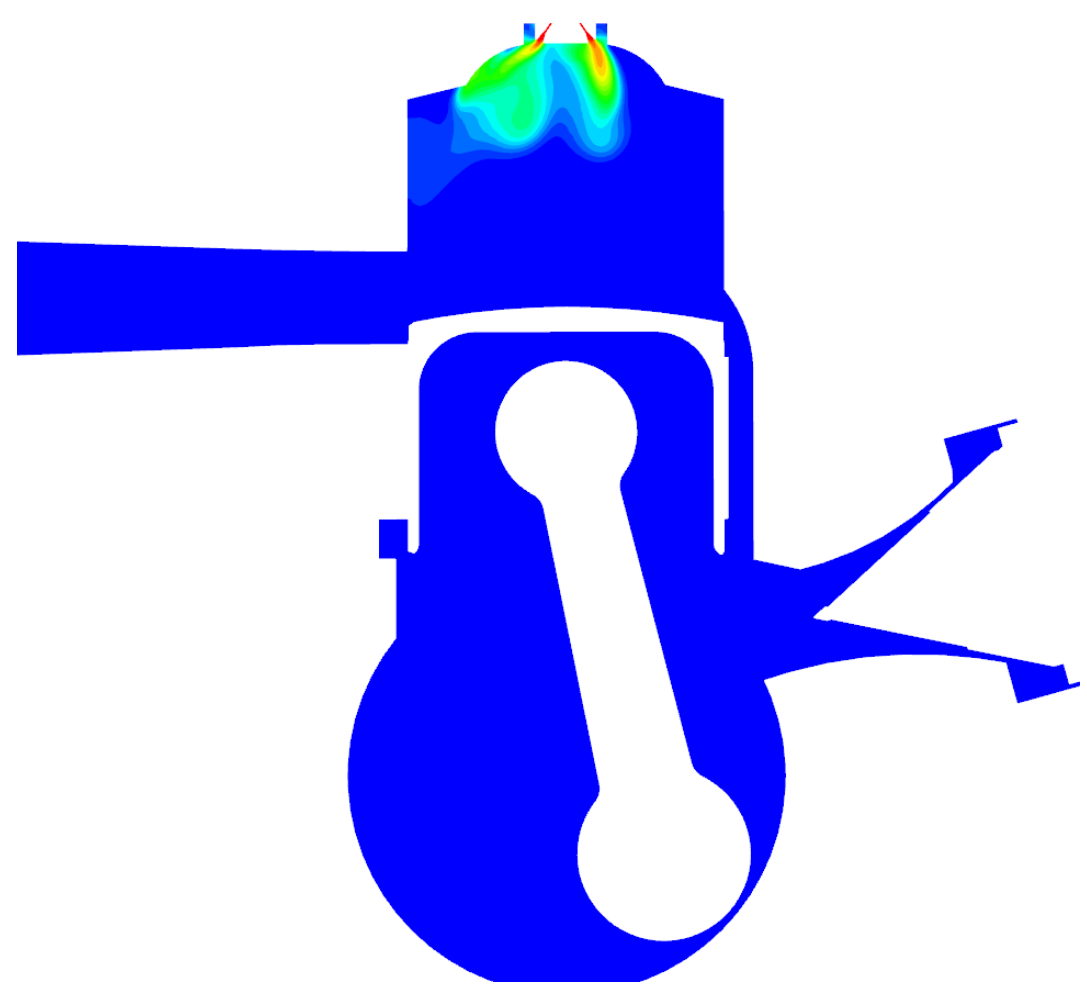

Figure 67. Full engine geometry modeled in CONVERGETM.

Figure 68 shows the crankcase pressure for both 1D and 3D simulations along with experimental data for comparison. The results showed a good consistency between simulations and experiments. This was completed to ensure gas dynamics during scavenging were not affected by an incorrect pressure from the crankcase.

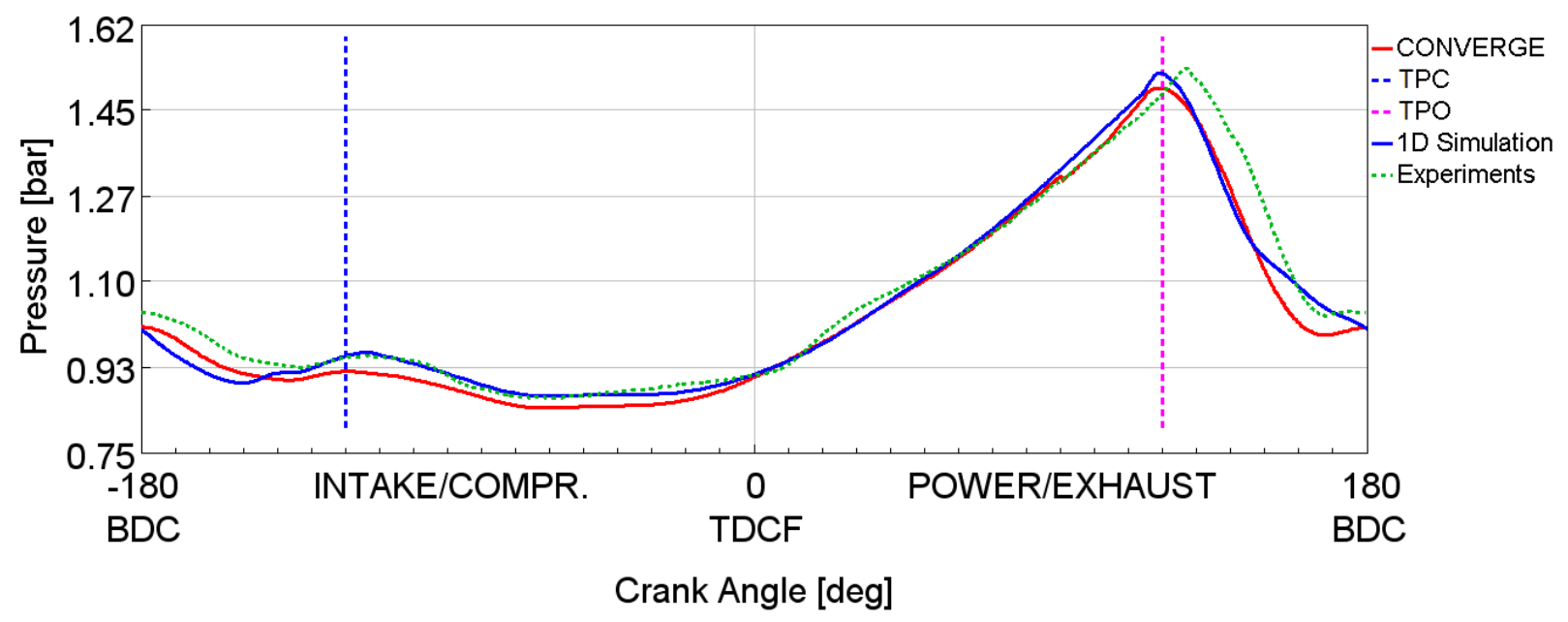

Figure 68. Crankcase pressure, 1D (GT-Power $\left.{ }^{\mathrm{TM}}\right)$ simulation, 3D $\left(\right.$ (CONVERGE $\left.^{\mathrm{TM}}\right)$ simulation, and experimental data, experiment curve was averaged over 200 recorded cycles. 
The in-cylinder trapped mass was accurate and equal to 22 milligrams (mg), which matched the results from TPA. It was also confirmed with compression side of the in-cylinder pressure curve matched with experiments. Then we examined in-cylinder gas dynamics. Figure 69 shows gas dynamics affected by the exhaust resonator. The red zone shows the fuel and a color bar is provided on the plot. The spectrum shows the stratification and blue represent anything other than fuel injected in that cycle.

The intent of the figure was to focus on how the reflected pressure wave helped with charge trapping. From 142 to 116 CAD BTDC, it showed that the tumble motion created by the boost port dominated the dynamics but enabled some fuel to escape from the cylinder. Injection timing was optimized for highest fuel trapping during the experiments prior to the $3 \mathrm{D}$ simulation. As the piston approached EPC timing and around 106 CAD BTDC, the reflected pressure wave started to affect the in-cylinder charge by pushing some escaped charge back into the cylinder. This continued until 98 CAD BTDC where it pushed nearly all the escaped fuel back into the cylinder. In addition, the strong tumble motion helped to keep most of the fuel mass from short circuiting. 


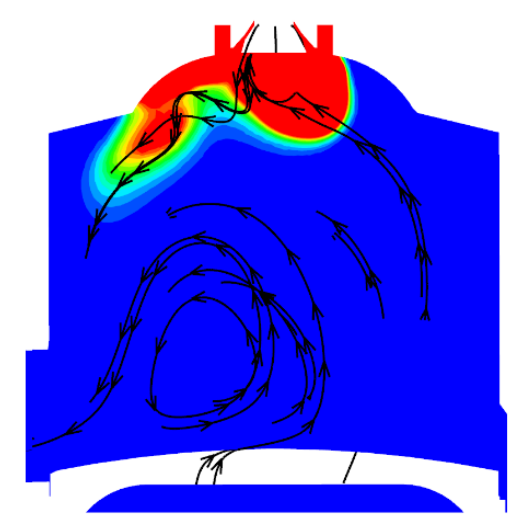

142 bTDC

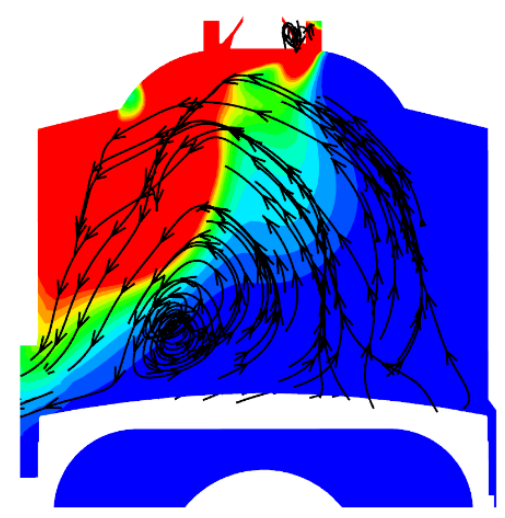

$116 \mathrm{bTDC}$

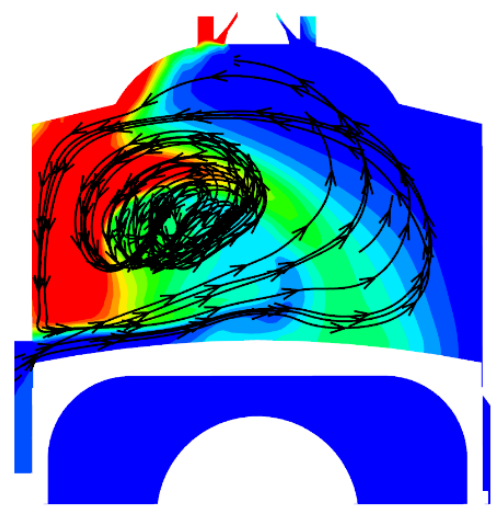

98 bTDC

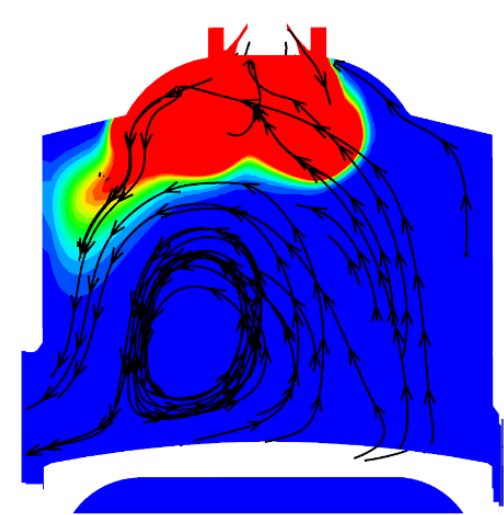

136 bTDC

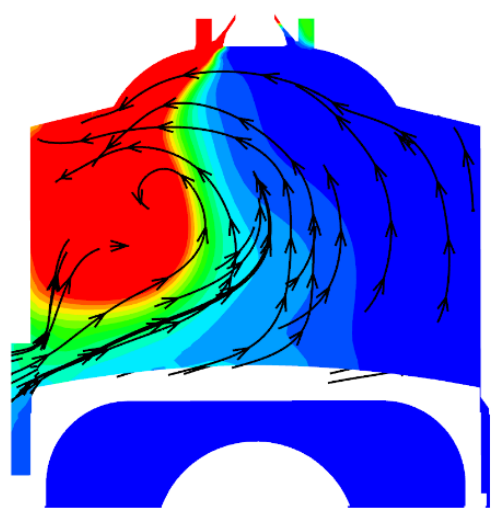

106 bTDC

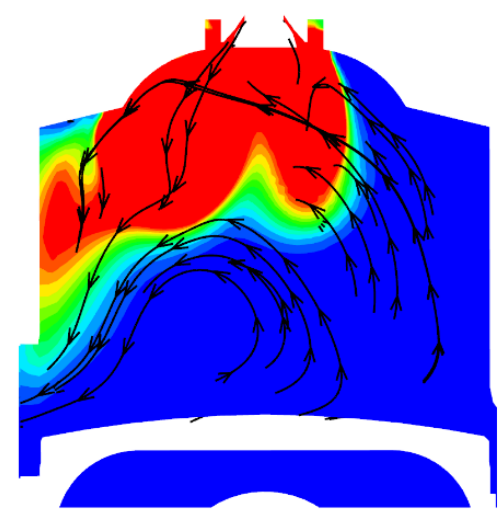

126 bTDC

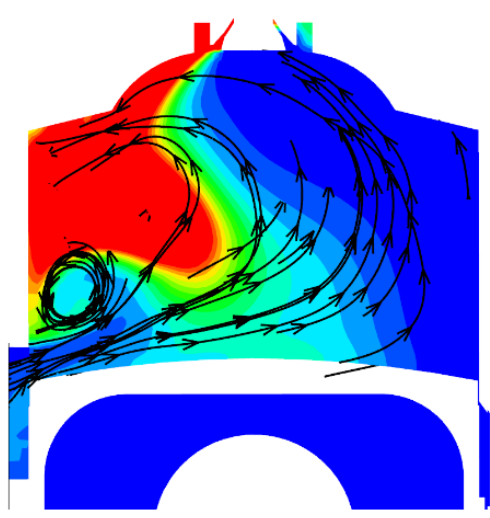

102 bTDC

\section{$\mathrm{CH}_{4}$ Mass Fraction}

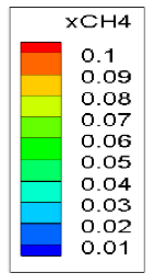

Figure 69. Exhaust resonators effect on in-cylinder gas dynamics and fuel trapping efficiency.

Figure 70 shows in-cylinder stratification evolution before spark timing. Note that color bar is shows the methane mass fraction from 0 to $10 \%$. The red zone shows area with $10 \%$ methane mass fraction and blue shows $0 \%$ methane mass fraction. After EPC, the combination of tumble and swirl motion changed the stratification paradigm inside of the cylinder. Simulations showed that 
the fuel air charge was not fully mixed by the point of ignition, meaning that there were some richer zones. Spark plug location initially was selected for ease of installation and convenient machining. According to the simulation, this location of the spark plug was outside of the bulk rich zone. While most literature recommend to keep the spark plug on the exhaust side of the combustion chamber [10], in this particular study, simulation showed that the intake side was more desirable based on the in-cylinder stratification from LPDI. 

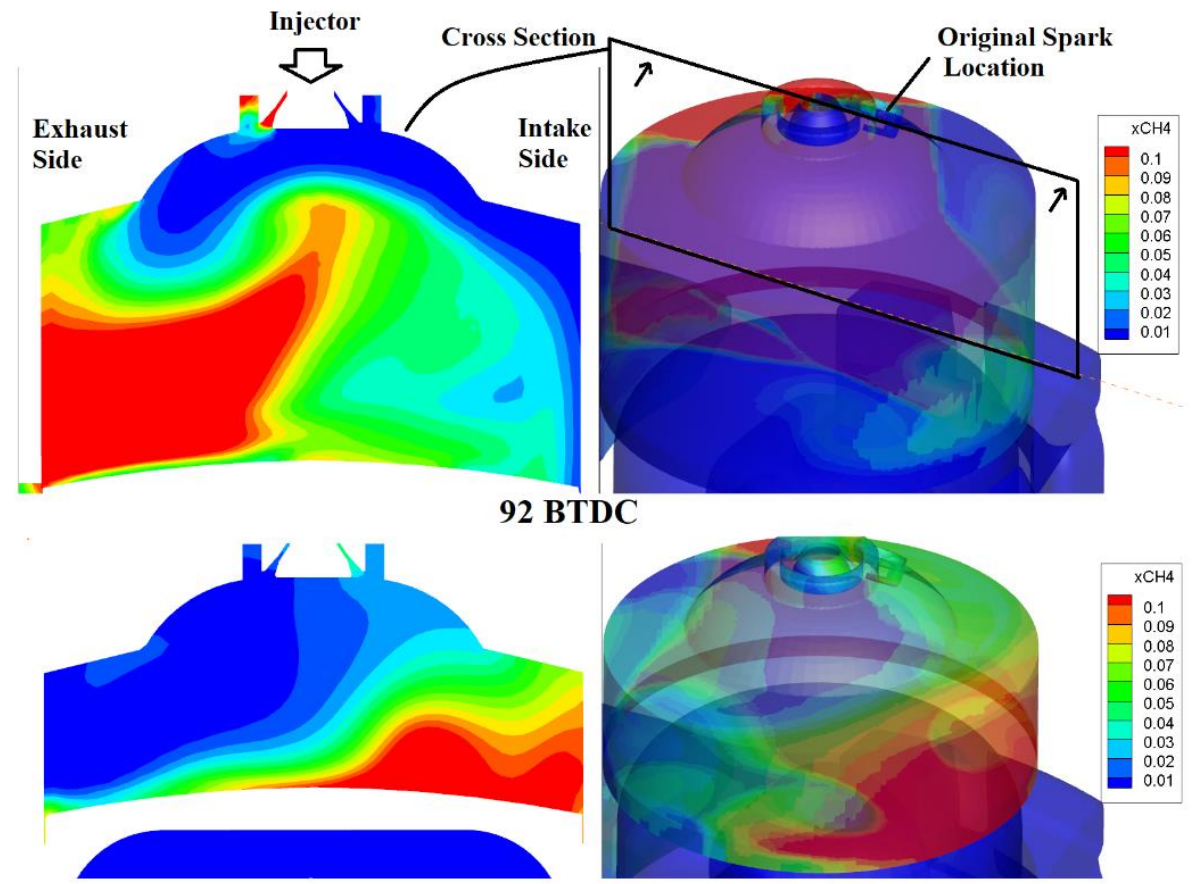

60 bTDC

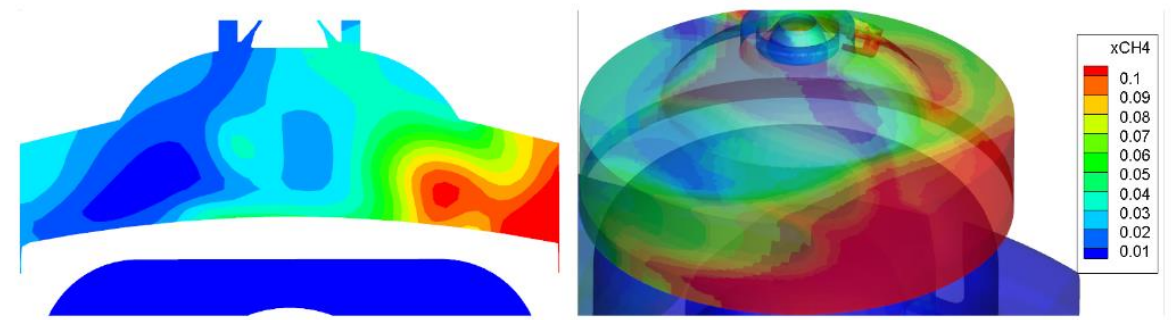

48 bTDC

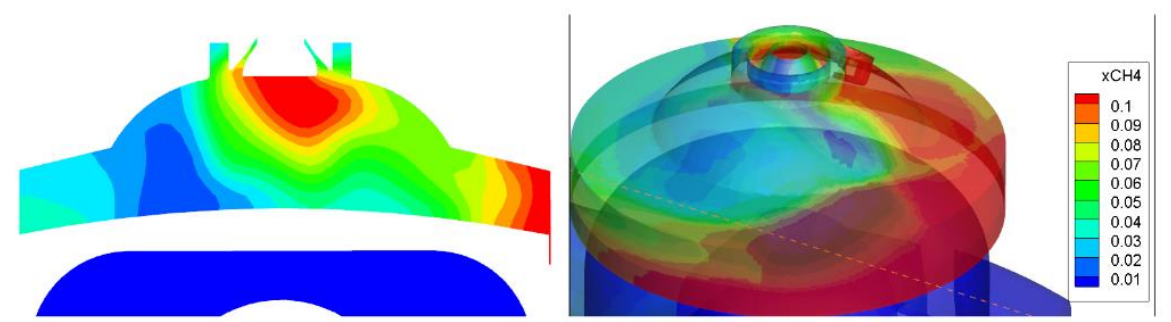

36 bTDC
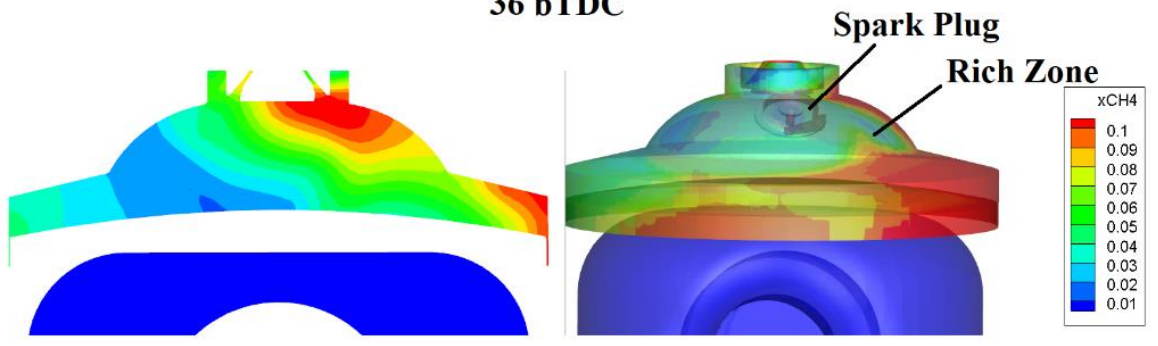

26 bTDC (around spark timing)

Figure 70. In-cylinder stratification evolution at different cranks angle degrees before TDC, spark timing was at 26 BTDC, color bar is showing methane mass fraction, red is showing $10 \%$ and blue $0 \%$ methane mass fraction. 


\subsubsection{Experimental Validation for Spark Plug Location Optimization}

The theory behind spark plug location was that since most of the fuel was shown to be trapped in the CFD study, it was likely that most of HC emissions in the exhaust were due to charge stratification and that the spark plug location was outside of the majority rich zone. To determine the impact of spark plug location, engine modifications were completed, and new engine configuration was tested.

Figure 71 shows the delivery ratio for the engine operating with the two different spark plug locations. The new optimal location yielded a higher delivery ratio. This was due in part to higher peak cylinder pressures resulting into higher pressure at EPC. This impacted the performance of the exhaust resonator diffuser, which enabled a stronger suction wave through the cylinder. It is also noted that relocation enabled slightly leaner operation. As shown in Figure 71, achieving delivery ratio higher than unity is possible [10].

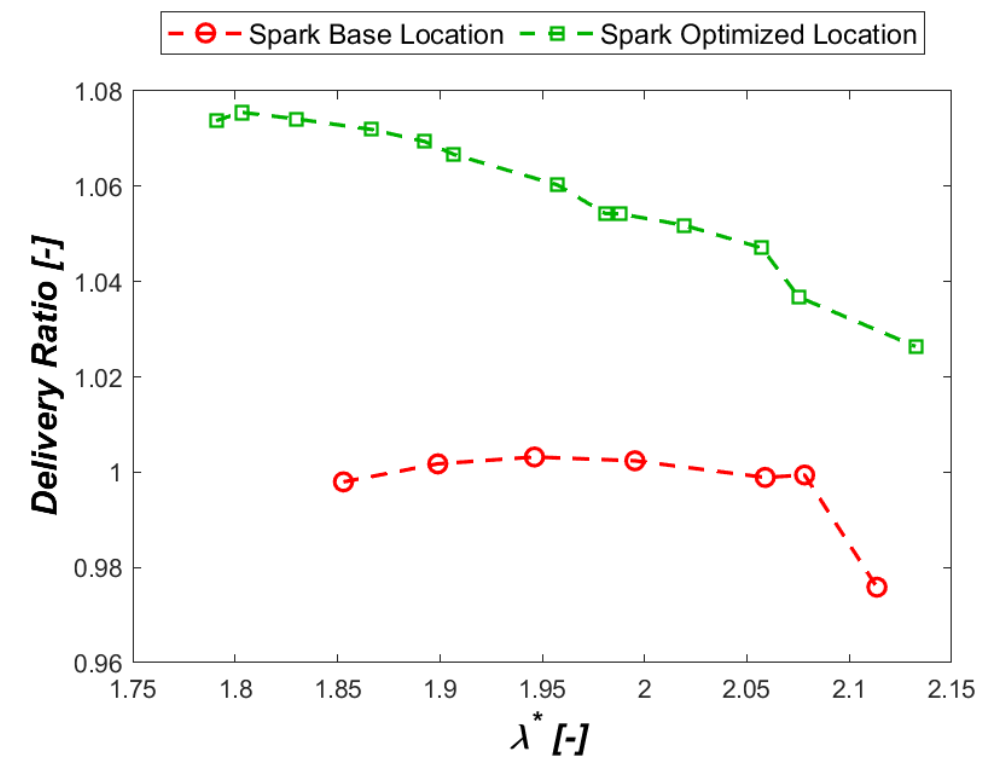

Figure 71. Delivery ratio comparison for base location and optimized location of spark plug, each datapoint is averaged over 90 seconds of continuous data measurement.

Figure 72 shows the BTE for engine operation on two spark plug locations. Optimized spark location showed a peak BTE of 27.5\% where the original spark location peak BTE was around $26 \%$. As discussed later, the major differences were increased combustion efficiency and lower unburnt fuels. 


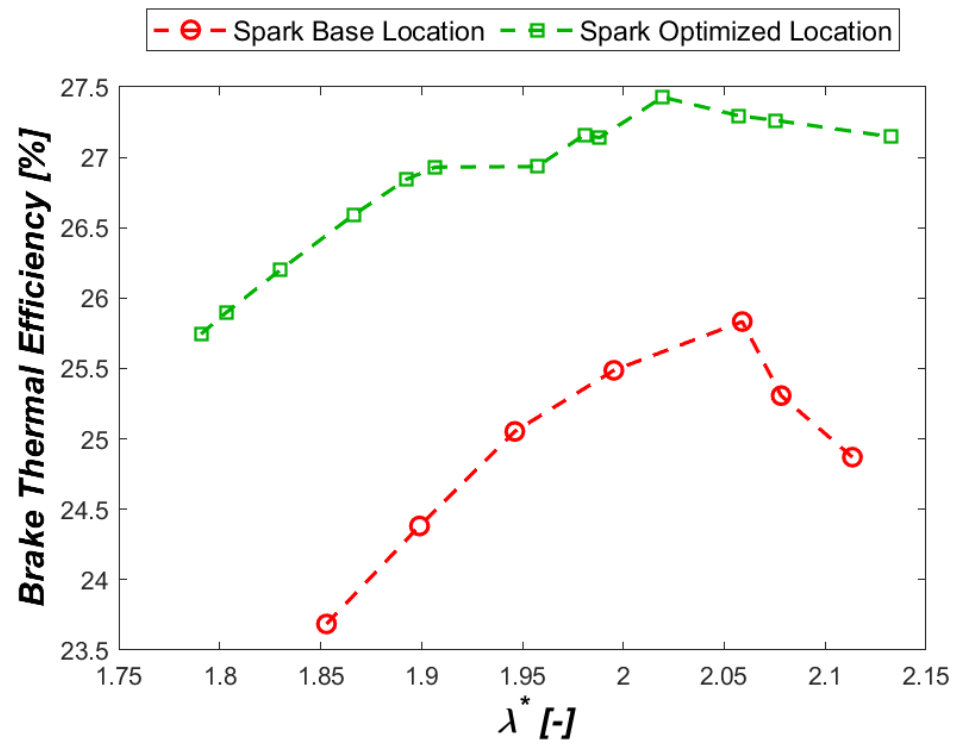

Figure 72. BTE comparison for base location and optimized location of spark plug, each datapoint is averaged over 90 seconds of continuous data measurement.

Figure 73 and Figure 74 show total $\mathrm{HC}$ and incomplete combustion (CO) energy losses for the two spark locations. THC decreased with the optimized spark location over the entire $\lambda^{*}$ range. While the best result for baseline spark location was 7\%, THC loss with the optimized spark location showed a minimum of $4.5 \%$, a $32 \%$ relative reduction. In addition, THC losses were less dependent on AFR with optimized spark location. This was due to the new location within the rich zone and that burn duration, as shown later, was shorter.

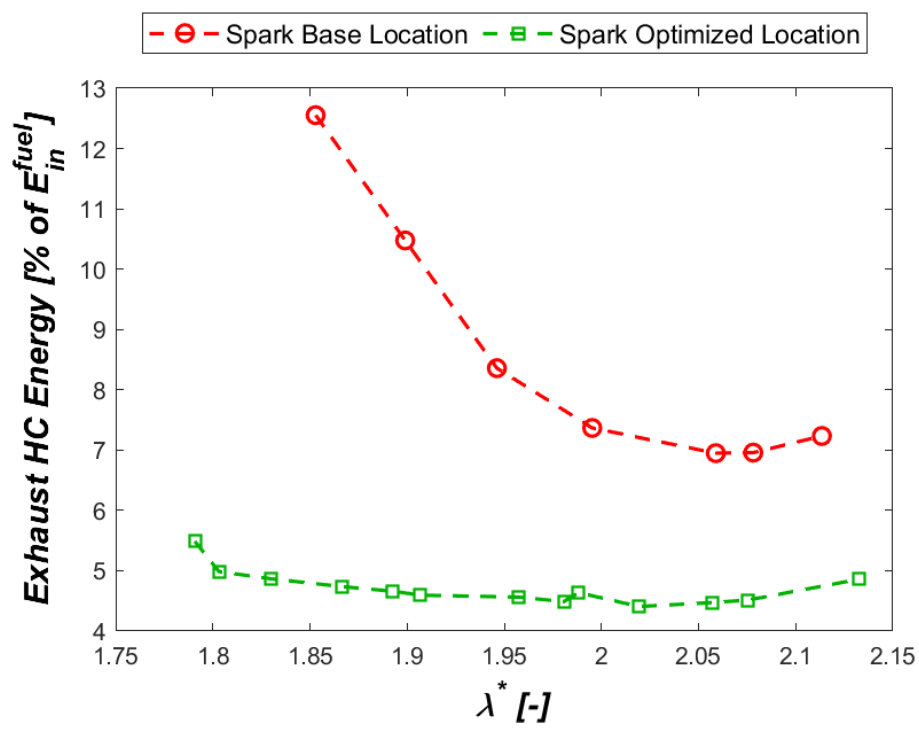

Figure 73. Exhaust total HC comparison for base location and optimized location of spark plug, each datapoint is averaged over 90 seconds of continuous data measurement. 
$\mathrm{CO}$ energy content also decreased with the optimized spark location. Another factor which helped to reduce both $\mathrm{CO}$ and $\mathrm{HC}$, was that at the start of combustion the spark plug region was less stratified. This required lower fuel mass and decreased the likelihood of incomplete combustion.

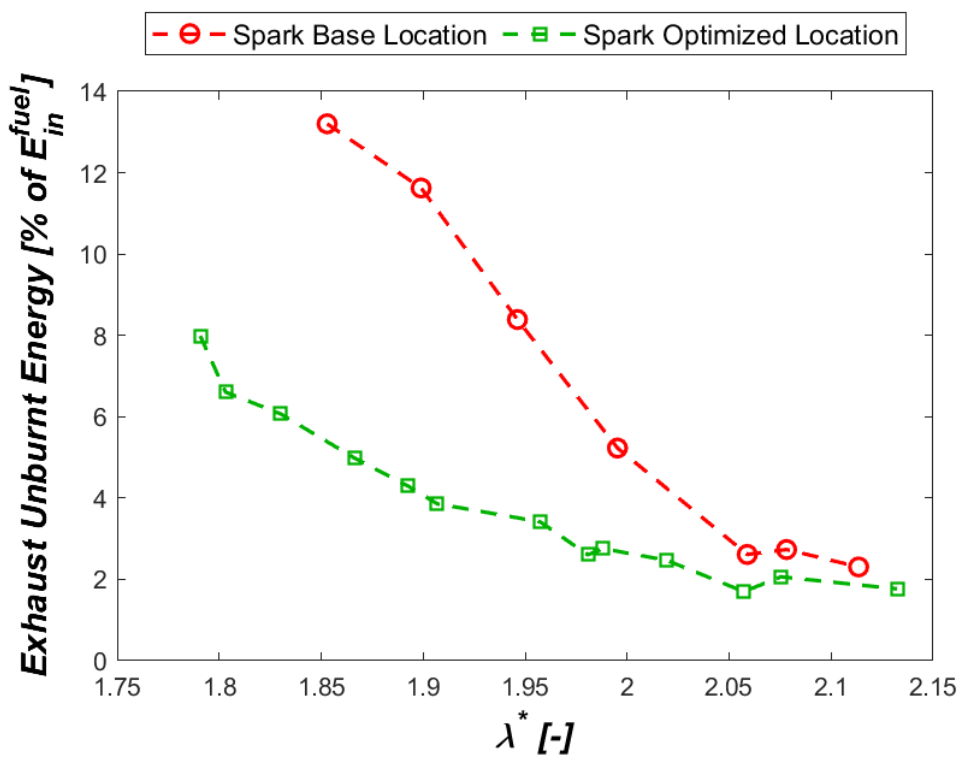

Figure 74. Exhaust $\mathrm{Co}$ and $\mathrm{H}_{2}$ energy for base location and optimized location of spark plug, each datapoint is averaged over 90 seconds of continuous data measurement.

Figure 75 shows the sum of THC and incomplete combustion energy losses for two spark locations. Base location of spark showed a minimum combustible loss of around $10 \%$ where the optimized location showed a minimum value of $6 \%$, a $40 \%$ relative reduction. When comparing the total combustible losses averaged over the $\lambda^{*}$ range, the reduction was even higher, at around $50 \%$, due to higher losses in richer operations. 


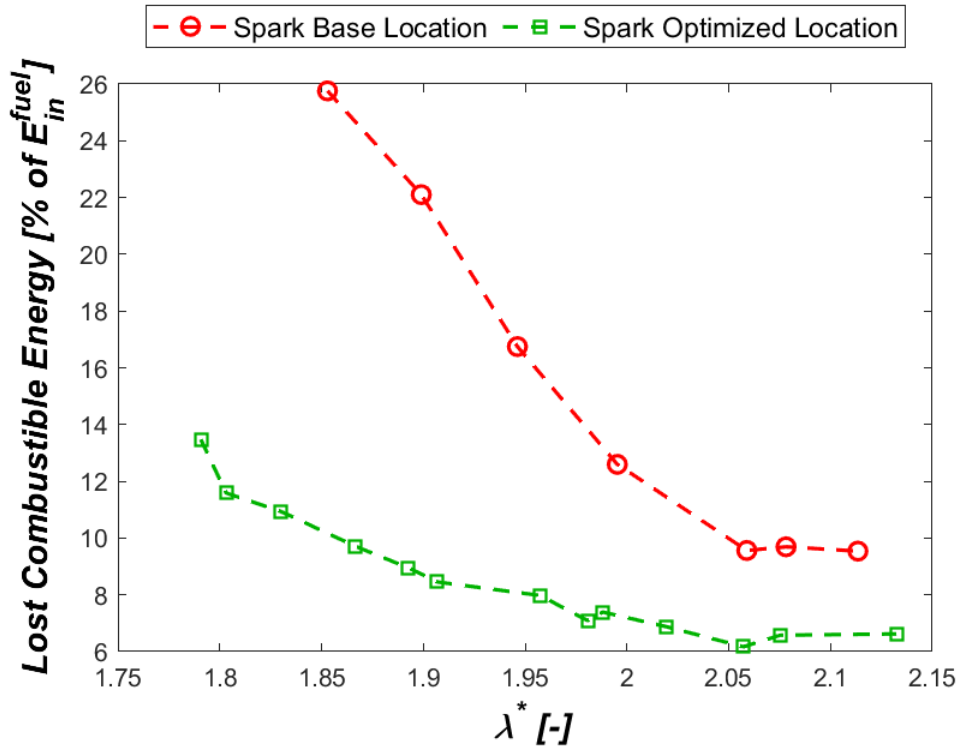

Figure 75. Total combustible content of exhaust for base location and optimized location of spark plug, each datapoint is averaged over 90 seconds of continuous data measurement.

Due to the reasons discussed above and as shown in Figure 76, the indicated efficiency for the new optimized spark location was higher. Spark base location yielded a maximum indicated efficiency of $30.4 \%$ where with optimized spark location showed a maximum value of $31.4 \%$.

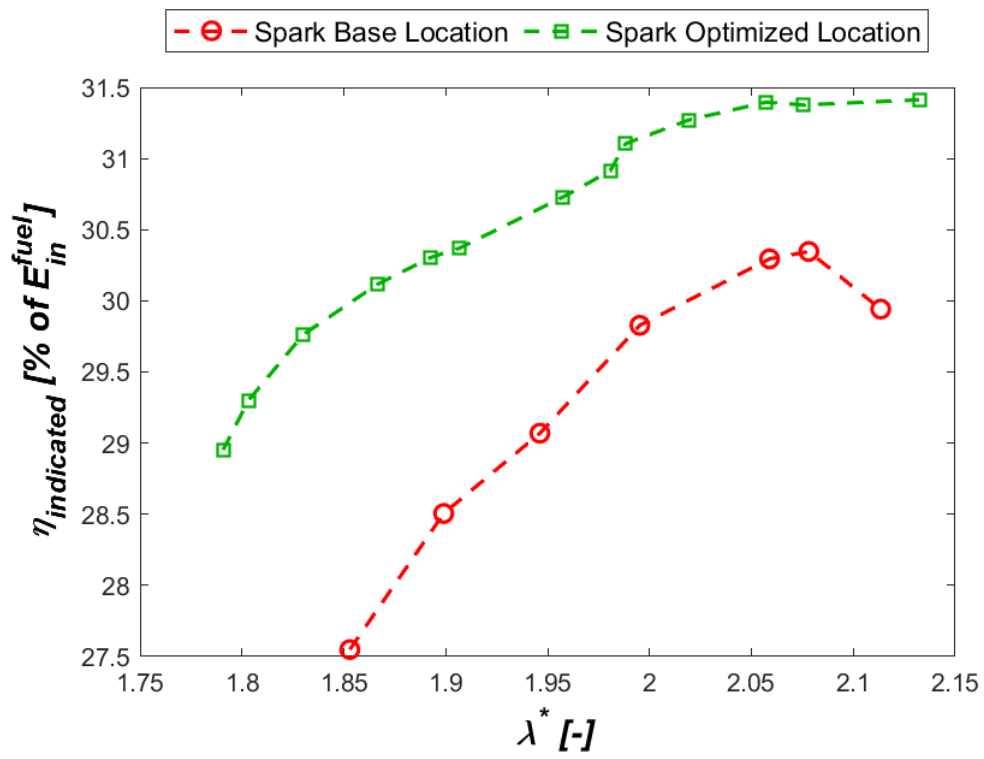

Figure 76. Indicated efficiency for base location and optimized location of spark plug, fuel flow was averaged over 90 seconds of continuous data measurement and IMEP averaged over 200 cycles. 
Figure 77 supports the claim of shorter combustion duration with optimized spark location. Combustion duration in experiments was defined as the time for 10-90\% MFB in units of CAD. While the original location showed an average combustion duration around 50 CAD, the optimized spark location showed an average around $40 \mathrm{CAD}$. This shorter combustion duration ensured a lower COV of IMEP in most of the engine operation conditions as shown in Figure 78. Note that even with imperfect mixing on LPDI, the combustion stability approached the range for PI operation with perfect mixing. This shows the effectiveness of all the improvements including the exhaust and spark location optimization. Referring to Figure 52, for 5400 RPM with the beta design and original spark location, only 3 points were below $5 \% \mathrm{COV}$ and those points were near rich limits. Whereas with optimized exhaust (base location line in Figure 78) combustion stability was acceptable over a wider range of operation. Combustion stability showed even further improvement with spark location optimization.

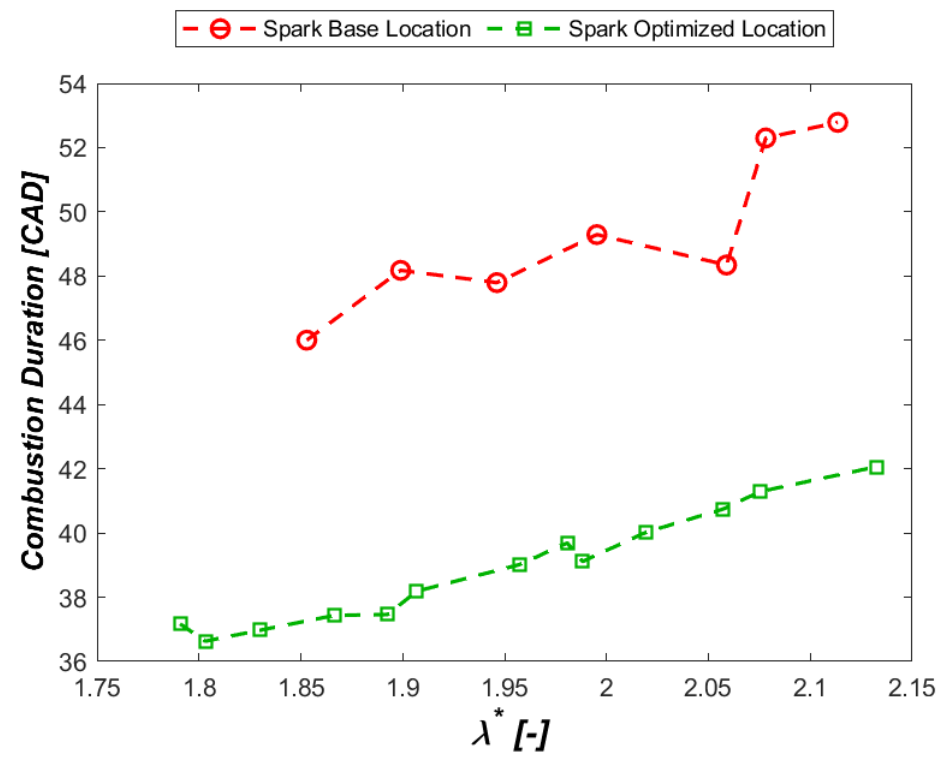

Figure 77. Combustion duration comparison for base location and optimized location of spark plug, each datapoint is averaged over 200 engine cycles. 


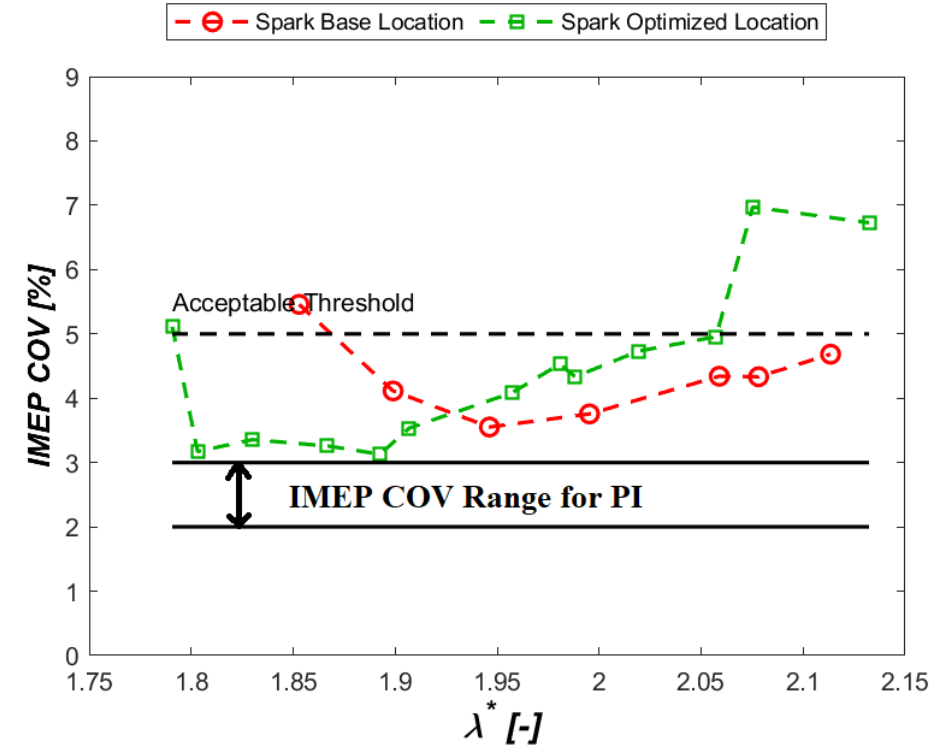

Figure 78. COV of IMEP for base location and optimized location of spark plug, each datapoint is averaged over 200 cycles.

\subsection{Fuel Quality Effect on the Performance}

After finalizing all optimizations on engine design, a fuel study was performed. The objective was to investigate the effect of fuel quality on system performance. Additionally, by adding an oxidation catalyst a detailed energy analysis was performed to identify the maximum potential of the system for micro-CHP systems operating on different fuels.

Table 28 shows the selected fuels properties. CNG1 had a higher methane and lower ethane content when compared to CNG2. Methane and propane represented the ends of the spectrum for current fuels used in residential applications. MN was calculated from Cummins Inc. proprietary methane number calculator [145]. 
Table 28. Tested fuel properties.

\begin{tabular}{|c|c|c|c|c|}
\hline Specifications & CNG1 & CNG2 & Methane & Propane \\
\hline C1 mol percent & 90.5 & 86 & 100 & 0 \\
\hline C2 mol percent & 5 & 12 & 0 & 0 \\
\hline C3 mol percent & 1 & 1 & 0 & 100 \\
\hline C4 mol percent & 0 & 0 & 0 & 0 \\
\hline N2 mol percent & 2.5 & 0.5 & 0 & 0 \\
\hline $\mathbf{C O}_{2}$ mol & 1 & 0.5 & 0 & 0 \\
\hline LHV [kJ/kg] & 46,480 & 48,482 & 50,000 & 46,350 \\
\hline AFR stoich & 15.87 & 16.51 & 17.12 & 15.57 \\
\hline M (kg/kmol) & 17.60 & 18.20 & 16.04 & 44.10 \\
\hline MN & 82.8 & 75.3 & 100 & 34.2 \\
\hline
\end{tabular}

Initially combustion stability was investigated as shown in Figure 79 to compare different fuels operation from leaner to richer regimes. Our focus was on the stable operating points and extra lean and rich conditions were examined to determine the maximum operation spectrum. It was found that combustion stability strongly affected the performance as presented in Figure 80 to Figure 83. Note that in Figure 78, all the experiments were performed using CNG1.

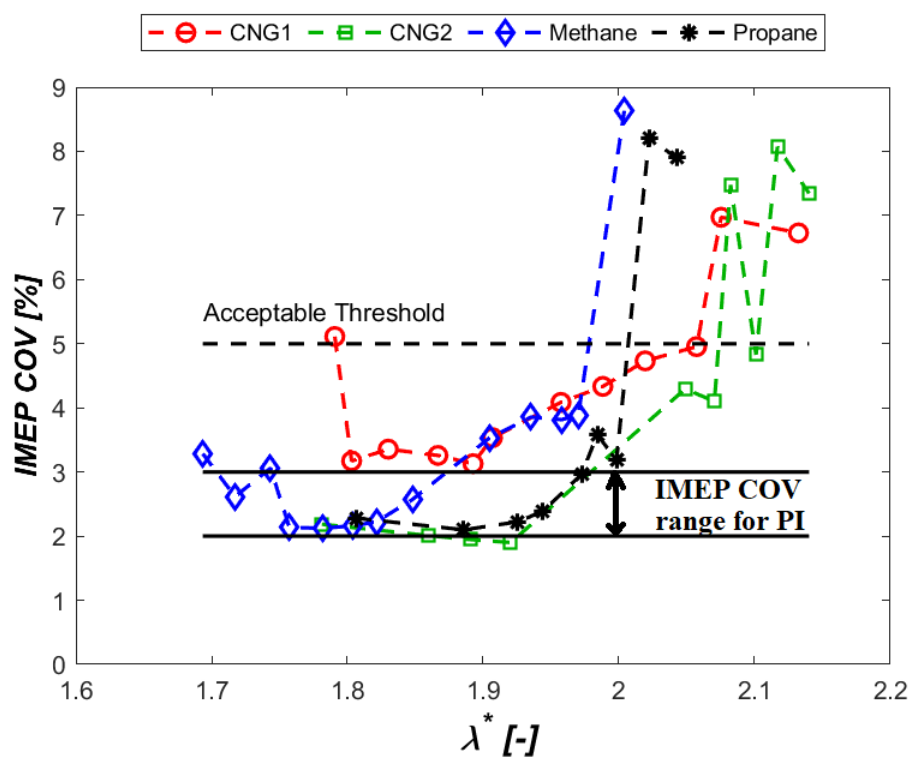

Figure 79. Combustion stability for different fuels, each point was averaged over 90 seconds of steady state operation.

Figure 80 shows the BTE and brake power for different fuels. CNG2 and propane showed the highest efficiency while methane and CNG1 showed lower values. Propane and CNG2 had heavier 
hydrocarbon content. In the context of LPDI, they seemed to operate better that lighter gaseous fuels. A more detailed energy analysis is presented next.
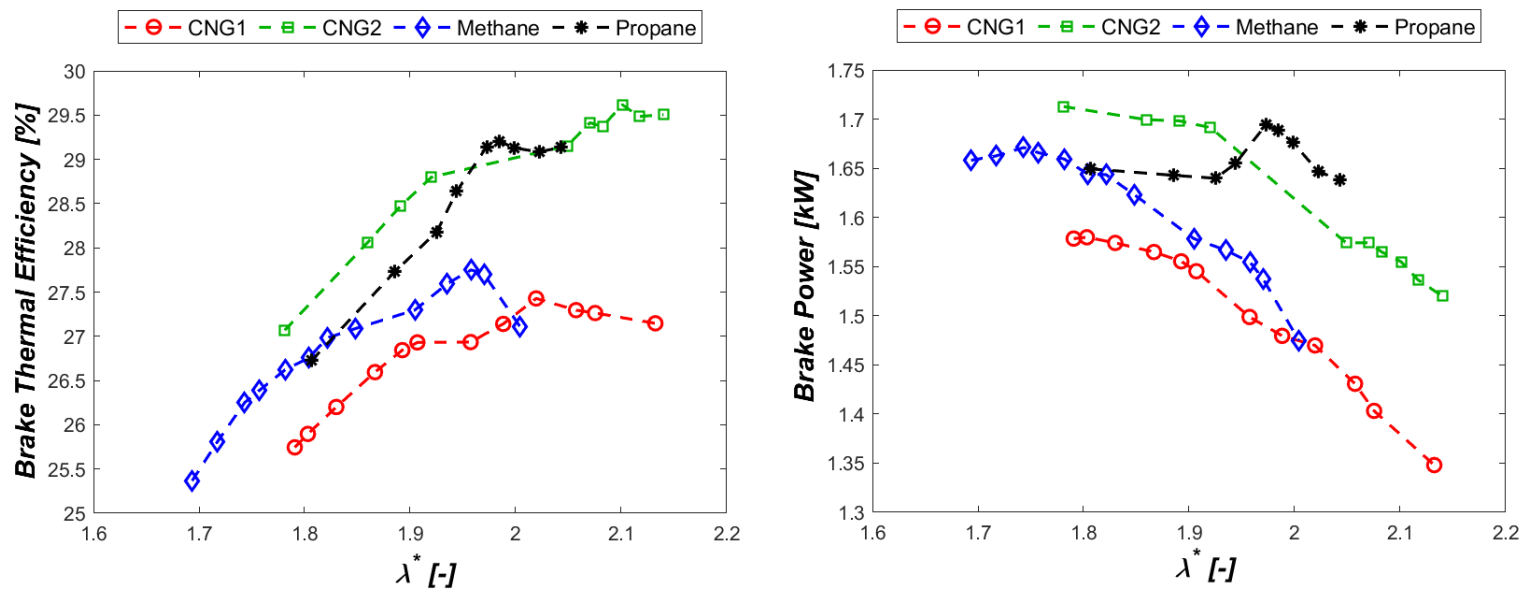

Figure 80. BTE and brake power for different fuels, each point was averaged over 90 second of steady state operation.

Figure 81 shows the heat transfer for different fuels. Methane showed the highest heat transfer rates for the NG fuels while propane heat loss varied across its narrower AFR region. CNG2 having heavier hydrocarbons, showed better performance in terms of lowered heat losses and due to faster combustion as shown in Figure 82. Propane had the highest power density and trapped energy per cycle, which showed the highest heat transfer of any operating points. Heat transfer was directly affected by peak pressure and combustion duration which varied with each fuel.

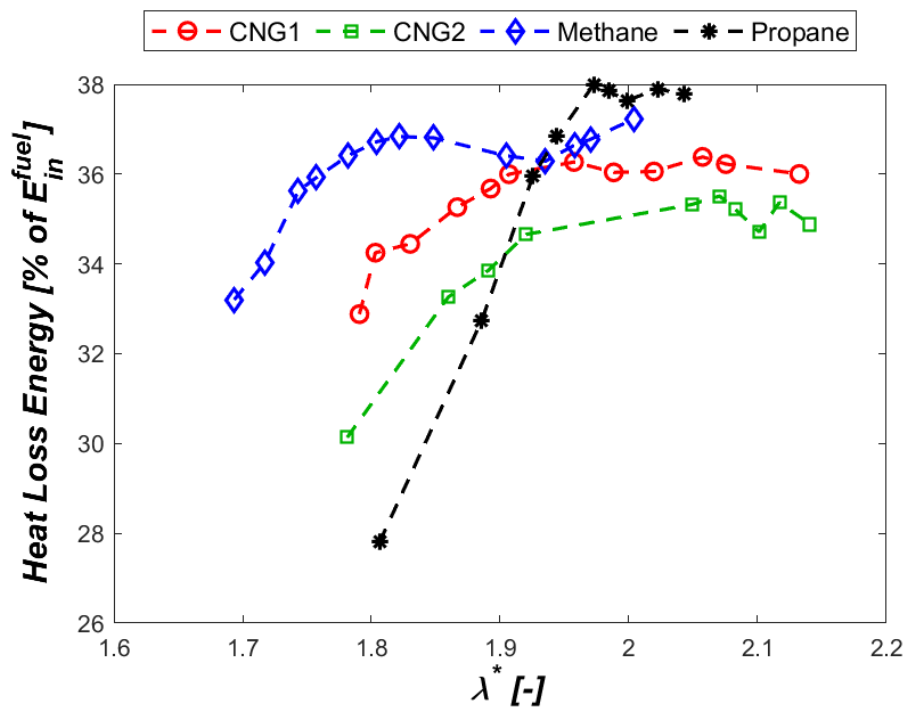

Figure 81. Cylinder heat transfer for different fuel operations, each point was averaged over 90 second of steady state operation. 
The reason that methane showed a higher heat loss was in part due to higher ignition delay and longer combustion duration as shown in Figure 82. Longer ignition delay forced the experiments for methane toward more advanced ignition timing to keep the combustion stable and achieve MBT timing. This earlier ignition timing led to higher peak pressures for methane. Having higher peak pressures and longer combustion duration allowed for additional heat transfer losses for methane. Ignition timing was around $18 \mathrm{CAD}$ BTDC for propane and varied from 21 to $23.5 \mathrm{CAD}$ BTDC for the different NG compositions.
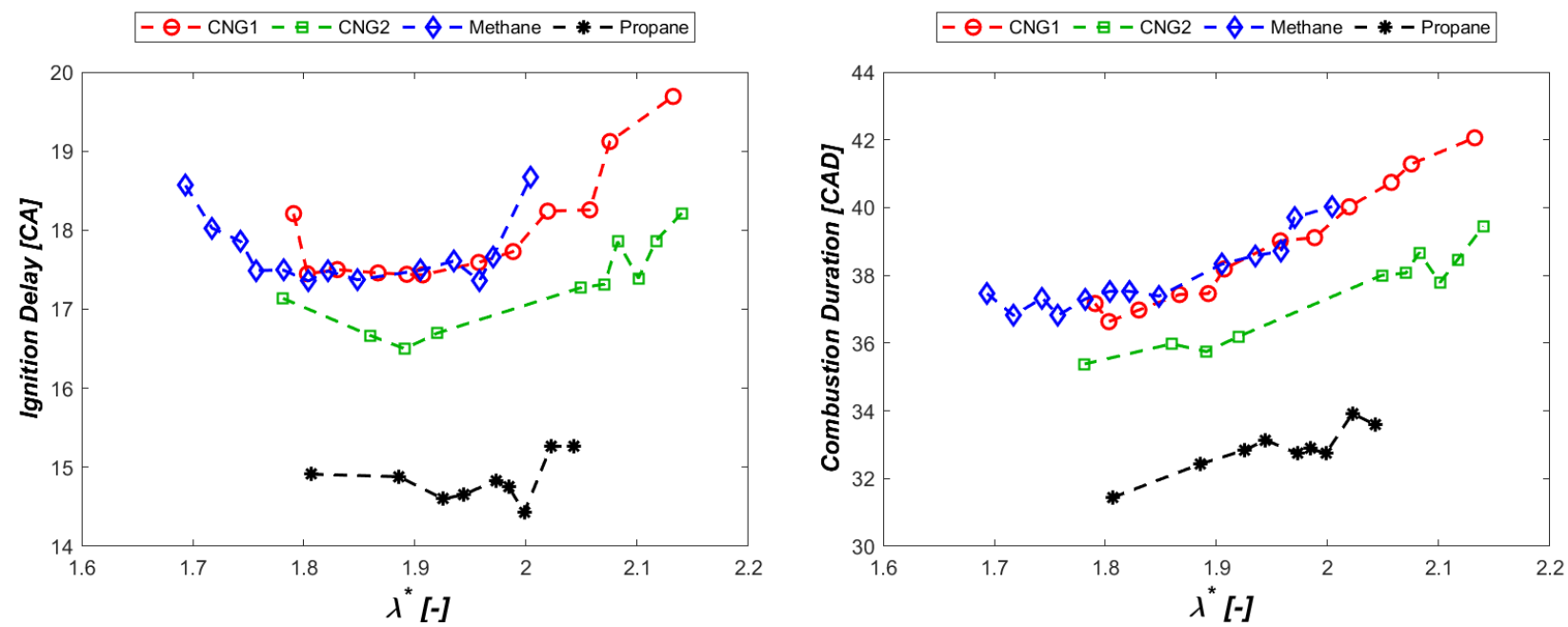

Figure 82. Ignition delay and combustion duration for different fuels, each point was averaged over 200 recorded cycles.

Figure 83 shows the exhaust chemical energy from incomplete combustion (dominated by $\mathrm{CO}$ ) and slipped fuel (C1-C3). Note that we could not experimentally, distinguish unburnt HC from slipped HC. However, the CFD study showed $98-99 \%$ of the fuel was trapped, so that ratio could be used as an offset.

Propane, the heaviest/densest fuel, showed the lowest HC in the exhaust. This was mainly due to its longer hydrocarbon chain which was easier to engage in combustion (requiring lower activation energy). The faster combustion as shown in Figure 82 confirms this explanation. However, a higher charge stratification expected from denser gaseous fuel, did not allow for complete combustion and propane showed the highest unburnt energy. Pure methane was on the other side of the spectrum compared to propane and CNG1 and CNG2 were in between. CNG1 being the lighter CNG showed a behavior more similar to pure methane. 

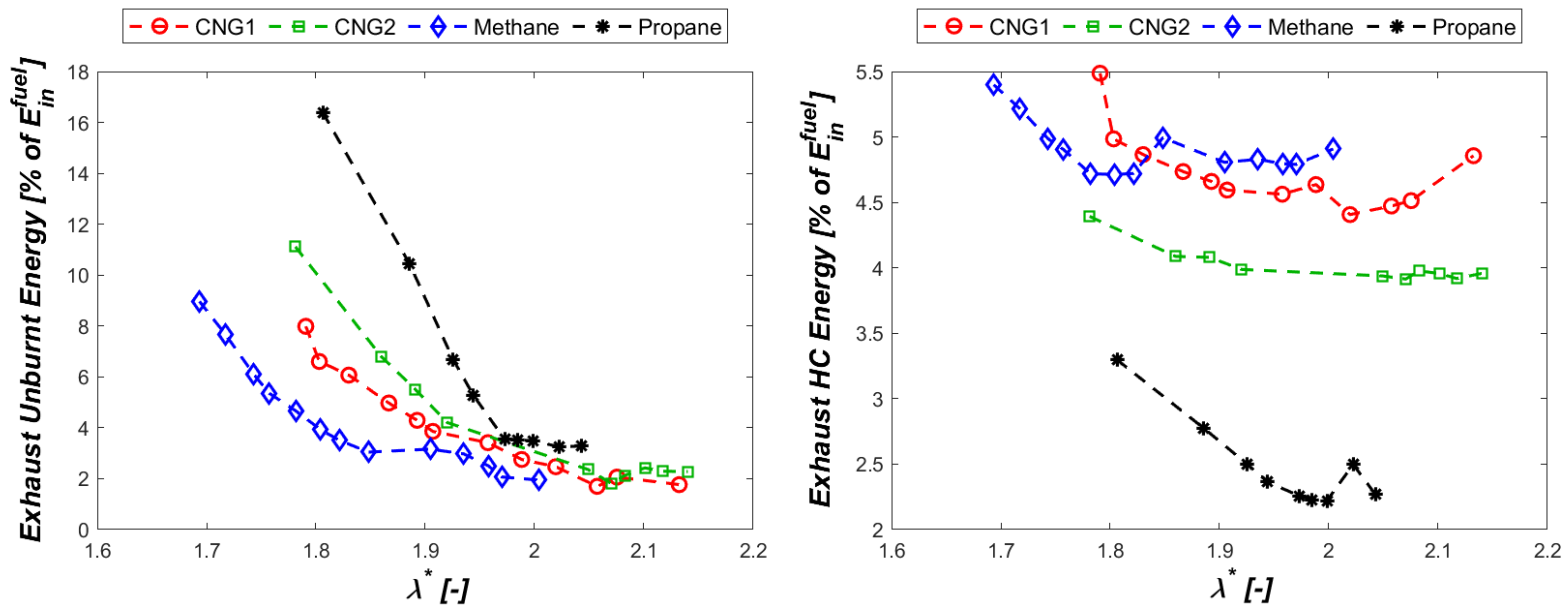

Figure 83. Unburnt (CO and $\mathrm{H}_{2}$ ) energy and total $\mathrm{HC}$ energy in exhaust, each point was averaged over 90 second of steady state operation.

\subsubsection{CHP Potential Analysis}

Previously all the energy pathways were quantified in detail. However, for a more realistic estimation, the heat potential of unburnt products in the exhaust must be considered. While hydrocarbons in NG and propane are difficult to catalyze, the CO can be easily oxidized which would improve the exhaust heat content for recovery in a CHP system.

Platinum based oxidation catalysts have low performance in catalyzing $\mathrm{HCs}$, especially lower alkanes at low temperatures[146], [147], [148]. However, oxidation of CO is well established [149] and literature has shown high conversion efficiencies (>90\%) at temperatures of $200{ }^{\circ} \mathrm{C}$ and lower. $\mathrm{CO}$ oxidation is exothermic, and its heat release can be calculated from Equation (70):

$$
\Delta_{r} H=\Delta_{f} H\left\{C O_{2(g)}\right\}-\Delta_{f} H\left\{C O_{(g)}\right\}-\Delta H\left\{O_{(P t)}\right\}
$$

Where, $\Delta_{f} H$ is the enthalpy of formation and $\Delta H\left\{O_{(P t)}\right\}$ is the heat required to release $\mathrm{O}$ radicals from the platinum sites. $\Delta_{r} H$ was reported to be about $173 \mathrm{~kJ} / \mathrm{mol}$ [150]. Using this heat release rate and a $99.3 \%$ oxidation efficiency, the theoretical added heat from $\mathrm{CO}$ oxidation was calculated. The total available heat from CO oxidation is presented in Table 29 which shows the averaged added heat energy from oxidation. The values were calculated as a percentage of the total fuel energy injected and the total CO energy. All fuels showed about $40 \%$ recovery of total CO 
energy and propane with the highest CO output, showed the highest values. Note that because of the catalyst and resonator sensitivity to heat, precautions must be taken to ensure that minimum light-off temperatures are obtained, and that placement does not negatively impact resonator performance.

Table 29. CO oxidation added heat averaged over the range of AFR, numbers are calculated based on experimental CO concentration from Equation (70).

\begin{tabular}{|c|c|c|c|}
\hline Energy Fraction & $\dot{\boldsymbol{E}}_{\text {Co }}^{\text {oxidation }} / \dot{\boldsymbol{E}}_{\text {Fuel }}^{\text {in }}$ & $\dot{\boldsymbol{E}}_{\text {Co }}^{\text {Oxidation }} / \dot{\boldsymbol{E}}_{\text {Co }}^{\text {exh }}$ & $\begin{array}{l}\text { Relative increase in exhaust sensible } \\
\text { heat }\end{array}$ \\
\hline Unit & $\%$ & $\%$ & $\%$ \\
\hline CNG1 & 2.23 & 39.7 & 10.0 \\
\hline CNG2 & 2.05 & 39.1 & 9.0 \\
\hline Methane & 2.36 & 38.7 & 10.2 \\
\hline Propane & 3.37 & 44.6 & 15.1 \\
\hline
\end{tabular}

\subsubsection{Heat Recovery Analysis}

Table 30 shows a detailed breakdown of all energy categories, which could be considered in estimating the peak utilization of micro-CHP system operating on each fuel. Note that for each fuel, data was averaged over the range of operating AFR. Peak utilization values were calculated based on full heat recovery of both cylinder and exhaust heat. Exhaust gas temperature and cylinder head temperature were included as they would be the inlet/boundary temperatures for the design of the heat exchangers. The cylinder heat has a lower quality compared to the exhaust heat since its heat transfer would occur at a lower temperature. The Consumer Product Safety Commission recommends a domestic hot water upper temperature limit of $49^{\circ} \mathrm{C}$. Therefore, both heat sources could serve as heat inputs to domestic hot water [151]. In deploying a heat exchanger for the exhaust, caution should be taken to not affect the resonator and catalyst performance. 
Table 30. Cylinder and exhaust heat for different fuels and their occurring temperatures for best BTE points, peak UF is based on $100 \%$ heat recovery.

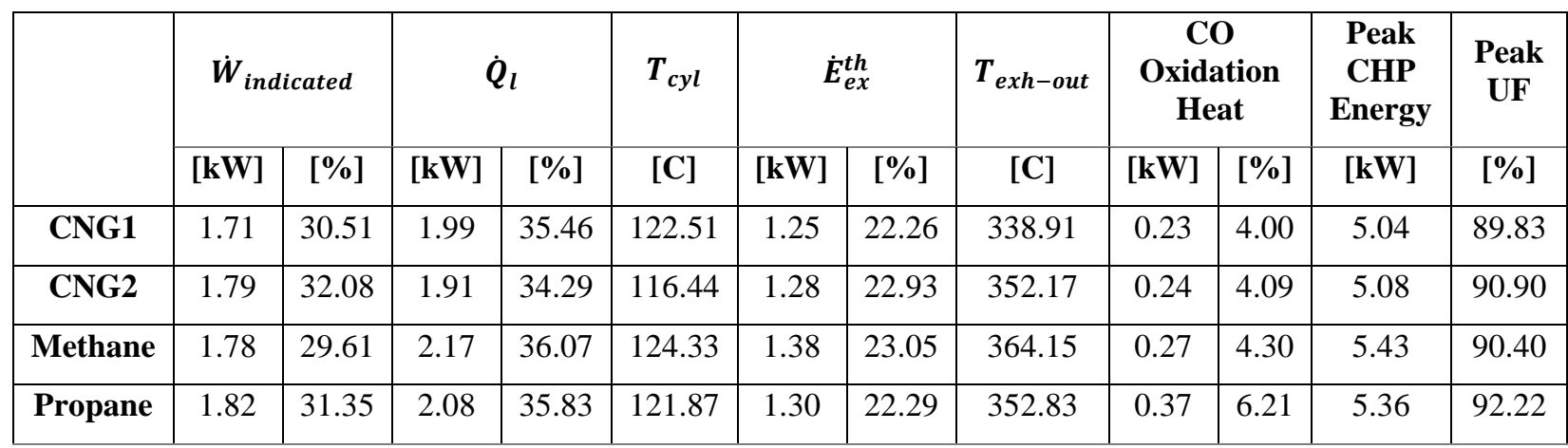

To estimate the system's UF with varied heat exchanger effectiveness from $50 \%$ to $100 \%$ as presented in Table 31 and shown in Figure 84. Peak utilization factor was obtained based on full heat recovery of exhaust and cylinder heat. Note that propane, as the most power dense fuel, showed the highest peak UF of $92.2 \%$, while methane showed the lowest peak UF of $89.8 \%$. Lower fuel slip combined with higher heat transfer made propane the best performing fuel from a UF standpoint. As heat exchanger effectiveness increased, those fuels showing highest heat content (propane and methane) started drifting upward showing a better UF.

Table 31. System's UF calculated for incremental heat exchanger effectiveness values, cylinder heat transfer plus exhaust heat accounted for total available heat in heat exchanger.

\begin{tabular}{|c|c|c|c|c|c|c|c|c|c|c|c|}
\hline & \multicolumn{10}{|c|}{ UF } \\
\hline $\begin{array}{c}\text { Heat Exchanger } \\
\text { Effectiveness }\end{array}$ & $\mathbf{0 . 5 0}$ & $\mathbf{0 . 5 5}$ & $\mathbf{0 . 6 0}$ & $\mathbf{0 . 6 5}$ & $\mathbf{0 . 7 0}$ & $\mathbf{0 . 7 5}$ & $\mathbf{0 . 8 0}$ & $\mathbf{0 . 8 5}$ & $\mathbf{0 . 9 0}$ & $\mathbf{0 . 9 5}$ & $\mathbf{1 . 0 0}$ \\
\hline CNG1 & 60.1 & 63.1 & 66.0 & 69.0 & 72.0 & 74.9 & 77.9 & 80.9 & 83.8 & 86.8 & 89.7 \\
\hline CNG2 & 61.4 & 64.3 & 67.3 & 70.2 & 73.1 & 76.1 & 79.0 & 82.0 & 84.9 & 87.8 & 90.8 \\
\hline Methane & 59.9 & 63.0 & 66.0 & 69.1 & 72.1 & 75.1 & 78.2 & 81.2 & 84.2 & 87.3 & 90.3 \\
\hline Propane & 61.7 & 64.8 & 67.8 & 70.9 & 73.9 & 76.9 & 80.0 & 83.0 & 86.1 & 89.1 & 92.1 \\
\hline
\end{tabular}

As tested in multiple national laboratories, a current state-of-the-art micro-CHP prototype system produced $27.2 \%$ connecting rod thermal efficiency, $23.5 \%$ fuel to electrical efficiency with a total system UF of $74.5 \%$ [125]. Connecting rod thermal efficiency was calculated by deducting any losses in the crank and clutch system. This could be equivalent to rod efficiency in a linear engine setup. It was found that heat transfer plus exhaust sensible heat accounted for around $3.4 \mathrm{~kW}, 65 \%$ of total fuel energy - to produce around $1.38 \mathrm{~kW}$ brake power and $1.17 \mathrm{~kW}$ electricity. The system 
was able to recover around $2.5 \mathrm{~kW}$ out of $3.4 \mathrm{~kW}$ total heat, yielding a heat exchanger effectiveness of around $75 \%$.

If the same effectiveness is applied to the current research system, referring to Table 31, the UF ranges from $74.9 \%$ for $\mathrm{CNG} 1$ and $76.9 \%$ for propane. Higher total heat plus lower fuel loss caused propane and CNG2 to show a better UF.

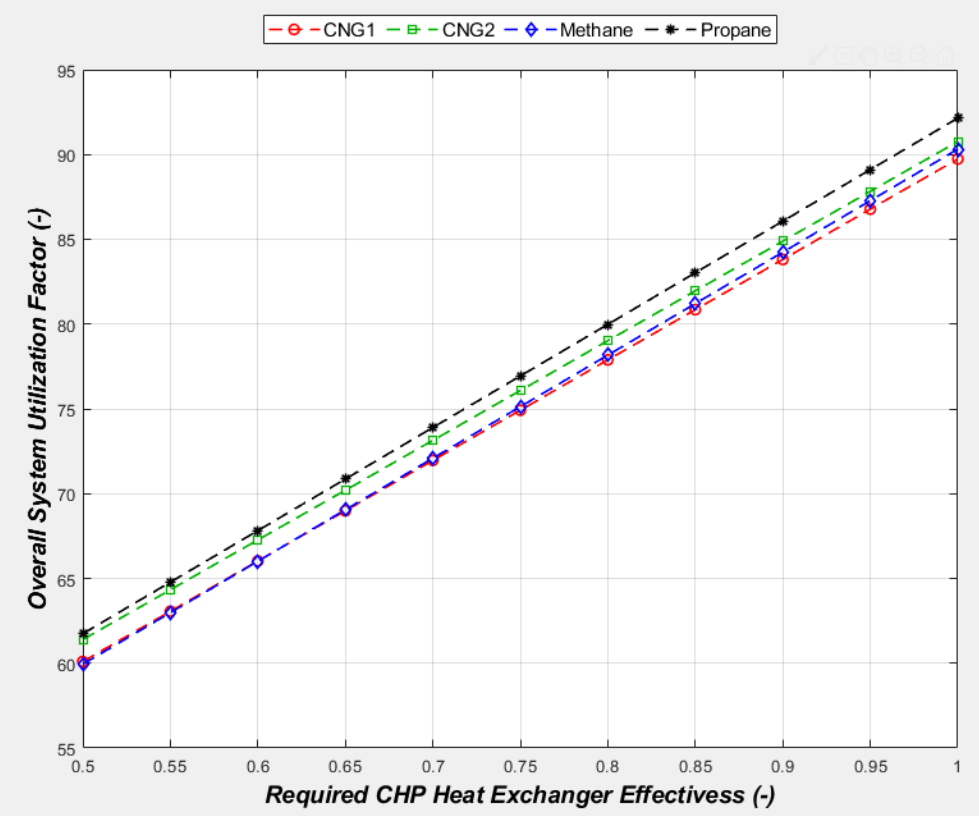

Figure 84. Overall utilization factor versus the required heat exchanger effectiveness for the CHP system.

\subsection{Oxidation Catalyst Experiments}

An oxidation catalyst was tested on the two ends of the fuel spectrum. Propane was tested since it was the highest alkane and assumed to be catalyzed easier than methane. Pure methane was tested since methane is the most difficult fuel to be catalyzed. The objective was to investigate the catalysts effect on the system performance parameters. Of the biggest concern were efficiency, added heat (CO oxidation) for recovery, exhaust methane, and NMHC oxidation.

A platinum only catalyst was tested. These catalysts have showed $\mathrm{CO}$ oxidation efficiencies up to 99.3\%. Figure 85 shows an example of continuous data from a cold start test that included an oxidation catalyst. At around the catalyst inlet temperature of $250{ }^{\circ} \mathrm{C}$ there is an inflection point 
in the temperature versus time curve, which corresponded to a dramatic decrease in post catalyst $\mathrm{CO}$ concentration. The average resonator outlet temperatures for all fuels was greater than $250^{\circ} \mathrm{C}$.

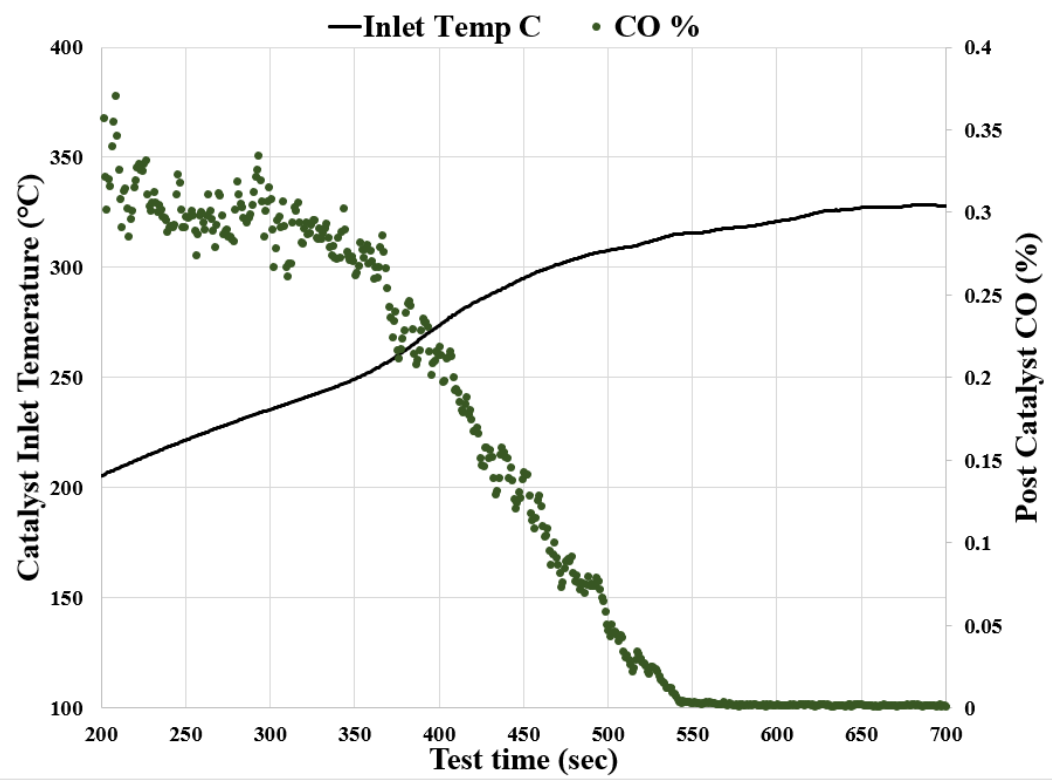

Figure 85. CO oxidation plot from cold-start to light-off temperature of the catalyst.

The catalyst was a flow through design, but the addition of any catalyst and exhaust piping could add backpressure on the exhaust which could negatively impact performance of the resonator and engine. Figure 86 presents the changes in delivery ratio for methane and propane. Note that the added backpressure did decrease delivery ratio, but in both cases the tuned system was capable of achieving delivery ratios at or above 1.0.
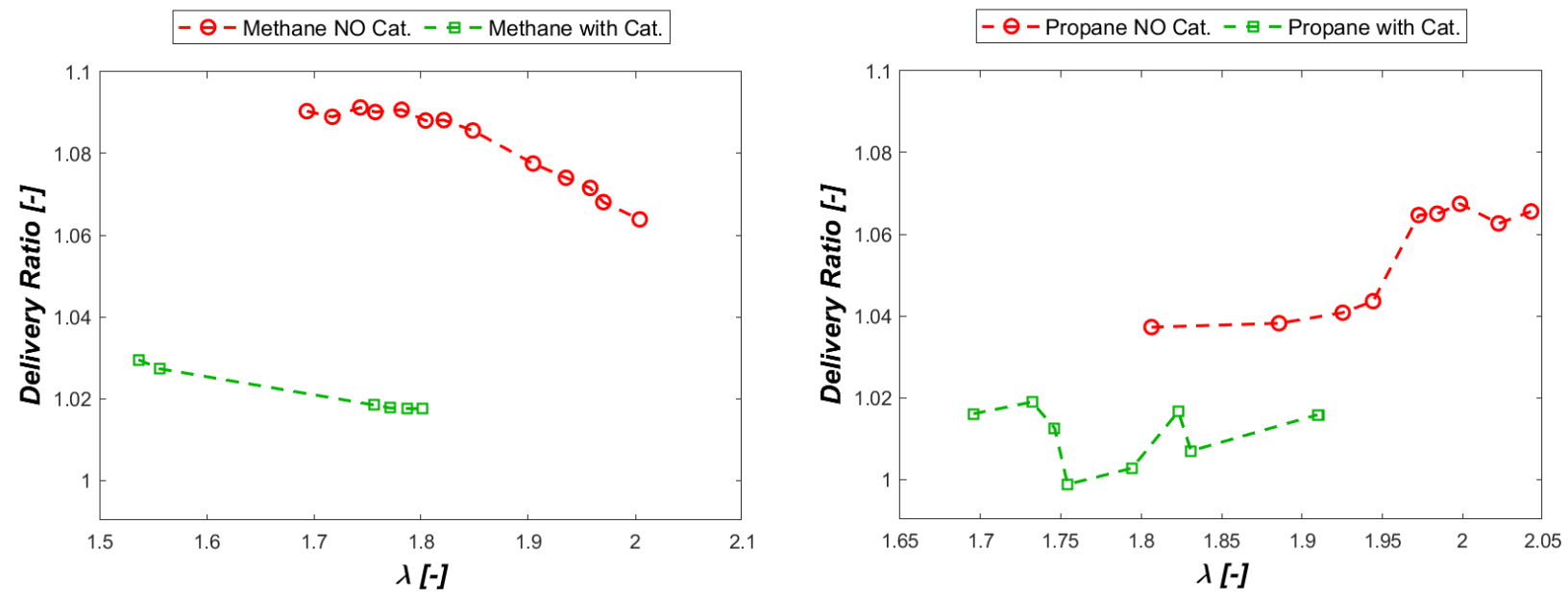

Figure 86. Delivery ratio before and after catalyst installation for methane and propane operation, each point was averaged over 90 seconds of steady state operation. 
Figure 87 shows the effect of the added catalyst on indicated efficiency. While methane showed less than a $1 \%$ reduction in absolute value of the efficiency, propane had about a $1 \%$ reduction in indicated efficiency. While a decrease in efficiency is proportional to a decrease in UF, it could be offset if the additional exhaust heat was recovered. This reduction was compensated with an increase in total heat available in both fuels operations as shown in Figure 88. Methane showed a $2-4 \%$ increase in total heat dependent on the AFR and propane showed a 3-6\% increase. This additional heat originating from the catalyst could then be used in CHP system. Note that the additional heat was calculated after the catalyst, so harvesting it would not affect the catalyst's performance. For both methane and propane, adding the catalyst reduced the peak BTE between 0.5 and $1 \%$ in absolute value. However, the available heat increased more than $2 \%$ for methane and more than $3 \%$ for propane. Even with lowest heat exchanger effectiveness (50\%), the system's UF would improve for both fuels.
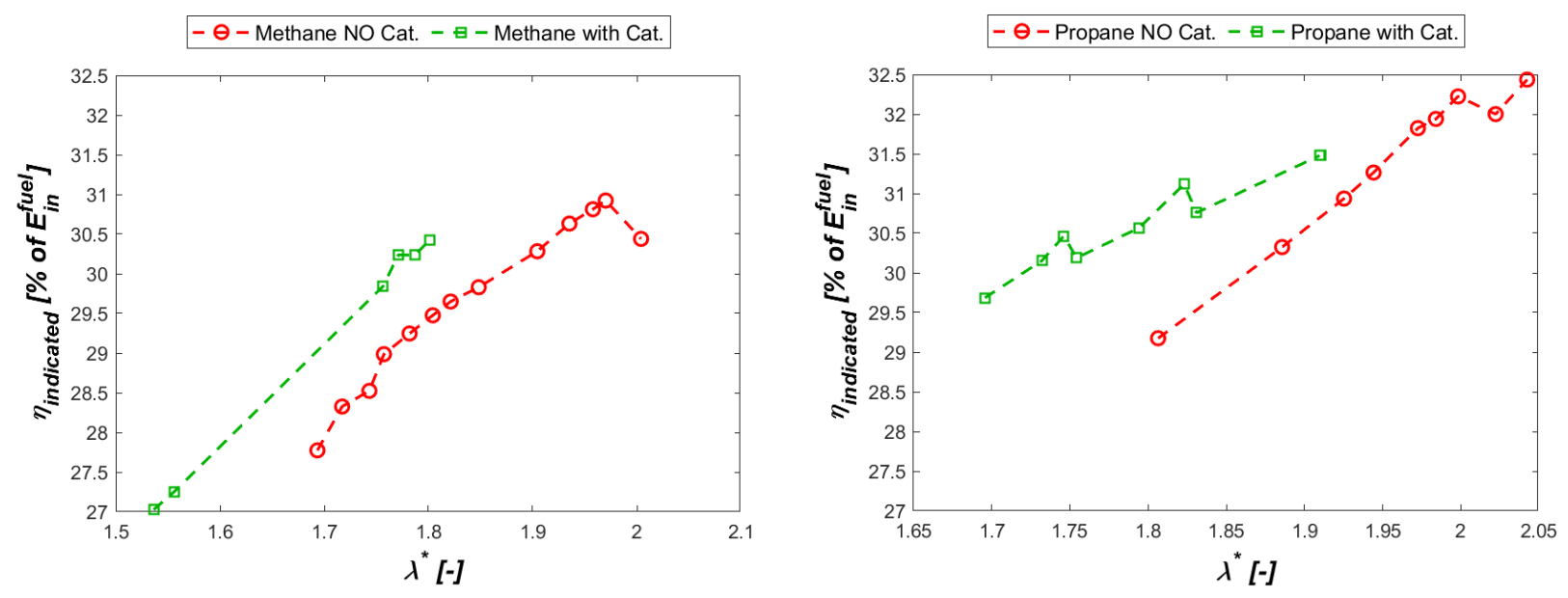

Figure 87. Indicated efficiency before and after catalyst installation for methane and propane operation, each point was averaged over 90 seconds of steady state operation. 

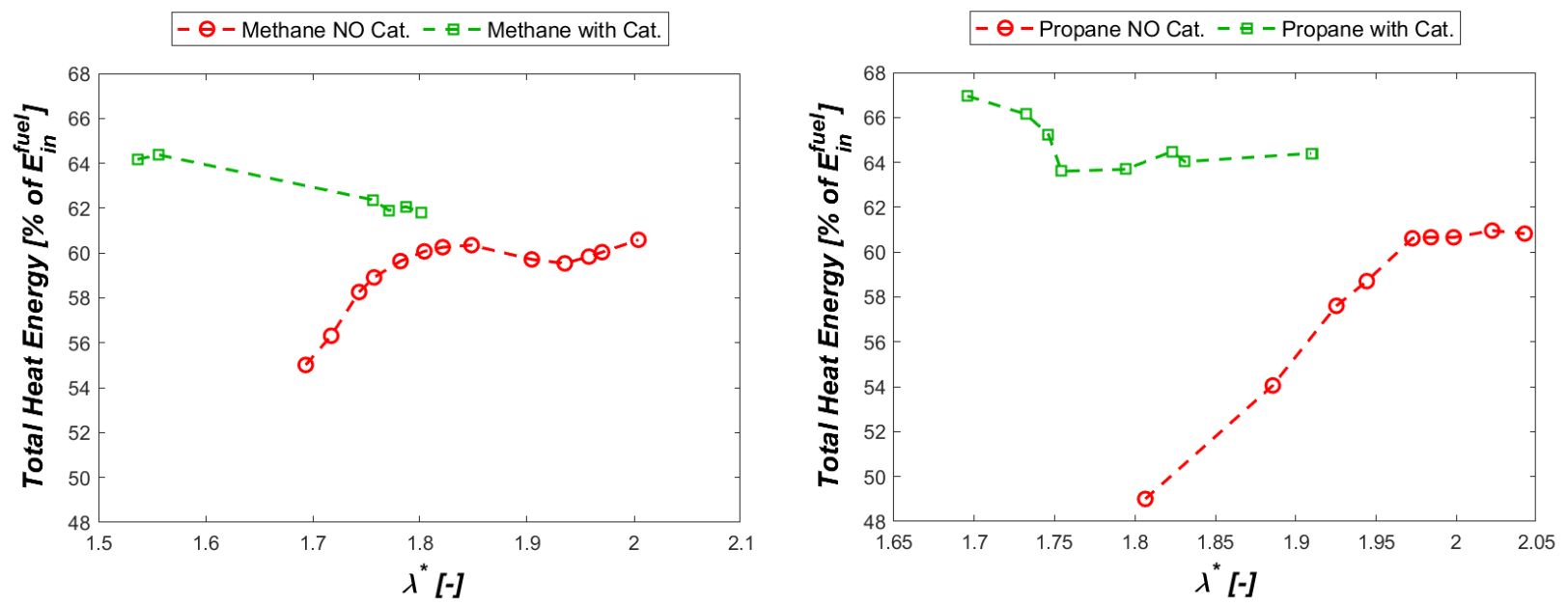

Figure 88. Total available heat before and after catalyst installation for methane and propane operation, each point was averaged over 90 seconds of steady state operation.

The source of additional heat was mainly from the oxidation of $\mathrm{CO}$ in both cases. A higher increase in propane heat was due to additional NMHC oxidation in catalyst as shown in Figure 88. For propane, while nearly all $\mathrm{CO}$ was oxidized, only some of the fuel was oxidized as shown in Figure 89. Fuel oxidation was higher during richer operation since the catalyst temperature was higher at those points. As the engine moved toward leaner operation, exhaust HC energy started converging to the case of no catalyst operation. That meant at those points, the catalyst did not oxidize the HC in the exhaust. In methane operation however, the catalyst did not affect the $\mathrm{HC}$, which was all methane. Engine operation was pushed toward a richer regime to examine if it could trigger methane oxidation, but it only added the unburnt fuel as additional HC energy as shown in Figure 90. Note that unburnt is referred to $\mathrm{CO}$ plus $\mathrm{H}_{2}$ energy content. 

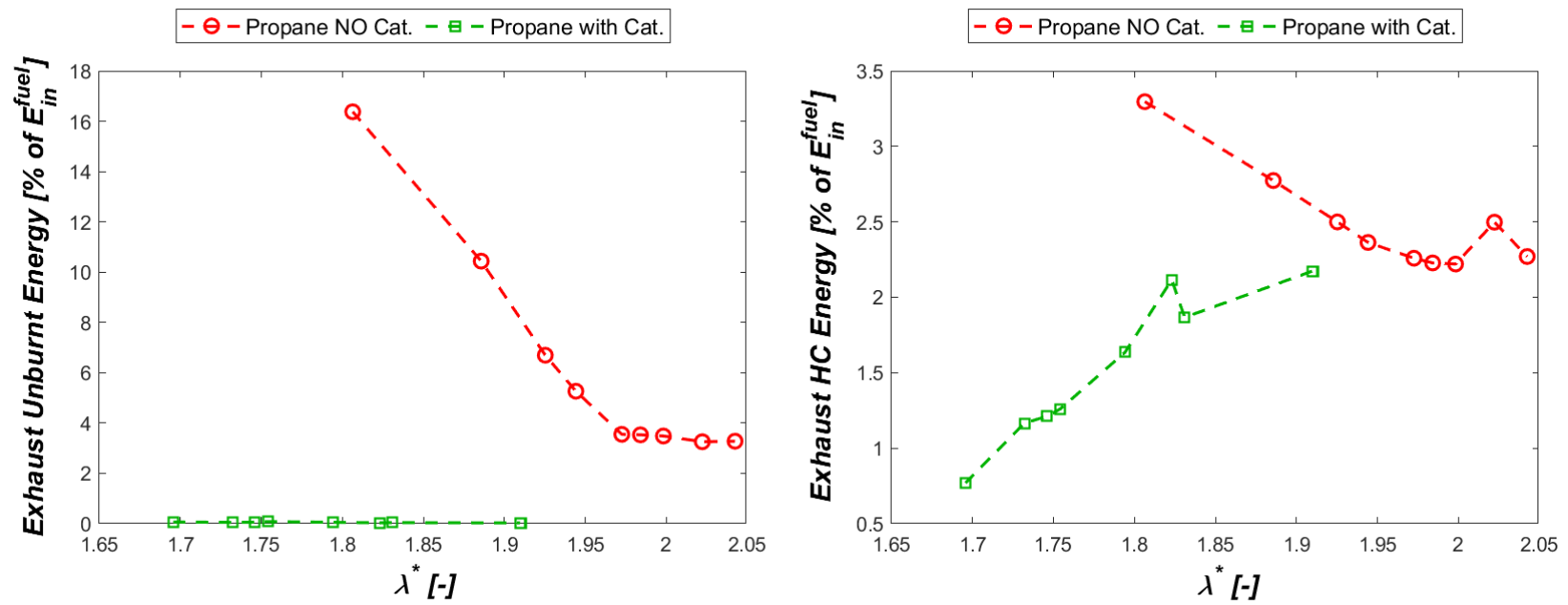

Figure 89. Propane operation chemical energy losses before and after catalyst, each point was averaged over 90 seconds of steady state operation.
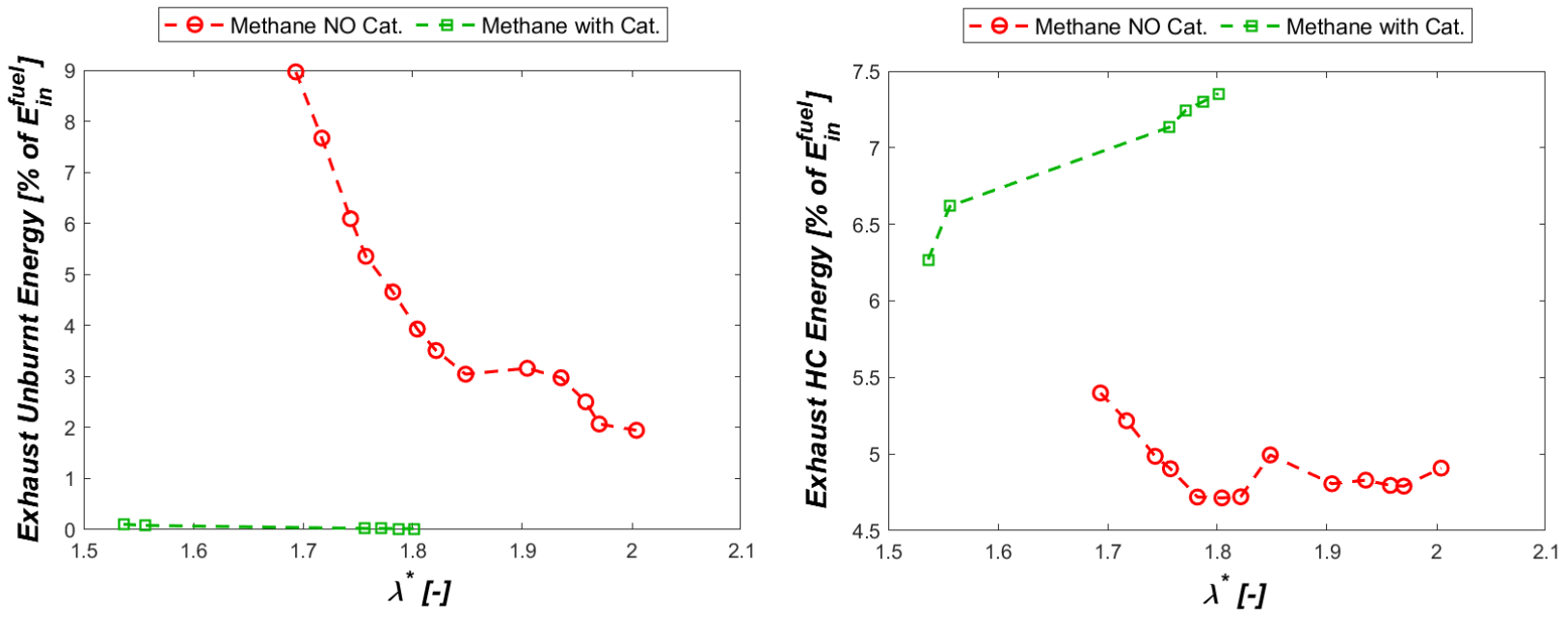

Figure 90. Methane operation chemical energy losses before and after catalyst, each point was averaged over 90 seconds of steady state operation. 


\subsection{Energy, Emissions, and Cost Analysis}

Figure 91 through Figure 94 show the energy distribution of each fuel at the operating point with peak BTE and COV of IMEP less than $5 \%$.

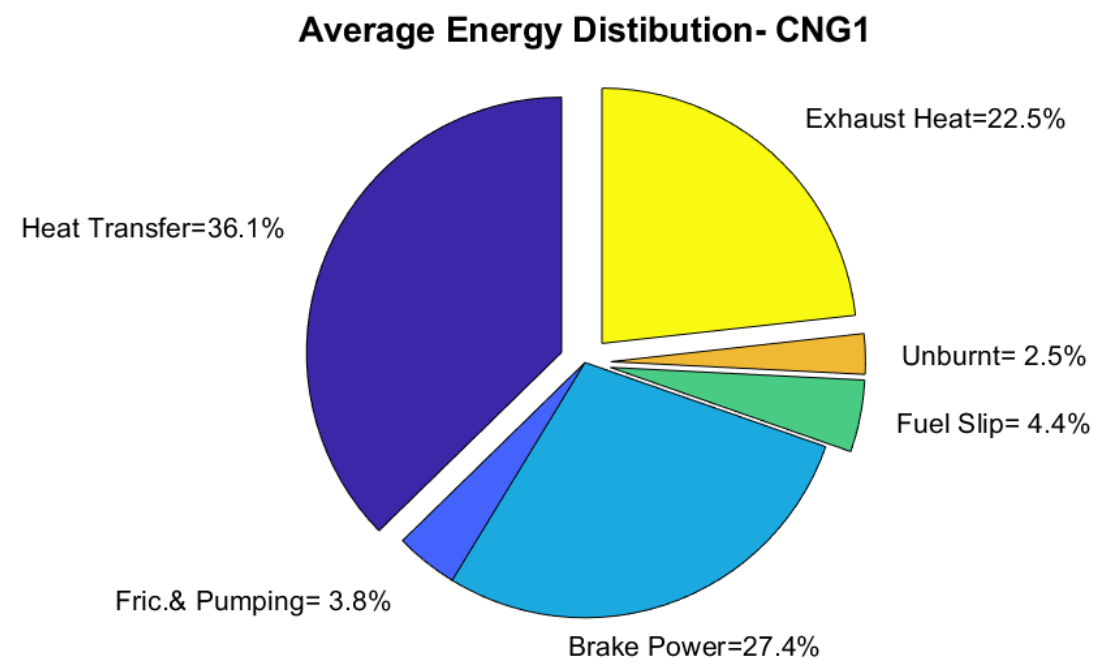

Figure 91. Energy distribution of peak BTE point with COV of IMEP less than $5 \%$ for CNG1, results are averaged for 90 second steady state operating condition.

Average Energy Distibution- CNG2

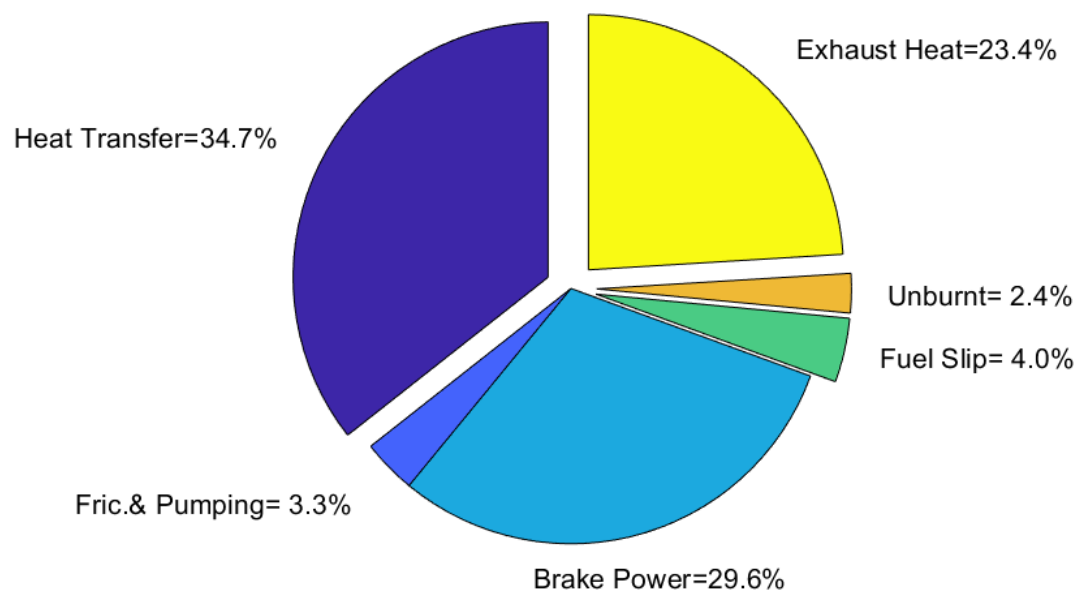

Figure 92. Energy distribution of peak BTE point with COV of IMEP less than 5\% for CNG2, results are averaged for 90 second steady state operating condition. 


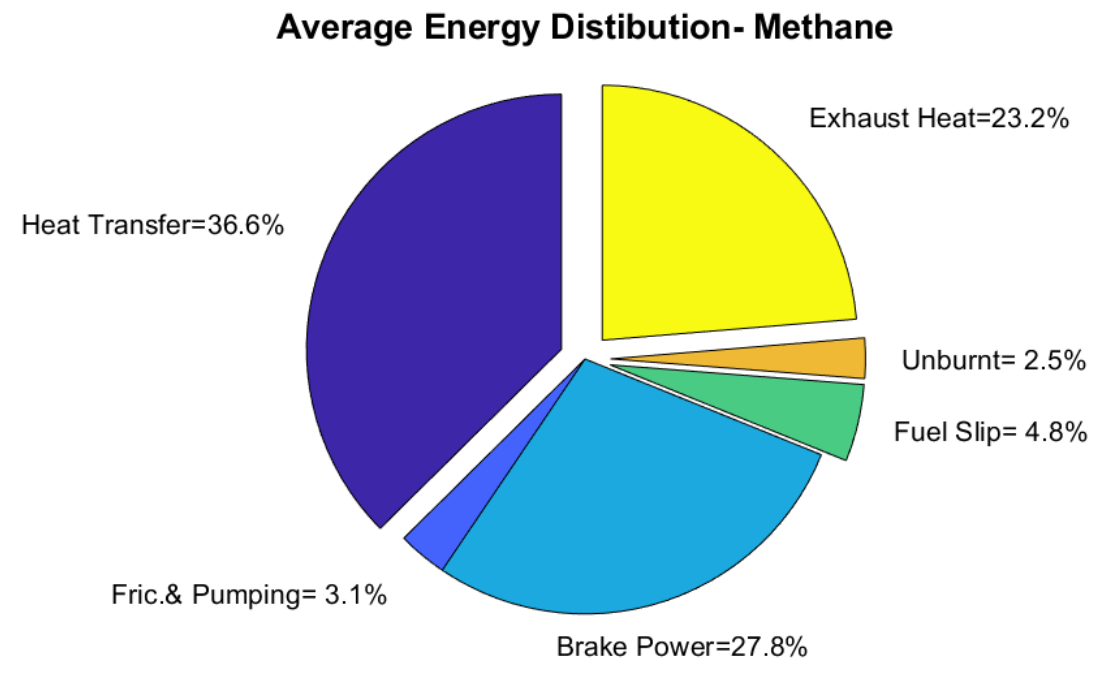

Figure 93. Energy distribution of peak BTE point with COV of IMEP less than 5\% for pure methane, results are averaged for 90 second steady state operating condition.

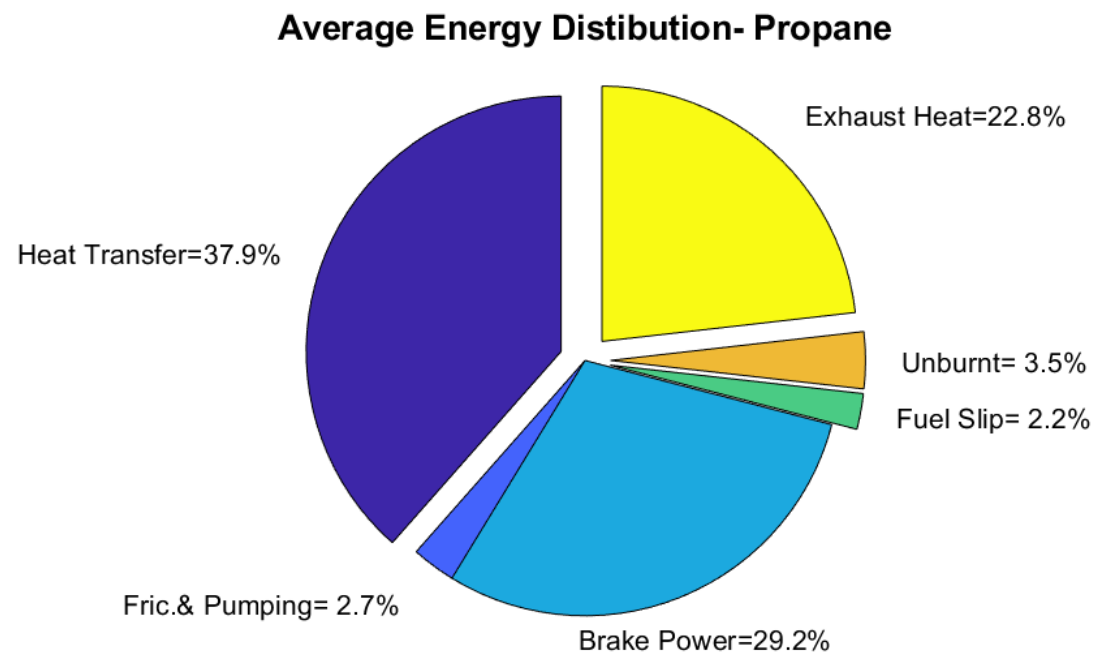

Figure 94. Energy distribution of peak BTE point with COV of IMEP less than $5 \%$ for pure propane, results are averaged for 90 second steady state operating condition.

Table 32 shows the summary of UF calculations for the peak BTE operating point of each fuel. Even though CNG2 had the highest BTE, propane operation showed the highest UF due to added exhaust heat. 
Table 32. System UF at peak BTE point for each fuel in [\%] of total fuel injected, 75\% effectiveness was assumed to waste heat recovery.

\begin{tabular}{|c|c|c|c|c|c|}
\hline & $\begin{array}{c}\text { Brake } \\
\text { Power } \\
{[\mathbf{k W ]}}\end{array}$ & $\begin{array}{c}\text { Brake } \\
\text { Efficiency } \\
{[\%]}\end{array}$ & $\begin{array}{c}\text { Heat recovery } \\
\text { based on 75\% } \\
\text { effectiveness } \\
{[\%]}\end{array}$ & $\begin{array}{c}\text { Calculated CO } \\
\text { Oxidation heat } \\
\mathbf{4 0 \%}\end{array}$ & $\begin{array}{c}\text { of CO energy }) \\
{[\%]}\end{array}$ \\
\hline CNG1 & 1.47 & 27.4 & 44 & 1 & 72.4 \\
\hline CNG2 & 1.55 & 29.6 & 43.6 & 1 & 74.2 \\
\hline Methane & 1.55 & 27.8 & 44.9 & 1 & 73.7 \\
\hline Propane & 1.69 & 29.2 & 45.5 & 1.4 & 76.1 \\
\hline
\end{tabular}

Table 33 shows the emissions for peak BTE operation for the various fuels. The GWP values of methane, ethane, and propane for 100 year time horizon used in this investigation were 25, 5.5 and 3.3, respectively [152]. Note that $\mathrm{CO}_{2}$ equivalent emissions were the sum of $\mathrm{CO}_{2}$, and the $\mathrm{CO}_{2}$ equivalents from use of GWPs of methane, ethane, and propane.

Table 33. Specific emissions in $\mathrm{g} / \mathrm{kWhr}$ for two ends of the fuel spectrum, values represent raw emissions for peak BTE points with COV of IMEP less than 5\%.

\begin{tabular}{|c|c|c|c|c|}
\hline & CNG1 & CNG2 & Methane & Propane \\
\hline Methane (GHG) & 11.03 & 8.94 & 12.10 & 0.29 \\
\hline NMHC & 0.48 & 0.55 & 0.30 & 5.63 \\
\hline NO $_{\mathbf{x}}$ & 7.83 & 8.58 & 10.19 & 10.2 \\
\hline NMHC+NO & 8.31 & 9.13 & 10.48 & 15.83 \\
\hline $\mathbf{C O}$ & 21.25 & 18.91 & 20.74 & 30.98 \\
\hline $\mathbf{C O}_{\mathbf{2}}$ & 673 & 632 & 644 & 739 \\
\hline Equivalent $\mathbf{C O}_{2}$ & 950 & 857 & 944 & 765 \\
\hline
\end{tabular}

The engine energy distribution of a small, state-of-the-art micro-CHP system from Honda, tested in multiple national laboratories, is presented in Figure 95 and Table 34 [125]. The engine was four-stroke and utilized an advanced Atkinson cycle to improve the efficiency. 
Table 34. Energy distribution for Honda micro-CHP system.

\begin{tabular}{|c|c|c|}
\hline & \multicolumn{2}{|c|}{ Value } \\
\hline Energy Group & {$[\mathbf{k W}]$} & {$[\%]$} \\
\hline Total fuel & 5.05 & 100 \\
\hline Work (electric) & 1.2 & 23.7 \\
\hline Cylinder Heat Transfer & 1.9 & 37.6 \\
\hline Exhaust heat & 1.4 & 27.7 \\
\hline Exhaust Chemical Energy & 0.16 & 3.12 \\
\hline Friction + Pumping Loss & 0.19 & 3.76 \\
\hline Generator Loss & 0.20 & 3.96 \\
\hline
\end{tabular}

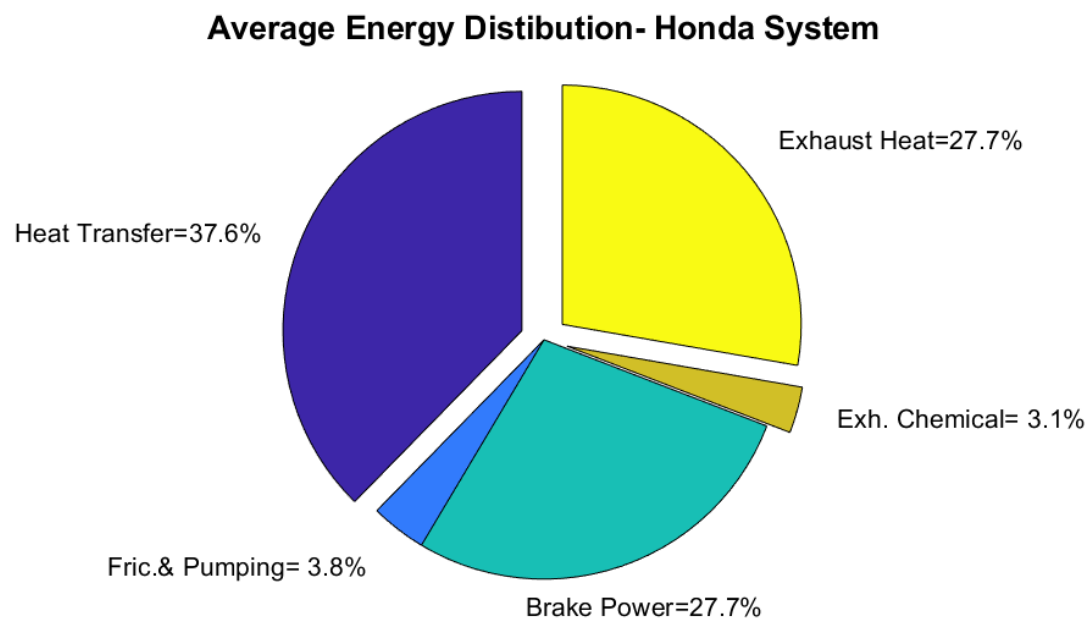

Figure 95. State-of-the-art micro-CHP system's engine energy distribution.

To compare the potential of the optimized system with an oxidation catalyst, the energy distributions are presented in Figure 96 and Figure 97 for peak BTE points of methane and propane, respectively. 


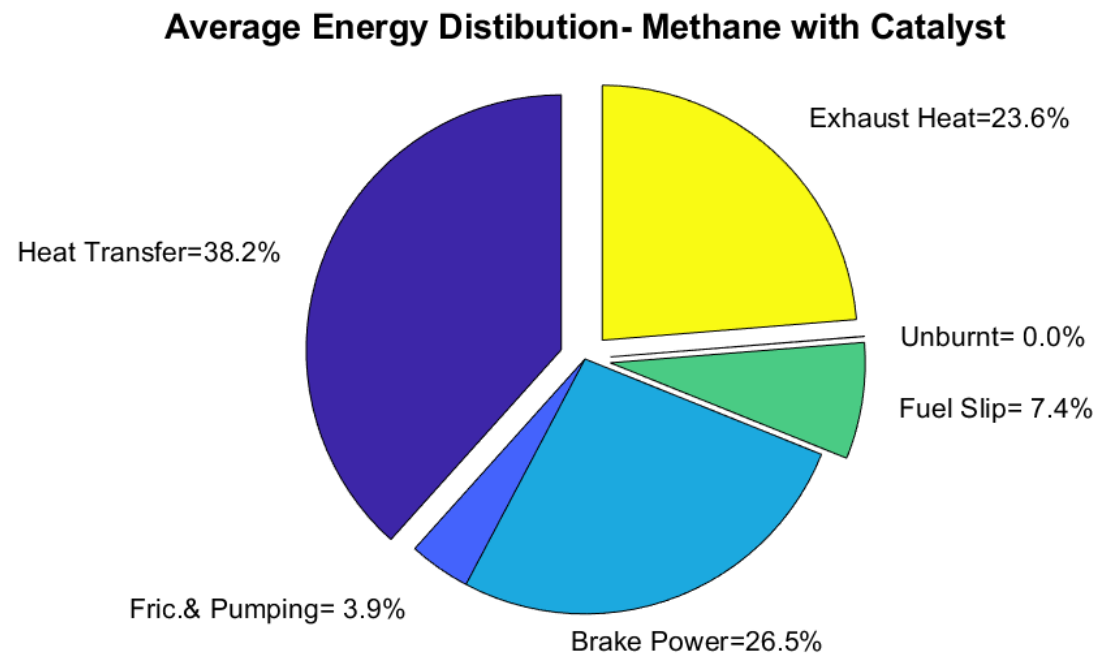

Figure 96. Engine energy distribution operating on methane with oxidation catalyst installed after exhaust resonator, the operating point was the peak BTE with COV of IMEP less than $5 \%$.

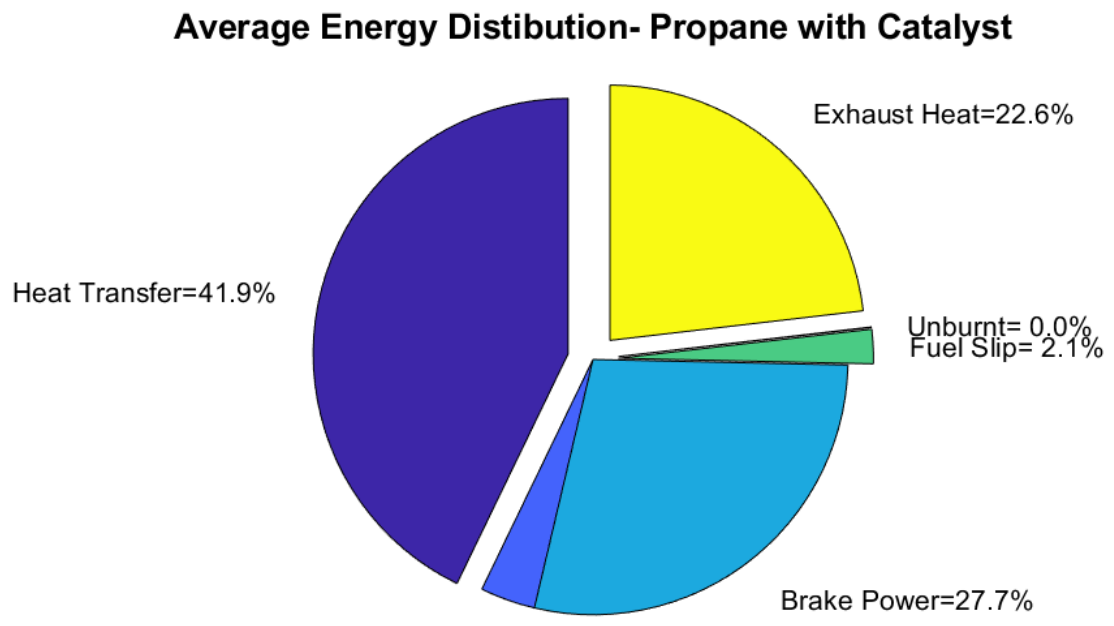

Fric. \& Pumping $=3.4 \%$

Figure 97. Engine energy distribution operating on propane with oxidation catalyst installed after exhaust resonator, the operating point was the peak BTE with COV of IMEP less than $5 \%$.

Table 35 provides a comparison of the two fuel extremes with catalysts as compared to Honda commercial system. When comparing the Honda system with methane operation, the data shows that the optimized system, with simple two-stroke technology, was comparable in terms of BTE and overall UF. The two-stroke showed an impressive power density when compared to Honda 
system. Note that the Honda engine was PI, so that part of power density was sacrificed the lower cost PI injector.

Table 35. Engine and system comparison for Honda state-of-the-art CHP system and engine used in this research, methane and propane were run on the two-stroke engine.

\begin{tabular}{|c|c|c|c|c|c|c|c|}
\hline & \multicolumn{6}{|c|}{ Engine Performance and Specifications } & $\begin{array}{c}\text { CHP } \\
\text { System }\end{array}$ \\
\hline Cases & $\begin{array}{c}\text { Brake } \\
\text { Power } \\
{[\mathbf{k W}]}\end{array}$ & $\begin{array}{c}\text { Displacement } \\
{\left[\mathbf{c m}^{3}\right]}\end{array}$ & $\begin{array}{c}\text { Engine } \\
\text { Type }\end{array}$ & $\begin{array}{c}\text { Power } \\
\text { density } \\
{[\mathbf{W} /} \\
\left.\mathbf{c m}^{3}\right]\end{array}$ & $\begin{array}{c}\text { Brake } \\
\text { Efficiency } \\
{[\%]}\end{array}$ & $\begin{array}{c}\text { Heat recovery } \\
\text { based on 75\% } \\
\text { effectiveness } \\
{[\%]}\end{array}$ & $\begin{array}{c}\text { Systems } \\
\text { UF } \\
{[\%]}\end{array}$ \\
\hline Methane & 1.53 & 38 & $\begin{array}{c}\text { Two- } \\
\text { stroke }\end{array}$ & 40.3 & 26.5 & 46.4 & 72.9 \\
\hline Propane & 1.66 & 38 & $\begin{array}{c}\text { Two- } \\
\text { stroke }\end{array}$ & 43.7 & 27.7 & 48.4 & 76.1 \\
\hline $\begin{array}{c}\text { Honda Engine } \\
\text { tested on methane }\end{array}$ & 1.38 & 163 & $\begin{array}{c}\text { Four- } \\
\text { Stroke }\end{array}$ & 8.5 & 27.7 & 46.8 & 74.5 \\
\hline
\end{tabular}

Table 36 shows the specific emissions for methane and propane operation for the engine with oxidation catalysts installed. For each case, the peak BTE point with COV of IMEP less than 5\% was selected. Note that non-handled equipment with $\mathrm{V}_{\mathrm{d}}<66$ were in the class I-A engine family and regulated emissions are presented in the last column. Based on these regulations, the current application research engine will pass the regulation. However, given that the engine application would be for power generation, comparing the emissions with power plant data would give a more realistic estimate of the system's impacts. This analysis is presented later in this section.

Table 36. Specific Emissions in $\mathrm{g} / \mathrm{kWhr}$ for all fuels, values represent measurements after DOC catalyst for peak BTE points with COV of IMEP less than 5\%.

\begin{tabular}{|c|c|c|c|}
\hline & Methane & Propane & $\begin{array}{c}\text { Non-handheld equipment } \\
\text { regulations (Class I-A) }\end{array}$ \\
\hline Methane (GHG) & 16.61 & 0.30 & - \\
\hline NMHC & 3.31 & 5.48 & - \\
\hline NO $_{\mathbf{x}}$ & 12.29 & 9.54 & 50 \\
\hline NMHC+NO & 15.59 & 15.02 & 610 \\
\hline $\mathbf{C O}$ & 0.16 & 0.38 & - \\
\hline $\mathbf{C O}_{\mathbf{2}}$ & 696 & 832 & - \\
\hline Equivalent $\mathbf{C O}_{2}$ & 1122 & 858 & - \\
\hline
\end{tabular}


Figure 98 shows the waterfall chart including all the experimental modifications that were validated. The original engine was converted to operate on fumigated NG and yielded an 8\% BTE. Applying intake and exhaust optimization each added around 2\% (absolute, each), making the engine about $12 \%$ efficient. On the original engine, we performed a study on combustion chamber shape and there were improvements in both power density and efficiency [59]. However, the engine brake power was still below $1 \mathrm{~kW}$ even with those improvements. Therefore, we revisited the options for improved engine designs, specifically the cylinder bore, porting, and intake method.

Finally, an engine was selected which had the desired combustion chamber shape, modified transfer ports, added boost port, and reed valve on the crankcase. This is shown as cylinder optimization in the waterfall chart and was obtained by the boosted engine operation that included optimized intake and exhausts, which improved BTE to 15\%. All of the additional modifications were then applied on the boosted engine. Direct injection was expected to improve efficiency dramatically since it was shown that around $38 \%$ of the fuel was slipping with PI operation. LPDI added $9 \%$ to BTE, which improved BTE to $24 \%$. A $1 \mathrm{D}$ simulation and optimization was then performed that targeted an improved multi-variable exhaust design. This 1D optimization yielded an additional increase of about $2 \%$ to the BTE. A 3D simulation was performed to investigate incylinder stratification. It was found that the spark location could be optimized, and that such modifications added another 1.5\% BTE making the engine operate at around $27.4 \%$ BTE. Note that fuel variation was not included in this waterfall chart and BTE could be higher based on the fuel variation study presented before. Peak BTE occurred for CNG2 with $29.6 \%$ brake power from total fuel injected.

Note that some modifications were dual objectives. For example, intake and exhaust optimizations were important for both for efficiency and power density. However, their effect on power density was so high that they could not be eliminated even if they had only marginally improved the efficiency. This is important when a cost analysis discussion is presented. 


\section{BTE EVOLUTION}

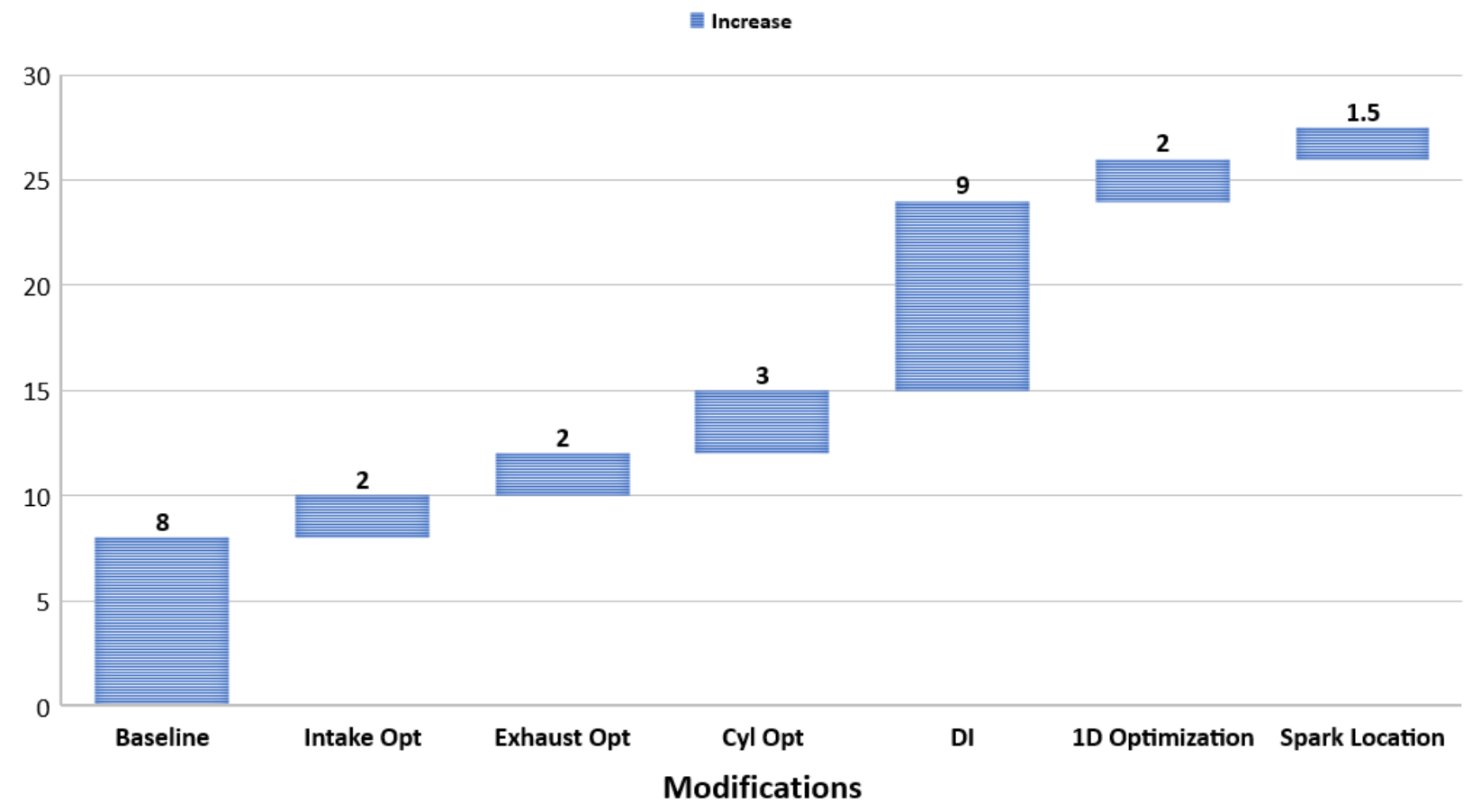

Figure 98. Final waterfall chart showing the evolution of system BTE when each modification was applied. Note - results presented for CNG1.

Figure 99 shows the price stepping chart starting from the baseline up to the most efficient design. A baseline price included $\$ 299$ for the baseline engine and the costs associated with conversion to natural gas - this included the ECU which was $\$ 360$ plus ignition coil setting the baseline price at $\$ 760$. The intake optimization excluded the stock intake and carburetor ( $\$ 45$ for carb, $-\$ 6$ for air filter housing while it added $\$ 60$ for the new intake. Exhaust optimization excluded the stock exhaust for $\$ 9.99$ where it added $\$ 250$ for the new design. For cylinder optimization the difference was between the costs of the stock engine which was \$299 and the full custom engine - \$695. LPDI added $\$ 500$ and spark rotation added $\$ 150$. The final price for a single unit development was \$2055. The estimation of mass production costs of course could be reduced based on economies of scale. Table 37 shows the net cost of each hardware optimization. 


\section{PRICE STEPPING CHART}

를 Increase 를 Decrease

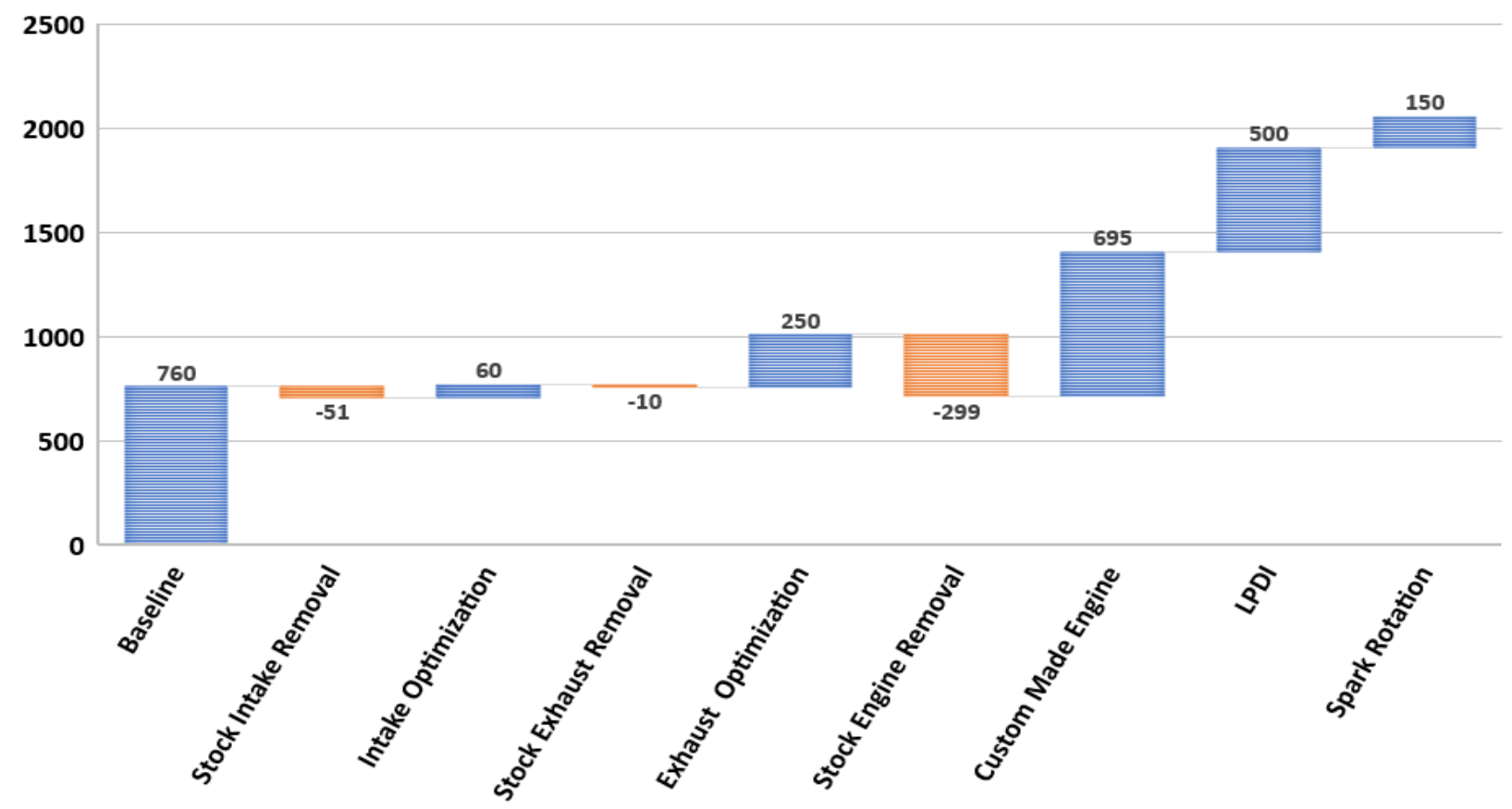

Figure 99. Stepping chart for price evolution for single engine modifications to achieve highest BTE as presented in Figure 98.

Table 37. Net cost of hardware optimization for engine optimization.

\begin{tabular}{|c|c|c|}
\hline & Net added Cost [\$] & Engine Cost [\$] \\
\hline Baseline & & 760 \\
\hline Intake Optimization & 10 & 770 \\
\hline Exhaust Optimization & 240 & 1010 \\
\hline Cylinder Optimization & 395 & 1405 \\
\hline LPDI & 500 & 1905 \\
\hline 1D Optimization & 0 & 1905 \\
\hline Spark Location & 150 & 2055 \\
\hline
\end{tabular}

Due to similar nature of optimization for the same color highlighted rows in Table 37, they were merged together and used in Table 38 for a cost analysis. This meant that spark location optimization was merged into cylinder optimization and 1D optimization was merged with exhaust optimization. 
According to US Energy Information Administration (EIA), the annual average price of natural gas delivered to residential customers was between 10 to 11 US dollars per 1000 cubic feet (\$/MCF) over the past 5 years [153] [154]. A median value of $\$ 10.50$ was used for this cost analysis. EIA performed a residential energy consumption in 2015, including 118.2 million homes in US. Average annual electricity usage was $10,720 \mathrm{~kW}$-hr or equivalent to $1.24 \mathrm{~kW}$ constant usage throughout the year [155]. This average power value was used for calculating the fuel cost necessary to produce it.

Intake optimization, exhaust optimization, and LPDI needed additional hardware installation on the final engine design. Therefore, each of these changes were separately applied to the baseline to isolate each change. Each of these modifications were applied separately to the baseline and savings and return of investment (ROI) were calculated. Note that results from 1D optimization of exhaust was merged with empirical exhaust optimization and result for spark plug location optimization was merged with cylinder optimization for a simpler comparison. Results showed that LPDI had the highest potential in savings. Intake optimization had the quickest return on investment (ROI), while exhaust optimization and LPDI showed similar ROI values.

Table 38. Cost analysis of three major modifications on the engine, based on $1.24 \mathrm{~kW}$ output for one year 24/7 operation.

\begin{tabular}{|c|c|c|c|c|c|}
\hline & BTE [\%] & $\begin{array}{c}\text { Fuel needed for } \\
\mathbf{1 0 , 7 2 0 ~ k W h} \\
\text { engine output } \\
{\left[\mathbf{f t}^{\mathbf{3}} \text { ] }\right.}\end{array}$ & $\begin{array}{c}\text { Annual fuel } \\
\text { cost [\$] }\end{array}$ & $\begin{array}{c}\text { Saving/ } \\
\text { year [\$] }\end{array}$ & $\begin{array}{c}\text { ROI } \\
\text { [years] }\end{array}$ \\
\hline Baseline & 8.00 & 526,597 & 5529 & & - \\
\hline $\begin{array}{c}\text { Only Intake Optimization } \\
\text { Applied to Baseline }\end{array}$ & 10.00 & 421,277 & 4423 & 1106 & 0.01 \\
\hline $\begin{array}{c}\text { Only Exhaust Optimization } \\
\text { Applied to Baseline }\end{array}$ & 11.20 & 376,140 & 3949 & 1580 & 0.16 \\
\hline $\begin{array}{c}\text { Cylinder Optimization } \\
\text { Applied to Baseline }\end{array}$ & 10.57 & 398,506 & 4184 & 1345 & 0.29 \\
\hline $\begin{array}{c}\text { LPDI Applied to Baseline } \\
\text { All together Applied to } \\
\text { Baseline }\end{array}$ & 11.89 & 354,256 & 3720 & 1810 & 0.28 \\
\hline \multicolumn{1}{|c|}{} & 27.50 & 153,192 & 1609 & 3921 & 0.19 \\
\hline
\end{tabular}

To analyze how the optimized engine performed in terms of cost and emissions, when compared to current energy providers a large-scale comparison was performed. To form proper combinations 
of energy sources used in residential applications, a simplified matrix based on possible combinations in Table 39. This formed the way following analysis plots were generated. Note that with GENSETS it was considered that both electric and heat for a home would be provided by the micro-CHP system.

Table 39. Simplified energy source combination of residential applications for cost and emission analysis.

\begin{tabular}{|c|c|c|c|c|}
\hline \multicolumn{2}{|c|}{ All Energy } & \multicolumn{2}{c|}{ Electricity Source } \\
\cline { 2 - 3 } & $\begin{array}{c}\text { Average electric } \\
\text { (From NG and coal } \\
\text { power plants) }\end{array}$ & \\
\hline \multirow{4}{*}{ Heat Source } & $\begin{array}{c}\text { Average electric (From } \\
\text { NG and coal power } \\
\text { plants) }\end{array}$ & $\begin{array}{c}\text { State1: Electric+ } \\
\text { Electric Heat }\end{array}$ & $\begin{array}{c}\text { GENSETS } \\
\text { Operating on } \\
\text { NG engine }\end{array}$ & $\begin{array}{c}\text { GENSETS } \\
\text { operating on } \\
\text { Propane } \\
\text { engine }\end{array}$ \\
\cline { 2 - 3 } & Pipeline NG & $\begin{array}{c}\text { State 2: Electric+ } \\
\text { NG Heat }\end{array}$ & \\
\cline { 2 - 3 } & Propane & $\begin{array}{c}\text { State 3: Electric+ } \\
\text { Propane Heat }\end{array}$ & \\
\hline
\end{tabular}

To simplify the matrix, cost and emissions for coal and NG power plants were averaged in most plots. In addition, to obtain electricity and emissions output from the current optimized system, a generator and transmission efficiency of $86 \%$ and $94 \%$ were applied to engine power output respectively as performed in literature [125]. Note that the data for NG and propane operation were obtained from after catalyst installation experiments operating on methane and propane, respectively.

Figure 100 shows the cost analysis for electricity generation from the current system operating on NG and propane when compared to average energy from the electric grid. The cost of electricity generation was $\$ 1125$ for grid electric where it was $\$ 1826$ and $\$ 4991$ for NG and propane, respectively. For electricity use only, the current grid price showed an advantage. 


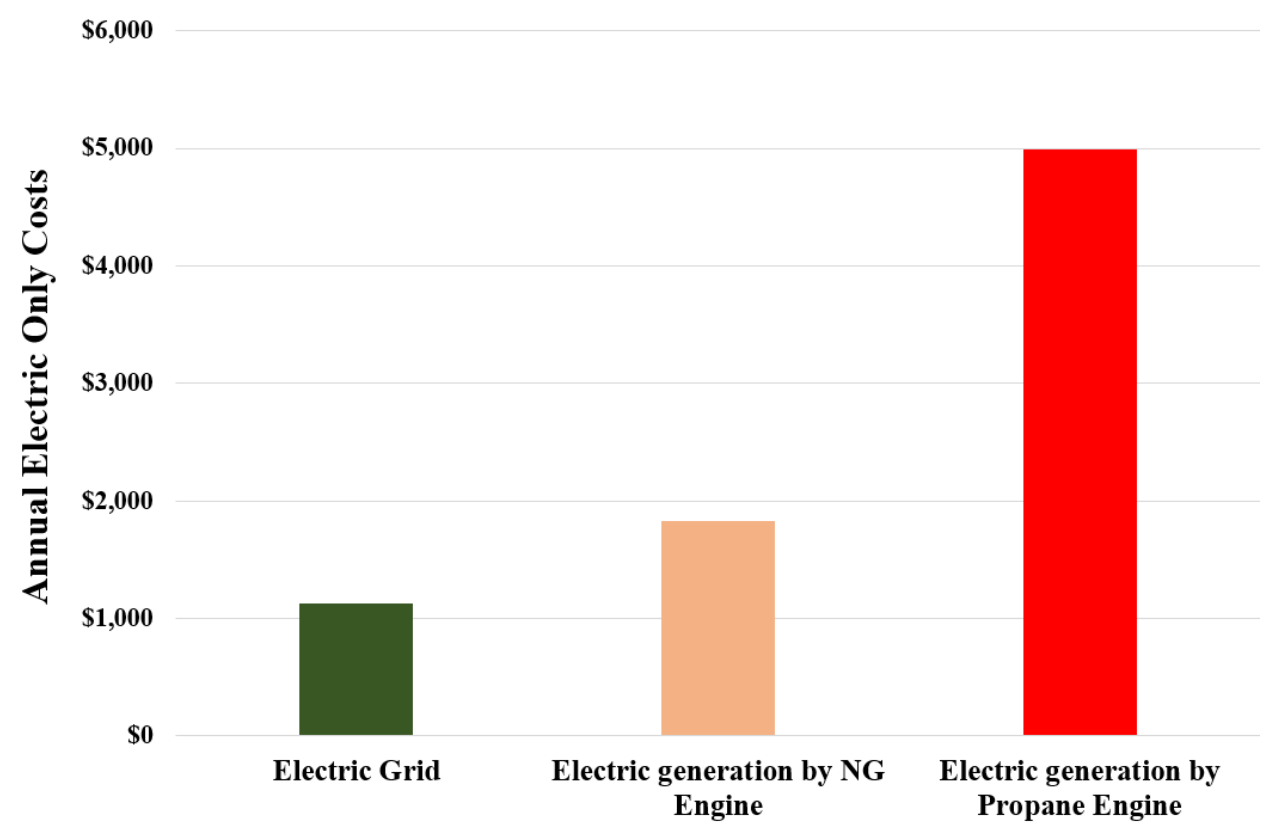

Figure 100. Electric generation cost from grid, NG engine and propane engine, engine is referred to the current research engine.

When including the heat energy in the analysis, the current system showed improved potential with NG operation as shown in Figure 101. Note that electric was referred to as the average value from coal and natural gas power plants. Analyses showed that using grid electric plus NG heat would result in a cost of $\$ 1723$ for annual energy consumption of 10,720 kW-hr. Based on $75 \%$ waste heat recovery (WHR) assumptions form literature, 94\% transmission efficiency, and 86\% generator efficiency the current engine operating on NG could result into \$1826 annual cost, yielding lower annual energy costs than two conventional cases shown in Figure 101. 


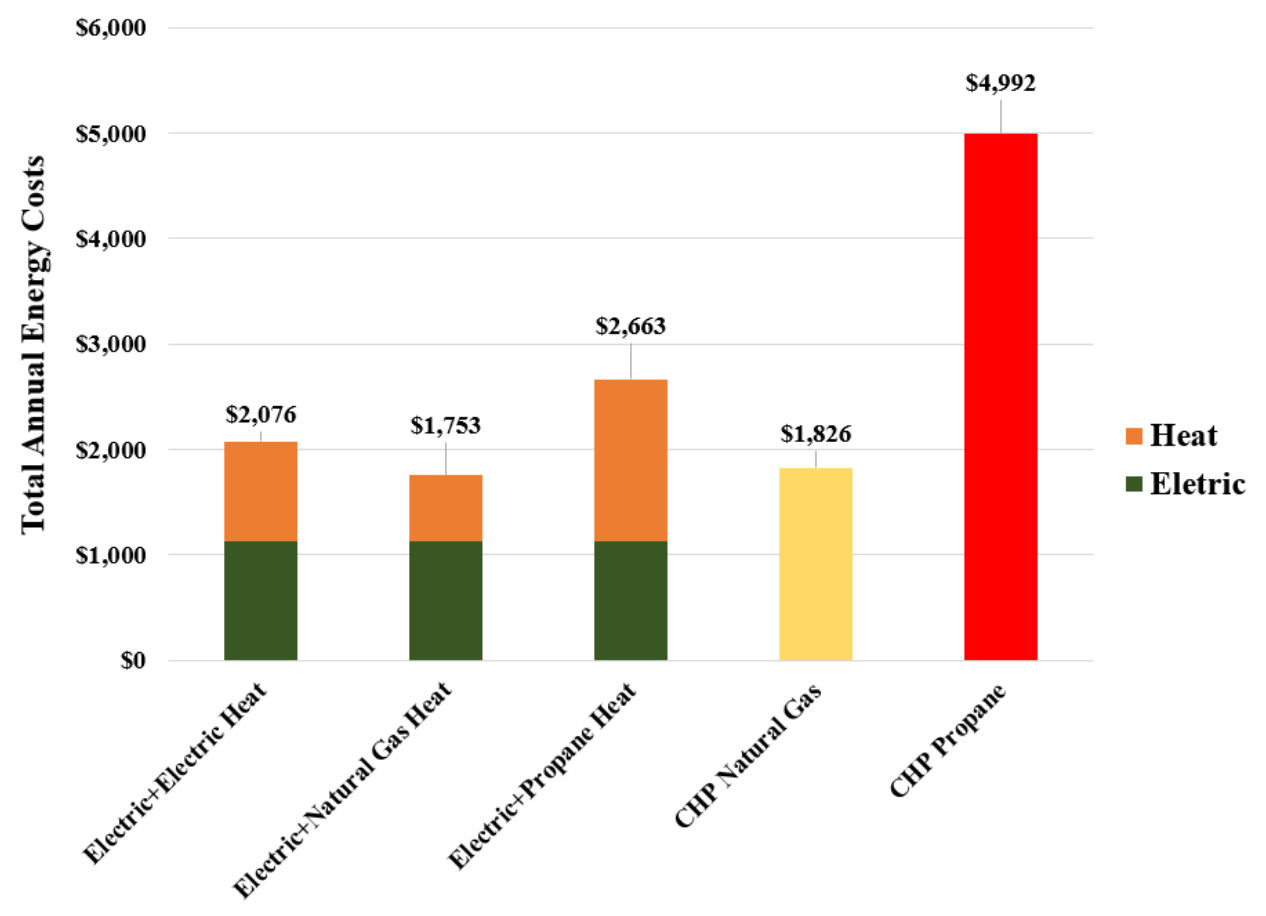

Figure 101. Total energy cost form different source of heat for homes.

As for emissions, $\mathrm{CO}_{2}$ equivalent and $\mathrm{NO}_{\mathrm{x}}$ in metric tons were calculated for power plants, $\mathrm{NG}$, and propane operation on the current engine. Figure 102 shows the $\mathrm{CO}_{2}$ equivalent results from different sources of energy for total energy consumption per year. In all bars the assumption was that the electric was provided from average value of the grid reported by coal and NG power plants. The difference of bars in each case was the energy source used for heat. If electric was used as the heat source, it showed that it would increase the $\mathrm{CO}_{2}$ emissions. Using $\mathrm{NG}$ as the heat source proved to be the best option when using grid electricity. Methane and propane lines show the carbon footprint lines if the current engine drives a CHP system to provide the total energy of the home. The 'Coal and Coal' line was worst case scenario when the conventional electric and electric for winter heating were both provided by a coal power plant. Note that government data did include powerplants that were combined cycle. 


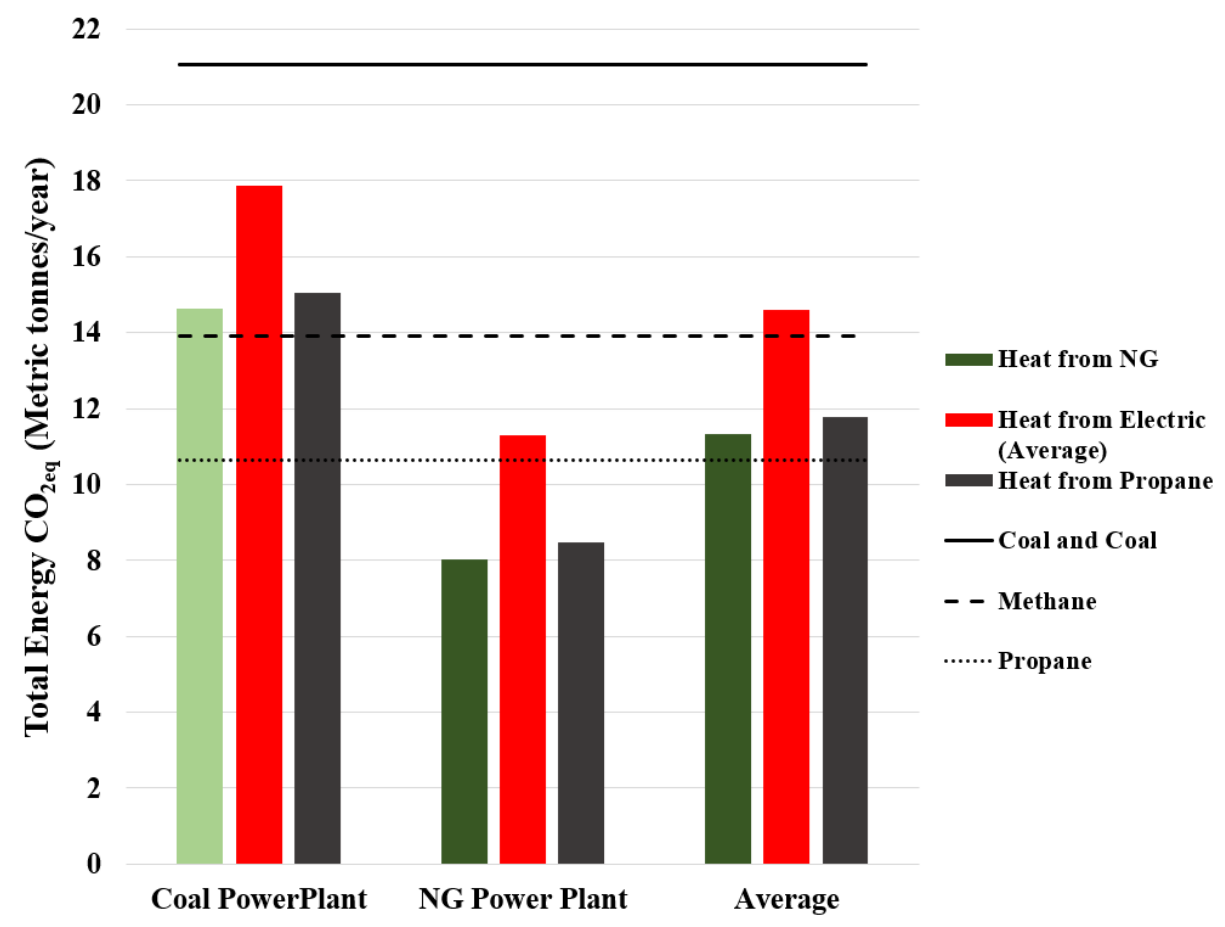

Figure 102. $\mathrm{CO}_{2}$ equivalent results for different sources of total energy.

Figure 103 shows the $\mathrm{NO}_{\mathrm{x}}$ emissions in metric tonnes per year, for different energy sources. The current grid average showed an average value of 0.018 tonnes per year to produce $10,720 \mathrm{kWh}$. Note that government power plant data included sites where aftertreatment systems were deployed [156]. So, the lower $\mathrm{NO}_{\mathrm{x}}$ included sites that deployed SCR and our engine can achieve lower $\mathrm{NO}_{\mathrm{x}}$ with a similar $\mathrm{NO}_{\mathrm{x}}$ reduction strategy. The current engine showed 0.152 and 0.118 metric tonnes for methane and propane operations, respectively. This means that for this engine to meet the current power plant $\mathrm{NO}_{\mathrm{x}}$ emissions levels, an SCR system with conversion efficiency of above $88 \%$ would be required. Achieving this range of conversion efficiency is possible with the right combination of exhaust temperatures and SCR material. Copper based SCRs have shown above $90 \%$ conversion efficiency at inlet temperatures of 200 to $330{ }^{\circ} \mathrm{C}$, while iron SCRs have shown above $90 \%$ conversion efficiency at temperatures of 330 to $530{ }^{\circ} \mathrm{C}$ [157]. Note that due to presence of excessive oxygen in the exhaust flow in two-stroke engines, the implementation of three-way catalysts would not be effective. 


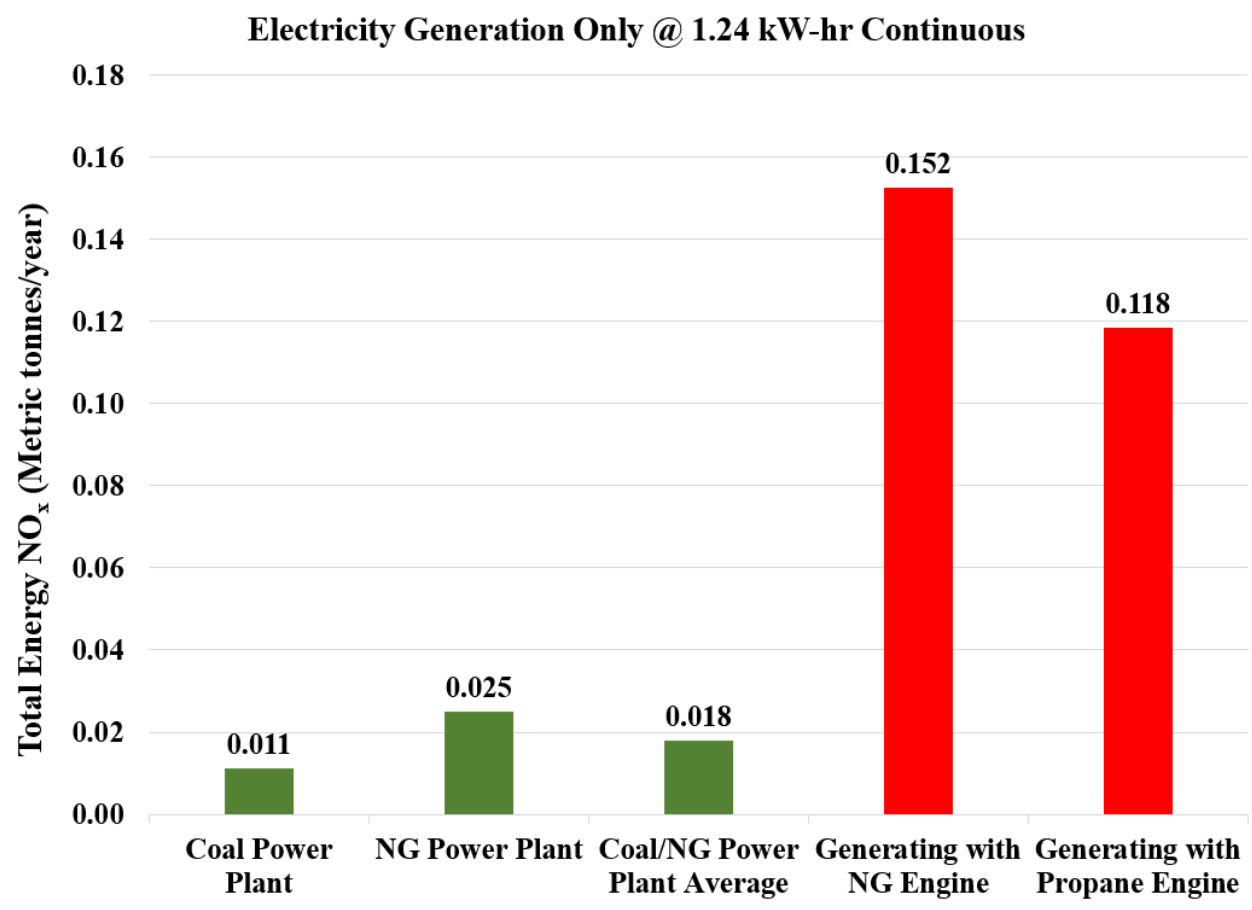

Figure 103. $\mathrm{NO}_{\mathrm{x}}$ emissions from different sources of energy providing total energy of a home in a year. 


\section{Conclusions and Framework}

\subsection{Summary}

The objective of this research was to use literature, experiments, and 1D and 3D models to optimize the energy efficiency of a NG two-stroke engine for CHP applications. Based on the results of these efforts a general framework was developed which can serve as a tool for other researchers and industry. The goal was to use the optimized engine design in the GENSETS application.

An experimental laboratory was developed to measure system performance and emissions. Incylinder, crankcase, and exhaust pressures were recorded in crank angle resolution by Kistler ${ }^{\mathrm{TM}}$ Kibox. Low frequency $(1-10 \mathrm{~Hz})$ data including mass flows, temperatures, dynamometer, and emission analyzers outputs were measured using an in-house software. The engine was controlled by an open source ECU and its software. Most of the slider crank engine experiments were performed at 5400 RPM. A data analysis platform was developed to combine both high and low frequency data for analysis. This included basic calculations, carbon balance, energy distribution and more. Experiments started with gasoline engine that was converted to operate electronically with an ECU on and using NG. Optimization initially started with intake, exhaust, and cylinder designs mostly from literature recommendations. Then a thorough experimental investigation was performed for LPDI operation. After implementing LPDI, a proper baseline was identified for 1D system simulations and used for exhaust resonator optimization using a genetic algorithm in GTPower ${ }^{\mathrm{TM}}$. These new data served as a baseline for subsequent CFD simulations. In 3D simulations, gas dynamic effects on fuel trapping and charge stratification within the cylinder were investigated and spark plug location was optimized. This step closed the optimization efforts and direction moved toward assessment of gaseous fuel composition impacts on the system performance considering the engine as an energy source for a micro-CHP system. Two natural gas blends, pure methane, and pure propane were tested and analyzed. An oxidation catalyst was then added, and pure methane and propane were tested representing both ends of the gaseous fuel spectrum. Finally, a techno-economic analysis was performed to determine the potential of the system in energy markets and to highlight the cost benefits of major framework steps. 


\subsection{Major Conclusions}

- A framework for energy optimization of small two-stroke engines for micro-CHP application was developed. Following this framework, a relatively simple LPDI two-stroke engine can achieve similar performance as an advanced over expanded four-stroke engine at much smaller size. The framework may more than triple the BTE compared to conventional two-stroke designs.

- The best case BTE was achieved by CNG2 showing 29.6\% This was lower than ARPA-E target. However, looking at the state-of-the-art micro-CHP system's engine, it was at $27 \%$ BTE. This is the common issue in this size engines that they suffer from high heat transfer in the order of $35 \%$ of total fuel energy [135]. This is where bigger size engines with around $500 \mathrm{cc}$ displacement per cylinder, see below $20 \%$ of total fuel energy lost as heat transfer [51].

- NG port fuel operation with no intake and exhaust optimization was only at 8\% BTE.

- Intake optimization increased the power by a factor of 2.17 , delivery ratio by $80 \%$ and BTE by $25 \%$, relatively.

- Exhaust optimization from literature recommendations and commercially available components improved the BTE $20 \%$ relative to non-optimized stock exhaust operating on PI. It showed 40-65\% relative improvements in delivery ratio dependent upon design and adjustments for peak power. It was observed that if the design target is maximizing trapping ratio, one must sacrifice some delivery ratio gains.

- With new cylinder including the head optimization, added boost port, enlarged bore, and modified transfer ports, BTE by $25 \%$ relative to baseline engine. It was observed that delivery ratio increased relatively $20 \%$ and power density increased by $25 \%$.

- LPDI increased the BTE by $60 \%$ relative to PI, recovering most of the slipped fuel, owing to a higher efficiency and balanced energy distribution which improved UF. 
- A 1D simulation optimization showed another relative increase in BTE of $8.3 \%$ compared to literature recommended exhaust designs. When combining effects of $1 \mathrm{D}$ simulation optimization with recommended literature designs, BTE increased by $40 \%$ non-optimized stock exhaust operating on PI.

- While literature's rule of thumb was mostly focused on one factor (independent variable) and objective at a time, 1D simulation was able to combine all factors and find the best combination within the design space for variety of objectives which in this case was thermal efficiency.

- A 3D CFD model helped with spark plug location optimization based on charge stratification at spark timing, yielded an additional relative increase of 5.7\% for BTE when compared to non-optimized location. This impact was attributed in the form of chemical energy recovery and more complete combustion. It decreased the combustion duration by more than $20 \%$ when compared to non-optimized location. In optimizing spark location, engine speed impacts the charge stratification in the cylinder and spark timing determines at what crank angle degree one must examine the charge distribution for spark plug placement. The benefits shown here were for engine speeds of 5400 RPM and spark timing at 26 CAD BTDC.

- In fuel variation tests, denser NGs with higher alkanes showed higher BTE mostly due to lower incomplete combustion and unburnt products. Propane showed the highest power density and higher heat available for CHP systems. This made its UF to be the highest among fuels tested.

- In oxidation catalyst tests, it was shown that except for rich cases of propane operation, a platinum only oxidation catalyst did not have any major effect on HC oxidation. However, the catalyst added heat from 2 to $6 \%$ for methane and propane, which would translate to an improved UF which more than offsets slight reductions in brake thermal efficiency.

- With $75 \%$ heat exchanger effectiveness and available heat from experiments, this size engine can supply up to $24,000 \mathrm{kWh}$ heat for a year while generating $10,720 \mathrm{kWh}$ of electricity. Six month average US winter heat energy was reported around 14,000 kWh. 
This shows that this system may be capable of meeting the required heat for home while supplying the needed electric power.

- With optimal spark location, even with a stratified mixture, a highly stable combustion (COV of IMEP less than 5\%) with at least $20 \%$ faster combustion was achieved.

- Applying LPDI resulted in the largest reduction in fuel costs to produce $10,720 \mathrm{kWh}$ (US annual average electricity). It would have saved $\$ 1810$ on NG price when compared to PI operation. Exhaust optimization (including 1D simulations), cylinder optimization (including spark location), and intake were next in the line for savings. Total savings on fuel cost with all optimization applied was estimated as \$3910 annually.

- If class I-A emissions regulations for non-handheld devices was a compliance metric, the optimized engine was compliant with regulations. However, one should note for this category only $\mathrm{HC}+\mathrm{NO}_{\mathrm{x}}$ and $\mathrm{CO}$ are regulated whereas in power generation all data including $\mathrm{CO}_{2}$ equivalents and $\mathrm{NO}_{\mathrm{x}}$ were important.

- When comparing $\mathrm{CO}_{2}$ equivalent to data from coal and NG power plants, depending on different combinations of heat source for the home, this optimized engine could serve as the prime mover for a micro-CHP system with better performance. With coal power plant electric and any other source for heat, the optimized engine had lower $\mathrm{CO}_{2}$ emissions for both methane and propane. If all heat was provided by the average value for coal or NG power plants, the system would still emit less $\mathrm{CO}_{2}$ equivalent emissions.

- When comparing the $\mathrm{NO}_{\mathrm{x}}$ emissions with power plant data, the conclusion was that the engine operating on $\mathrm{NG}$ would require an SCR with $84 \%$ or more $\mathrm{NO}_{\mathrm{x}}$ conversion efficiency to perform equally or better than current power plants (many of which employ similar SCR technologies). This value was $88 \%$ for propane operation. Copper SCR systems have their peak conversion efficiency at lower temperature when compared to iron SCR and would likely perform well given the ranges of experimental exhaust temperatures.

- As for the cost of energy per year based on 10,720 kWh annual consumption, the optimized engine would operate very close to the current cheapest energy source combination, which was using average electric from the grid and NG for heating purposes. This would cost $\$ 1753$ while the optimized micro-CHP system providing the total energy of the house with 
NG, would cost $\$ 1826$ on fuel standing lower than any other common combinations. Propane operation could cost up to $\$ 4992$ so, it did not seem like a viable option for large scale deployment except to serve remote, off-the-grid locations where it was the only available energy source. 


\subsection{Framework}

Using a combination of experimental and modeling research combined with literature, I have developed a framework for optimization of micro-CHP applications that use gaseous fuels and two-stroke combustion cylinders. This general framework can be used by researchers and industry as a set of "rules of thumb or guidelines" for the design or modification of small engines that could serve as the prime movers of micro-CHP systems. Following these guidelines will significantly improve the utilization factor and performance of a micro-CHP system by improving efficiency, reducing emissions, maximizing useable heat, and improving combustion stability.

Note that this optimization focused on an application where power, stroke, and frequency were defined as fixed targets. Stroke and frequency limitations were imposed by nature of future application to oscillating linear alternators whereby frequency and stroke are limiting design factors. Included in this framework are empirical elements from literature that should be included when a set of initial design variables may be more flexible.

\section{1). General Engine Design or Selection}

- It was shown that increased speed enabled improved efficiency mainly from a reduction in heat loss. Reciprocating speed impacts on wear/durability and electrical generation speed and efficiency must be investigated.

- Power density - engine design should include a boost port and reed valves, as they are often excluded for small engines which would serve micro-CHP systems.

\section{2). Operation requirements}

- This framework requires electronic control of the engines, which is typically neglected for engines of this displacement range. This requires proper hardware and calibrations for robustness. A trigger wheel with ability to discretize each revolution to at least $10 \mathrm{CAD}$ intervals and an ECU. The ECU can achieve higher resolutions by interpolating and be used for high resolution control of ignition and injection (0.1 of CAD). 


\section{3). Intake Optimization for Improved Breathing}

- Literature estimates that intake resonators with frequency about 2 times the piston frequency should yield the highest improvement in delivery ratio and power. This was confirmed in this work with laboratory experiments as well as improvement in BTE.

\section{4). Exhaust Optimization for Further Improvements in Breathing}

- Literature suggested methods for designing exhaust resonators with the aim of improved power density, however, exhaust tuning was also demonstrated as important for efficiency optimization.

- Rules of thumb in literature can be used with commercially available components following Helmholtz theory to improve delivery ratio and trapping efficiency.

- More improvements can be made with slight geometric adjustments. A 1D simulation can be used to determine a design that provides further improvements. This served as a costeffective method (even though it required experimental efforts) because the final optimized design would be used for mass production of system components.

\section{5). Cylinder Design Optimization}

- Head design is recommended such that it is dome shape and dome's area is $50 \%$ of the bore area. The idea is to minimize the squish band volume and improve the combustion efficiency (reducing flame quenching). In the experiments it was observed that it could increase BTE by $10 \%$ relative improvements in the BTE and power density.

- A boost port is recommended by literature to increase the scavenging efficiency and tumble motion for a better mixing and this was confirmed here for small displacement two stroke engines.

- Transfer port area and angle are considered as impactful parameters for delivery ratio and mixing by literature and were validated with a custom design.

- Exhaust port timing and area is identified by literature as impactful for both delivery ratio and trapping ratio due to its direct interaction with exhaust resonator. 


\section{6). Low-Pressure Direct Injection}

- Outwardly opening poppet style air injectors can serve as the basis for delivery of gaseous fuels onto small-displacement two-stroke engines as a method to simultaneously reduce emissions and improve efficiency. Such a physical design enables the use of low gas pressures which are more likely available and would negate additional compression work.

- Due to overlap of scavenging and injection event in LPDI operation, controlling SOI was of high importance for highest trapping ratio.

- DOI affects the injected plume penetration, charge stratification, and injector's ability to inject fast enough with engine's high speed. For engines of this size and speed with current commercial injectors, a fine balance must be selected. Note that an engine speed 5400 RPM combined with a short stroke $(30 \mathrm{~mm})$ there were only 11 milli seconds in an engine revolution. Total injection durations for this work were on the order of 1 milli second.

- Subtle ignition timing control is needed for maximum power output and best efficiency.

\section{7). Optimal Spark Plug Placement}

- CFD simulation showed that with LPDI, charge stratification investigations with crank angle resolution were necessary to find the optimal location for spark plug based on MBT timing and operating speed. Engine speed and fuel composition are two important parameters affecting the details of stratification in this study. Note that in addition to speed and timing, fuel characteristics should be examined to ensure accurate modeling of stratification.

- In experiments spark plug modification improved brake power, delivery ratio, combustion efficiency, and BTE.

\section{8). CHP Analysis}

- An oxidation catalyst added to the total recoverable heat from engine operation - 2-6\% of total fuel energy for methane and propane. With $75 \%$ heat exchanger effectiveness this additional recovered heat would be added to CHP system's UF. 
Note that the order in this framework matters. Engine selection effects all optimizations that follow. Intake optimization should take place first since it does not interact with the cylinder directly unlike exhaust resonator (especially where reed valves are implemented). Exhaust resonator optimization is recommended second to provide the best wave resonance for improving the cylinder trapping ratio. Cylinder optimization and LPDI can be completed together to optimize mixing. Cylinder optimization would help the power density, combustion efficiency and lower heat transfer. The LPDI strategy must be selected based on engine size and its scavenging paradigm. Completing these steps, a reasonable baseline would be formed for system simulation and optimization. Following the system optimization, CFD investigations for further optimization should be performed. 


\subsection{Recommendations}

Initially, the outcomes of this research were to be transferred to an oscillating linear engine alternator. By the end of this dissertation the transition to linear engine has not happened. There are few recommendations when transferring this framework to the linear engine:

- Linear engine scavenging must be revisited with CFD and compared to slider crank engine. This is simply because linear engine piston velocity profiles are different than slider crank engines. This can be addressed with confidence, with additional CFD modeling.

- Linear engines have the ability to obtain variable compression ratios and its control in terms of combustion stability is more challenging. MBT timing and injection timing control should be revisited after transferring to the linear engine.

- If the linear engine operates at a different frequency compared the slider crank, the framework should be followed to achieve peak efficiency at the desired frequency. Note that for small variations in frequency, efficiency would not change dramatically but speed does impact multiple operating parameters.

As for slider crank research, a wide range of technology and hardware screening was performed to improve the BTE of a small displacement two-stroke engine to $27.5 \%$. However, there are still some areas that could receive more attention for further improvements in the future.

- Note that this research effort was not completely exhaustive and further improvements could likely be made using subtle port and timing modifications by additional 1D and 3D simulations.

- Currently, due to central injection, the spark had to mounted at an angle. However, combustion chamber shape was designed for a centrally installed spark plug. A comprehensive cylinder head optimization by CFD study should be performed to optimize the shape of the combustion chamber as well as spark plug and injector locations. 
- For steady state operation and a given speed, further CFD modeling would help in further optimizing the port timing. For exhaust port timing optimization, a co-simulation of 1D and 3D CFD is recommended.

- An investigation on how much additional EGR can help to reduce the $\mathrm{NO}_{\mathrm{x}}$ seems to be very crucial given the high $\mathrm{NO}_{\mathrm{x}}$ level of the engine. If found effective, a new round of optimization can be performed to optimize the EGR level for minimizing the $\mathrm{NO}_{\mathrm{x}}$. Alternatively, an SCR system with conversion efficiency above $88 \%$ will allow the microCHP system to provide annual total energy of a home with equal or better $\mathrm{NO}_{\mathrm{x}}$ than current power plants. This engine did not show any $\mathrm{NH}_{3}$ in the exhaust so passive SCR would likely not be an option for $\mathrm{NO}_{\mathrm{x}}$ reduction.

- Given that copper SCRs have their peak conversion efficiency at lower temperatures when compared to iron SCRs, a study of after-treatment configuration would help to find the correct placement for SCR and oxidation catalyst to ensure proper light-off, proper resonator temperature, and heat recovery.

- With the high amount of heat transfer for all fuels, applying a thermal barrier coating to cylinder head and piston crown, should be investigated in the future. This will likely enhance the heat content in the exhaust for waste heat recovery and may improve catalyst oxidation of HCs.

- Research should examine implementing a knock sensor or other novel approach to find the MBT ignition timing based on fuel quality variation. In this case, the knock sensor response should be used to determine the best combustion phasing which can represent a few percent change in BTE. 


\section{References}

[1] Lawrence Livermore National Laboratory, "Energy Flow Charts," Department of Energy, 2015. [Online]. Available: https://flowcharts.llnl.gov/. [Accessed: 06-Feb-2019].

[2] Energy Information Administration, "Electricity - Energy Explained, Your Guide To Understanding Energy," U.S. Energy Information Administration (EIA). 2015. [Online]. Available: https://www.eia.gov/energyexplained/?page=us_energy_home. [Accessed: 06-Feb2019].

[3] F. C. Barbosa, "Natural Gas and Biogas Use in Transit Bus Fleets - A Technical, Operational and Environmental Approach,” 23rd SAE Brazil International Congress and Display, Technical Paper 2014-36-0194, 2014.

[4] E. Ansari, M. Shahbakhti, and J. Naber, "Optimization of performance and operational cost for a dual mode diesel-natural gas RCCI and diesel combustion engine,” Applied Energy, vol. 231, pp. 549-561, 2018.

[5] Advanced Research Projects Administration - Energy, "MOVE," 2012. [Online]. Available: https://arpa-e.energy.gov/?q=arpa-e-programs/move. [Accessed: 03-Feb-2019].

[6] American Gas Association, "About Natural Gas." [Online]. Available: https://www.aga.org/about-natural-gas. [Accessed: 03-Feb-2019].

[7] Advanced Research Projects Administration - Energy, "GENSETS.” [Online]. Available: https://arpa-e.energy.gov/?q=arpa-e-programs/gensets. [Accessed: 02-Feb-2019].

[8] US Energy Information Administration, "How much electricity does an American home use," 2011. [Online]. Available: http://www.eia.gov/tools/faqs/faq.cfm?id=97\&t=3. [Accessed: 03-Feb-2019].

[9] US Energy Information Administration, "Residential energy consumption survey," 2017. [Online]. Available: https://www.eia.gov/consumption/residential/reports/2015/overview/index.php?src=< Consumption Residential Energy Consumption Survey (RECS)-f3. [Accessed: 03-Feb-2019]. 
[10] J. B. Heywood, Two-Stroke Cycle Engine: It's Development, Operation and Design. Taylor \& Francis Group, New York, NY, 1999.

[11] N. Z. Meymian, N. N. Clark, T. Musho, M. Darzi, D. Johnson, and P. Famouri, “An optimization method for flexural bearing design for high-stroke high-frequency applications," Cryogenics., vol. 95, no. June, pp. 82-94, 2018.

[12] M. Nuti, Emissions from Two-Stroke Engines. SAE International, Warrendale, PA, 1998.

[13] E. G. Groff, “Automotive Two-Stroke-Cycle Engine Development in the 1980-1990's," SAE Technical Paper 2016-01-0177, 2016.

[14] C. J. Ulishney, "Experimental Design, Testing, and Evaluation of Methods to Improve the Efficiency and Reduce Emissions from a Small Two-stroke Natural Gas Engine," West Virginia University, Thesis, 2018.

[15] J. L. Banks, "National Emissions from Lawn and Garden Equipment," US Environmental Protection Agency, Boston, MA, 2015.

[16] B. Auler, J. Rodenbeck, J. Lügger, and E. Gorenflo, "Oil-in-gasoline lubricated onecylinder four-stroke engine for chainsaws," Journal of MTZ Worldwide., vol. 66, no. 6, pp. 1214, Jun. 2005.

[17] Farmers Guide, "3-Fuel-injected chainsaw for easier starting and better economy _ Farmers Guide." [Online]. Available: https://www.farmersguide.co.uk/2018/04/fuel-injected-chainsawfor-easier-starting-and-better-economy/. [Accessed: 02-Feb-2019].

[18] G. P. Blair, Design and Simulation of Two-Stroke Engines. SAE International, Warrendale, PA, 1996.

[19] J. B. Heywood, Internal Combustion Engine Fundamentals. New York, N.Y.: McGraw Hill, 1988.

[20] A. Boretti and J. Scalzo, “A Novel Valve-Less Supercharged Small Two-stroke Engine of Top Brake Efficiency Above 36\% and Power Density above $100 \mathrm{KW} /$ Liter," 8th SAEINDIA International Mobility Conference \& Exposition and Commercial Vehicle Engineering Congress (SIMCOMVEC), 2013. 
[21] Q. Xiong, Y. Moriyoshi, K. Morikawa, Y. takahashi, T. Kuboyama, and T. Yamada, "Improvement in Thermal Efficiency of Lean Burn Pre-Chamber Natural Gas Engine by Optimization of Combustion System," SAE Technical Paper 2017-01-0782, 2017.

[22] V. Pradeep, S. Bakshi, and A. Ramesh, "Direct injection of gaseous LPG in a two-stroke SI engine for improved performance,” Applied Thermal Engineering, vol. 89, pp. 738-747, 2015.

[23] N. Baijal, "Basics of Marine Engineering." [Online]. Available: http://basicsofmarineengineering.blogspot.com/. [Accessed: 03-Sep-2019].

[24] A. Trattner, S. Schmidt, R. Kirchberger, H. Eichlseder, A. Kölmel, M. Raffenberg and T. Gegg "Future Engine Technology in Hand-Held Power Tools." SAE International Journal of Engines, vol. 5, no. 4, Oct-2012, pp. 1912-1929.

[25] R. Chandra, V. K. Vijay, P. M. V Subbarao, and T. K. Khura, "Performance evaluation of a constant speed IC engine on CNG, methane enriched biogas and biogas," Applied Energy, vol. 88, no. 11, pp. 3969-3977, 2011.

[26] A. Yousefi and M. Birouk, "Investigation of natural gas energy fraction and injection timing on the performance and emissions of a dual-fuel engine with pre-combustion chamber under low engine load,” Applied Energy, vol. 189, pp. 492-505, 2017.

[27] E. Shim, H. Park, and C. Bae, "Intake air strategy for low HC and CO emissions in dualfuel (CNG-diesel) premixed charge compression ignition engine,” Applied Energy, vol. 225, pp. 1068-1077, 2018.

[28] E. Navarro, T. J. Leo, and R. Corral, "CO2 emissions from a spark ignition engine operating on natural gas-hydrogen blends (HCNG)," Applied Energy, vol. 101, pp. 112-120, 2013.

[29] J. Zheng and J. A. Caton, "Second law analysis of a low temperature combustion diesel engine: Effect of injection timing and exhaust gas recirculation," Energy, vol. 38, no. 1, pp. 7884, 2012.

[30] A. Alamia, I. Magnusson, F. Johnsson, and H. Thunman, "Well-to-wheel analysis of biomethane via gasification, in heavy duty engines within the transport sector of the European Union," Applied Energy, vol. 170, pp. 445-454, 2016. 
[31] X. Kan, D. Zhou, W. Yang, X. Zhai, and C.-H. Wang, "An investigation on utilization of biogas and syngas produced from biomass waste in premixed spark ignition engine," Applied Energy, vol. 212, pp. 210-222, 2018.

[32] B. Yang, C. Xi, X. Wei, K. Zeng, and M.-C. Lai, "Parametric investigation of natural gas port injection and diesel pilot injection on the combustion and emissions of a turbocharged common rail dual-fuel engine at low load," Applied Energy, vol. 143, pp. 130-137, 2015.

[33] G. Jennings, Two-Stroke Tuner's Handbook: Fundamentals, the crank train, cylinder heads, expansion champers, cylinder scavenging, port timing, crankcase pumping, carburetion, ignition. 2007.

[34] M. C. Besch, A. N. Covington, D. Johnson, N. Fowler, and R. Heltzel, "Effects of EGR Addition onto Combustion Stability and Alternator Performance Variability of a Small, SingleCylinder Diesel Generator,” SAE Technical Paper 2016-32-0063, 2016.

[35] W. Mitianiec, "Improvements of Crankcase Delivery Ratio in Two-Stroke Engines with Volume Intake System,” SAE Technical Paper 1999-01-3334, 1999.

[36] V. Mariucci, A. Selamet, and K. D. Miazgowicz, "Effect of Primary Intake Runner Tapers and Bellmouths on the Performance of a Single Cylinder Engine," SAE Technical Paper 2007-010382, 2007.

[37] B. A. Jawad, A. L. Lounsbery, and J. P. Hoste, "Evolution of Intake Design for a Small Engine Formula Vehicle," SAE Technical Paper 2001-01-1211, 2001.

[38] B. Jawad, K. Yee, S. Arslan, and L. Liu, "Improving Engine Performance Through Intake Design,” SAE 2013 World Congress \& Exhibition, 2013.

[39] F. J. Wallace and M. H. Nassif, "Air Flow in a Naturally Aspirated Two-stroke Engine," Proceedings of the Institution of Mechanical Engineers, vol. 168, no. 1, pp. 515-544, Jun. 1954.

[40] F. J. Laimböck, "The Potential of Small Loop-Scavenged Spark-Ignition Single Cylinder Two-Stroke Engines" SAE Technical Paper 910675, 1991. 
[41] R. F. Huang, M.-P. Hsu, W. L. Chen, and K. Lee, "On the tuning pipe of a two-stroke engine for scooter-type motorcycles," Proceedings of the Institution of Mechanical Engineers, Part C: Journal of Mechanical Engineering Science, vol. 213, no. 8, pp. 861-866, 1999.

[42] J. Adair, D. Olsen, and A. Kirkpatrick, "Exhaust Tuning of Large-Bore, Multicylinder, Two-Stroke, Natural Gas Engines," International Journal of Engine Research, vol. 7, no. 2, pp. 131-141, 2006.

[43] R. Pearson, M. Bassett, P. Virr, S. Lever, and A. Early, "Exhaust System Gas-Dynamics in Internal Combustion Engines," ASME Proceedings: Advancements in Engine and Emissions Technology, no. 42061. pp. 187-196, 2006.

[44] O. Obodeh and A. D. Ogbor, "Improving the Performance of Two-stroke Motorcycle with Tuned Adjustable Exhaust Pipe," Research Journal of Applied Sciences, Engineering and Technology, vol. 1, no. 2, pp. 59-65, 2009.

[45] J. Marti, "Implementation of an exhaust system for an opposed piston two-stroke HCCI engine," KTH, Thesis, 2010. [Online]. Available: http://www.divaportal.se/smash/get/diva2:460049/FULLTEXT01.pdf. [Accessed: 06-June-2019].

[46] R. Gustafsson, "A Practical Application to Reduce Exhausts Emissions on a Two-Stroke Engine with a Tuned Exhaust Pipe,” Small Engine Technology Conference \& Exposition, 2006.

[47] R. S. Benson, R. D. Garg, and D. Woollatt, "A numerical solution of unsteady flow problems," International Journal of Mechanical Sciences, vol. 6, no. 1, pp. 117-144, 1964.

[48] G. P. Blair and M. C. Ashe, "The Unsteady Gas Exchange Characteristics of a Two-Cycle Engine," SAE International Off-Highway and Powerplant Congress and Exposition, 1976.

[49] G. P. Blair and M. B. Johnston, "Unsteady Flow Effects in Exhaust Systems of Naturally Aspirated, Crankcase Compression Two-Cycle Internal Combustion Engines," National Farm, Construction and Industrial Machinery Powerplant, Transportation, 1968.

[50] A. Goswami, S. Vashist, and A. Nayyar, "Effect of Compression Ratio on the Performance Characteristics of Spark Ignition Engine Fueled with Alternative Fuels: A Review," SAE World Congress \& Exhibition, SAE Technical Paper 2015-01-0766, 2015. 
[51] A. Javaheri, V. Esfahanian, A. Salavati-Zadeh, and M. Darzi, "Energetic and exergetic analyses of a variable compression ratio spark ignition gas engine," Energy Conversion and Management, vol. 88, pp. 739-748, 2014.

[52] Y. Motoyama and T. Gotoh, "The Effect of Higher Compression Ratio in Two-Stroke Engines," Small Engine Technology Conference \& Exposition, SAE Technical Paper 93A090, 1993.

[53] J. Zheng, H. Wang, B. Wang, and Z. Huang, "Effect of the compression ratio on the performance and combustion of a natural-gas direct-injection engine," Proceedings of the Institution of Mechanical Engineers, Part D: Journal of Automobile Engineering, vol. 223, no. 1, pp. 85-98, 2009.

[54] N. Kapilan, R. P. Reddy, and T. P. Prakash, "Effect of Injection Timing and Compression Ratio on the Performance and Emissions of 2 -S SI Engine with in-Cylinder Injection of Methanol," Powertrain \& Fluid Systems Conference \& Exhibition, SAE Technical Paper 200501-3711, 2005.

[55] J. Fredriksson and I. Denbratt, "Simulation of a Two-Stroke Free Piston Engine," 2004 SAE Fuels \& Lubricants Meeting \& Exhibition, SAE Technical Paper 2004-01-1871 2004.

[56] A. S. Krishna, J. M. Mallikarjuna, and D. Kumar, "Effect of engine parameters on incylinder flows in a two-stroke gasoline direct injection engine," Applied Energy, vol. 176, pp. 282-294, 2016.

[57] M. Darzi, D. Johnson, C. Ulishney, M. Bade, and N. Zamani, "Baseline evaluation of ignition timing and compression ratio configurations on efficiency and combustion stability of a small-bore, two-stroke, natural gas engine," ASME Proceedings: International Mechanical Engineering Congress and Exposition (IMECE), vol. 6, 2017.

[58] M. Darzi, D. Johnson, C. Ulishney, M. Bade, N. Zamani, G. Thompson, N. Clark, P. Famouri, "Quantification of Energy Pathways and Gas Exchange of a Small Port Injection SI Two-Stroke Natural Gas Engine Operating on Different Exhaust Configurations," SAE World Congress Experience, SAE Technical Paper 2018-01-1278, 2018. 
[59] D. Johnson, M. Darzi, C. Ulishney, M. Bade, and N. Zamani, "Methods to Improve Combustion Stability, Efficiency, and Power Density of a Small, Port-Injected, Spark-Ignited, Two-Stroke Natural Gas Engine," in ASME. Internal Combustion Engine Division Fall Technical Conference, Volume 2: Emissions Control Systems; Instrumentation, Controls, and Hybrids; Numerical Simulation; Engine Design and Mechanical Development, vol. 2, pp. V002T07A008, 2017.

[60] M. Darzi, D. Johnson, C. Ulishney, M. Bade, N. Zamani, G. Thompson, N. Clark, P. Famouri, "Continuously Varying Exhaust Outlet Diameter to Improve Efficiency and Emissions of a Small SI Natural Gas Two-Stroke Engine by Internal EGR," SAE World Congress Experience, SAE Technical Paper 2018-01-0985, 2018.

[61] M. Darzi, D. Johnson, C. Ulishney, and N. Clark, "Low pressure direct injection strategies effect on a small SI natural gas two-stroke engine's energy distribution and emissions," Applied Energy, vol. 230, pp. 1585-1602, 2018.

[62] M. Araki, H. Kishamoto, K. Nakajima, M. Maehara, S. Shiga, H. Nakamura, T. Obokata, "A CNG Two-stroke Cycle S.I. Engine Using Intermittent Low Pressure Fuel Injection from Scavenging Ports," Fifth International SAE India Mobility Conference on Emerging Automotive Technologies Global and Indian Perspective, SAE Technical Paper 2008-28-0004, 2008.

[63] S. Hatakeyama, Y. Sekiya, T. Murayama, S. Nakai, T. Sako, and H. Tsunemoto, “A Study on In-Cylinder Injection of Low Pressure Natural Gas for Performance Improvement of Small Sized Two-Stroke SI Engines," International Spring Fuels \& Lubricants Meeting, SAE Technical Paper 2001-01-1959, 2001.

[64] F. Bozza, A. Gimelli, L. Andreassi, V. Rocco, and R. Scarcelli, "1D-3D Analysis of the Scavenging and Combustion Process in a Gasoline and Natural-Gas Fuelled Two-Stroke Engine,” SAE World Congress \& Exhibition, SAE Technical Paper 2008-01-1087, 2008.

[65] V. Pradeep, S. Bakshi, and A. Ramesh, "Scavenging port based injection strategies for an LPG fuelled two-stroke spark-ignition engine," Applied Thermal Engineering, vol. 67, no. 1, pp. 80-88, 2014. 
[66] K. Kim, J. Kim, S. Oh, C. Kim, and Y. Lee, "Evaluation of injection and ignition schemes for the ultra-lean combustion direct-injection LPG engine to control particulate emissions," Applied Energy, vol. 194, pp. 123-135, 2017.

[67] G. Tadesse and A. R. A. Aziz, "Effect of Boost Pressure on Engine Performance and Exhaust Emissions in Direct-Injection Compressed Natural Gas (CNG-DI) Spark Ignition Engine," Small Engine Technology Conference \& Exposition, SAE Technical Paper 2009-320135, 2009.

[68] C. $\mathrm{Hu}$ and S. Hou, "Investigations on Combustion Process of Low-pressure CNG Compound Direct Injection Spark-ignited Engines," Small Engine Technology Conference \& Exposition, SAE Technical Paper 2010-32-0052, 2010.

[69] L. Arnone, M. Janeck, M. Marcacci, R. Kirchberger, M. Pontoppidan, and R. Busi, "Development of a Direct Injection Two-Stroke Engine For Scooters," Small Engine Technology Conference \& Exposition, SAE Technical Paper 2001-01-1782, 2001.

[70] M. Badami, M. R. Marzano, F. Millo, and P. Nuccio, "Comparison Between Direct and Indirect Fuel Injection in an S.I. Two-Stroke Engine," Small Engine Technology Conference \& Exposition, SAE Technical Paper 1999-01-3311, 1999.

[71] OptiMax ${ }^{\mathrm{TM}}$, “Two-stroke direct fuel injection.”. [Online]. Available: http://www.durdel.de/download/mercury/optimax/mercury-optimax-english.pdf. [Accessed: 01Feb-2019].

[72] H. Z. Foudray and J. B. Ghandhi, "Scavenging Measurements in a Direct-Injection TwoStroke Engine," Small Engine Technology Conference \& Exposition, SAE Technical Paper 200332-0081, 2003.

[73] Julian, "Husqvarna TE300i Review," 2018. [Online]. Available: https://rideexpeditions.com/husqvarna-te300i-new-benchmark/. [Accessed: 03-Feb-2019].

[74] N. Goddard, “KTM's New Fuel-Injected Two-Strokes Could Save the Endangered Engine," Popular $\quad$ Mechanics, [Online]. Available: https://www.popularmechanics.com/cars/motorcycles/a27046/ktm-two-stroke-transfer-portinjection-tpi/. [Accessed: 03-Feb-2019]. 
[75] N. Mavinahally, V. Jay, R. Sharu, and M. Vinayaka, "Multi-Layer Stratified (MuLS) TwoStroke Engine," 2012 Small Engine Technology Conference \& Exhibition, SAE Technical Paper 2012-32-0119, 2012.

[76] M. Shahsavan and J. H. Mack, "Numerical study of a boosted HCCI engine fueled with nbutanol and isobutanol," Energy Conversion and Management, vol. 157, no., pp. 28-40, 2018.

[77] M. Rahimi Boldaji, B. Gainey, and B. Lawler, "Thermally stratified compression ignition enabled by wet ethanol with a split injection strategy: A CFD simulation study," Applied Energy, vol. 235, pp. 813-826, 2019.

[78] M. Morovayiyan, M. Shahsavan, M. Shen, and J. H. Mack, "Investigation of the Effect of Electrode Surface Roughness on Spark Ignition," Proceedings of the ASME 2018 Internal COmbustion Fall Technical Conference, pp. 1-8, 2018.

[79] J. Martin, A. Boehman, R. Topkar, S. Chopra, U. Subramaniam, and H. Chen, “Intermediate Combustion Modes between Conventional Diesel and RCCI," SAE International Journal of Engines vol. 11, no. 6, pp-835-860, 2018.

[80] R. D. Reitz and G. Duraisamy, "Review of high efficiency and clean reactivity controlled compression ignition (RCCI) combustion in internal combustion engines," Progress in Energy and Combustion Science, vol. 46, pp. 12-71, 2015.

[81] J. E. Dec and Y. Yang, "Boosted HCCI for High Power without Engine Knock and with Ultra-Low NOx Emissions - using Conventional Gasoline," SAE International Journal of Engines, vol. 3, no. 1, pp. 1086-2010, Apr. 2010.

[82] H. Wang, D. Delvescovo, M. Yao, and R. D. Reitz, "Numerical Study of RCCI and HCCI Combustion Processes Using Gasoline, Diesel, iso-Butanol and DTBP Cetane Improver," SAE International Journal of Engines, vol. 8, no. 2, pp. 850-2015, 2015.

[83] R. D. Reitz and G. Duraisamy, "Review of high efficiency and clean reactivity controlled compression ignition (RCCI) combustion in internal combustion engines," Progress in Energy and Combustion Science, vol. 46, pp. 12-71, 2015. 
[84] J. Olsen and R. J. Crookes, "Experiments in Dual Fuelling a Compression Ignition Engine by Injecting Di-Methyl Ether as a Pilot Fuel to Ignite Varying Quantities of Natural Gas," Asia Pacific Automotive Engineering Conference, SAE Technical Paper 2007-01-3624, 2007.

[85] K. Bullin and P. Krouskop, "Composition Variety Complicates Processing Plans for US Shale Gas," Oil and Gas Journal, vol. 107, no.10, pp. 50-55, 2009.

[86] Environmental Protection Agency, "53-Small Nonroad Spark-Ignition Engines Certification and Compliance for Vehicles and Engines _ US EPA." [Online]. Available: https://19january2017snapshot.epa.gov/vehicle-and-engine-certification/small-nonroad-sparkignition-engines_.html. [Accessed: 20-Aug-2001].

[87] W. W. Pulkrabek, Engineering fundamentals of the internal combustion engine. Pearson Prentice Hall, Upper Saddle River, New Jersey 2004.

[88] Y. Miyasaka et al., "Comparison of Combustion Characteristics Under Internal EGR and External EGR in a DI Diesel Engine," Society of Automotive Engineers of Japan, SAE Technical Paper 2010-08-0478, 2010.

[89] H. Fernandes, C. Q. Pimenta, W. N. Rodrigues, R. B. de Souza Montemor, and J. E. M. Barros, "Experimental Investigation of Internal Exhaust Gas Recirculation on a Variable Valve Actuation Spark Ignition Engine Operating with Gasoline and Ethanol," 25th SAE Brazil International Congress and Display, SAE Technical Paper 2016-36-0399, 2016.

[90] D. Johnson, M. Besch, N. Fowler, R. Heltzel, and A. Covington, “Addition of Exhaust Gas Recirculation Onto a Large-Bore, Two-Stroke Natural Gas Engine, and its Effects on Fuel Consumption, Emissions, and Combustion," ASME Proceedings :Large Bore Engines, pp. V001T01A005, 2016.

[91] F. L. Watson and G. Hong, “Application of Exhaust Pipe Restriction Technique to a Small Two-Stroke Engine," Small Engine Technology Conference \& Exposition, SAE Technical Paper 2007-32-0032, 2007.

[92] M. Yao, B. Zhang, Z. Zheng, Z. Chen, and Y. Xing, "Effects of exhaust gas recirculation on combustion and emissions of a homogeneous charge compression ignition engine fuelled with 
primary reference fuels," Proceedings of the Institution of Mechanical Engineers, Part D: Journal of Automobile Engineering, vol. 221, no. 2, pp. 197-213, 2007.

[93] K. Dinesh and S. Aravind, "A Survey on EGR System in 2-Stroke SI Engine in Two Wheeler," International Journal of Innovative Research in Science, Engineering and Technology, vol. 5, no. 11, pp. 19994-20000, 2016.

[94] Advanced Research Projects Administration - Energy, "MOVE," 2012. [Online]. Available: https://arpa-e.energy.gov/?q=arpa-e-programs/move. [Accessed: 03-May-2018].

[95] EIA, "What is the efficiency of different types of power plants? - FAQ - U.S. Energy Information Administration (EIA), $\quad 2013 . \quad$ [Online]. Available: https://www.eia.gov/tools/faqs/faq.php?id=107. [Accessed: 05-Feb-2019].

[96] US EPA, “About the CHP Partnership _ Combined Heat and Power (CHP) Partnership," 2018. [Online]. Available: https://www.epa.gov/chp/about-chp-partnership. [Accessed: 04-Sep2018].

[97] A. Ondeck, T. F. Edgar, and M. Baldea, "A multi-scale framework for simultaneous optimization of the design and operating strategy of residential CHP systems," Applied Energy, vol. 205, pp. 1495-1511, 2017.

[98] M. Bianchi, A. De Pascale, and P. R. Spina, "Guidelines for residential micro-CHP systems design,” Applied Energy, vol. 97, pp. 673-685, 2012.

[99] G. Vishwanathan, J. P. Sculley, A. Fischer, and J.-C. Zhao, "Techno-economic analysis of high-efficiency natural-gas generators for residential combined heat and power," Applied Energy, vol. 226, pp. 1064-1075, 2018.

[100] P. Capaldi, "A high efficiency $10 \mathrm{kWe}$ microcogenerator based on an Atkinson cycle internal combustion engine," Applied Thermal Engineering, vol. 71, no. 2, pp. 913-920, 2014.

[101] R. Mikalsen, Y. D. Wang, and A. P. Roskilly, "A comparison of Miller and Otto cycle natural gas engines for small scale CHP applications," Applied Energy, vol. 86, no. 6, pp. 922927, 2009. 
[102] Yanmar Energy Systems, "High-efficiency generator: CP5WN," 2015. [Online]. Available: http://www.yanmar-es.com/wp-content/uploads/CP5WN-Spec-Sheet.pdf. [Accessed: 05-Feb-2019].

[103] H. Mahabadipour, K. K. Srinivasan, and S. R. Krishnan, "A second law-based framework to identify high efficiency pathways in dual fuel low temperature combustion," Applied Energy, vol. 202, pp. 199-212, 2017.

[104] Y. Li, M. Jia, Y. Chang, S. L. Kokjohn, and R. D. Reitz, "Thermodynamic energy and exergy analysis of three different engine combustion regimes," Applied Energy, vol. 180, pp. 849$858,2016$.

[105] J. K. Ausserer, M. D. Polanka, J. A. Baranski, K. D. Grinstead, and P. J. Litke, "Measurement of Loss Pathways in Small, Two-Stroke Internal-Combustion Engines," SAE International Journal of Engines, vol. 10, no. 2, pp. 128-143, 2017.

[106] A. Trattner, F. Kupelwieser, P. Pertl, F. Winkler, S. Schmidt, and R. Kirchberger, "Thermodynamic Limits of Efficiency Enhancement of Small Displacement Single-Cylinder Engines," JSAE/SAE 2015 Small Engine Technologies Conference \& Exhibition, 2015.

[107] P. Piecha et al., "Investigations and Analysis of Working Processes of Two-Stroke Engines with the Focus on Wall Heat Flux," SAE International Journal of Engines, vol. 9, no. 4, pp. 23562367, 2016.

[108] P. Orbaiz and M. Brear, "Energy Balance of a Spark Ignition Engine Running on Hydrogen, Synthesis Gas and Natural Gas," SAE 2014 World Congress \& Exhibition, Technical Paper 2014-01-1337, 2014.

[109] M. Abbasi, M. Chahartaghi, and S. M. Hashemian, "Energy, exergy, and economic evaluations of a CCHP system by using the internal combustion engines and gas turbine as prime movers," Energy Conversion and Management, vol. 173, pp. 359-374, 2018.

[110] B. Johnson and C. Edwards, "Exploring the Pathway to High Efficiency IC Engines through Exergy Analysis of Heat Transfer Reduction," SAE International Journal of Engines, vol. 6, no. 1, pp. 150-166, 2013. 
[111] İ. Sezer and A. Bilgin, "Effects of charge properties on exergy balance in spark ignition engines," Fuel, vol. 112, pp. 523-530, 2013.

[112] K. Ebrahimi and C. Koch, "Symmetric Negative Valve Overlap Effects on Energy Distribution of a Single Cylinder HCCI Engine," SAE World Congress Experience, SAE Technical Paper 2018-01-1250, 2018.

[113] O. Selinger-Lutz, G. Pratidino, R. Hollinger, D. Fischer, B. Koch, and C. Wittwer, "Flexibility assessment of a pool of residential micro combined heat and power systems," Energy Conversion and Management, vol. 172, pp. 228-236, 2018.

[114] PennState College of Earth and Mineral Siences, "Natural Gas Composition and Specifications." [Online]. Available: https://www.e-education.psu.edu/fsc432/content/naturalgas-composition-and-specifications. [Accessed: 04-Sep-2018].

[115] M. M. Foss, "Interstate Natural Gas-Quality Specifications \& Interchangeability," Energy Economics Research,2004. [Online]. Available: http://www.beg.utexas.edu/files/energyecon/global-gas-andlng/CEE_Interstate_Natural_Gas_Quality_Specifications_and_Interchangeability.pdf. [Accessed: 04-Dec-2018].

[116] J. Kidnay, Arthur J. Kidnay, William R. Parrish, Daniel G. McCartney, Fundamentals of Natural Gas Processing. CRC Press, Taylor \& Francis Group, Boca Raton, FL 2006.

[117] FLORIDA POWER \& LIGHT COMPANY, "Natural Gas Specs Sheet," 2004. [Online]. Available: https://www.naesb.org/pdf2/wgq_bps100605w2.pdf. [Accessed: 06-Sep-2018].

[118] J. Vavra, M. Takats, V. Klir, and M. Skarohlid, "Influence of Natural Gas Composition on Turbocharged Stoichiometric SI Engine Performance," SAE International Powertrains, Fuels \& Lubricants Meeting, SAE Technical Paper 2012-01-1647, 2012.

[119] M. D. Feist, M. Landau, and E. Harte, "The Effect of Fuel Composition on Performance and Emissions of a Variety of Natural Gas Engines," SAE International Journal of Fuels Lubrications, vol. 3, no. 2, pp. 100-117, 2010. 
[120] K. Kim, H. Kim, B. Kim, and K. Lee, "Effect of Natural Gas Composition on the Performance of a CNG Engine,” Oil \& Gas Science and Technology, vol. 64, no. 2, pp. 199-206, Mar. 2009.

[121] R. Amirante et al., "Effects of natural gas composition on performance and regulated, greenhouse gas and particulate emissions in spark-ignition engines," Energy Conversion and Management, vol. 143, pp. 338-347, 2017.

[122] M. Flekiewicz, G. Kubica, and B. Flekiewicz, "The Analysis of Energy Conversion Efficiency in SI Engines for Selected Gaseous Fuels," SAE International Powertrain, Fuels \& Lubricants Meeting, SAE Technical Paper 2014-01-2692, 2014.

[123] Wisconsin Distributed Resources Collaborative and WIDRC, "Introduction to Micro Combined Heat \& Power (CHP)," 2015. [Online]. Available: https://www.wisconsindr.org/library/presentations/WiDRC\%20Presentation\%20011615.pdf. [Accessed: 02-Feb-2019].

[124] R. James, A. Dindal, Z. Willenberg, and K. Riggs, "Environmental Technology Verification Report: WTW Measurement Systems Cyanide Electrode CN 501 with Reference Electrode R 503 D and Ion Pocket Meter 340 i," U.S. Environmental Protection Agency, Columbus, Ohio, 2003.

[125] Z. Taie, B. West, J. Szybist, D. Edwards, J. Thomas, S. Huff, G. Vishwanathan, C. Hagen, "Detailed thermodynamic investigation of an ICE-driven, natural gas-fueled, $1 \mathrm{kWe}$ micro-CHP generator," Energy Conversion and Management, vol. 166, pp. 663-673, 2018.

[126] Code of Federal Regulations, "Control of Emissions From New, Small Nonroad SparkIgnition Engines And Equipment," 2018. [Online]. Available: https://www.ecfr.gov/cgi-bin/textidx?SID=c6a9a3a72681f2085457c55b75ac31ba\&mc=true \&node=se21.2.133_1156\&rgn=div8. [Accessed: 02-Feb-2019].

[127] D. R. Johnson, R. Heltzel, A. C. Nix, N. Clark, and M. Darzi, “Greenhouse gas emissions and fuel efficiency of in-use high horsepower diesel, dual fuel, and natural gas engines for unconventional well development," Applied Energy, vol. 206, no. April, pp. 739-750, 2017. 
[128] D. R. Johnson, R. Heltzel, A. C. Nix, N. Clark, and M. Darzi, "Regulated Gaseous Emissions from In-use High Horsepower Drilling and Hydraulic Fracturing Engines," Journal of Pollution Effects and Control, vol. 5, no. 2, 2017.

[129] Electronic Code of Federal Regulations- Section 90, "Certification procedure - determining engine displacement, engine class, and engine families," 2012. [Online]. Available: https://www.law.cornell.edu/cfr/text/40/90.116\#b. [Accessed: 04-Feb-2019].

[130] F. Balduzzi, G. Vichi, L. Romani, and G. Ferrara, "CFD Analysis of the Effect of the Injection Pressure on a Small 2S LPDI Engine,” in JSAE/SAE 2015 Small Engine Technologies Conference \& Exhibition, SAE Technical Paper 2015-32-0760, 2015.

[131] F. Balduzzi et al., "Development of a Low Pressure Direct Injection System for a Small 2S Engine. Part I - CFD Analysis of the Injection Process," SAE International Journal of Engines, vol. 8, no. 4, pp. 1885-1897, 2015.

[132] L. Romani et al., "Development of a Low Pressure Direct Injection System for a Small 2S Engine. Part II - Experimental Analysis of the Engine Performance and Pollutant Emissions," in SAE 2015 World Congress \& Exhibition, AE Technical Paper 2015-01-1730, 2015.

[133] L.-P. Yang, E.-Z. Song, S.-L. Ding, R. J. Brown, N. Marwan, and X.-Z. Ma, "Analysis of the dynamic characteristics of combustion instabilities in a pre-mixed lean-burn natural gas engine," Applied Energy, vol. 183, pp. 746-759, 2016.

[134] B. Fan, J. Pan, W. Yang, W. Chen, and S. Bani, "The influence of injection strategy on mixture formation and combustion process in a direct injection natural gas rotary engine," Applied Energy, vol. 187, pp. 663-674, 2017.

[135] M. Darzi, D. Johnson, C. Ulishney, and D. Oliver, "Gaseous fuels variation effects on first and second law analyses of a small direct injection engine for micro-CHP systems," Energy Conversion and Management, vol. 184, pp. 609-625, 2019.

[136] S. Potul, R. Nachnolkar, and S. V Bhave, "Analysis Of Change In Intake Manifold Length And Development Of Variable Intake System," International Journal Of Scientific \& Technology Research, vol. 3, no. 5, pp. 223-228, 2014. 
[137] Y. Cengal and M. Boles, Thermodynamics: An Engineering Approach. Sixth Edition, McGraw Hill, New York, NY, 2008.

[138] D. R. Stull and H. Prophet, JANAF thermochemical tables, second edition. Gaithersburg, MD, 1971.

[139] C. Dolu and L. Kuddusi, "The effect of reactor height on coal gasification,", Thermal Science, vol. 21, no. 5, pp. 1937-1951, 2017.

[140] L. Caretto, "Introduction to Combustion Analysis," 2010. [Online]. Available: http://www.csun.edu/ lcaretto/me483/combustion.pdf. [Accessed: 21-Aug-2018].

[141] Gamma Technology, "Engine Performance Manual.” 2018, https://www.gtisoft.com/.

[142] Convergent Science, "Converge Manual.” 2018, https://convergecfd.com/.

[143] J. W. Murdock, Fundamental Fluid Mechanics for the Practicing Engineer. Taylor \& Francis, Boca Raton, FL, 1993.

[144] M. A. Liberman, Introduction to Physics and Chemistry of Combustion: Explosion, Flame, Detonation. Springer, Verlag Berlin Heidelberg, 2010.

[145] Cummins Westport, "Fuel Quality Calculator." 2015. [Online]. Available: https://www.cumminswestport.com/fuel-quality-calculator. [Accessed: 21-Feb-2019].

[146] S. Williams, L. (Robin) Hu, T. Nakazono, H. Ohtsubo, and M. Uchida, "Oxidation Catalysts for Natural Gas Engine Operating under HCCI or SI Conditions," SAE International Journal of Fuels and Lubrications, vol. 1, no. 1, pp. 326-337, 2008.

[147] D. BOUNECHADA, "Strategies for the enhancement of low-temperature catalytic oxidation of methane emissions," Milan Polytechnic, Dissertation, 2011.

[148] Y. Xi, N. Ottinger, and Z. G. Liu, "Development of a Lab Reactor System for the Evaluation of Aftertreatment Catalysts for Stoichiometric Natural Gas Engines," SAE World Congress Experience, SAE Technical Paper 2017-01-0999, 2017.

[149] B. V L'vov and A. K. Galwey, "Catalytic oxidation of CO on platinum," Journal of Thermal Analysis and Calorimetry, vol. 111, no. 1, pp. 145-154, 2013. 
[150] Y. Y. Yeo, L. Vattuone, and D. A. King, "Calorimetric heats for CO and oxygen adsorption and for the catalytic CO oxidation reaction on Pt\{111\}," Journal of Chemical Physics, vol. 106, no. 1 , pp. 392-401, 1997.

[151] The U.S. Consumer Product Safety Commission, "Hot water burn prevention and consumer safety," 5098, 2012. [Online]. Available: https://www.cpsc.gov/s3fs-public/5098.pdf. [Accessed: 02-Feb-2019].

[152] Ø. Hodnebrog, S. B. Dalsøren, and G. Myhre, "Lifetimes, direct and indirect radiative forcing, and global warming potentials of ethane (C 2 H 6 ), propane (C $3 \mathrm{H} 8$ ), and butane (C 4 H 10 )," Atmospheric Science Letters, vol. 19, no. 2, pp. 1-7, 2018.

[153] U.S. Energy Information Administration, "U.S. Price of Natural Gas Delivered to Residential Consumers," 2019. [Online]. Available: https://www.eia.gov/dnav/ng/hist/n3010us3m.htm. [Accessed: 05-Feb-2019].

[154] U.S. Energy Information Administration, "Selected national average natural gas prices," 2019. [Online]. Available: https://www.eia.gov/naturalgas/monthly/pdf/table_03.pdf. [Accessed: 05-Feb-2019].

[155] EIA, "Residential Energy Consumption Survey (RECS)," 2018. [Online]. Available: https://www.eia.gov/consumption/residential/data/2015/index.php?view=consumption.

[Accessed: 06-Feb-2019].

[156] EPA, "Air Pollution Control Technology Fact Sheet - Selective Non-Catalytic Reduction,", 2002. [Online]. Available: https://www3.epa.gov/ttncatc1/dir1/fscr.pdf. [Accessed: 06-June2019].

[157] K. Boriboonsomsin et al., "Real-world exhaust temperature profiles of on-road heavy-duty diesel vehicles equipped with selective catalytic reduction," Science of The Total Environment, vol. 634, pp. 909-921, 2018. 